Florida International University

FIU Digital Commons

FIU Electronic Theses and Dissertations

University Graduate School

7-24-2003

\title{
A dosimetry and radiobiological model for intravascular brachytherapy treatment planning with radioisotope emitting stents
}

Maria Alejandra Caceres

Florida International University

DOI: $10.25148 /$ etd.FI14052525

Follow this and additional works at: https://digitalcommons.fiu.edu/etd

Part of the Biomedical Engineering and Bioengineering Commons

\section{Recommended Citation}

Caceres, Maria Alejandra, "A dosimetry and radiobiological model for intravascular brachytherapy treatment planning with radioisotope emitting stents" (2003). FIU Electronic Theses and Dissertations. 1961.

https://digitalcommons.fiu.edu/etd/1961 
FLORIDA INTERNATIONAL UNIVERSITY

Miami, Florida

A DOSIMETRY AND RADIOBIOLOGICAL MODEL FOR INTRAVASCULAR BRACHYTHERAPY TREATMENT PLANNING WITH

RADIOISOTOPE EMITTING STENTS

\author{
A thesis submitted in partial fulfillment of the \\ requirements for the degree of \\ MASTER OF SCIENCE \\ in \\ BIOMEDICAL ENGINEERING \\ by
}

Maria Alejandra Caceres

2003 
To: Dean Vish Prasad

College of Engineering

This thesis, written by Maria Alejandra Caceres, and entitled A Dosimetry and Radiobiological Model for Intravascular Brachytherapy Treatment Planning with Radioisotope Emitting Stents, having been approved in respect to style and intellectual content, is referred to you for judgment.

We have read this thesis and recommend that it be approved.

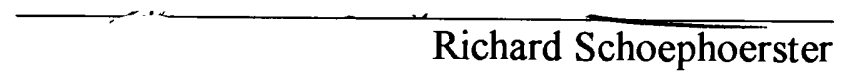

Anthony McGoron

Juan Franquiz, hajor Professor

Date of Defense: July 24, 2003

The thesis of Maria Alejandra Caceres is approved.

Dean Vish Prasad

College of Engineering

Florida International University, 2003

ii 


\section{ACKNOWLEDGMENTS}

First and foremost I would like to thank my major professor Dr. Juan Franquiz for allowing me the opportunity to work on this project. His guidance, support and patience were invaluable throughout the course of this project. I would like to show my gratitude to Dr. Michael Stabin for providing the results of the Monte Carlo simulations that were helpful in the validation of the dose point kernel model. I also extend my appreciation to Mr. Ricardo Garcia from Bionucleonics, Inc. for providing the stent design and coordinates that were used in this work. I apologize to any of those people I may have left out and I am grateful to everyone who in some way contributed to the success of this work. 
A DOSIMETRY AND RADIOBIOLOGICAL MODEL FOR INTRAVASCULAR BRACHYTHERAPY TREATMENT PLANNING

WITH RADIOISOTOPE EMITTING STENTS

by

Maria Alejandra Caceres

Florida International University, 2003

Miami, Florida

Professor Juan Franquiz, Major Professor

The aim of this study was to develop a practical, versatile and fast dosimetry and radiobiological model for calculation of the 3D dose distribution and radiobiological effectiveness of radioactive stents. The algorithm was written in Matlab 6.5 programming language and is based on the dose point kernel convolution. The dosimetry and radiobiological model was applied for evaluation of the $3 \mathrm{D}$ dose distribution of ${ }^{32} \mathrm{P},{ }^{90} \mathrm{Y}$, ${ }^{188} \mathrm{Re}$ and ${ }^{177} \mathrm{Lu}$ stents. Of the four, ${ }^{32} \mathrm{P}$ delivers the highest dose, while ${ }^{90} \mathrm{Y},{ }^{188} \mathrm{Re}$ and ${ }^{177} \mathrm{Lu}$ require high levels of activity to deliver a significant therapeutic dose in the range of 15-30 Gy. Results of the radiobiological model demonstrated that the same physical dose delivered by different radioisotopes produces significantly different radiobiological effects. This type of theoretical dose calculation can be useful in the development of new stent designs, the planning of animal studies and clinical trials, and clinical decisions involving individualized treatment plans. 


\section{TABLE OF CONTENTS}

CHAPTER

PAGE

1. INTRODUCTION

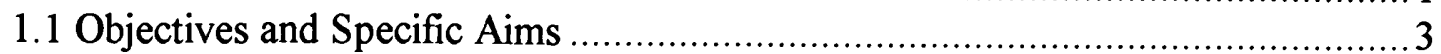

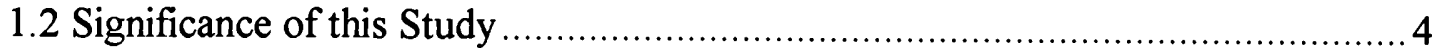

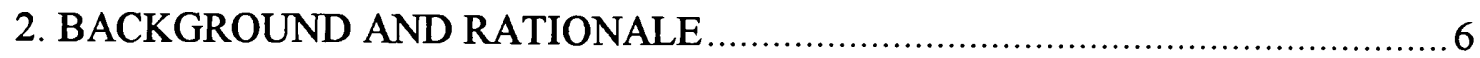

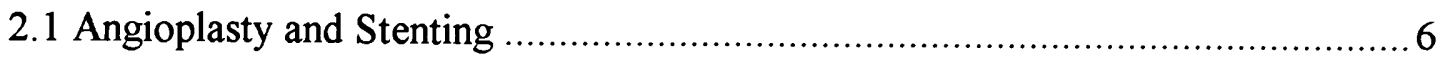

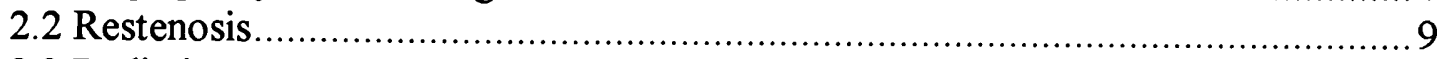

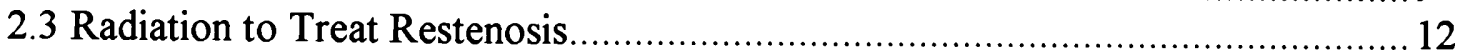

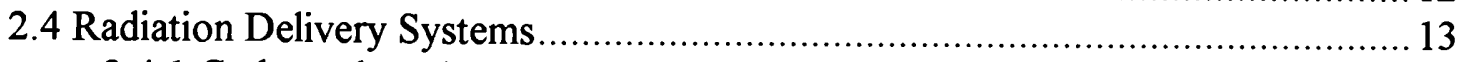

2.4.1 Catheter-based systems...................................................... 13

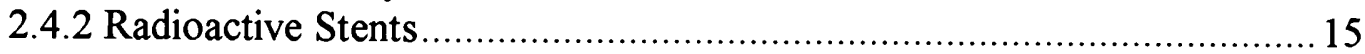

2.4.2.1 Preclinical Studies (Animal Studies) ........................................ 17

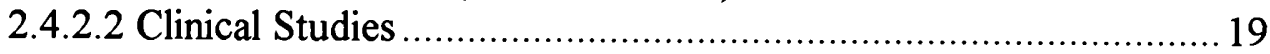

2.4.2.3 Edge Restenosis or "Candy Wrapper Effect"............................20

2.5 Beta and Gamma Emitters: Radioisotopes in Intravascular Brachytherapy .......... 21

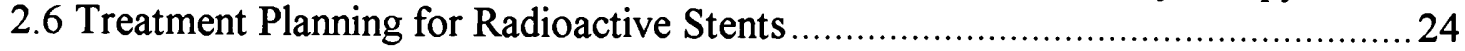

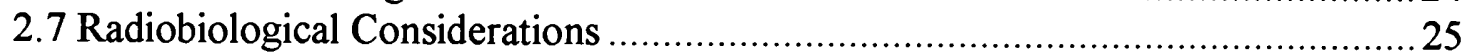

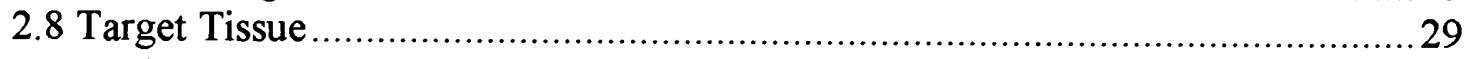

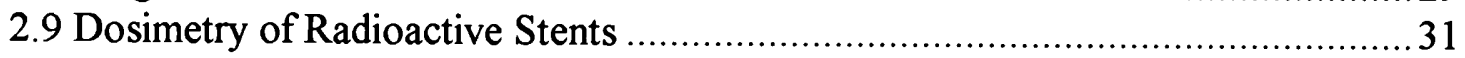

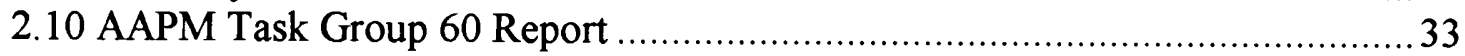

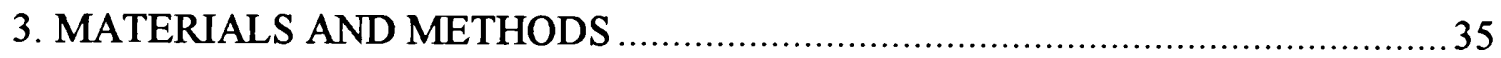

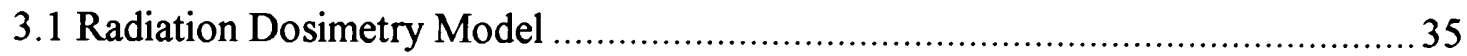

3.1.1 Dose Point Kernel Convolution ........................................................... 36

3.1.2 Dose Point Kernel ................................................................ 38

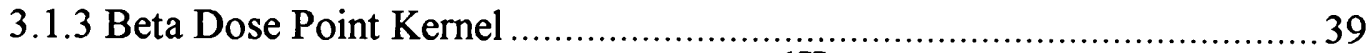

3.1.4 Dose Point Kernel of Beta Emissions of ${ }^{177} \mathrm{Lu}$........................................ 41

3.1.5 Dose Point Kernel of Gamma Emissions of ${ }^{177} \mathrm{Lu}$ and ${ }^{188} \mathrm{Re} \ldots \ldots \ldots \ldots \ldots \ldots . . . . . . .43$

3.2 Radiobiological Model ............................................................................. 45

3.2.1 Relative Effectiveness per unit Dose for a Permanent Implant ................46

3.2.2 RE for Implant Containing Two Different Radioisotopes ..................... 48

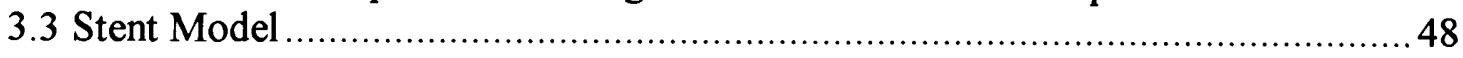

3.4 Algorithm for Radiation Dosimetry Model ................................................. 50

3.4.1 Dose Calculation Algorithm Flowchart .............................................. 51

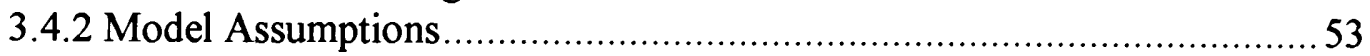

3.4.3 Conversion of Units..................................................................... 53

3.4.4 Attenuation Correction Factor for Dose Point Kernel Calculation

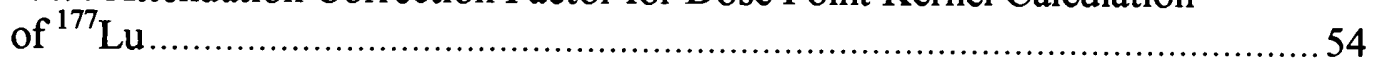

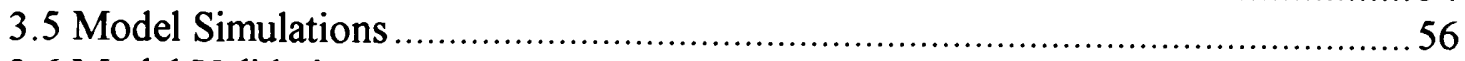

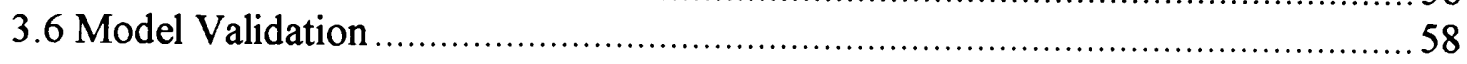




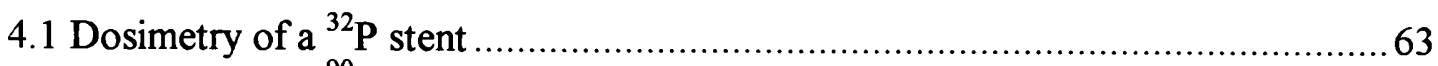

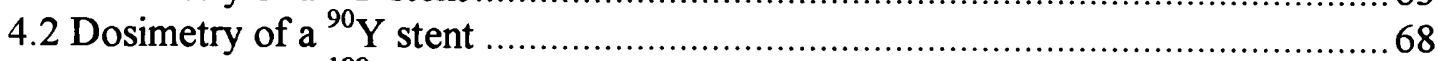

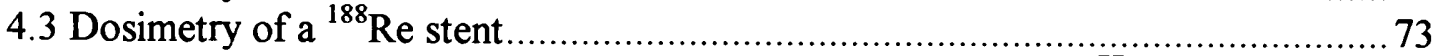

4.4 Self-Attenuation Correction Factor for DPK Calculation of a ${ }^{177} \mathrm{Lu}$ stent............8 80

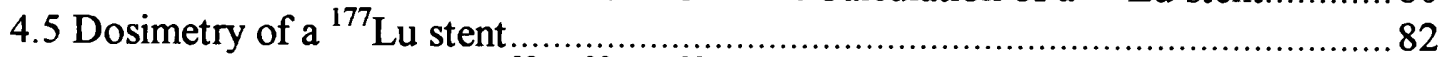

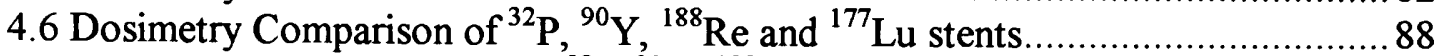

4.7 Radiobiological Modeling for ${ }^{32} \mathrm{P},{ }^{90} \mathrm{Y},{ }^{188} \mathrm{Re}$, and ${ }^{177} \mathrm{Lu}$ Stents ...................... 89

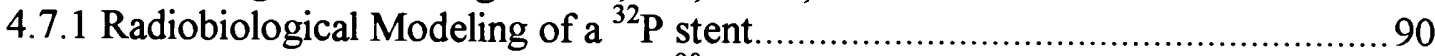

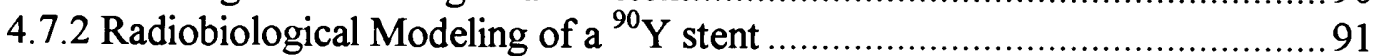

4.7.3 Radiobiological Modeling of a ${ }^{188}$ Re stent ........................................ 92

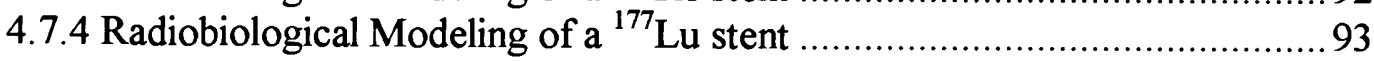

4.8 Combinations of Isotopes within the Same Stent ......................................... 95

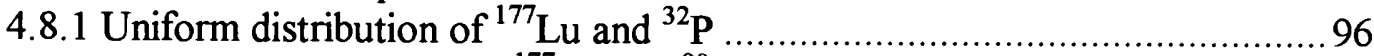

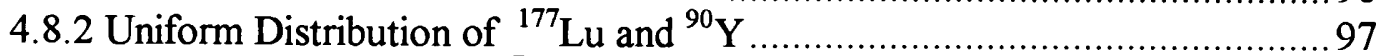

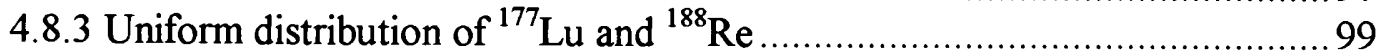

4.9 Modification of Radioisotope Distribution at Stent Edges ............................. 100

4.9.1 Different radioisotopes at stent edges ................................................ 100

4.9.2 Increase of activity at stent edges ("dumbbell effect") ............................. 103

4.9.2.1 ${ }^{32} \mathrm{P}$ stent with $3 \mathrm{x}$ the activity at the stent edges.................................. 103

4.9.2.2. ${ }^{90} \mathrm{Y}$ stent with $3 \mathrm{x}$ the activity at the stent edges ........................... 105

4.9.2.3 ${ }^{188} \mathrm{Re}$ stent with $3 \mathrm{x}$ the activity at the stent edges............................ 107

4.9.2.4. ${ }^{177} \mathrm{Lu}$ with $3 \mathrm{x}$ the activity at the stent edges .................................. 109

4.10. Validation of DPK convolution method with Monte Carlo simulation of a ${ }^{32} \mathbf{P}$ Cylinder

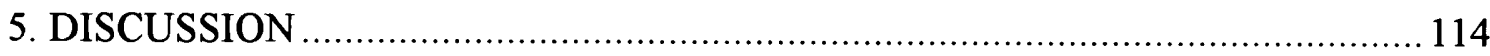

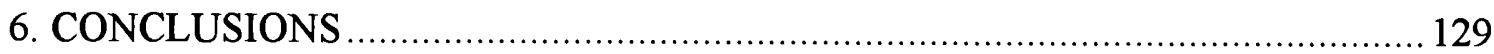

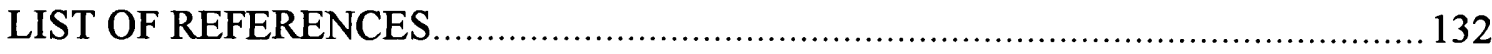

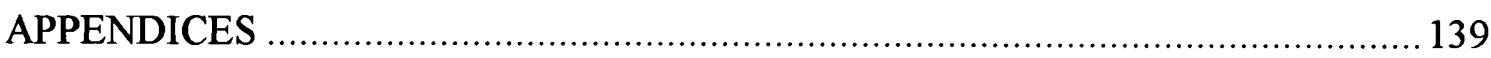




\section{LIST OF TABLES}

TABLE

PAGE

Table 2-1: Properties of Radioisotopes used in IVBT 23

Table 3-1: Properties of Radioisotopes used in Radiation Dosimetry Model 39

Table 3-2: Functions and $r^{2}$ values for DPK expressions of selected radioisotopes 41

Table 3-3: Beta and Gamma energies of ${ }^{177} \mathrm{Lu}$ and ${ }^{188} \mathrm{Re}$

Table 3-4: Coefficients of the gamma DPK expression of ${ }^{188} \mathrm{Re}$

Table 3-5: Functions and $r^{2}$ values for gamma DPK of ${ }^{188} \operatorname{Re}$ and ${ }^{177} \mathrm{Lu}$ 44

Table 3-6: Summary of Values for Variables used in Radiobiological Model

Table 3-7: Radioisotope Distribution of Stent Geometry

Table 3-8: Stopping Power and CSDA range for the mean beta energy of ${ }^{32} \mathrm{P}$ emissions in a NiTi alloy

Table 4-1: Beta and Gamma components of total dose of a ${ }^{188} \mathrm{Re}$ stent 79

Table 4-2: Comparison of dose with and without self-attenuation correction factors for dose delivered by a ${ }^{177} \mathrm{Lu}$ stent

Table 4-3: Beta and gamma components of total dose of a ${ }^{177} \mathrm{Lu}$ stent 88

Table 4-4: Calculation of BED for ${ }^{32} \mathrm{P}$ stent at increasing radial distance. 90

Table 4-5: Calculation of BED for $\mathrm{a}^{90} \mathrm{Y}$ stent at increasing radial distance 91

Table 4-6. Calculation of BED for ${ }^{188}$ Re stent at increasing radial distance 92

Table 4-7: Calculation of BED for a ${ }^{177} \mathrm{Lu}$ stent at increasing radial distance 93

Table 4-8: Calculation of BED of each radioisotope for the same physical dose of $20 \mathrm{~Gy}$

Table 4-9: Calculation of BED for a combined ${ }^{177} \mathrm{Lu}$ and ${ }^{32} \mathrm{P}$ stent at increasing radial distance 
Table 4-10: Calculation of BED for a combined ${ }^{177} \mathrm{Lu}$ and ${ }^{90} \mathrm{Y}$ stent at increasing radial distance

Table 4-11: Calculation of BED for a combined ${ }^{177} \mathrm{Lu}$ and ${ }^{188} \mathrm{Re}$ stent at increasing radial distance. 100

Table 4-12: Dose calculation of a ${ }^{32} \mathrm{P}$ stent with variation in activity at stent edges...... 104

Table 4-13: Dose calculation of $\mathrm{a}^{90} \mathrm{Y}$ stent with variation in activity at stent edges ..... 107

Table 4-14: Dose calculation of a ${ }^{188}$ Re stent with variation in activity at stent edges

Table 4-15: Dose calculation of a ${ }^{177} \mathrm{Lu}$ stent with variation in activity at stent edges

Table 4-16: Tabulated parameters for calculation of attenuation correction factor for ${ }^{32} \mathrm{P}$ cylinder used in validation of DPK convolution.

Table 4-17: Comparison between Monte Carlo and DPK dose values for increasing radial distance

Table 4-18: Dose at increasing radial distance for DPK radiation dosimetry model and published results from Janicki et al. (1997)

Table A-1: Nuclear Properties of ${ }^{177} \mathrm{Lu}$

Table A-2: Spectrum calculation and distribution of the beta emission with maximum energy of $0.498 \mathrm{MeV}(79 \%)$.

Table A-3: Spectrum calculation and distribution of the beta emission with maximum energy of $0.385 \mathrm{MeV}(9.1 \%)$

Table A-4: Spectrum calculation and distribution of the beta emission with maximum energy of $0.177 \mathrm{MeV}(12.0 \%)$

Table A-5: Complete beta energy spectrum of ${ }^{177} \mathrm{Lu}$

Table B-1: Contribution of each energy bin to DPK of ${ }^{177} \mathrm{Lu}$ for distances ranging from 0.01 to $0.2 \mathrm{~cm}$

Table B-2: Beta DPK of ${ }^{177} \mathrm{Lu}$

Table C-1: Dose to water per gamma ray emission from a point source for gamma energy $0.208 \mathrm{MeV}(11.0 \%)$ 
Table C-2: Dose to water per gamma ray emission from a point source for gamma energy $0.113 \mathrm{MeV}(6.4 \%)$

Table C-3: Gamma DPK of ${ }^{177} \mathrm{Lu}$ 158

Table D-1: Stent Coordinates. 160 


\section{LIST OF FIGURES}

FIGURE

PAGE

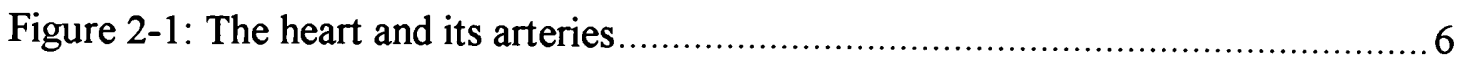

Figure 2-2: Overview of PTCA procedure …..................................................... 7

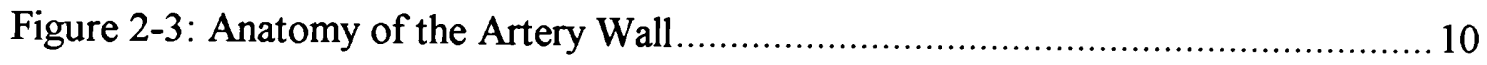

Figure 2-4: Restenosis as a result of neointimal hyperplasia ................................. 11

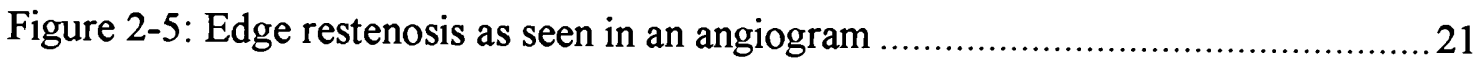

Figure 2-6: Mechanism of Action of Damage of Ionizing Radiation............................26

Figure 2-7: Direct and Indirect Action of Ionizing Radiation .................................. 27

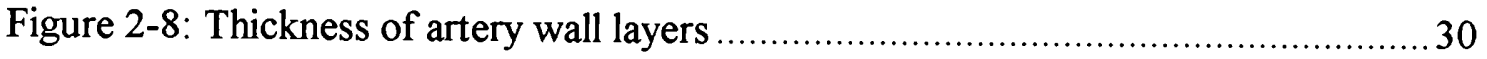

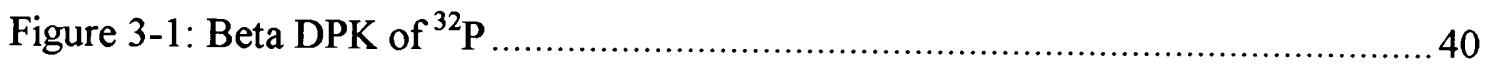

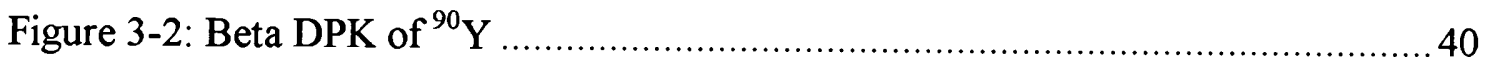

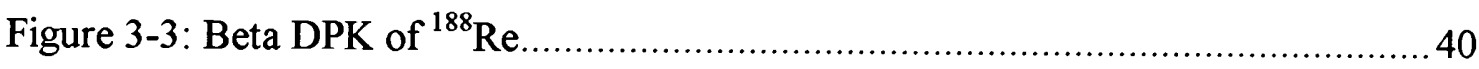

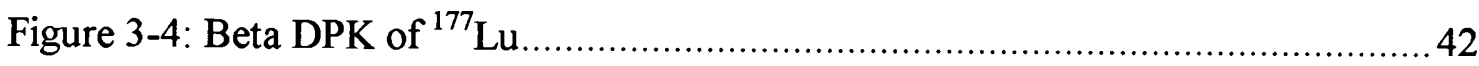

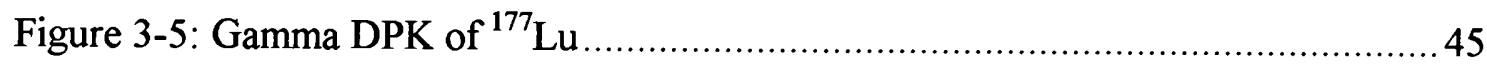

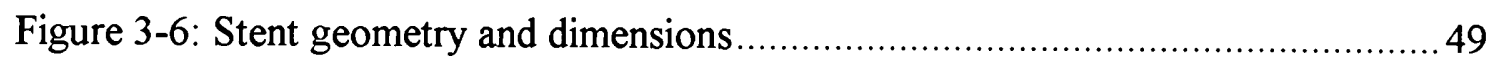

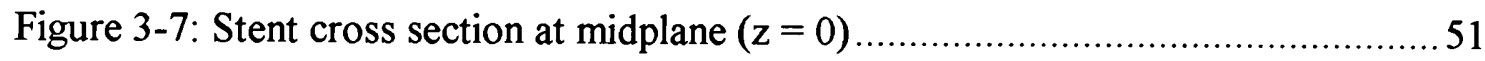

Figure 3-8: Diagram of Dose Calculation Algorithm ............................................ 52

Figure 3-9: Portion of stent strut with attenuation correction ....................................55

Figure 3-10: Radioisotope distribution at stent edges .......................................... 57

Figure 3-11: Dimensions of ${ }^{32} \mathrm{P}$ cylinder used in MCNP and DPK calculations ............58

Figure 3-12: Angle range defining contributing points to dose at target ....................6 60 
Figure 3-13: Contributing points to dose at target for a segment along the stent $\mathrm{z}$ axis

Figure 4-1: 2D plot of dose distribution of $\mathrm{a}^{32} \mathrm{P}$ stent 64

Figure 4-2: 3D map of dose to tissue after total decay of a ${ }^{32} \mathrm{P}$ stent at $0.1 \mathrm{~mm}$ exterior to the stent surface.

Figure 4-3: 3D map of dose to tissue after total decay of a ${ }^{32} \mathrm{P}$ stent at $0.5 \mathrm{~mm}$ exterior to the stent surface.

Figure 4-4: 3D map of dose to tissue after total decay of a ${ }^{32} \mathrm{P}$ stent at $1.0 \mathrm{~mm}$ exterior to the stent surface.

Figure 4-5: 3D map of dose to tissue after total decay of a ${ }^{32} \mathrm{P}$ stent at $2.0 \mathrm{~mm}$ exterior to the stent surface. 66

Figure 4-6: The variation of dose with radial distance of $\mathrm{a}^{32} \mathrm{P}$ stent. 67

Figure 4-7: The variation of dose with axial distance of $\mathrm{a}^{32} \mathrm{P}$ stent

Figure 4-8: 2D plot of dose distribution of ${ }^{90} \mathrm{Y}$ stent 68

Figure 4-9: 3D map of dose to tissue after total decay of a ${ }^{90} \mathrm{Y}$ stent at $0.1 \mathrm{~mm}$ exterior to the stent surface.

Figure 4-10: 3D map of dose to tissue after total decay of a ${ }^{90} \mathrm{Y}$ stent at $0.5 \mathrm{~mm}$ exterior to the stent surface.

Figure 4-11: 3D map of dose to tissue after total decay of a ${ }^{90} \mathrm{Y}$ stent at $1.0 \mathrm{~mm}$ exterior to the stent surface

Figure 4-12: 3D map of dose to tissue after total decay of a ${ }^{90} \mathrm{Y}$ stent at $2.0 \mathrm{~mm}$ exterior to the stent surface

Figure 4-13: The variation of dose with radial distance of a ${ }^{90} \mathrm{Y}$ stent 72

Figure 4-14: The variation of dose with axial distance of $\mathrm{a}^{90} \mathrm{Y}$ stent 72

Figure 4-15: 2D plot of dose distribution of $a{ }^{188} \mathrm{Re}$ stent 73

Figure 4-16: 3D map of dose to tissue after total decay of a ${ }^{188} \mathrm{Re}$ stent at $0.1 \mathrm{~mm}$ exterior to the stent surface. 
Figure 4-17: 3D map of dose to tissue after total decay of a ${ }^{188} \operatorname{Re}$ stent at $0.5 \mathrm{~mm}$ exterior to the stent surface.

Figure 4-18: 3D map of dose to tissue after total decay of a ${ }^{188} \mathrm{Re}$ stent at $1.0 \mathrm{~mm}$ exterior to the stent surface.

Figure 4-19: 3D map of dose to tissue after total decay of a ${ }^{188} \mathrm{Re}$ stent at $2.0 \mathrm{~mm}$ exterior to the stent surface.

Figure 4-20: The variation of dose with radial distance of a ${ }^{188} \mathrm{Re}$ stent 76

Figure 4-21: The variation of dose with axial distance of a ${ }^{188} \mathrm{Re}$ stent.

Figure 4-22: Contribution of gamma energy to total dose of a ${ }^{188} \operatorname{Re}$ stent 78

Figure 4-23: Beta and gamma components of dose delivered by $a{ }^{188} \operatorname{Re}$ stent 79

Figure 4-24: Comparison of dose with and without attenuation correction for a ${ }^{177}$ Lu stent.

Figure 4-25: 2D plot of dose distribution of a ${ }^{177} \mathrm{Lu}$ stent

Figure 4-26: 3D map of dose to tissue after total decay of a ${ }^{177} \mathrm{Lu}$ stent at $0.1 \mathrm{~mm}$ exterior to the stent surface.

Figure 4-27: 3D map of dose to tissue after total decay of a ${ }^{177} \mathrm{Lu}$ stent at $0.5 \mathrm{~mm}$ exterior to the stent surface.

Figure 4-28: 3D map of dose to tissue after total decay of a ${ }^{177} \mathrm{Lu}$ stent at $1.0 \mathrm{~mm}$ exterior to the stent surface.

Figure 4-29: 3D map of dose to tissue after total decay of a ${ }^{177} \mathrm{Lu}$ stent at $2.0 \mathrm{~mm}$ exterior to the stent surface.

Figure 4-30: The variation of dose with radial distance of a ${ }^{177} \mathrm{Lu}$ stent 85

Figure 4-31: The variation of dose with axial distance of a ${ }^{177} \mathrm{Lu}$ stent. 86

Figure 4-32: Contribution of gamma energy to total dose delivered by a ${ }^{177} \mathrm{Lu}$ stent .... 87

Figure 4-33: Beta and gamma components of dose delivered by a ${ }^{177} \mathrm{Lu}$ stent 87

Figure 4-34: Comparison of radial dose distribution of four radioisotopes 88

Figure 4-35: Comparison of axial dose distribution of four radioisotopes 89 
Figure 4-36: Comparison of BED and physical absorbed dose of a ${ }^{32} \mathrm{P}$ stent .............. 90

Figure 4-37: Comparison of BED and physical absorbed dose of $\mathrm{a}^{90} \mathrm{Y}$ stent ............. 91

Figure 4-38: Comparison of BED and physical absorbed dose of a ${ }^{188} \operatorname{Re}$ stent ........... 92

Figure 4-39: Comparison of BED and physical absorbed dose of a ${ }^{177} \mathrm{Lu}$ stent ........... 93

Figure 4-40: Variation of dose rate with radial distance of ${ }^{32} \mathrm{P},{ }^{90} \mathrm{Y},{ }^{188} \mathrm{Re}$ and ${ }^{177}$ Lu stents.

Figure 4-41: 2D plot of dose distribution of a combined ${ }^{177} \mathrm{Lu}$ and ${ }^{32} \mathrm{P}$ stent .............. 96

Figure 4-42: Comparison of BED and physical absorbed dose of a combined ${ }^{177} \mathrm{Lu}$ and ${ }^{32} \mathrm{P}$ stent

Figure 4-43. 2D plot of dose distribution of a combined ${ }^{177} \mathrm{Lu}$ and ${ }^{90} \mathrm{Y}$ stent. 97

Figure 4-44: Comparison of BED and physical absorbed dose of a combined ${ }^{177} \mathrm{Lu}$ and ${ }^{90} \mathrm{Y}$ stent

Figure 4-45: 2D plot of dose distribution of a combined ${ }^{177} \mathrm{Lu}$ and ${ }^{188} \mathrm{Re}$ stent. 99

Figure 4-46: Comparison of BED and physical absorbed dose of a combined ${ }^{177} \mathrm{Lu}$ and ${ }^{188} \mathrm{Re}$ stent.

Figure 4-47: Comparison of a ${ }^{32} \mathrm{P}$ stent with ${ }^{188} \mathrm{Re}$ and ${ }^{90} \mathrm{Y}$ at stent edges. 101

Figure 4-48: Comparison of ${ }^{32} \mathrm{P}$ stent with ${ }^{188} \mathrm{Re}$ and ${ }^{90} \mathrm{Y}$ at stent edges normalized to the stent edge

Figure 4-49: Comparison of a ${ }^{32} \mathrm{P}$ stent with $10 \mathrm{x}$ activity of ${ }^{188} \mathrm{Re}$ and ${ }^{90} \mathrm{Y}$ at stent edges.

Figure 4-50: 2D plot of dose distribution of $\mathrm{a}^{32} \mathrm{P}$ stent with $3 \mathrm{x}$ activity at the stent edges.

Figure 4-51: Comparison of dose as a function of axial distance from a uniform ${ }^{32} \mathrm{P}$ stent and ${ }^{32} \mathrm{P}$ stent with $3 \mathrm{x}$ the activity at the stent edges. 104

Figure 4-52: $2 \mathrm{D}$ plot of dose distribution of a ${ }^{90} \mathrm{Y}$ stent with $3 \mathrm{x}$ the activity at the stent edges 
Figure 4-53: Comparison of dose as a function of axial distance from a uniform

${ }^{90} \mathrm{Y}$ stent and ${ }^{90} \mathrm{Y}$ stent with $3 \mathrm{x}$ the activity at the stent edges

Figure 4-54: $2 \mathrm{D}$ plot of dose distribution of a ${ }^{188} \mathrm{Re}$ stent with $3 \mathrm{x}$ the activity at the stent edges

Figure 4-55: Comparison of dose as a function of axial distance from a uniform ${ }^{188} \operatorname{Re}$ stent and $a^{188} \operatorname{Re}$ stent with $3 x$ the activity at the stent edges

Figure 4-56: $2 \mathrm{D}$ plot of dose distribution of a ${ }^{177}$ Lu stent with $3 \mathrm{x}$ the activity at the stent edges

Figure 4-57: Comparison of dose as a function of axial distance from a uniform ${ }^{17} \mathrm{Lu}$ stent and a ${ }^{177} \mathrm{Lu}$ stent with $3 \mathrm{x}$ the activity at the stent edges

Figure 4-58: Monte Carlo versus DPK convolution method for dose calculation as a function of radial distance from surface of cylinder.

Figure 4-59: Comparison of DPK radiation dosimetry model with published results (Janicki et al. (1997))

Figure A-1: Beta Spectrum of ${ }^{177}$ Lu with Maximum Energy of $0.498 \mathrm{MeV}(79 \%)$...... 144

Figure A-2: Beta Spectrum of ${ }^{177}$ Lu with Maximum Energy of $0.385 \mathrm{MeV}(9.1 \%)$..... 147

Figure A-3: Beta Spectrum of ${ }^{177}$ Lu with Maximum Energy of $0.177 \mathrm{MeV}(12.0 \%) \ldots 148$

Figure A-4: Complete Beta Energy Spectrum of ${ }^{177} \mathrm{Lu}$ 


\section{CHAPTER 1}

INTRODUCTION

Coronary artery disease (CAD) is the major cause of death in most western countries. Approximately 12,800,000 Americans suffer from CAD and nearly 500,000 die from heart attacks caused by CAD (2003 Heart and Stroke Statistical Update, American Heart Association). Therefore its treatment and prevention is of great interest to the cardiology community. $\mathrm{CAD}$ has been successfully treated with percutaneous transluminal coronary angioplasty (PTCA). However, restenosis, or re-narrowing of the artery, remains the major limitation of this technique with rates of approximately $30-50 \%$ (Fischell et al., 2000; Fox, 2002; King, 2002). The use of coronary stents in conjunction with balloon angioplasty has reduced restenosis rates by $20-30 \%$ as a result of their positive effect on elastic recoil and constrictive remodeling (Fox, 2002; King, 2002). Despite their success, in-stent restenosis is still a significant problem with stents, and the stent presence may in fact aggravate neointima formation. High in-stent restenosis rates represent a major impediment to the success of PTCA (Hehrlein and Kubler, 1997; Fischell, 1998; Nath et al., 1999; Fox, 2002).

Vascular irradiation, otherwise known as intravascular brachytherapy (IVBT) has emerged as a prophylaxis for the prevention of restenosis after angioplasty, and is considered a very promising anti-restenosis therapy (Kuntz and Baim, 2000; Serruys and Kay, 2000; Sims et al., 2002; Fox, 2002). A radiation delivery platform such as a radioactive stent provides a mechanism in which mechanical and irradiation benefits can be combined. The three main components of restenosis identified as early recoil, 
remodeling and neointimal hyperplasia, can all be successfully treated with a radioactive stent. The stent itself serves as a scaffold, thus maintaining the lumen of the artery open, even after early recoil soon after the angioplasty procedure. In addition, the ionizing radiation emitted from the stent has been shown to have positive effects on the reduction of neointimal growth and negative vascular remodeling (Mintz et al., 1996; Schwartz and Holmes, 2002).

The safety and efficacy of radioactive stents has been well demonstrated in several animal studies (Hehrlein et al., 1995; Carter and Laird, 1996; Fischell, 1998; Carter et al., 1999; John et al., 2000), yet experimental results are inconsistent and restenosis at stent edges, otherwise known as the "candy wrapper effect", remains a major problem with this treatment modality (Albeiro et al., 2000b; Fischell et al., 2000; Serruys and Kay, 2000; Fox, 2002). This can be attributed to geographic miss, excessive barotrauma during the stent implantation procedure, or inadequate irradiation at the stent edges due to the rapid dose falloff of the radiation source (Fischell et al., 2000; Serruys and Kay, 2000; Fox, 2002). It is clear that for radioactive stents to be successful, the problem of edge restenosis must be overcome. This requires an in-depth evaluation of different candidate radioisotopes and possibly a combined dose delivery strategy to maximize radiation at stent edges.

The planning of any radiotherapy treatment is a crucial step in the overall success of the treatment. Dosimetric analysis is a first and necessary step as it is important to characterize and optimize the dose that will be delivered to the arterial wall tissue. While the overall benefits of intravascular brachytherapy are well documented, uncertainties still remain with uniform radiation delivery, optimal radioisotope, radiation dose, dose 
rate, initial activity and target tissue (Fischell et al., 2000; Fox, 2002). Ultimately, the goal of a radioactive stent is to deliver an appropriate dose and dose rate to prevent restenosis with an acceptable level of toxicity.

In addition to an in-depth dosimetric analysis, an intravascular brachytherapy treatment planning system should include an a priori evaluation of the radiobiological effect of the treatment. In IVBT, the dose values reported are those of physically absorbed dose. However, the real therapeutic effect depends on the radiobiology of the tissue being irradiated, and therefore other parameters should be considered, such as the initial dose rate, half-life of the radioisotope being used, repair capability of the tissue, and the type of tissue being irradiated (Dale, 1985, 1993; Brenner et al., 1996; Hall et al., 1988, 1999; Brenner and Hall, 2001; Mitchell, 2002). The concept of BED, or biological equivalent dose, takes these parameters into account for dose calculation. This comparison of physical absorbed dose and biological equivalent dose is very important, particularly when comparing the effectiveness of different radioisotopes and could be a significant factor in dose prescription. Thus far, there is no treatment planning system in intravascular brachytherapy specifically designed for radioactive stents that takes into account both the physical dose and the biologically equivalent dose.

\subsection{Objectives and Specific Aims}

The main objectives and specific aims of this work are as follows:

1. To develop a practical and fast algorithm based on the dose point kernel (DPK) convolution for calculation of the $3 \mathrm{D}$ dose distribution of radioactive stents. This 
dosimetry model will be equipped to accommodate variations in stent geometry and dimension, radioisotope(s) and initial activity. Results will be shown as depth-dose profiles in the longitudinal and axial directions.

2. To develop an algorithm that calculates the $3 \mathrm{D}$ radiobiological effectiveness of the dose distribution of radioactive stents in the form of BED (Biological equivalent dose).

3. To apply the dosimetry and radiobiological models to stents with the following radioisotopes: ${ }^{32} \mathrm{P},{ }^{90} \mathrm{Y},{ }^{188} \mathrm{Re}$ and ${ }^{177} \mathrm{Lu}$, and combinations of these, to characterize the 3D dosimetry of each and demonstrate the potential for use in intravascular brachytherapy.

4. To validate the dosimetry model by comparing the results of the dose point kernel convolution with those of Monte Carlo simulations in a ${ }^{32} \mathrm{P}$ cylinder.

\subsection{Significance of this Study}

This is a development work in which we have implemented an algorithm based on the DPK convolution that calculates both the physical absorbed dose and BED of radioactive stents. This model offers the advantage of fast computation times and versatility in radioisotope selection, stent geometry and dimensions, and initial activity. It allows the evaluation of different radioisotopes, or combinations of such, for addressing the problem of edge restenosis and as well as to improve the overall dose distribution of a radioactive stent. The intention of this model is twofold. It serves as a dosimetry tool to calculate the three-dimensional dose distribution of the radiation emitted from a 
radioactive stent, and functions as a radiotherapy treatment planning system by evaluating the radiobiological damage to the tissue. The model's final results can be used to aid in the development of industrial designs of a radioactive stents, the planning of animal and clinical trials, and possibly in the planning of an individualized intravascular brachytherapy treatment with a radioactive stent. 


\section{CHAPTER 2 \\ BACKGROUND AND RATIONALE}

\subsection{Angioplasty and Stenting}

Atherosclerotic artery disease is primarily caused by accumulation of fatty debris from the blood in the arteries resulting in a narrowing or stenosis of the arterial lumen, which consequently compromises blood flow (Nath et al., 1999). Many arteries are subject to this condition, particularly the coronary arteries, which supply blood to the heart muscle itself. Stenosis in the coronary arteries can cause much damage to heart as a result of poor oxygenation of tissues as well as by impairing the heart's electrical conduction system, which can potentially lead to a life-threatening arrhythmia, ischemia and myocardial infarction (Fox, 2002).

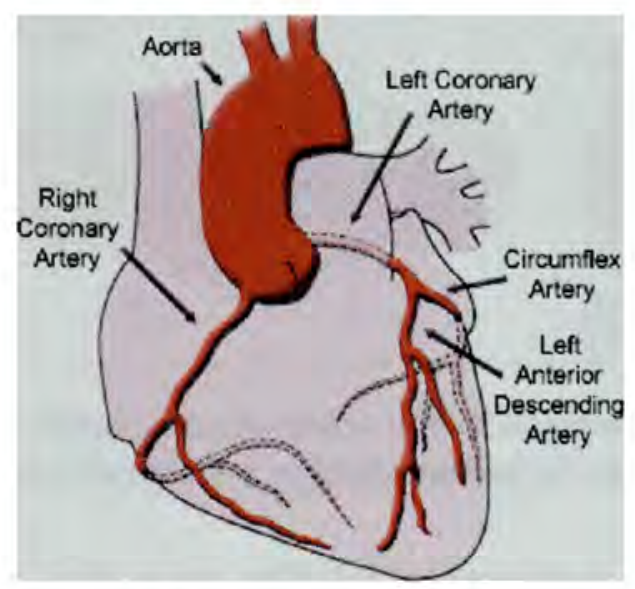

Figure 2-1. The heart and its arteries

The late 1950's witnessed the advent of bypass surgery for treatment of diseased coronary arteries. In 1977, the method of coronary artery bypass graft was introduced and consisted of taking a segment of a vein from the patient's leg and inserting the graft into the diseased artery (Fox, 2002). However, these two methods are very invasive since they 
require a major operation that involves opening the patient's chest. In 1977, Andreas Gruentzig introduced PTCA, or percutaneous transluminal coronary angioplasty, which consists of the inflation of a balloon catheter in the narrowed area of the coronary artery, thereby restoring a stable lumen with a diameter similar to that of a normal artery (Figure 2-2) (Fox, 2002; King, 2002).

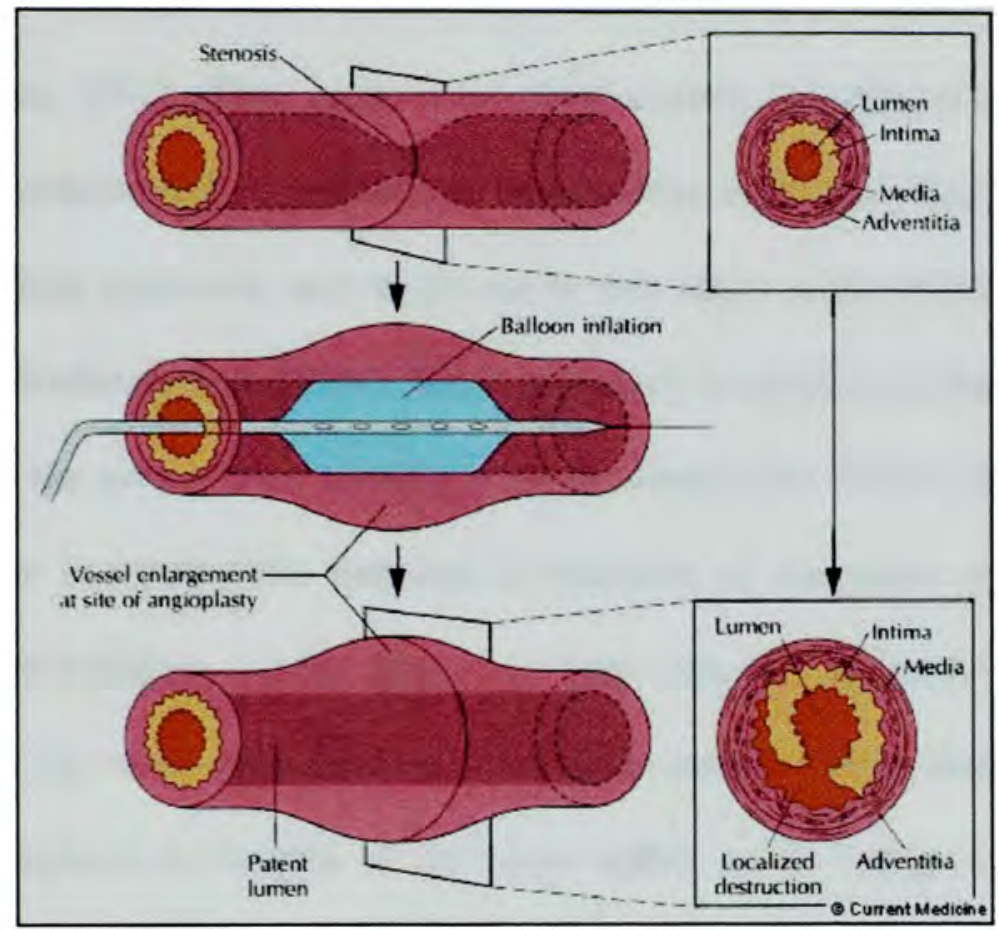

Figure 2-2. Overview of PTCA procedure (from: http://www.incirculationimagebank.net/03/).

PTCA, a less invasive and more affordable procedure, proved to be an attractive alternative to bypass surgery. When compared with coronary bypass graft surgery, patients treated with PTCA have lower initial costs and fewer complications. However, restenosis is angioplasty's major setback, limiting the long-term success of the procedure often requiring repeat revascularization in approximately $30 \%$ of patients within six months (Wurdeman et al., 1998). Of the more than 400,000 angioplasties performed 
every year in the United States, 30 to $40 \%$ of them result in a post-angioplasty restenotic lesion (King, 2002).

The use of intracoronary stenting has revolutionized catheter-based revascularization of stenosed vessels. Stents are hollow mesh-wire tubes made of stainless steel or a nickel-titanium alloy that are delivered via the angioplasty balloon or can be self-expandable and serve as scaffolding to hold the artery open, thereby restoring blood flow (Fox, 2002). They account for approximately $70-90 \%$ of all interventional cardiology procedures and in conjunction with balloon angioplasty have been found to significantly reduce restenosis rates as shown by two major trials reported by Serruys et al. (1994) and Fischman et al. (1994). Stents are purely a mechanical means of preventing early recoil of the artery, thus creating a larger lumen than PTCA alone. They have proven effective in treating the first two components of restenosis: elastic recoil and remodeling. Nevertheless, stents have not been entirely successful in eliminating restenosis due to tissue proliferation, and have actually been found to stimulate neointimal hyperplasia in $20-30 \%$ of the cases within six to twelve months following angioplasty (Fox, 2002). In-stent restenosis remains problematic, particularly in smaller vessels and longer lesions (Janicki et al., 1999) with rates ranging anywhere from 31$50 \%$ as reported by several animal and clinical studies (Fischell et al., 2000).

As a result of these findings, the interventional cardiology community has come up with a variety of techniques in an attempt to treat or prevent restenosis. Such techniques include balloon angioplasty, additional stenting or supplementing repeat balloon angioplasty with excimer laser, high-speed rotational atherectomy and directional atherectomy (King, 2002). Numerous pharmacological agents with antiproliferative 
properties have been tested for their potential to inhibit restenosis with mostly disappointing results (Serruys et al., 2001). Strategies consisting of local delivery of cytotoxic drugs and suicide gene therapy have been unsuccessful because of the risk of undesired toxicity to surrounding healthy tissues (King, 2002). These genetic and pharmacological interventions have great potential for success but mechanisms of drug delivery need much improvement before they can be considered the standard treatment modality. The use of ionizing radiation in intravascular brachytherapy has significantly reduced restenosis rates in several randomized trials (Sims, 2002; Kuntz, 2002), and is therefore considered to be one of the most promising methods for treatment and prevention of coronary artery restenosis.

\subsection{Restenosis}

Restenosis is clinically defined as a narrowing of the arterial lumen that is equal to or exceeds $50 \%$ of the lumen diameter in adjacent normal segments of that artery (King, 2002). The expanding angioplasty balloon can apply pressures of up to 20 atmospheres for time periods ranging from seconds to minutes. Not only does this expand the lesion site narrowed by plaque, but it can also disrupt and injure the tunicae intima and media and even the tunica adventitia of the arterial wall (Figure 2-3). Restenosis is the result of the overstretch injury and exaggerated wound healing response of the damaged artery wall stimulated by the application of these pressures during the angioplasty procedure. It is a complex problem, although three main mechanisms are identified as leading causes (King, 2002). 


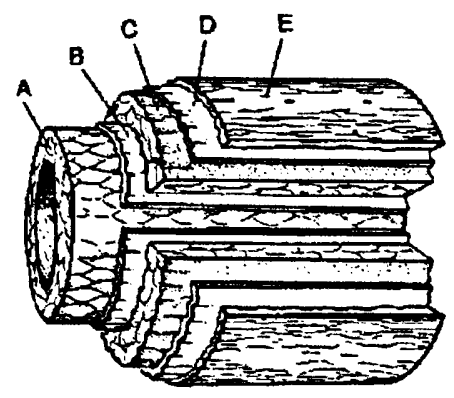
A: Tunica intima
B: Internal elastic lamina
C: Tunica media
D: External elastic lamina
E: Tunica adventitia

Figure 2-3. Anatomy of the artery wall

The first and most immediate mechanism is elastic recoil, which occurs promptly after the initial overstretch of the artery and does not seem to progress much beyond the first few minutes after the deflation of the angioplasty balloon (King, 2002). It represents the slow return of the overstretched tissue from the expansion of the balloon to its initial diameter. On average, this has been quantified at $50 \%$ of the artery cross-sectional area or one-third of the lumen diameter (King, 2002).

A second mechanism of restenosis has been identified as that of wound contracture or remodeling, which occurs in subsequent weeks following PTCA. The entire artery can become contracted so that the external elastic lamina occupies a much smaller circumference compared to what it did immediately following the procedure (Fox, 2002; King, 2002; Wilcox, 2002). Remodeling is in essence the change in artery diameter following coronary angioplasty, which can either be favorable or unfavorable. A favorable remodeling occurs when the artery is partially enlargened to compensate for neointimal growth and plaque. On the contrary, an unfavorable or negative remodeling occurs when the artery contracts, that is, the diameter decreases in addition to lumen loss caused by neointimal thickening (Pasterkamp et al., 2000; Schwartz and Holmes, 2002). 
It has been concluded through animal studies that the tunica adventitia plays an extremely important role in vascular remodeling, because it is this outermost layer that forms a ring of connective tissue around the artery (Rubin, 2002). The adventitia contributes to remodeling through a constriction of the external elastic lamina and an accumulation of myofibroblasts (Wilcox et al., 1996). Furthermore, several animal studies, as well as some clinical studies supported by intravascular ultrasound indicate that remodeling may be even more important than neointimal growth in the onset of restenosis (Mintz et al., 1996).

The third and last mechanism associated with restenosis is that of neointimal hyperplasia, which normally occurs within the first six months after stent implantation. Neointimal hyperplasia is characterized by an active and aggressive migration of smooth muscle cells from the outer layers of the artery and into the lumen, which can cause a very severe obstruction of the artery (Figure 2-4). It is mainly a proliferative response to overstretch balloon injury, which causes cracks and tears in the vessel wall (Fox, 2002; King, 2002). This injury leads to a series of immunological responses in which monocytes, macrophages and lymphocytes infiltrate the site of injury.

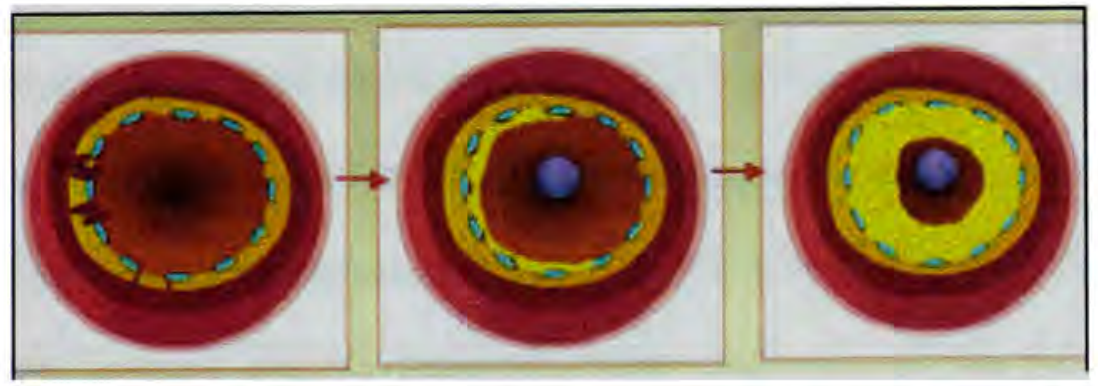

Figure 2-4. Restenosis as a result of neointimal hyperplasia 
Platelet aggregation follows, stimulating the release of certain cytokines such as PDGF, or platelet derived growth factor, which ultimately results in the proliferation of smooth muscle cells and myofibroblasts (King, 2002; Sims, 2002). This cascade of events eventually ends in the migration of smooth muscle cells from their usual location in the media and/or adventitia, to the intima. In a matter of weeks to months, this healing site begins to resemble a fibrous plaque as neointimal growth extends in to the arterial lumen resulting in restenosis.

\subsection{Radiation to Treat Restenosis}

Intravascular brachytherapy has emerged as an attractive candidate therapy for the treatment of restenosis and is considered a promising anti-restenosis technology (Kuntz and Baim, 2000; Serruys and Kay, 2000; Fox, 2002). It involves treating restenosis with a radioactive source within the arterial lumen. "Brachy" which means "short" in Greek, implies that a highly localized radiation is applied within short distances in the artery. Preclinical and clinical studies have generally shown that applying ionizing radiation in the dose range of 15-30 Gy can significantly reduce the incidence of restenosis in patients who have undergone angioplasty (Nath et al., 1999). The effects of ionizing radiation have been thoroughly studied for the past half-century, and its effects on cell death can be attributed to DNA damage in the form of single-stranded or more importantly, doublestranded breaks that ultimately result in chromosomal aberrations that prove to be lethal when the cell attempts division (Mitchell, 2002). This concept has been successfully. adopted by radiation oncologists for the treatment of cancer, and has also been applied for the treatment of restenosis. The rationale for use of intravascular irradiation to inhibit 
restenosis is based on the increased radiosensitivity of actively proliferating cells to the lethal effects of ionizing radiation. In intravascular brachytherapy, the most important mechanistic endpoint is the inability of a cell to clonogenically divide, thereby preventing restenosis due to neointimal hyperplasia and remodeling (Mitchell, 2002).

\subsection{Radiation Delivery Systems}

One method of irradiation is that of external beam treatments. Major advantages of this type of treatment include an extremely uniform dose delivery to the arterial wall as well as greater accuracy of dose calculations (Fox, 2002). However, because of the nature of this treatment, it is almost impossible to avoid radioactively treating significant portions of the heart and other tissues beyond it (Fox, 2002). This presents an undesired risk since it is well documented that irradiation can potentially induce coronary artery disease (Stewart et al., 1995). Furthermore, it has been documented that a late effect of external beam irradiation, when applied at a high rate can result in a fibrosis, leading to severe carotid or coronary artery restenosis (Silverberg at al, 1978).

\subsubsection{Catheter-based systems}

Brachytherapy of an intravascular nature for treatment of arterial restenosis can be delivered via two main platforms: temporary catheter-based systems such as radioactive ribbons and balloons and permanent implants in the form of radioactive stents. In catheter-based systems, high-intensity radioactive sources in the form of thin wires, seeds, or ribbons attached to the end of a specially designed catheter are introduced to the site of angioplasty (Fox, 2002; Sims, 2002). For example, in a catheter-based $\gamma$ - 
irradiation system, a ribbon containing sealed sources of ${ }^{192}$ Iridium is inserted into a catheter. An angiogram confirms that the region is in place, covering in entirety the region of interest, and after 10-20 minutes, the ribbon is removed. The Cordis Checkmate IRT $\square$ is one such system involving ${ }^{192}$ Ir that consists of an array of cylindrical-shaped seeds contained in a nylon ribbon (Jani et al., 2002). Alternatively, a catheter-based $\beta$ irradiation system delivers $\beta$-emitting radioisotopes such as ${ }^{32} \mathrm{P}$ or ${ }^{90} \mathrm{Y}$ to the treatment area for a period of 2-5 minutes. The Guidant Galileo $^{\text {TM }}$ Intravascular Radiotherapy System is an example of a catheter-based system that uses a ${ }^{32} \mathrm{P}$ wire as the radiation source (Raizner et al., 2002). Radioactive sources are also encased to form a "seed train" that can be delivered to the lesion site using a manual or hydraulic system. The Novoste Beta-Cath $^{\mathrm{TM}}$ is one another device that uses a hydraulic system to deliver the betaemitting ${ }^{90} \mathrm{Sr} /{ }^{90} \mathrm{Y}$ radioactive seeds to the lesion site using a closed catheter (Jani et al., 2002). The Cordis Checkmate ${ }^{\mathrm{TM}}$ system and Novoste's Beta-Cath ${ }^{\mathrm{TM}}$ system were FDA approved in 2000 , and the Guidant Galileo ${ }^{\mathrm{TM}}$ system was approved in 2001. All of these systems are currently implemented in a clinical setting. These methods have given satisfactory results, although centering and geographic miss pose some problems.

Since the angioplasty procedure entails the insertion of saline-filled balloon into the artery, this suggests that a balloon filled with a radioactive liquid, such as liquid ${ }^{186} \mathrm{Re}$ can be a feasible method of delivering radiation to the artery wall. The main advantage of radioactive liquid-filled balloons, perhaps over all of the other types of brachytherapy, is that it can be applied to all arteries, regardless of size, degree of calcification and tortuosity (Fox, 2002; Weinberger and Knapp, 2002). In addition, a radioactive liquidfilled balloon guarantees adequate centering in the arterial lumen, feat that is not as easily 
achieved in catheter-based systems. However, there are some concerns about balloon rupture, which could deliver high doses of radiation directly into the patient's blood stream. Because there is such risk in spillage of radioactive liquid, and the potential damage to the patient and lab personnel, as well as the logistics involved in filling, handling and disposing of radioactive solutions, radioactive liquid-filled balloons proves to be a cumbersome technique and not the method of choice of many clinicians (Fox, 2002).

The use of gas-filled balloons in intravascular brachytherapy has also been explored. This approach is similar to the liquid-filled balloon approach but with the radioactive material in a gaseous state. ${ }^{133}$ Xenon has been investigated as a candidate for this type of radiation delivery system (Apple and Waksman, 2002). The balloon dilation catheter is filled with the radioactive gas and dilated at the lesion site so as to deliver the radiation dose to the arterial wall. The inert chemical property of ${ }^{133} \mathrm{Xe}$ offers enormous safety and limits radiation exposure to the medical staff. Other novel approaches being tested for intravascular brachytherapy include the catheter-based soft x-ray generator and the ${ }^{99 \mathrm{~m}} \mathrm{Tc}$ injecting system (Fox, 2002; Apple and Waksman, 2002).

\subsubsection{Radioactive Stents}

Permanent implants in the form of radioactive stents have been a very attractive proposal since their foundation (Hehrlein and Kubler, 1997; Fischell, 1888;2000; Fox, 2002). A radioactive stent eliminates the need of a repeat revascularization, as the angioplasty/stenting procedure is done in concurrence with the irradiation procedure. Furthermore, procedures in the catheterization lab are identical to those already 
performed, as radioactive stents are delivered via the femoral artery to the target site in the same manner as non-radioactive stents. Radioactive beta-emitting stents offer the advantage of uniform dosimetry, safety for laboratory personnel, as well as easy storage (Fox, 2002). Because it is a permanent implant, problems with adequate disposal of radioactive materials are eliminated. Adequate centering of the radioactive source, which is a problem with radioactive wires and seeds, is not an issue with radioactive stents because of the direct contact with the vessel circumference (Fischell, 1998; Fox, 2002). Artery wall irradiation after radioactive stent implantation is maintained in the days and weeks following the procedure, thereby covering the whole period of cell proliferation (Fischell, 1998; John et al., 2001).

The activity of a radioactive stent is up to 10,000 times lower than the activity levels of other sources used in catheter-based vascular brachytherapy (Hehrlein and Kubler, 1997; Fischell, 1998). Although stent activities are much lower, the total dose delivered by a permanently implanted stent is similar to that of a high activity radioactive seed. The main distinction between the two is the time sequence in which the radiation is delivered. For example, a $1 \mu \mathrm{Ci}{ }^{32} \mathrm{P}$ stent, which has a half-life of 14 days, delivers the same total dose as a 5-minute exposure of a $6 \mathrm{mCi}^{32} \mathrm{P}$ wire (Amols, 1999). Furthermore, this low level of activities allows manual handling and eliminates the need for radioisotope licensing in the catheterization lab. Radioactive stents have an inherent dosimetry advantage in that the radioactive source is in intimate contact with the artery wall. However, the dose distribution is extremely nonuniform due to the gridded nature of stent geometry. 
Radioactive stents combine both mechanical and therapeutical benefits for restenosis prevention. The stent itself, due to its scaffolding action, supports the artery wall, while radiation prevents growth of smooth muscle cells that can occlude the lumen of the artery. In addition, it has been observed that ionizing radiation, or vascular brachytherapy can have some favorable effects on treating the remodeling aspect of restenosis by inhibiting the proliferation of the adventitial myofibroblast (Rubin, 2002). When looking at the post-angioplasty artery as a wound undergoing a process analogous to wound contraction, the adventitial myofibroblast is believed to occupy a pivotal role in constricting the blood vessel, thus leading to a lumen narrowing in the case of a negative remodeling (Scott et al., 1996; Wilcox et al., 1996; Rubin, 2002). In consequence, it can be postulated that a radioactive stent, with proper usage, radioisotope selection and initial activity, can be extremely promising in treating the three mechanisms associated with restenosis: early recoil, due to the scaffolding action, and constrictive remodeling and neointimal hyperplasia as a consequence of ionizing radiation.

\subsubsection{Preclinical Studies (Animal Studies)}

Stent-based coronary brachytherapy to prevent restenosis has been studied in preclinical and clinical trials for almost a decade. Several animal models have given testimony to the fact that radioactive stents are capable of reducing or even eliminating neointimal hyperplasia. In 1994, Fischell et al. demonstrated that a ${ }^{32} \mathrm{P}$ impregnated stent wire with an activity of $0.006 \mu \mathrm{Ci}$ inhibited smooth muscle cell proliferation in cell culture. Hehrlein et al. (1995) were the first to describe the use of radioactive stents, 
which they implanted in non-diseased rabbit iliac arteries. The results of their study, using radioactive stents with low doses (max. $35 \mu \mathrm{Ci}$ ) potently inhibited smooth muscle cell proliferation and neointimal hyperplasia in the rabbit model (Hehrlein et al., 1995). They found that neointima formation was markedly reduced by the implantation of the radioactive stent in a dose-dependent fashion. In the control model, in which a nonradioactive stent was implanted, there was a $30 \pm 2 \%$ neointimal growth compared to the $0.5 \pm 0.1 \%$ seen in the model with the radioactive stent implanted (Hehrlein et al., 1995).

Carter and Laird (1996) reported studies in swine models using low-dose irradiation from $\beta$-particle emitting stents. The initial stent activity was $0.14 \mu \mathrm{Ci}$ and the dose delivered to the arterial wall was approximately 3 Gy over the 4-week study period. A $37 \%$ reduction in neointimal area and a $32 \%$ reduction in stenosis for $\beta$-particle emitting stents were observed when compared to non-radioactive control stents at the end of the 4-week period. In another set of experiments by Carter et al. (1999), the effects of beta particle-emitting stents with activities ranging from $3-23 \mu \mathrm{Ci}$ were evaluated in normal pig coronary arteries. At 28 days from implantation a reduction in the medial and neointimal cell density was observed which inversely correlated with the radiation dose. Neointimal proliferation was also lower for the radioactive stent as compared to the nonradioactive stent. Several other studies have been performed in different animal models such as the porcine and canine model with overall inconsistent results (Carter and Fischell, 1998; Virmani et al., 2002). 


\subsubsection{Clinical Studies}

Animal models can only partially mimic the restenosis process after angioplasty and stent implantation in humans. In 1996, IRIS (Isostent for Restenosis Intervention Study) was the first study done on patients using the ${ }^{32} \mathrm{P}$ Palmaz-Schatz stent. In this study, 30 patients underwent successful stent placement with an activity between 0.5 and $1.5 \mu \mathrm{Ci}$ (Hehrlein and Fischell, 2002). Thirty days post-treatment, there were no adverse effects, and in fact a considerable expansion of the arterial lumen was observed. However, a 6-month follow-up revealed a $31 \%$ restenosis rate.

The Milan dose-response study (Albeiro et al., 2000a), which ran from October 1997 to October 1998, explored the short and intermediate term results of the ${ }^{32} \mathrm{P}$ stent in patients with coronary artery disease. Eighty-one patients were used for this study, and they were divided into three groups depending on the activity level of the stent: $0.75-3.0$ $\mu \mathrm{Ci}$ (Group 1), 3.0-6.0 $\mu \mathrm{Ci}$ (Group 2) and 6.0-12.0 $\mu \mathrm{Ci}$ (Group 3). This trial demonstrated the safety of using these ranges of activity levels. The low incidence of late thrombosis was also observed. After a 6-month follow-up, no deaths occurred and intra-stent neointimal hyperplasia was reduced in a dose-related manner, but intra-lesion restenosis rates were 52\% in Group 1, 41\% in Group 2 and 50\% in Group 3 (Albeiro et al., 2000a). This trial generated disappointing results in that they identified the "candy wrapper effect", or edge restenosis. It is hypothesized that decreased radiation doses at the edges of the stent might actually stimulate restenosis, while higher doses in the middle inhibit it (van der Giessen et al., 2001). Barotrauma at stent edges during the implantation procedure might be a factor as well. A second phase of this trial was initiated using 
higher activity levels, but yielded similar results despite less aggressive implantation techniques using pressures of only 8 to $10 \mathrm{~atm}$ (Albeiro et al., 2000b).

Other European clinical studies involving the implantation of ${ }^{32} \mathrm{P}$ radioactive stents were conducted in Vienna and Rotterdam. The Rotterdam group did not observe cases of edge restenosis in ${ }^{32} \mathrm{P}$ radioactive stents of 0.75 to $1.5 \mu \mathrm{Ci}$ (Hehrlein and Fischell, 2002). However, they reported a restenosis rate of $43 \%$ occurring only at stent edges in an additional group of lesions treated by ${ }^{32} \mathrm{P}$ radioactive stents of higher activities in the range of 6 to $12 \mu \mathrm{Ci}$. The Vienna group treated 36 patients with ${ }^{32} \mathrm{P}$ radioactive stents with activities between 5.36 and $20.77 \mu \mathrm{Ci}$. At a 6-month follow-up, 15 patients showed signs of edge restenosis (Hehrlein and Fischell, 2002).

\subsubsection{Edge Restenosis or "Candy Wrapper Effect"}

Despite much hope and hype and an overall initial success in reduction of neointimal area, some clinical and animal trials have exposed several pitfalls pertaining to the radioactive stent. Most notably, the biggest hindrance of radioactive stents, is that of edge restenosis, nicknamed the "candy-wrapper effect" because of its appearance in an angiogram. Figure 2-5 shows the tight stenosis at the stent edges, which are marked by arrows. This phenomenon has generally been observed 2 to $3 \mathrm{~mm}$ distal and proximal to the stent (Albeiro et al., 2000b; Serruys and Kay, 2000; van der Giessen et al., 2001). This is believed to be the cause of inadequate dose delivery to target tissues after they have been injured by the angioplasty procedure. The angioplasty balloon that delivers the radioactive stent is usually longer than the stent itself resulting in barotrauma at the edges 
to which there is no radiation and therefore no inhibition of cellular growth. Experimental results from animal models have also suggested that low doses of radiation might in fact

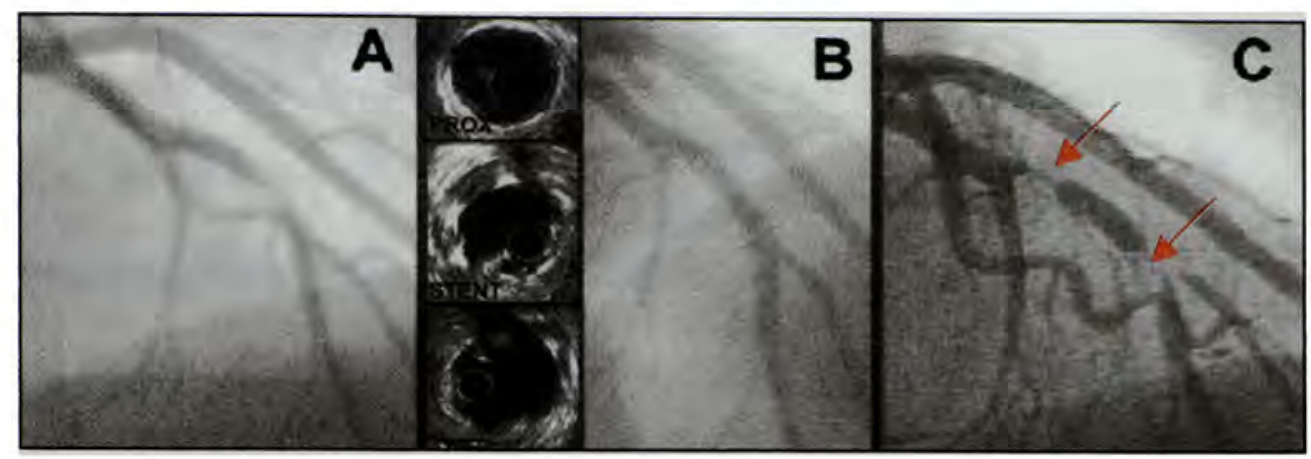

Figure 2-5. Edge restenosis as seen in an angiogram (Circulation, Albeiro et al., 2000b).

stimulate neointimal growth (Amols, 1999a). Another cause is geographic miss, or failure of completely irradiating the target lesion. Finally, edge restenosis can also be a result of the basic physics of a radioactive stent. At the ends of the stent, the dose will be very close to $50 \%$ of its value at the center due to steep dose gradients, especially in the case of beta emitters (Amols, 1999a; Serruys and Kay, 2000; van der Giessen et al., 2001).

\subsection{Beta and Gamma Emitters: Radioisotopes in Intravascular Brachytherapy}

The radioisotopes used in intravascular brachytherapy include both beta and gamma emitters. Radiation energy from beta emitters in characterized by high energy with low tissue penetration applied in short time periods, which diminishes rapidly with distance from the source. Nevertheless, beta particle emitters in contact with the arterial wall are for the most part sufficient to induce cell death of superficial smooth muscle cell layers in the intima and media, but not the adventitia (Amols, 1999a; Fox, 2002). 
However, the limited depth of penetration of beta emitters poses the advantage of minimal exposure to adjacent tissues.

Yet, despite the fact that beta emitters are practical for use in the catheterization lab because of minimal exposure to remote tissues and staff, they can also present some challenges for effective delivery of radiation to the arterial wall in the case of large, highly calcified vessels, and the rapid fall-off dose may also be problematic. Gamma emitters, on the other hand, offer the advantage of higher tissue penetration, making it ideal for larger vessels with highly calcified plaques. Gamma radiation generally has lower energy, but it must be applied for larger periods of time for maximum effectiveness (Amols, 1999a; Fox, 2002). As a result, much more precaution must be taken to shield the surrounding tissues as well as the catheterization lab personnel. Beta emitters also yield higher doses per emission than $\gamma$-sources and hence the specific activities required for $\beta$-emitters are at least an order of magnitude lower than for $\gamma$-sources. It is also important to note that the dose rate for a given activity of a beta-emitter is much greater than for a similar activity of a gamma-emitter (Fox, 2002). Therefore, a beta-emitting source has a much lower activity than a gamma-emitting source. Table 2-1 shows the properties of some the radioisotopes used in IVBT.

In IVBT, particularly in the case of a permanent implant such as a radioactive stent, the selection of the radioisotope in critical. A compromise between an acceptable half-life, energy, range and ease of production is necessary for a cost-efficient and feasible production of a radioactive stent. The ideal radioactive source would be one that displays a low energy gamma emission, which would provide a uniform dose distribution 
Table 2-1. Properties of Radioisotopes used in IVBT (animal trials, clinical trials, theoretical calculations).

\begin{tabular}{|c|c|c|c|c|}
\hline Isotope & $\begin{array}{c}\text { Emission } \\
\text { Type }\end{array}$ & Half-life & $\begin{array}{c}\text { Average } \\
\text { Energy } \\
\text { (MeV) }\end{array}$ & $\begin{array}{c}\text { Maximum } \\
\text { Energy } \\
(\mathrm{MeV})\end{array}$ \\
\hline${ }^{32} \mathrm{P}$ & Pure $\beta$ - & $14.28 \mathrm{~d}$ & 0.695 & 1.709 \\
\hline${ }^{90} \mathrm{Y}$ & $\beta-$ & $2.67 \mathrm{~d}$ & 0.761 & 2.282 \\
\hline${ }^{192} \mathrm{Ir}$ & $\begin{array}{l}\beta- \\
\gamma\end{array}$ & $73.8 \mathrm{~d}$ & $\begin{array}{c}0.224 \\
\text { NA }\end{array}$ & $\begin{array}{l}0.672 \\
0.317\end{array}$ \\
\hline${ }^{133} \mathrm{Xe}$ & $\begin{array}{c}\beta- \\
\gamma\end{array}$ & $5.243 \mathrm{~d}$ & $\begin{array}{c}0.115 \\
\text { NA }\end{array}$ & $\begin{array}{l}0.346 \\
0.081 \\
\end{array}$ \\
\hline${ }^{188} \mathrm{Re}$ & $\begin{array}{c}\beta- \\
\gamma\end{array}$ & $16.94 \mathrm{hr}$ & $\begin{array}{c}0.706 \\
\text { NA }\end{array}$ & $\begin{array}{l}2.118 \\
0.155\end{array}$ \\
\hline${ }^{103} \mathrm{Pd}$ & X-rays & $16.99 \mathrm{~d}$ & $\overline{\mathrm{NA}}$ & 0.040 \\
\hline${ }^{125} \mathrm{I}$ & $\mathrm{X}$-rays & $59.4 \mathrm{~d}$ & NA & 0.046 \\
\hline${ }^{48} \mathrm{~V}$ & $\begin{array}{c}\beta+ \\
\gamma\end{array}$ & $16 \mathrm{~d}$ & $\begin{array}{c}0.230 \\
\text { NA }\end{array}$ & $\begin{array}{l}0.690 \\
0.511 \\
\end{array}$ \\
\hline${ }^{131} \mathrm{Cs}$ & $\gamma$ & $9.7 \mathrm{~d}$ & NA & 0.030 \\
\hline
\end{tabular}

and negligible doses to surrounding healthy tissues. Similar dose characteristics could also be obtained with a very high-energy beta emitter (Amols, 1999a). Unfortunately, these ideal sources do not exist as most commonly available gamma sources are of too high an energy, or too low an activity and dose rate. Similarly, most beta sources have too low an energy, too short a half-life, or excessive amounts of gamma contamination (Amols, 1999a). In addition, half-life considerations are extremely important. It should be long enough to cover the period of cell proliferation after the onset of restenosis, yet short enough to not cause any detrimental effects as a result of permanently remaining in the body. 


\subsection{Treatment Planning for Radioactive Stents}

Unlike the situation with a cancerous tumor, where one is interested in killing all cells, intravascular brachytherapy does not set out to completely liquidate all the cells responsible for causing artery obstruction. Doing so would mean application of higher than wanted doses which would inevitable lead to injury to unwanted tissues, leading to a number of complications and adverse effects. Instead, the inherent focus of this treatment is to limit the proliferative potential of a group of clonogenic cells, whether they are smooth muscle cells from the media or adventitia (Brenner et al., 1996; Hall et al., 1999). Because smooth muscle cells are somatic cells, they have limited cycles of cell division before they naturally senesce, and therefore do not require the high doses of radiation that cancerous cells for effective treatment of the problem. It is only necessary to inhibit the proliferation of a considerable portion of the cell population so that the surviving fraction of cells runs out of reproductive ability before sufficient progeny are produced to cause restenosis (Brenner et al., 1996; Hall et al., 1999). This presents the notion of a therapeutic window, a rather narrow margin between the radiation dose required to effectively treat the problem, and that which can result in undesirable damage to the artery wall. A very low dose, such as $10-12$ Gy might not be enough to effectively treat the problem, or might delay rather than prevent restenosis, while a dose near 30 Gy might be excessive, causing unwanted injury to healthy tissues. It is believed that a dose somewhere between 15-30 Gy might be enough to inhibit restenosis (Hall et al., 1999; Nath et al., 1999).

The use of a treatment planning system in vascular brachytherapy can provide the interventional cardiologist with a tool for prescribing, evaluating and reporting the dose 
given to a patient, or an animal in the case of animal studies. It can provide a means of documenting the treatment given, as well as further customizing the radiation dose for an individualized treatment plan (Fox, 1999). It may also allow an opportunity to retrospectively evaluate the influence of dose on the success or side effects of the treatment. Most importantly, this type of treatment planning process can be used to evaluate different treatments and give an a priori evaluation of the overall effectiveness of the treatment.

\subsection{Radiobiological Considerations}

Designing an optimal treatment for brachytherapy, or any other radiotherapy treatment for that matter, requires a detailed knowledge of radiobiological principles. Although animal studies and clinical trials provide the physical evidence of the efficacy of a treatment, a radiobiological perspective is necessary in understanding the fundamentals of any in vivo study. Radiation can inhibit restenosis because it kills cells by direct ionization of DNA, or by the creation of free radicals, which can interact with nearby water molecules (John et al., 2001; Mitchell et al., 2002). The free radicals and reactive ions produced by indirect effects, or radiation deposited directly can alter the purines and pyrimidines (bases) in DNA resulting in point mutations and cross-links, as well as disruption in the integrity of the phosphodiester bonds which join the nucleotides in each of the DNA strands. This can lead to double or single-stranded breaks in the DNA, translocations, and chromosome aberrations in the form of dicentrics and rings, all of which can potentially limit the proliferative potential of the cell eventually resulting in 
cell death (Hall, 1988, 1999; Mitchell, 2002). These ideas are illustrated in figures 2-6 and 2-7.

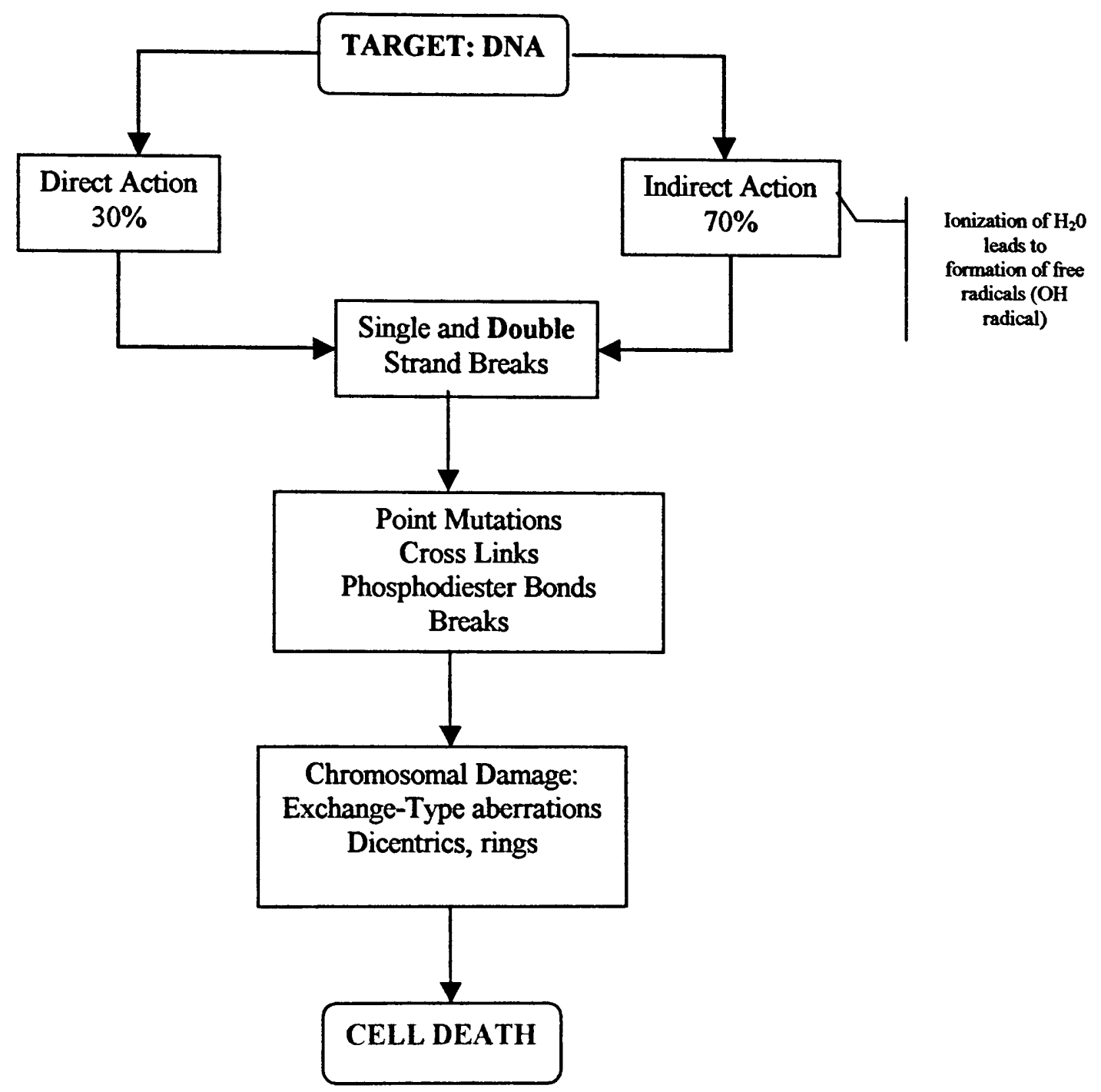

Figure 2-6. Mechanism of Damage of Ionizing Radiation 


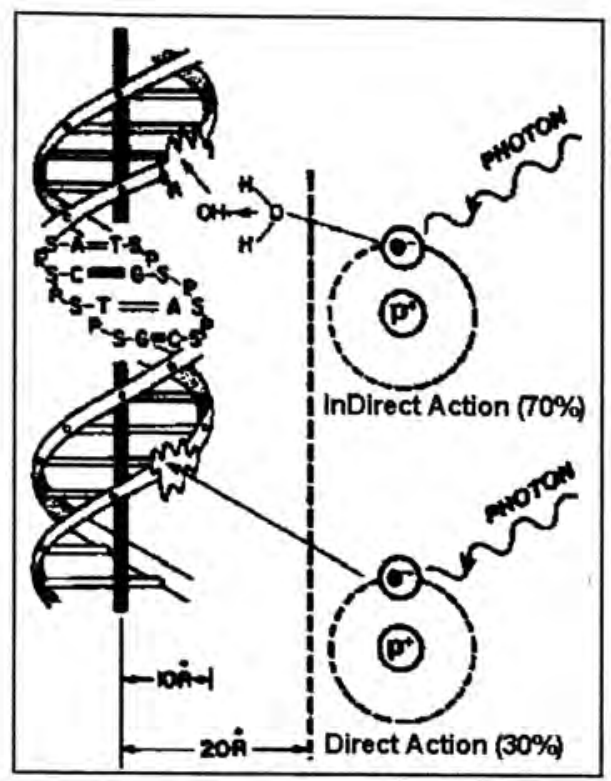

Figure 2-7. Direct and Indirect Action of Ionizing Radiation

Several studies in the 1960's demonstrated that certain portions of the cell cycle are more susceptible to radiation effects, with cells in G2 and mitosis stages of the cell cycle being the most radiosensitive (Hall et al., 1988). Damage occurs more readily when the chromosomes are greatly condensed in mitosis. This is important because tumor and cancer cells, or rapidly proliferating cells, undergo division more often than normal cells, and are therefore more susceptible to damage. This property is the foundation of why radiation is so successful in treating cancer. Therefore, rapidly dividing cells in the neointima are more susceptible to radiation and the reason why this treatment is successful in treating restenosis (Mitchell, 2002).

Biological tissues have the ability to accumulate and repair radiation damage. In terms of modeling the lesions to DNA, there are two main kinds of lesions: repairable 
lesions and irreversible lesions (Mitchell, 2002). A repairable lesion has a good probability of being repaired or misrepaired by at least one biochemical repair pathway. An irreversible lesion, on the other hand, has no chance of being repaired, and can be further sub-divided into fatal lesions and non-lethal mutations, which eventually result in cell death (Mitchell, 2002). Low levels of radiation can lead to a delay in cell division from which the cell can gradually recover and continue to divide as normal. Higher doses of radiation may inhibit cell division permanently, thus not allowing the cells to divide, ultimately resulting in death.

Central to the subject of radiobiology is the linear quadratic formalism or LQ model. Dose-response or dose-survival curves for all dose rates are fit to the linear quadratic formalism, which expresses the surviving fraction (S) of cells as a function of dose (D) (Dale, 1985; Brenner, 1997).

$$
S=e^{-\alpha D-\not D^{2}}
$$

The constants $\alpha$ and $\beta$ are characteristic of a given cell type and have units of $\mathrm{Gy}^{-1}$ and $\mathrm{Gy}^{-2}$ respectively. The ratio $\alpha / \beta$ is expressed in units of $\mathrm{Gy}$ and is of great clinical significance because it is a measure of the fractionated sensitivity of a tissue (Dale, 1993). They are also measures of two separate cell kill processes, type A and B (Giap et al., 1999). Type A damage is characterized by two critical targets (DNA strands) being hit simultaneously by a single radiation event resulting in cell death without repair (Dale, 1985; Giap et al., 1999). Type A damage is directly related to the linear component of the linear-quadratic formalism, $\alpha \mathrm{d}$. In Type $\mathrm{B}$, which is related to $\beta \mathrm{d}^{2}$ damage, each of the two critical sites is hit in sequence by different radiation events. When one of the two 
critical sites is damaged, there is evidence of sublethal damage. Over a period of time, the cell can either be killed by accumulation of sublethal damage or it can be repaired. At lower doses, the linear component dominates, while at higher doses, the quadratic term starts to dominate (Mitchell, 2002).

The LQ model is used for the radiobiological assessment of a particular radiation therapy. The biological effects of radiation are dependent on the parameters BED and RE which are derived from the LQ model, as they take into account $\alpha$ and $\beta$ constants of a given tissue, or more importantly the ratio of the two. Biological equivalent dose (or (BED) (also referred to as ERD or extrapolated response dose), is a single-figure measure of the biological effectiveness of a dosing strategy on a particular tissue (Dale 1985, 1993). The concept of BED is key in comparing different treatments, but the calculation of BED is made through another fundamental LQ parameter RE, or relative effectiveness per unit dose (Dale, 1985, 1993; Giap et al., 1999). RE is dimensionless and measures the effectiveness of a given unit of dose to cause a specific biological endpoint taking into account the dose rate and repair capability of the tissue (Giap et al., 1999). BED (units are Gy) is equal to the product of RE and the absorbed dose at a specific point (Dale, 1985, 1993; Giap et al., 1999). Thus far, there is no radiobiological assessment of radioactive stents employing the concepts of $\mathrm{BED}$ and $\mathrm{RE}$ for comparing dosing strategies with different radioisotopes.

\subsection{Target Tissue}

There is yet to be a consensus as to what is the target tissue to be irradiated. In addition, a tolerance dose for the artery wall has not been established. It had long been 
speculated that neointimal growth was the result of proliferation of smooth muscle cells in the tunica media (Hehrlein et al., 1995). This fact has been challenged by the tunica adventitia as the source of proliferating cells, in particular the adventitial myofibroblast, which migrates through the media in to the arterial lumen (Scott et al., 1996; Wilcox et al., 1996, 2002). The different layers of the artery wall and their respective thicknesses are shown in Figure 2-8.

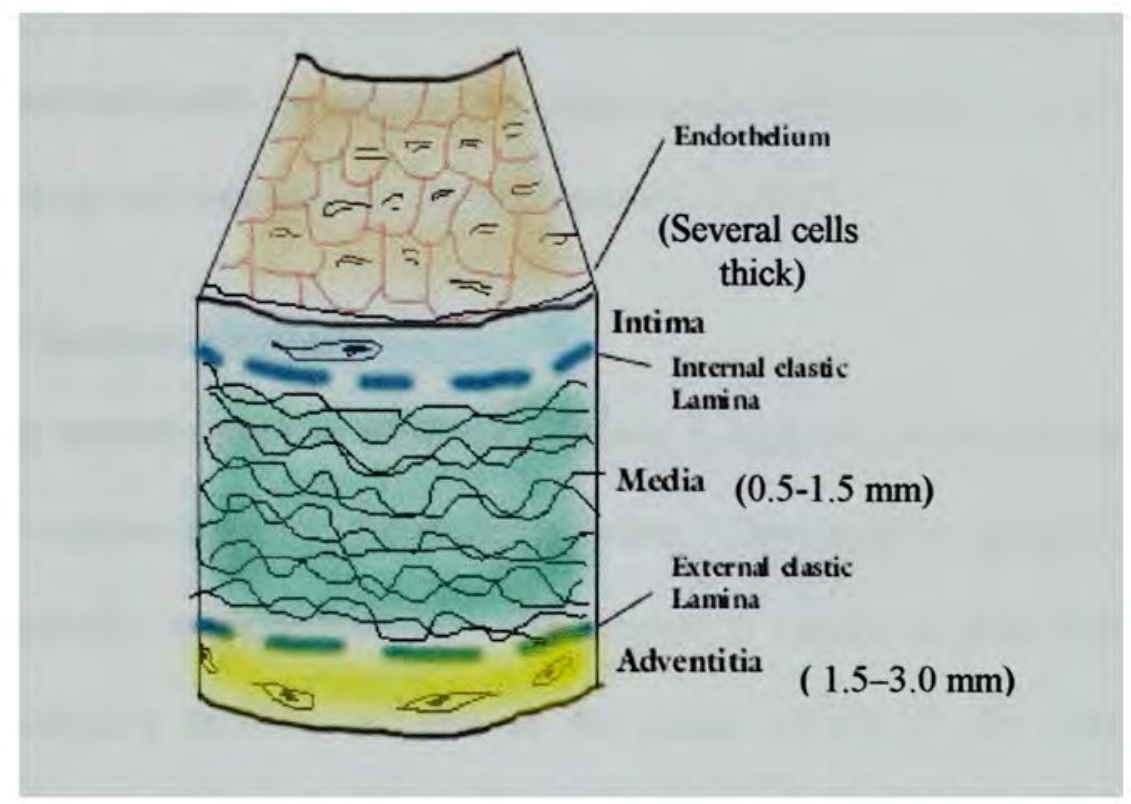

Figure 2-8. Thickness of artery wall layers

If this in fact is the case, then an effective radiation dose needs to be delivered at least 1 to $2 \mathrm{~mm}$ from the artery lumen (Fox, 2002). Further studies on the cellular cascade of events associated with restenosis present two main hypotheses. One points to the myofibroblast as being the target cell of interest, while the other focuses on the monocyte-derived macrophage (Rubin et al., 2002). The monocyte-derived macrophage has received much attention because it is a key manufacturer of a number of cytokines 
and growth factors responsible for the activation and promotion of myofibroblast or smooth muscle cell proliferation (Rubin et al., 1998, 2002). At present, most investigators believe the target lies in the adventitia with either macrophages or myofibroblasts being the cells responsible for triggering the complex biological processes that ultimately lead to medial smooth muscle cell proliferation and restenosis (Wilcox et al., 1996, 2002; Fox, 2002; Rubin et al., 2002). This further illustrates the overall complexity of the restenosis problem, and the interplay of factors that must come together in order to render any antirestenosis treatment successful. In general, for restenosis modeling purposes, it is correct to deliver radiation up to $3 \mathrm{~mm}$ from the arterial lumen (Fox, 2002).

\subsection{Dosimetry of Radioactive Stents}

Dosimetric considerations in all forms of brachytherapy are extremely important. In the case of the radioactive stent, the matter is further complicated by the fact that the stent is a permanently implanted device. This implies a careful consideration of a particular radioisotope's half-life, as well as the initial activity of the stent. The dosimetric characterization of the radiation field in both longitudinal and radial directions, of any brachytherapy source is generally the first step prior to animal and clinical studies that might pave the way for future commercialization of a particular treatment.

In conventional brachytherapy dose delivered to a target point is specified at a distance of $1 \mathrm{~cm}$ from the source (Nath et al., 1999). Consequently a large volume of experimental and theoretical dosimetry data is available for source to target distances of 1 $\mathrm{cm}$ or more and the dosimetry of both gamma and beta emitters is well established at 
these distances. In vascular brachytherapy, the distribution of radiation dose around the source is difficult to measure because the sources have very small diameters and the dose distribution must be determined very close to the source, usually less than $5 \mathrm{~mm}$ (Amols, 1999a; Fox, 1999; Nath et al., 1999). At such small distances the dosimetry is complicated due to the steep dose gradients, low energy secondary radiations and selfshielding effects of the radioactive source. The uncertainties in dosimetry are larger for low-energy beta-emitting sources than for gamma sources due to the limited range of the beta particles and the effect of heterogeneities in the medium (Amols, 1999a; Nath et al., 1999).

The near-filed dose distributions of a radioactive stent can be determined by both theoretical and experimental methods. Theoretical calculations are obtained from dose point kernel calculations and from Monte Carlo simulations. The dose point kernel (DPK) describes the distribution of absorbed dose around point-isotropic sources of electrons and beta particles in water (Berger, 1971; Prestwich, 1989; Cross, 1992). In 1995, Prestwich et al. presented the results of a dose distribution study around a uniform cylinder of ${ }^{32} \mathrm{P}$ using the DPK method. In this model, the source of radioactivity was uniformly distributed on the two-dimensional surface of a cylinder. The stent can be modeled as a cylinder, although it in fact possesses a quite intricate and detailed geometry. The gridded architecture of a stent is an important consideration of these dosimetric determinations as the radiation is expected to be higher in the proximity of the struts than in the spaces in between struts. To overcome this problem and to elaborate on the model presented by Prestwich et al. (1995), another group of researchers calculated the near-field dose of $\mathrm{a}^{32} \mathrm{P}$ stent using the dose point kernel and a cylindrical coordinate 
system to simulate the wire mesh geometry of the stent (Janicki et al., 1997). The dose distribution generated by the beta particles emitted from the radioisotope was computed at distances ranging from 0.1 to $3 \mathrm{~mm}$ from the stent surface. A later study by Janicki et al. (1999) introduced a new model taking into account the scaling property of the dose point kernel function which can be extended to a heterogeneous medium with a density different to that of water. Because in a realistic artery the presence of plaque can allow attenuation of the beta particles, incorporating plaque density in a theoretical model has some advantageous effects.

Monte Carlo simulations have also been used by several groups of investigators to study the dose distributions surrounding radioactive stents ( $\mathrm{Li}$ et al., 1998; Reynaert et al., 1999, 2001; Fox and Henson, 2000). Monte Carlo codes, in particular the MCNP (Monte Carlo N-Particle Transport Code System), is a multimaterial, 3-D, arbitrary geometry, electron/photon/neutron transport code developed at the Los Alamos National Laboratory ( $\mathrm{Li}$ et al., 1998). This type of theoretical simulation can be achieved by specifying the specific energy assumed for the radioactive source, the architecture assumed for the stent, the specific depth assumed for the radioactive species in the stent material, and the inclusion or exclusion of nonhomogenous material or the absorption or scatter of stent struts (Coffey and Duggan, 2002).

\subsection{AAPM Task Group 60 Report}

The AAPM (American Association of Physicists in Medicine) Task Group 60 has developed a series of recommendations based on several early dosimetric studies for dose specifications in intravascular brachytherapy (Nath et al., 1999). It is recommended to 
use $0.5 \mathrm{~mm}$ from the surface of the stent as the reference depth and a total treatment time of 28 days as a common framework for the dose field characterization (Nath et al., 1999). A time period of 28 days is reasonable because it falls within the time frame of restenosis onset, namely the first few weeks to two months after stent placement. The desired objective of the dosimetric characterization of a radioactive stent is to determine the $3 \mathrm{D}$ dose rate per unit of activity around the stent deployed in an angioplasty balloon catheter, as well as to demonstrate the circumferential and longitudinal uniformity of the dose delivered by the stent (Nath et al., 1999). Furthermore, the AAPM recommends that the three-dimensional dose distributions around the stent be carefully determined before animal and clinical trials. The model described in this study will take into account the recommendations of the AAPM, although it will be equipped to calculate the dose at a depth less than $0.5 \mathrm{~mm}$ and times greater or less than 28 days. The results presented in this work are for lifetime doses delivered by the stent under the assumption that the stent is a permanent implant unless otherwise stated. 


\section{CHAPTER 3 \\ MATERIALS AND METHODS}

This chapter provides an outline of the development of the radiation dosimetry and radiobiological model that was used to calculate the $3 \mathrm{D}$ dose distribution and radiobiological effectiveness of a radioactive stent. It includes the set of equations that govern the dose point kernel convolution method, the calculation of beta and gamma dose point kernels, and the equations of the radiobiological model. In addition, information on the stent geometry that was used, as well as details on the algorithm using the dose point kernel convolution and the different dose calculations that were done is also provided in this section. This chapter closes with the validation of results obtained from the dose point kernel convolution method to those obtained through Monte Carlo simulations.

\subsection{Radiation Dosimetry Model}

The radiation dosimetry model is based on the dose point kernel (DPK) convolution. Several investigators have used the dose point kernel for calculation of 3D dose distribution of radioactive stents (Prestwich, et al.., 1995; Duggan et al., 1998; Janicki et al., 1997, 1999). The dosimetry model is equipped for the calculation of absorbed dose at any specified point defined radially and longitudinally from the surface of the stent. In addition to its versatility regarding stent geometries, it will also allow dose calculation of stents with different radioisotopes or combinations of radioisotopes and initial activities. In this project, the dosimetry of a ${ }^{177} \mathrm{Lu},{ }^{32} \mathrm{P},{ }^{188} \mathrm{Re}$, and ${ }^{90} \mathrm{Y}$ stent was determined as well as that of combinations of these radioisotopes. 


\subsubsection{Dose Point Kernel Convolution}

Absorbed dose due to any source can be computed by splitting the extended source into a series of point sources and summing up the individual contributions (Berger, 1971; Janicki et al., 1997). In other words, the dose at each target point in tissue will receive contributions from each point source. The initial activity is distributed uniformly over the surface or the volume of the stent. The stent is the source of radiation, and is represented as a series of point sources defined by a set of coordinates $(x, y, z)$. This operation can be expressed in the form of a convolution integral as follows:

$$
D(r, t)=\frac{A_{0}}{S \lambda} \times[1-\exp (-\lambda t)] \times \int D P K\left(r-r^{\prime} \mid\right) t s,
$$

where $D(r, t)$ is the absorbed dose at a particular point in space and time, $A_{0}$ is initial activity of the stent uniformly distributed over the stent surface, $\lambda\left(\mathrm{h}^{-1}\right)$ is the decay constant of the radionuclide, $\mathrm{S}$ is the total active stent surface area $\left(\mathrm{mm}^{2}\right), \mathrm{t}(\mathrm{h})$ is the time interval after stenting, $D P K$ is the dose point kernel function for a specific radioisotope, and $r-r^{\prime}$ is the distance (mm) between a source point on the stent and the source point where the dose is calculated. The dose rate at any time $t$ after stent implantation is dependent on the initial activity and is given by:

$$
\dot{D}(t)=\dot{D}_{0} e^{-\lambda t},
$$

where $\dot{D}_{0}$ is the initial dose rate given by:

$$
\dot{D}_{0}(r)=\frac{A_{0}}{S} \times \int D P K(|r-r|) d s
$$


The total absorbed dose at time $t$ is obtained by integrating equation (2).

$$
\begin{aligned}
D(t) & =\int_{0}^{t} \dot{D}_{0} e^{-\lambda t} d t \\
& =\dot{D}_{0} \times\left(\frac{1-e^{-\lambda t}}{\lambda}\right)
\end{aligned}
$$

In the case of a radioactive stent that is inserted permanently in the patient, time $t$ is equal to infinity. The dose values obtained are the lifetime doses of the stent until complete decay of the radioisotope. Therefore, Equation (4) is converted to:

$$
D(r)=\frac{\dot{D}_{0}}{\lambda}
$$

The source points, which are the coordinates defining the stent itself, are designated as $r^{\prime}(\mathrm{mm})=\left(\mathrm{x}^{\prime}, \mathrm{y}^{\prime}, \mathrm{z}^{\prime}\right)$. The target points, or the points defining the artery wall depth at which the dose is calculated, are defined by the coordinates $r(\mathrm{~mm})=(\mathrm{x}, \mathrm{y}$, $\mathrm{z}$ ). The $\mathrm{z}$ coordinates will cover the length of the stent and extend $5 \mathrm{~mm}$ beyond the edges of the stent at intervals of $0.125 \mathrm{~mm}$. The $\mathrm{x}$ and $\mathrm{y}$ coordinates extend radially from the surface of the stent up to a distance of $5 \mathrm{~mm}$ from the surface of the stent. Absorbed dose was calculated at intervals of $0.125 \mathrm{~mm}$. Dose values were calculated starting from 0.1 $\mathrm{mm}$ from the stent surface. The distance between source and target points is given by the following equation:

$$
r=\sqrt{\left(x-x^{\prime}\right)^{2}+\left(y-y^{\prime}\right)^{2}+\left(z-z^{\prime}\right)^{2}}
$$




\subsubsection{Dose Point Kernel}

The dose point kernel (DPK) describes the spherically symmetrical dose-rate distribution of absorbed dose around an isotropic source obtained from Monte Carlo simulations of beta or gamma radiations in water (Berger 1971; Giap et al., 1995). The DPK function $K\left(r, r^{\prime}\right)$ defines the dose rate at a point $r$ delivered by a point source of unit cumulative activity located at $r$ '. For radioisotopes having beta and gamma emissions, the dose point kernel consists of two components. Therefore the absorbed dose in the target tissue has contributions from both beta and gamma radiations. This additive expression for DPK is as follows:

$$
D P K\left(r, r^{\prime}\right)=D P K_{\gamma}\left(r, r^{\prime}\right)+D P K_{\beta}\left(r, r^{\prime}\right)
$$

where $D P K_{\gamma}\left(r, r^{\prime}\right)$ and $D P K_{\beta}\left(r, r^{\prime}\right)$ are the DPK for the gamma and beta radiations respectively. The following table illustrates the main properties of the radioisotopes used in the radiation dosimetry model. Of note is the fact that ${ }^{32} \mathrm{P}$ and ${ }^{90} \mathrm{Y}$ emit pure beta energy, therefore the dose delivered is given only by the convolution over the target points of the beta DPK. On the other hand, even though ${ }^{177} \mathrm{Lu}$ and ${ }^{188} \mathrm{Re}$ decay by mainly by beta emissions, they also emit a low energy gamma radiation and also have a gamma DPK component contributing to the total dose. 
Table 3-1. Properties of Radioisotopes used in Radiation Dosimetry Model

\begin{tabular}{|c|c|c|c|c|}
\hline $\begin{array}{c}\text { Radio- } \\
\text { isotope }\end{array}$ & Half-life & Energy & $\begin{array}{c}\text { Maximum } \\
\text { Energy } \\
(\mathrm{MeV})\end{array}$ & $\begin{array}{c}\text { Average } \\
\text { Energy } \\
(\mathrm{MeV})\end{array}$ \\
\hline${ }^{177} \mathrm{Lu}$ & $6.734 \mathrm{~d}$ & $\begin{array}{c}\text { beta } \\
\text { gamma }\end{array}$ & $\begin{array}{c}0.498 \\
0.113(6.4 \%) \\
0.208(11.0 \%)\end{array}$ & $\begin{array}{c}0.134 \\
\mathrm{NA}\end{array}$ \\
\hline${ }^{188} \mathbf{R e}$ & $16.94 \mathrm{~h}$ & $\begin{array}{c}\text { bamma } \\
0.155(14.9 \%)\end{array}$ & $\begin{array}{c}0.706 \\
\mathrm{NA}\end{array}$ \\
\hline${ }^{32} \mathrm{P}$ & $14.28 \mathrm{~d}$ & beta & $\begin{array}{c}1.73(1.25 \%) \\
0.478(1.01 \%)\end{array}$ & \\
\hline${ }^{90} \mathrm{Y}$ & $2.67 \mathrm{~d}$ & beta & 2.282 & 0.769 \\
\hline
\end{tabular}

\subsubsection{Beta Dose Point Kernel}

Beta DPK of ${ }^{32} \mathrm{P},{ }^{188} \operatorname{Re}$ and ${ }^{90} \mathrm{Y}$ were obtained from the tabulated data of Cross et al. (1992). These data were derived from Monte Carlo radiation transport simulations of beta particles in water considering the beta spectrum of different radioisotopes. The DPK represents the dose expressed in units of $\frac{n G y \cdot \mathrm{cm}^{2}}{B q \cdot h r}$ as a function of a distance $r(\mathrm{~mm})$ emitted by an isotropic point source. Figures 3-1 through 3-3 show the DPK curves of ${ }^{32} \mathrm{P},{ }^{90} \mathrm{Y}$ and ${ }^{188} \mathrm{Re}$. For these radioisotopes, DPK data was fit to an analytical expression shown in Table 3-2. 


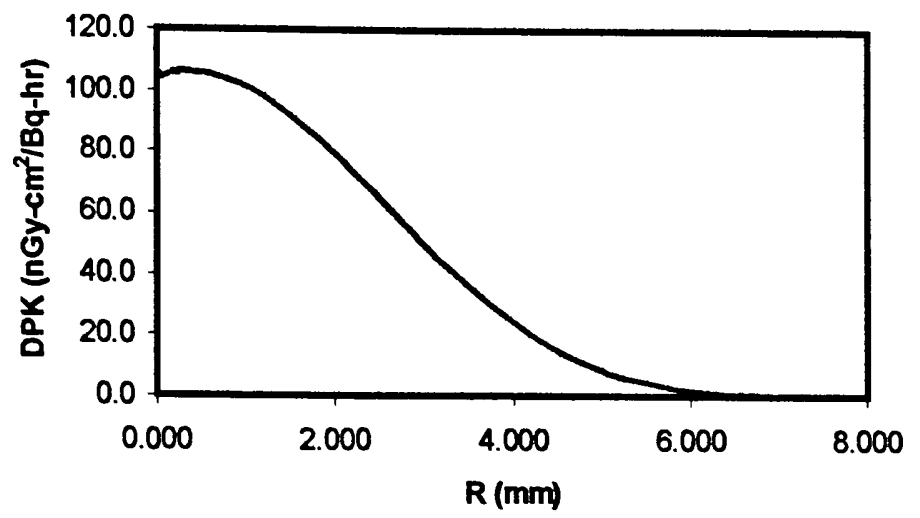

Figure 3-1. Beta DPK of ${ }^{32} P$

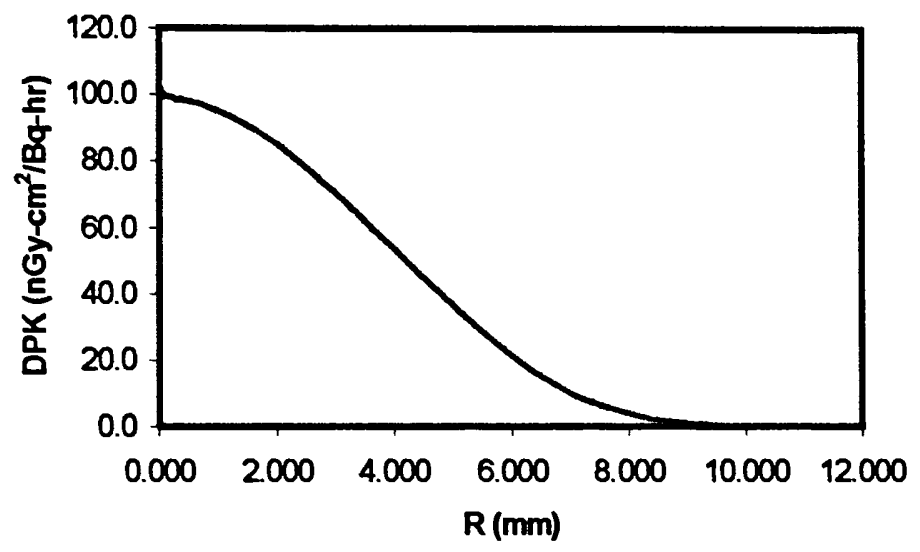

Figure 3-2. Beta DPK of ${ }^{90} Y$

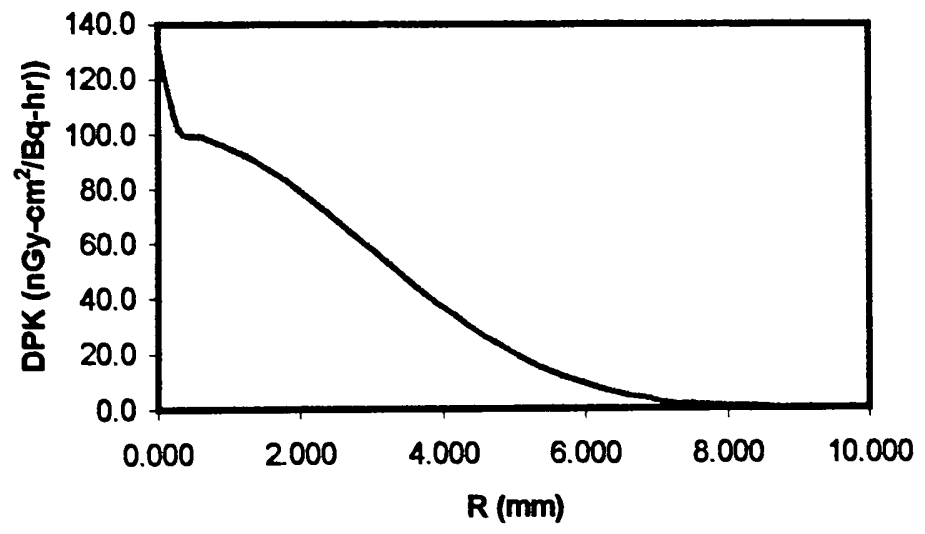

Figure 3-3. Beta DPK of ${ }^{188} \mathrm{Re}$ 
Table 3-2. Functions and $r^{2}$ values for DPK expressions of selected radioisotopes

\begin{tabular}{|c|c|c|}
\hline $\begin{array}{c}\text { Radio- } \\
\text { isotope }\end{array}$ & Equation & $\begin{array}{c}r^{2} \\
\text { Value }\end{array}$ \\
\hline${ }^{32} \mathbf{P}$ & $D P K(r)_{\beta}=-0.016 r^{5}+0.0866 r^{4}+1.8508 r^{3}-15.253 r^{2}+9.889 r+104.6$ & 0.9999 \\
\hline${ }^{90} \mathbf{Y}$ & $D P K(r)_{\beta}=-0.0058 r^{5}+0.1258 r^{4}-0.655 r^{3}-0.7175 r^{2}-5.0275 r+101$ & 0.9997 \\
\hline${ }^{188} \operatorname{Re}$ & $D P K(r)_{\beta}=0.0131 r^{6}-0.3731 r^{5}+4.0461 r^{4}-20.505 r^{3}+48.831 r^{2}-66.652 r+126.89$ & 0.9964 \\
\hline
\end{tabular}

\subsubsection{Dose Point Kernel of Beta Emissions of ${ }^{177} \mathrm{Lu}$}

Since ${ }^{177} \mathrm{Lu}$ is just recently being used in radiotherapy applications, there is not readily available DPK data in published literature for this radioisotope. The DPK of the beta emissions of ${ }^{177} \mathrm{Lu}$ was calculated by using the following equation:

$$
D P K\left(r, r^{\prime}\right)_{\beta}=\sum_{i=1}^{N} \frac{n_{i}\left(E_{i}\right)}{N} \times D P K\left(r, r^{\prime}, E_{i}\right),
$$

where $\operatorname{DPK}\left(r, r^{\prime}\right)_{\beta}$ is the DPK of the beta radiations, $D P K\left(r, r^{\prime} E_{i}\right)$ is the DPK of the beta particles of energy $E_{i}, N$ is the total number of electrons emitted by disintegration of the radioisotope, and $n_{i}\left(E_{i}\right)$ is the number of particles of a particular energy $E_{i}$. This method makes use of DPK values for beta particles of specific energies over the energy spectrum of ${ }^{177} \mathrm{Lu}$. The DPK of beta particles $K\left(r, r^{\prime} E\right)_{i}$ at different energies $E$ has been calculated by Cross et al. (1992) by means of Monte Carlo radiation transport simulations. The calculation of the spectrum of beta emissions of ${ }^{177} \mathrm{Lu}\left(n_{i}\left(E_{i}\right) / N\right)$ is shown in Appendix A. The calculations for determining the DPK of beta emissions of ${ }^{177} \mathrm{Lu}$ are provided in 
Appendix B. Figure 3-4 shows the beta DPK for ${ }^{177}$ Lu. Because the fitting of the DPK data of ${ }^{177} \mathrm{Lu}$ to an analytical expression yielded a high error percentage, beta DPKs were stored as a lookup table in the dosimetry model. The beta DPK for each distance $r$ was calculated by logarithmic linear interpolation according to the following equation:

$$
D P K(r)=\frac{\ln \left(D P K_{1}\right)-\left[\ln \left(D P K_{1}\right)-\ln \left(D P K_{2}\right)\right] \times\left(d i s_{1}-r\right)}{d i s_{1}-d i s_{2}},
$$

where $r$ is the distance of interest between the source and target points, $D P K_{1}$ and $D P K_{2}$ are the DPK values for distances dis 1 and dis $s_{2}$ respectively, and $D P K(r)$ is the dose point kernel for the distance of interest.

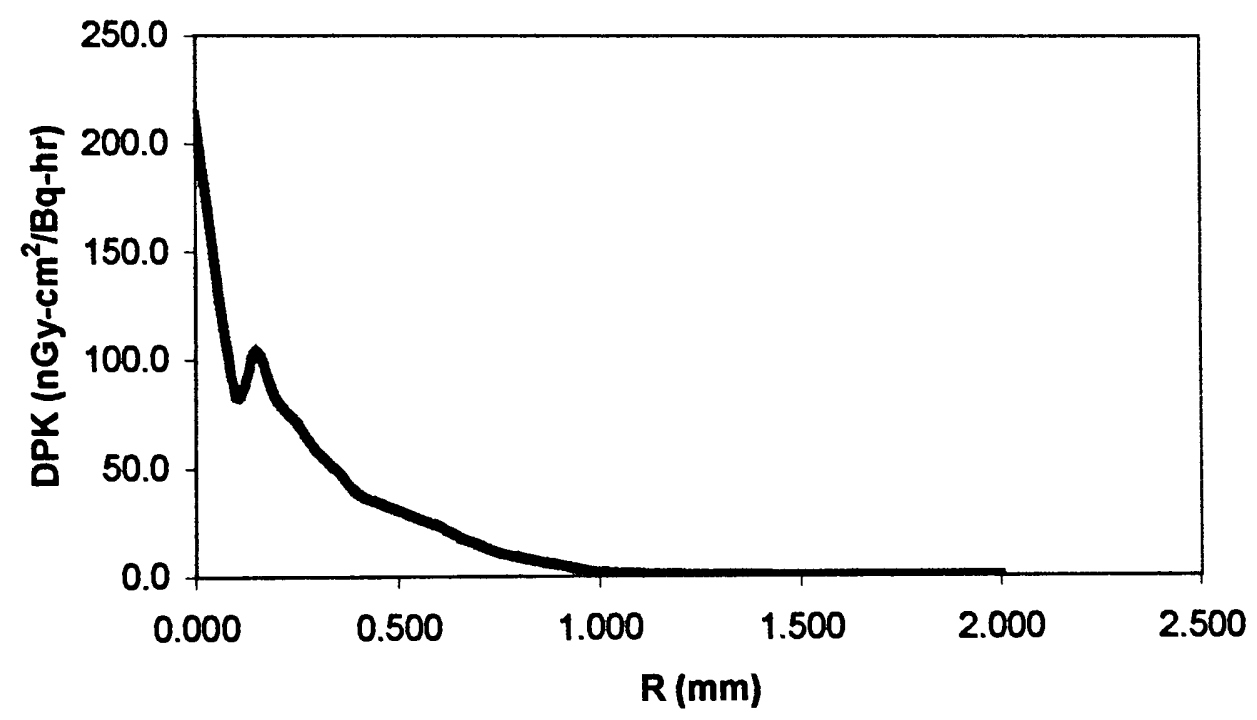

Figure 3-4. Beta DPK of ${ }^{177} \mathrm{Lu}$ 


\subsubsection{Dose Point Kernel of Gamma emissions of ${ }^{177} \mathrm{Lu}$ and ${ }^{188} \mathrm{Re}$}

Dose point kernel data of gamma emissions are not readily available in a tabulated fashion like the beta DPK provided by Cross et al. (1992). Both ${ }^{177} \mathrm{Lu}$ and ${ }^{188} \mathrm{Re}$ emit non-negligible gamma radiation that must be accounted for in the total dose calculation.

Table 3-3. Beta and Gamma energies of ${ }^{177} \mathrm{Lu}$ and ${ }^{188} \mathrm{Re}$

\begin{tabular}{|c|c|c|c|c|}
\hline Isotope & Half-life & Energy & $\begin{array}{c}\text { Maximum } \\
\text { Energy } \\
(\mathrm{MeV})\end{array}$ & $\begin{array}{c}\text { Average } \\
\text { Energy } \\
(\mathrm{MeV})\end{array}$ \\
\hline${ }^{177} \mathrm{Lu}$ & $6.734 \mathrm{~d}$ & $\begin{array}{l}\text { beta } \\
\text { gamma }\end{array}$ & $\begin{array}{c}0.498 \\
0.208(11.0 \%) \\
0.113(6.4 \%) \\
\end{array}$ & $\begin{array}{c}0.134 \\
\mathrm{NA}\end{array}$ \\
\hline${ }^{188} \mathrm{Re}$ & $16.94 \mathrm{~h}$ & $\begin{array}{l}\text { beta } \\
\text { gamma }\end{array}$ & $\begin{array}{c}2.118 \\
0.155(14.9 \%) \\
0.633(1.25 \%) \\
0.478(1.01 \%)\end{array}$ & $\begin{array}{c}0.706 \\
\text { NA }\end{array}$ \\
\hline
\end{tabular}

Furhang et al. (1996) have derived a mathematical expression of photon or gamma dose kernels for several radioisotopes, including ${ }^{188}$ Re. The gamma DPK was generated in water for the full gamma emission spectrum of the radioisotope through Monte Carlo simulations (Furhang et al., 1996). For the calculation of gamma DPK of ${ }^{188} \operatorname{Re}$, the following expression was used:

$$
D P K(r)_{\gamma}=\sum_{i}^{i_{M a X}}\left(\frac{a_{-2}}{r^{2}}+\frac{a_{-1}}{r}+a_{0}+a_{1} \cdot r+a_{2} \cdot r^{2}\right)_{i} e^{-m_{i} \cdot r}
$$

where $r$ is the distance in $\mathrm{cm}$, and DPK is expressed in $c G y / B q \cdot s$. The coefficients for this expression are listed in Table 3-4. 
Table 3-4. Coefficients of the gamma DPK expression of ${ }^{188} \mathbf{R e}$

\begin{tabular}{|c|c|}
\hline $\mathbf{a}_{-2}$ & $2.162 \times 10^{-12}$ \\
\hline $\mathbf{a}_{-1}$ & $1.444 \times 10^{-12}$ \\
\hline $\mathbf{a}_{\mathbf{0}}$ & $3.455 \times 10^{-13}$ \\
\hline \multirow{2}{*}{$\mathbf{m}$} & $1.298 \times 10^{-14}$ \\
\hline Error $_{\max }$ & 0.10739 \\
\hline
\end{tabular}

Table 3-5. Functions and $r^{2}$ values for gamma DPK expressions of ${ }^{188} \operatorname{Re}$ and ${ }^{177} \mathrm{Lu}$

\begin{tabular}{|c|c|c|}
\hline $\begin{array}{c}\text { Radio- } \\
\text { isotope }\end{array}$ & Equation & $r^{2}$ \\
\hline${ }^{188} \mathrm{Re}$ & $K(r)_{\gamma}=\left[\frac{2.162 \times 10^{-12}}{r^{2}}+\frac{3.455 \times 10^{-13}}{r}+1.298 \times 10^{-14}\right] e^{-0.10739 r}+\left[\frac{1.444 \times 10^{-12}}{r^{2}}\right] e^{-5.197}$ & N/A \\
\hline${ }^{177} \mathrm{Lu}$ & $K(r)_{\gamma}=0.0071 r^{6}-0.0447 r^{5}+0.1107 r^{4}-0.1377 r^{3}+0.0896 r^{2}-0.0253 r+0.0428$ & 0.9669 \\
\hline
\end{tabular}

${ }^{177} \mathrm{Lu}$ is a relatively new in radiotherapy treatment and as a result was not among the radioisotopes whose gamma DPK was calculated by Furhang et al., (1996). In this case the gamma DPK of ${ }^{177} \mathrm{Lu}$ was calculated by using the gamma energy tables of Luxton and Jozsef (1999), which were calculated through EGS4 Monte Carlo simulations for gamma rays with energies between $10 \mathrm{keV}$ and $2 \mathrm{MeV}$. These tables present the dose of a gamma ray of particular energy emitted in water as a function of distance radial distance from a point source (Luxton and Jozsef, 1999). The dose for gamma emissions of $0.208 \mathrm{MeV}(11 \%)$ and $0.113 \mathrm{MeV}(6.4 \%)$ was calculated using these tables and a logarithmic linear interpolation according to equation 9. Dose is expressed in nGy$\mathrm{cm}^{2} / \mathrm{Bq}-\mathrm{hr}$. The total dose from the two gamma energies is obtained by multiplying each dose value at a specific energy by its fraction and summing up the two components according to the following equation: 


$$
D P K(r)_{r}=\left(f_{1} \times D P K_{1}(r)\right)+\left(f_{2} \times D P K_{2}(r)\right)
$$

Refer to Appendix $\mathrm{C}$ for results of the interpolation calculation and the final gamma DPK data. This data was plotted and fit to the analytical expression shown in table 3-5. Figure 3-5 shows the curve of the gamma DPK of ${ }^{177} \mathrm{Lu}$.

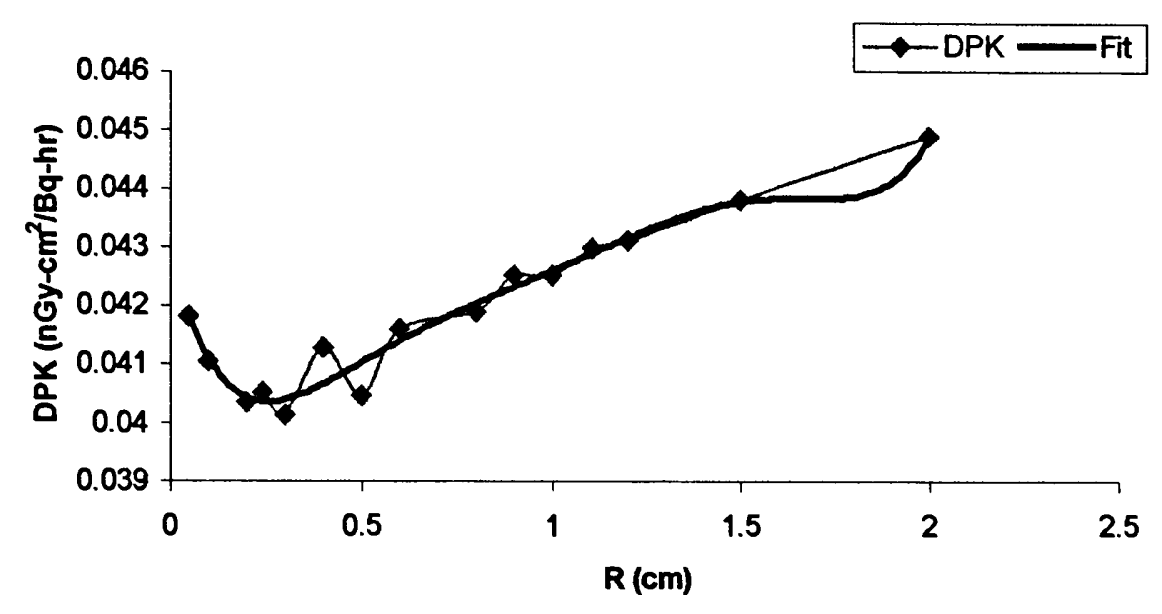

Figure 3-5. Gamma DPK of ${ }^{177} \mathrm{Lu}$

\subsection{Radiobiological Model}

The main purpose of the radiobiological model is to compare the physical absorbed dose at a specific target point with the biological equivalent dose at that same point taking into account the initial dose rate, repair probability of the tissue, duration of treatment and biological endpoint ( $\alpha / \beta$ ratio) (Dale, 1985, 1993; Giap et al., 1999). The radiobiological impact of the different radioisotope distribution is assessed by means of two main parameters, BED and RE. Biological equivalence dose (BED) and relative 
effectiveness per unit dose (RE) are the focus of the radiobiological model. BED is a measure of the biological consequences to the tissue receiving a particular dose. RE measures the effectiveness of a given dose. These parameters are derived from the linear-quadratic (LQ) formalism, which expresses the surviving fraction (S) of cells as a function of dose (D).

$$
S=e^{-\alpha D-\beta D^{2}}
$$

The constants $\alpha$ and $\beta$ are characteristic of a given cell type and have units of $G y^{-1}$ and $\mathrm{Gy}^{-2}$ respectively. $\mathrm{BED}$ and $\mathrm{RE}$ are related to the physical absorbed dose by the following expression:

$$
\operatorname{BED}(\mathrm{Gy})=\mathrm{RE} \times(\text { Absorbed dose) }
$$

\subsubsection{Relative Effectiveness per unit Dose for a Permanent Implant}

For a permanently implanted exponentially decaying source such as treatment of coronary artery disease with radioactive stents, the LQ parameter RE is represented by:

$$
\begin{aligned}
(R E)_{\infty} & =1+\frac{2 R_{0} \lambda}{\mu-\lambda}\left(\frac{\beta}{\alpha}\right)\left[\frac{1}{2 \lambda}-\frac{1}{\mu+\lambda}\right] \\
& =1+\frac{2 R_{0} \lambda}{\mu-\lambda}\left(\frac{\beta}{\alpha}\right) \frac{\mu-\lambda}{2 \lambda(\mu+\lambda)} \\
R E & =1+\frac{\dot{D}_{0}}{\mu+\lambda}\left(\frac{\beta}{\alpha}\right),
\end{aligned}
$$

where $\dot{D}_{0}$ is the initial dose rate delivered to the tissue and $\lambda$ is the radioactive decay constant of the implanted radionuclide. $\mu$ is the sublethal repair constant, which describes 
the probability for cells to repair the radiation damage per hour and is related to the repair half-life $\mathrm{T}_{1 / 2}$ by $\mu=\ln 2 / T^{1 / 2}$. The value of the repair half-life to be used in this model is taken from published literature (Brenner and Hall, 2001) and has been experimentally determined to be 0.5 hours for smooth muscle cells. The $\alpha / \beta$ ratio for early-responding vascular tissue has been estimated as $8 \mathrm{~Gy}$ (Brenner and Hall, 2001). This is assuming that the cells in the arterial wall responsible for the neointimal hyperplasia component of restenosis are rapidly proliferating cells and can be estimated more accurately as tumor or cancer cells than normal tissue. A summary of the values used in the radiobiological model is shown in Table 3-6. Included is also the values of $\lambda$ for each of the radioisotopes, which was calculated according to $\lambda=\ln 2 / t^{1 / 2}$, where $t^{1 / 2}$ is the half-life of the radioisotope.

Table 3-6. Summary of Values for Variables used in Radiobiological Model

\begin{tabular}{|c|c|}
\hline$\alpha / \beta$ ratio & $8 \mathrm{~Gy}$ \\
\hline Repair half-life & 0.5 hours \\
\hline$\mu$ (sublethal repair constant) & $1.386 \mathrm{~h}^{-1}$ \\
\hline & ${ }^{32} \mathrm{P}: 0.00202 \mathrm{~h}^{-1}$ \\
& ${ }^{90} \mathrm{Y}: 0.0108 \mathrm{~h}^{-1}$ \\
& ${ }^{188} \mathrm{Re}: 0.0409 \mathrm{~h}^{-1}$ \\
radionuclide) & ${ }^{177} \mathrm{Lu}: 0.00428 \mathrm{~h}^{-1}$ \\
\hline Dose rate & varies for each point \\
\hline Absorbed dose & varies for each point \\
\hline
\end{tabular}




\subsubsection{RE for Implant Containing Two Different Radioisotopes}

The dosimetry model will also be used to calculate the dose distribution of a stent containing two radioisotopes, one in the center or body of the stent, and another in the edges of the stent or a uniform distribution of a combination of radioisotopes. In this case, equation (14) will not be adequate because it only takes into account the biological effects of the dose rate and half-life of one radioisotope only, where in fact the two radioisotopes might have important effects, particularly if the half-lives differ greatly. For a permanent implant in which the dose is a result of a combination of two radioisotopes as in the case of the hybrid stent, the following equation was used (Chen, 2003):

$$
R E=1+\frac{\beta}{\alpha} \times \frac{\frac{\dot{D}_{01}^{2}}{\lambda_{1}\left(\lambda_{1}+\mu\right)}+\frac{\dot{D}_{02}^{2}}{\lambda_{2}\left(\lambda_{2}+\mu\right)}+2 \frac{\dot{D}_{01} \dot{D}_{02}\left(\lambda_{1}+\lambda_{2}+2 \mu\right)}{\left(\lambda_{1}+\lambda_{2}\right)\left(\lambda_{1}+\mu\right)\left(\lambda_{2}+\mu\right)}}{\frac{\dot{D}_{01}}{\lambda_{1}}+\frac{\dot{D}_{02}}{\lambda_{2}}},
$$

where $\dot{D}_{01}$ and $\dot{D}_{02}$ is the dose rate for isotopes 1 and 2 respectively, and $\lambda_{1}$ and $\lambda_{2}$ are the decay constants. The biological equivalent dose or BED is calculated in the same manner as that for a stent containing one radioisotope and is the product of $\mathrm{RE}$ and the absorbed dose.

\subsection{Stent Model}

The stent design used in this research is an example of a stent geometry that can be used for calculation of the dose distribution surrounding the stent. The stent (patent No. $6,187,037)$ was designed by Bionucleonics Inc, of Miami, FL. Cartesian coordinates 
$(\mathrm{x}, \mathrm{y}, \mathrm{z})$ are used in our model and arranged in a Microsoft Excel file and loaded into the program. The file with these stent source coordinates can be found in Appendix D. The dose calculation model described in this work can accommodate any set of coordinates that define the geometry of the stent. The stent has deployed dimensions of $15.25 \mathrm{~mm}$ in length and $4 \mathrm{~mm}$ in diameter with a strut thickness of $0.1527 \mathrm{~mm}$ (Satz, 2001). The stent is divided into 1840 pieces, or strut points, which are considered the point sources in the DPK convolution calculation. The detailed gridded architecture of the stent used in this research project is shown in Figure 3-6. It represents a projection of the stent into the $(\theta$, z) plane.

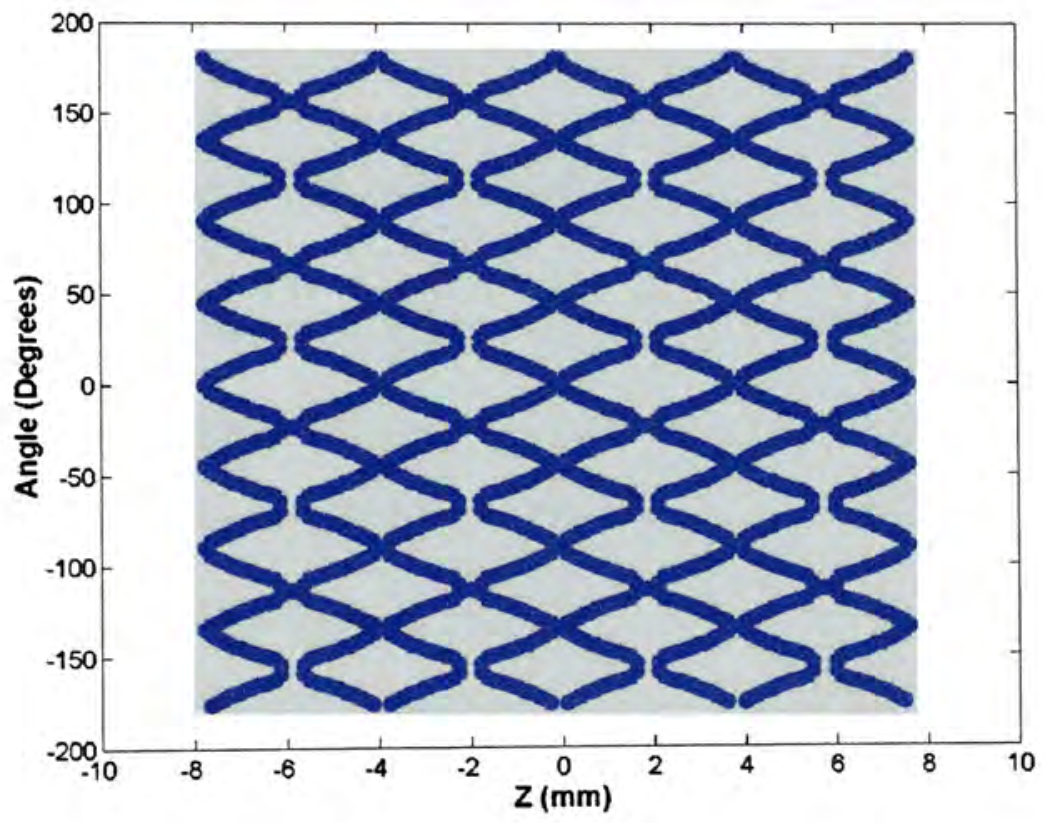

Figure 3-6. Stent geometry and dimensions

The stent developed by Bionucleonics Inc., has ${ }^{177} \mathrm{Lu}$ incorporated into a nickeltitanium alloy which when subsequently activated, yields an entirely uniform dispersion of the radioisotope, much more uniform than coating the alloy surface by ion 
implantation, vacuum deposition or other deposition technique (Satz, 2001). ${ }^{177}$ Lu shows an optimal combination of properties that make it very attractive in the preparation in this type of stents, including a wide cross-section in barns, which facilitates activation in a reactor and requires a shorter reaction time to achieve the preferred levels of radioactivity. ${ }^{177} \mathrm{Lu}$ has a half-life of 6.734 days with a maximum energy of $498 \mathrm{keV}$, an average energy of $134 \mathrm{keV}$ and gamma emissions of $113 \mathrm{keV}(6.4 \%)$ and $208 \mathrm{keV}$ (11.0\%) (Satz, 2001). The ${ }^{177} \mathrm{Lu}$ stent is $0.1 \%$ by weight lutetium. This stent design will be used for all other dose calculations with different radioisotopes. For radioisotopes other than ${ }^{177} \mathrm{Lu}$, the radiation was assumed as being on the surface of the stent, not embedded within the nickel-titanium alloy.

\subsection{Algorithm for Radiation Dosimetry Model}

The algorithm is written in Matlab 6.5 programming language (The MathWorks, Inc., Natick, Massachusetts) and is based on the dose point kernel (DPK) convolution. The DPK convolution method divides the extended source of radiation, in this case the stent, into a series of point sources. The dose at a target point is made up of the contributions of each of the individual point sources. For calculation purposes, the stent will be represented by a set of contiguous transaxial slices. Figure 3-7 represents a slice along the transaxial plane of the stent and the corresponding cross-section of stent struts. Each slice corresponds to one value of $z$ along the $z$-axis (length of stent), and contains the strut point $(x, y)$ for that value of $z$. The dose calculation algorithm calculates the dose 
delivered from each of the source point defining the stent architecture on a slice-by-slice basis.
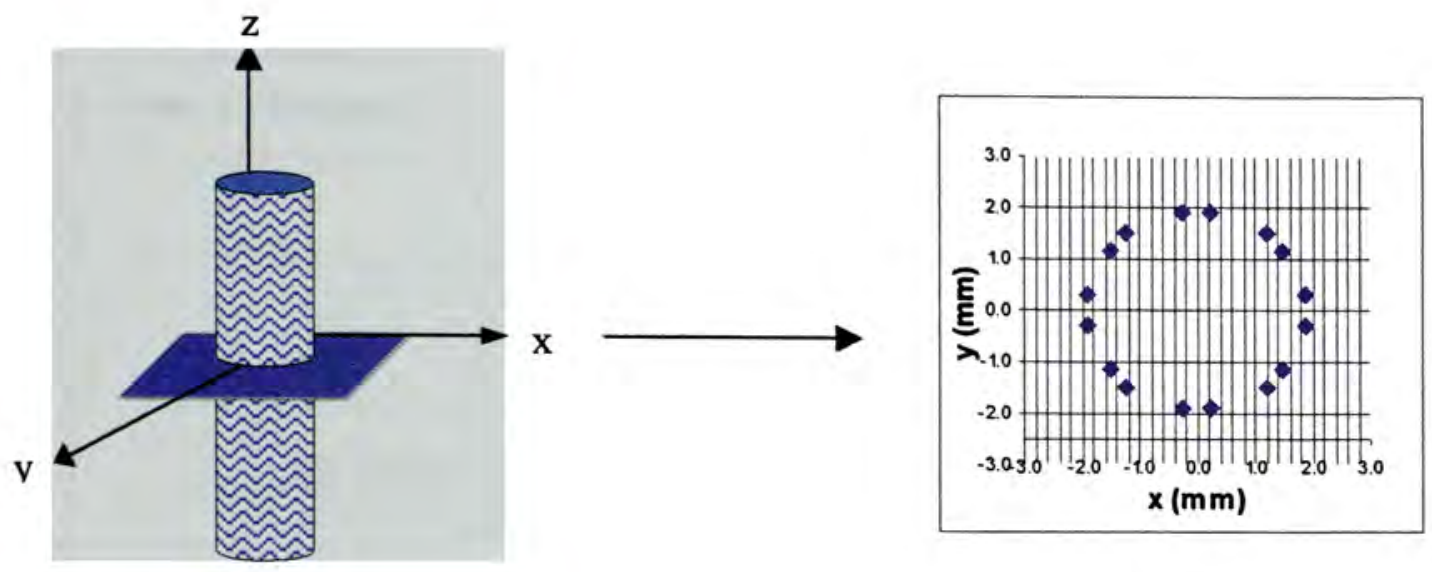

Figure 3-7. Stent cross section at midplane $(\mathrm{z}=0)$

\subsubsection{Dose Calculation Algorithm Flowchart}

Each slice along the $\mathrm{z}$ axis of the stent depends on the coordinates $\mathrm{x}$ and $\mathrm{y}$. Therefore, each stent coordinates can be represented by the following notation: $z(x, y)$, where $\mathrm{z}$ is $-7.75 \mathrm{~mm}$ to $7.75 \mathrm{~mm}$ at intervals of $0.125 \mathrm{~mm}$. For each slice $\mathrm{z}$ there are 16 sets of $(x, y)$ coordinates. Computation time was decreased by excluding the source points at which distances between source and target points extended beyond the range of the DPK for a particular radioisotope. Figure 3-8 shows a flow diagram of the algorithm for the radiation dosimetry model developed in this project. A sample of the algorithm code is provided in appendices $\mathrm{E}$ and $\mathrm{F}$. 


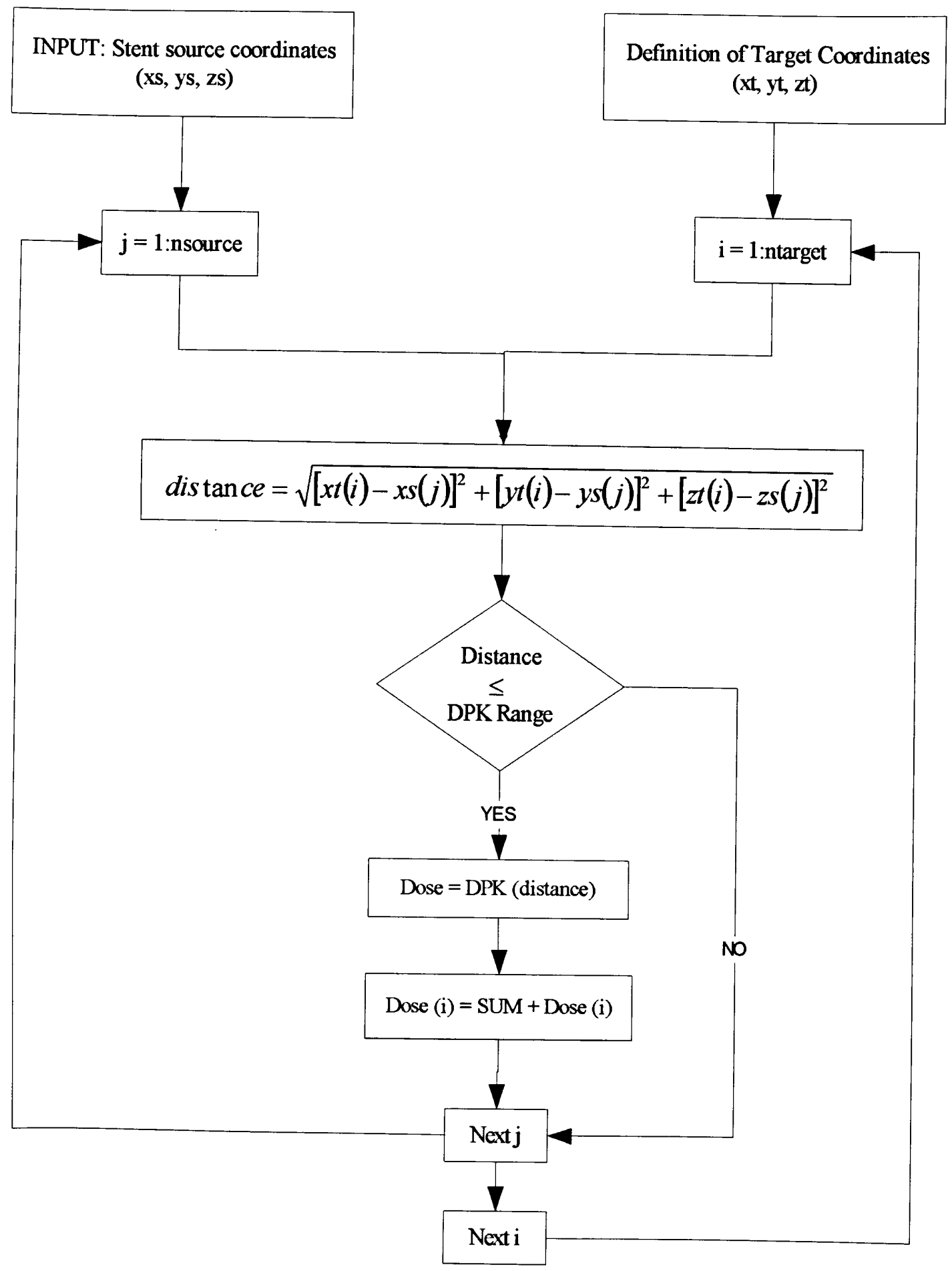

Figure 3-8. Diagram of Dose Calculation Algorithm 


\subsubsection{Model Assumptions}

The algorithm for calculation of dose distributions around radioactive stents is based on the following assumptions:

1) Absorbed dose is calculated for stent with deployed dimensions of $4 \mathrm{~mm}$ in diameter and $15.25 \mathrm{~mm}$ in length.

2) Medium (soft arterial tissue) is isotropic and homogeneous with attenuation properties close to that of water. The presence of plaque is not accounted for.

3) Dose is symmetrical around the stent, so for calculation efficiency purposes, only the dose in the first quadrant of the stent is calculated.

4) Absorbed dose is expressed per unit of activity in $\mathrm{cGy} / \mu \mathrm{Ci}$. cGy describes the dose delivered per gram of tissue. $\mu \mathrm{Ci}$ is the unit of activity, where activity is a measurement of the number of radioactive disintegrations or transformations an amount of radioactive material undergoes in a given period of time.

5) Stent is a permanently implanted therefore the convolution equation is integrated to time $\mathrm{t}=\infty$.

6) For ${ }^{177} \mathrm{Lu}$, source of radiation is embedded within the NiTi alloy. In this case, the dose delivered to tissue is corrected by a self-attenuation factor described in Section 3.4.3. For all other radioisotopes the source of radiation is simulated on the stent surface as a coating.

\subsubsection{Conversion of Units}

The DPK data in the tables of Cross et al. (1992) are expressed in units of $\mathrm{nGy} \cdot \mathrm{cm}^{2} / \mathrm{Bq} \cdot \mathrm{h}$. In our calculations, it was expressed in $\mathrm{cGy} \cdot \mathrm{mm}^{2} / \mu \mathrm{Ci} \cdot \mathrm{h}$. The conversion of units was performed as follows:

$$
k=\frac{n G y \cdot \mathrm{cm}^{2}}{B q \cdot h} \times \frac{10^{-7} c G y}{n G y} \times \frac{37,000 B q}{\mu C i} \times \frac{100 m^{2}}{\mathrm{~cm}^{2}}=\frac{0.37 c G y \cdot \mathrm{mm}^{2}}{\mu C i \cdot h}
$$

Therefore, to express the dose in units of $\mathrm{cGy} \cdot \mathrm{mm}^{2} / \mu \mathrm{Ci} \cdot \mathrm{h}$, the dose values obtained were multiplied by the conversion factor $\mathrm{k}=0.37$. 


\subsubsection{Attenuation Correction Factor for Dose Point Kernel Calculation of ${ }^{177} \mathrm{Lu}$}

The ${ }^{177} \mathrm{Lu}$ stent is made radioactive by a different manner altogether, one that has the potential for a more uniform distribution of the radioisotope, leading to a more uniform dose delivery to the artery wall. The lutetium is an integral part of the nickeltitanium alloy prior to its activation. For this reason, a correction factor needs to be introduced to account for the self-attenuation of the stent material. The self-attenuation by uniform dispersion of the radioactive source in the stent material is given by the following expression:

$$
\text { Actualdose }=D \times\left[1-\left(\frac{1}{T}\right) \rho \frac{d T}{d x} \Delta x\right]
$$

where the percentage loss of energy due to attenuation of beta particles is given by $\left(\frac{1}{T}\right) \rho \frac{d T}{d x} \Delta x$, in which $\frac{d T}{d x}$ is the total stopping power( the sum of the collision and radiative stopping powers) for NiTi alloy equal to $2.391 \mathrm{MeV}-\mathrm{cm}^{2} / \mathrm{g}$ (Berger et la, 2000), $\mathrm{T}$ is the average beta emission energy equal to $0.134 \mathrm{MeV}$, and $\rho$ is the density of the NiTi alloy equal to $6.45 \mathrm{~g} / \mathrm{cm}^{3}$.

The CSDA range (continuous slow down approximation) is a very close approximation to the average path length traveled by a charged particle as it slows down to rest (Attix, 1986, p.180; Berger et al., 2000). The $\mathrm{R}_{\text {CSDA }}$ of NiTi for beta particles with an average energy of $0.134 \mathrm{MeV}$ is $3.443 \times 10^{-2} \mathrm{~g} / \mathrm{cm}^{2}$ (Berger et al., 2000). This value, divided by the density of NiTi results in the range expressed only in units of distance $0.0534 \mathrm{~mm}$. This value was used to exclude those source points on the stent that have no 
contribution to the total dose at a particular target point. Assuming that the source of radioactivity is a point source located in the center of the stent strut, then the distance traveled by beta particles to the target point, which is equal to 0.07635 , or half the stent strut thickness, is greater than the CSDA range. For this reason the location of the point source was assumed to be in the center of half of the strut width, as shown in Figure 3-8. As a result, a quantity of $0.038175 \mathrm{~mm}$, or one fourth the strut width was added to each $\mathbf{x}$ and y coordinate defining the stent geometry in order to consider the point source in the center of the stent. In equation $18, \Delta \mathrm{x}$ is equal to $0.038175 \mathrm{~mm}$. This is the only segment that will be attenuated because the others are so out of range that none of the radiations will make it to the target point. In addition, the dose is multiplied by a factor of 0.5 taking into account the fact that the activity of half of the strut will have no contribution to the dose whatsoever.

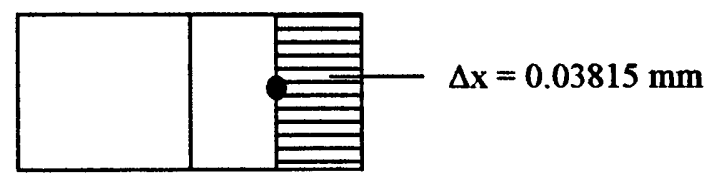

Figure 3-9. Portion of stent strut with attenuation correction

The attenuation due to gamma absorption was also calculated according to the exponential attenuation equation for gamma rays and x-rays (Attix, 1986, p.39). In this case $\Delta \mathrm{x}$ is $\frac{0.1527}{2}=0.076350$ or half of the stent strut thickness, under the assumption that the gamma radiation is emitted from the center of the stent strut.

$$
\text { attemuation }=e^{-\mu \Delta x}
$$




$$
\frac{\mu}{\rho_{N i T i}}=\left(\frac{\mu}{\rho}\right)_{N i} f_{N i}+\left(\frac{\mu}{\rho}\right)_{T i} f_{T i}
$$

where $\left(\frac{\mu}{\rho}\right)_{N i}$ and $\left(\frac{\mu}{\rho}\right)_{T i}$ are the linear mass attenuation coefficients for $\mathrm{Ni}$ and $\mathrm{Ti}$ respectively, which were obtained from the tables provided by Chantler et al. (2003). $f_{N i}$ and $f_{T i}$ are the fractions of each material that contribute to the total composition of the $\mathrm{NiTi}$, which is $50 \% \mathrm{Ni}$ and $50 \% \mathrm{Ti}$. The attenuation factors for both beta and gamma energies will be multiplied by the calculated dose values to obtain the corrected dose values due to the attenuation of the stent material. This was applied only in the case of ${ }^{177} \mathrm{Lu}$.

\subsection{Model Simulations}

One of the aims of this study is to theoretically evaluate different radioisotopes as potential candidates in a radioactive stent for the treatment and prevention of restenosis, as well as for the prevention of edge restenosis. In addition to characterizing the 3D dose distribution of ${ }^{32} \mathrm{P},{ }^{90} \mathrm{Y},{ }^{188} \mathrm{Re}$ and ${ }^{177} \mathrm{Lu}$ stents, combinations of these radioisotopes will also be explored such as shown in table 3-7. The geometric distribution of radioisotopes can be varied with ease. Two radioisotopes can be combined throughout the entire length of the stent. The $3 \mathrm{~mm}$ at both ends of the stent were simulated to include a radioisotope that is different from that in the center of the stent as shown in Figure 3-10. This also 
includes the "dumbbell effect" or the incorporation of higher activities of the radioactive source at the stent ends.

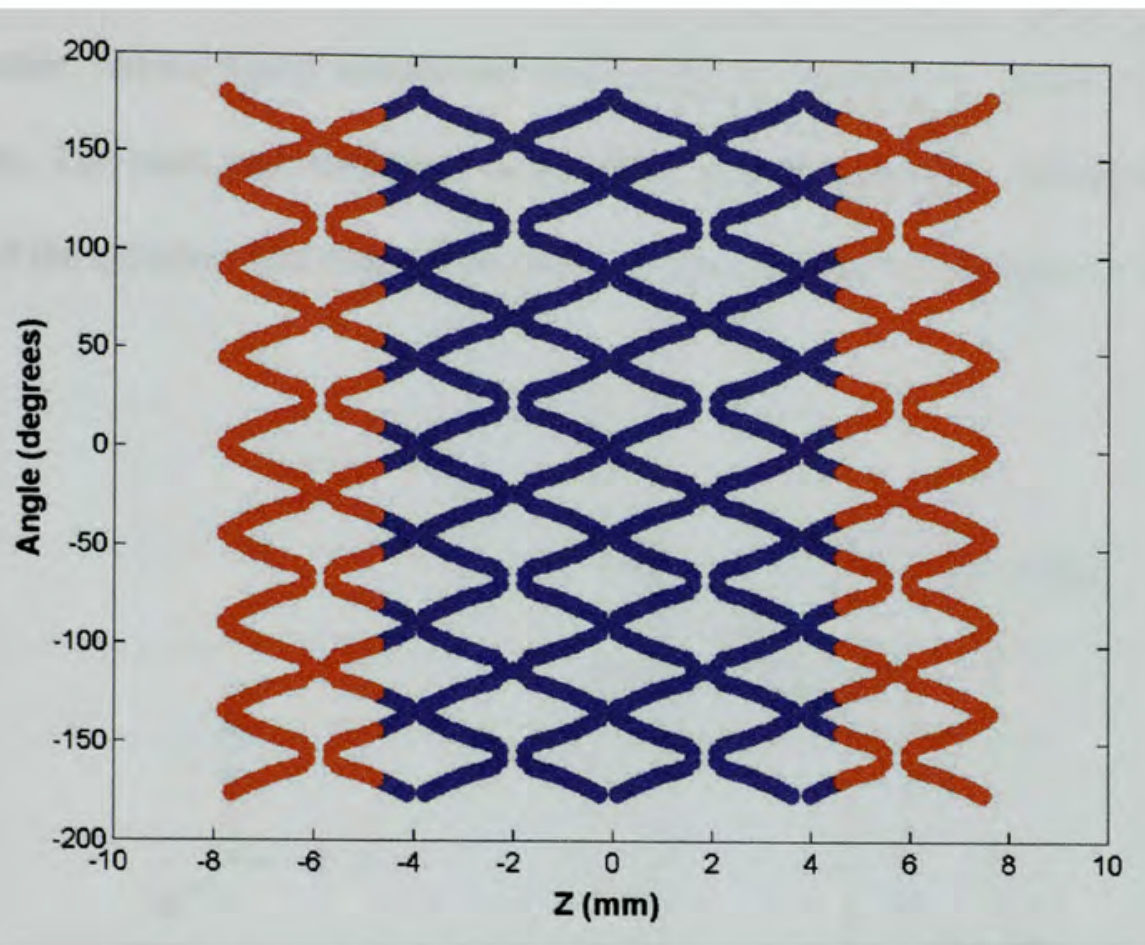

Figure 3-10. Radioisotope distribution at stent edges

Table 3-7. Radioisotope Distribution of Stent Geometry

\begin{tabular}{|c|c|c|}
\hline Stent Simulations & Stent Center & Stent Edges \\
\hline $\mathbf{1}$ & ${ }^{177} \mathrm{Lu}+{ }^{32} \mathrm{P}$ & ${ }^{177} \mathrm{Lu}+{ }^{32} \mathrm{P}$ \\
\hline $\mathbf{2}$ & ${ }^{177} \mathrm{Lu}+{ }^{90} \mathrm{Y}$ & ${ }^{177} \mathrm{Lu}+{ }^{90} \mathrm{Y}$ \\
\hline $\mathbf{3}$ & ${ }^{177} \mathrm{Lu}+{ }^{188} \mathrm{Re}$ & ${ }^{177} \mathrm{Lu}+{ }^{188} \mathrm{Re}$ \\
\hline $\mathbf{4}$ & ${ }^{32} \mathrm{P}$ & $3 \times{ }^{32} \mathrm{P}$ \\
\hline $\mathbf{5}$ & ${ }^{90} \mathrm{Y}$ & $3 \times{ }^{90} \mathrm{Y}$ \\
\hline $\mathbf{6}$ & ${ }^{188} \mathrm{Re}$ & $3 \times{ }^{188} \mathrm{Re}$ \\
\hline $\mathbf{7}$ & ${ }^{177} \mathrm{Lu}$ & $3 \times{ }^{177} \mathrm{Lu}$ \\
\hline $\mathbf{8}$ & ${ }^{32} \mathrm{P}$ & ${ }^{188} \mathrm{Re}$ \\
\hline $\mathbf{9}$ & ${ }^{32} \mathrm{P}$ & ${ }^{90} \mathrm{Y}$ \\
\hline
\end{tabular}




\subsection{Model Validation}

The validation of the DPK convolution for dosimetry calculation of radioactive stent was compared against the results obtained from Monte Carlo simulations using the MCNP code. Monte Carlo simulations were done by Michael G. Stabin of Vanderbilt University. The stent was simulated as a hollow cylinder with ${ }^{32} \mathrm{P}$ embedded within the volume of the cylinder. The dimensions of this cylinder are shown in Figure 3-11.
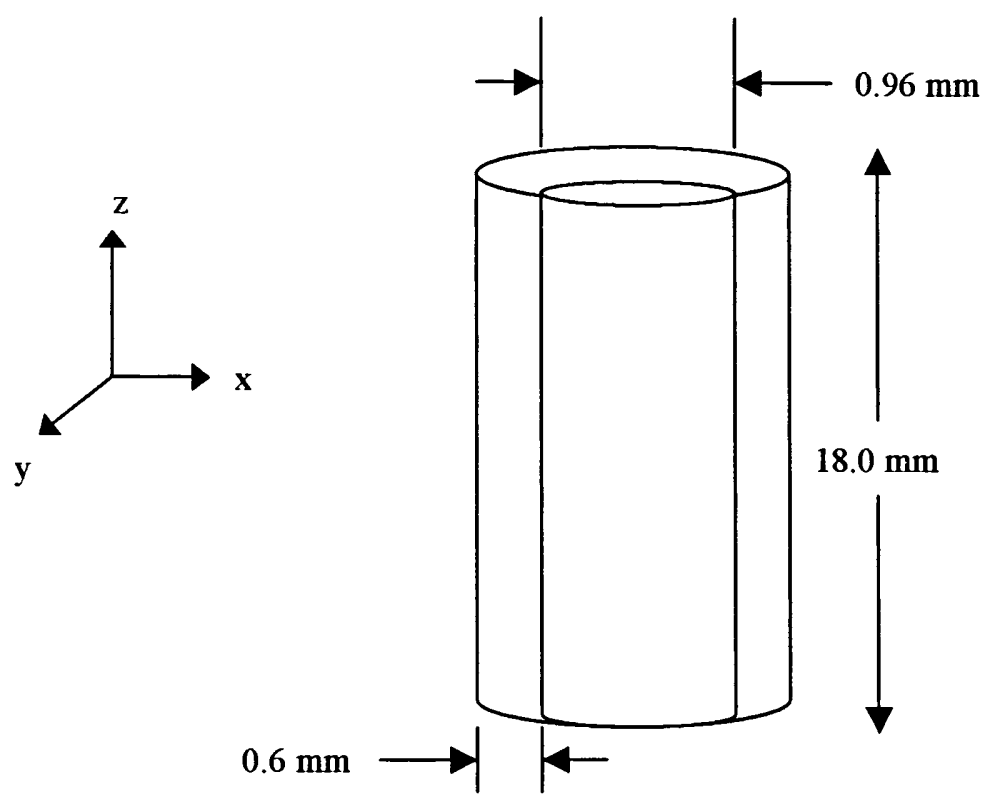

Figure 3-11. Dimensions of ${ }^{32} \mathrm{P}$ cylinder used in MCNP and DPK calculations

The dose was calculated at distances of $0.01,0.2,0.5,0.7,1.0,2.0$, and $4.0 \mathrm{~mm}$ from the surface of the stent at $z=0$ or the midplane of the stent. The Monte Carlo simulation was done under the following assumptions: 
1) Cylinder is made of $\mathrm{NiTi}(50 \% \mathrm{Ni}, 50 \% \mathrm{Ti})$.

2) The full beta energy spectrum of ${ }^{32} \mathrm{P}$ was used.

3) Dose was calculated as dose per electron emitted from the whole stent, not per unit, and was calculated for $3.7 \times 10^{-4} \mathrm{dps}$ at each emission point.

4) Dose is expressed in units of $\mathrm{cGy} / \mathrm{mCi}-\mathrm{h}$.

5) Dose calculation included the production of secondary electrons and bremssthralung.

6) The number of simulations yields a mean error of $6.1 \%$ in the calculations of the dose at the specified points.

The radiation dose from a ${ }^{32} \mathrm{P}$ cylinder was calculated at the same distances described above using the DPK dosimetry model developed in this project. The cylinder was defined by cylindrical coordinates with a radius of $0.48-1.08 \mathrm{~mm}$. The radius was divided to discrete intervals of $0.2 \mathrm{~mm}$, the length in intervals of $0.115 \mathrm{~mm}$ from -9 to 9 $\mathrm{mm}$, and the angle in intervals of 5 degrees, from 0 to 355 degrees. This is equivalent to 31,913 units of volume. The activity was $1 \mathrm{mCi}$ per unit. To make this calculation comparable to the Monte Carlo results, the issue of attenuation had to be addressed. Unlike Monte Carlo simulations, the DPK convolution method relies on using average values of attenuation. Therefore, in this type of calculation, the attenuation correction for the dose delivered by ${ }^{32} \mathrm{P}$ embedded within the volume of the NiTi cylinder relied on two main points: a) the elimination of all those source points of the cylinder whose distance traveled within the stent to the target point is greater than the CSDA range of the mean energy of ${ }^{32} \mathrm{P}$ in the NiTi material, and b) calculation and implementation of an attenuation factor for beta particles as described in equation 18, section 3.4.3. First and foremost, the CSDA range in $\mathrm{mm}$ was calculated for the mean beta energy of ${ }^{32} \mathrm{P}$ 
traveling across a NiTi material. This calculation was done using the values shown in Table 3-8.

Table 3-8. Stopping Power (dT/dx) and CSDA range for the mean beta energy of ${ }^{32} \mathrm{P}$ emissions in a NiTi alloy.

\begin{tabular}{|c|c|c|}
\hline Energy (MeV) & $\mathrm{dT} / \mathrm{dx}\left(\mathrm{Mev}-\mathrm{cm}^{3} / \mathrm{g}\right)$ & CSDA Range $\left(\mathrm{g} / \mathrm{cm}^{2}\right)$ \\
\hline 0.695 & 1.382 & 0.3942 \\
\hline
\end{tabular}

The range, calculated as:

$$
\frac{0.3942 \mathrm{~g} / \mathrm{cm}^{2}}{6.45 \mathrm{~g} / \mathrm{cm}^{3}}=6.11 \mathrm{~cm}=0.611 \mathrm{~mm}
$$

meaning that the width of the cylinder is greater than the range. The following assumptions were made based on this result, and were included in the selection of source coordinates defining the source components of the cylinder:

1) The angle was reduced to a range between $-45^{\circ}$ and $45^{\circ}$. This approximation is justified because the mean distance within the stent source points to the target points is greater than the CSDA range of $0.611 \mathrm{~mm}$.

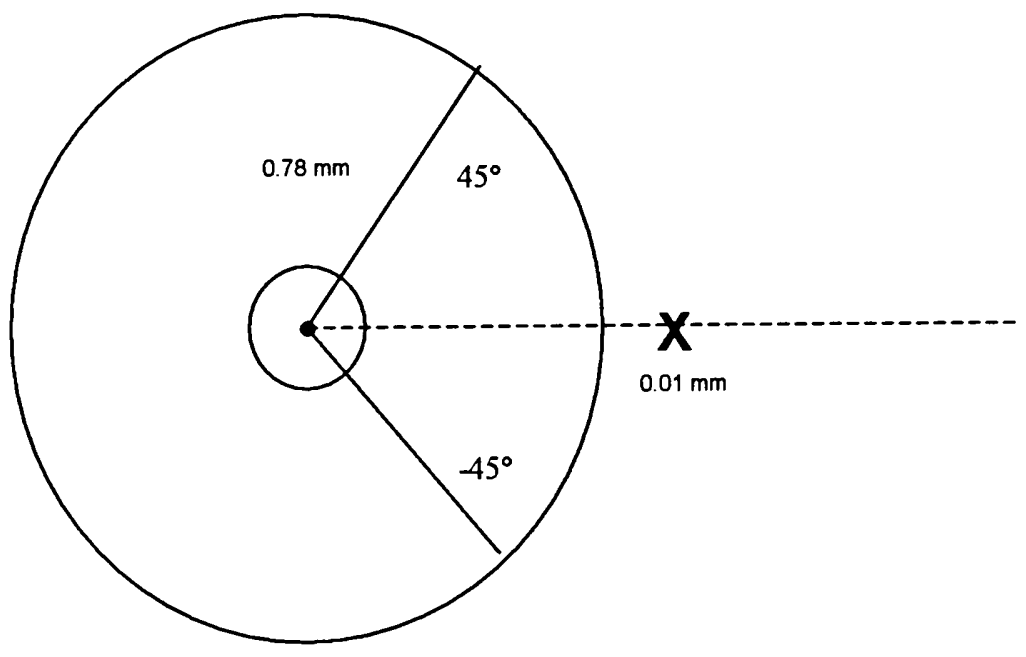

Figure 3-12. Angle range defining contributing points to dose at target 
mean distance within the stent

2) Only those points in the $\mathrm{z}$ range from $-0.23 \mathrm{~mm}$ to $0.23 \mathrm{~mm}$ contributed to the radiation dose. This assumption is justified by the fact that most of the source points outside of this range have distances within the stent greater than the CSDA range.

3) Approximately only half of the source points in the range $z \in[-0.23 \mathrm{~mm}, 0.23 \mathrm{~mm}]$ contributed to the radiation dose. The final dose values were thus multiplied by a factor of 0.5 .

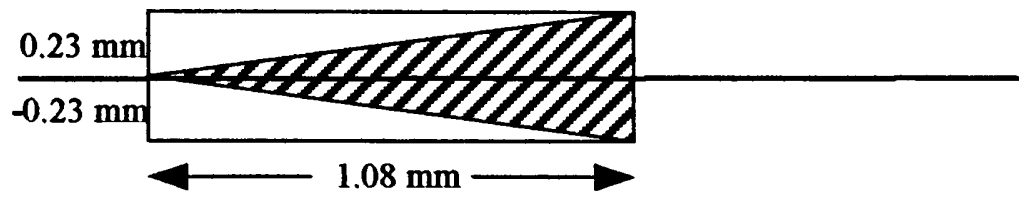

Figure 3-13. Contributing points to dose at target for a segment along the stent $\mathrm{z}$ axis

4) The dose was divided by 31,913 units of volume under the assumption that each unit has $1 \mathrm{mCi}$ of activity.

Attenuation correction for ${ }^{32} \mathrm{P}$ particles embedded within the volume of the stent was calculated according to:

$$
A F=1-\frac{1}{T} \rho \frac{d T}{d x} \Delta x
$$


where $\Delta \mathrm{x}$ is the mean distance from the source points included in the calculation to the stent surface. It was approximated by:

$$
\Delta x=\bar{d}-r,
$$

where $\bar{d}$ is the mean distance from source to target points, which was calculated by the code in Appendix $\mathrm{F}$, and $\mathrm{r}$ is the distance from the surface of the stent to the target point. 


\section{CHAPTER 4}

\section{RESULTS}

Results presented are for the lifetime dose delivered by the stent under the assumption that the stent is permanently implanted. Dose is expressed per unit of activity as $c \mathrm{~Gy} / \mu \mathrm{Ci}$. Radioactivity is assumed on the stent surface unless stated otherwise as in the case of ${ }^{177} \mathrm{Lu}$. A target distance of $2.0 \mathrm{~mm}$ is taken as a reference point with adventitial layer of the artery as the target tissue for prevention of cell proliferation due to neointimal hyperplasia and negative vascular remodeling.

\subsection{Dosimetry of a ${ }^{32} \mathbf{P}$ stent}

Figure 4-1 represents a 2D dosimetry plot for a stent coated with ${ }^{32} \mathrm{P}$ as a function of radial distances along the entire axis of the stent. The different curves are for doses at different depths into the arterial wall. In the near-field or $0.1 \mathrm{~mm}$ from the surface of the stent, the dose varies from 3000 to $4700 \mathrm{cGy} / \mu \mathrm{Ci}$ at the stent strut wires to $1000 \mathrm{cGy} / \mu \mathrm{Ci}$ in the interstices between struts. At a distance of $1.0 \mathrm{~mm}$, dose delivery is more homogenous with a cumulative dose of $\sim 500 \mathrm{cGy} / \mu \mathrm{Ci}$.

Figures 4-2 to 4-5 represent 3D dose maps extending from $-10 \mathrm{~mm} \leq \mathrm{z} \leq 10 \mathrm{~mm}$ at distances $\mathrm{d}=0.1,0.5,1.0$ and $2.0 \mathrm{~mm}$ from the stent surface. These plots are projections over the stent in the $(\theta, z)$ plane as shown in Figure 3-6 (Chapter 3). Shown is the dose for a segment over the stent between 0 and 45 degrees. These plots provide a clear view of the nonuniformity of the dose at very close distances to the stent. Evident is also the fall-off of the dose at the edges of the stent at $\sim-8.0$ and $8.0 \mathrm{~mm}$ on the $\mathrm{z}$ axis. 


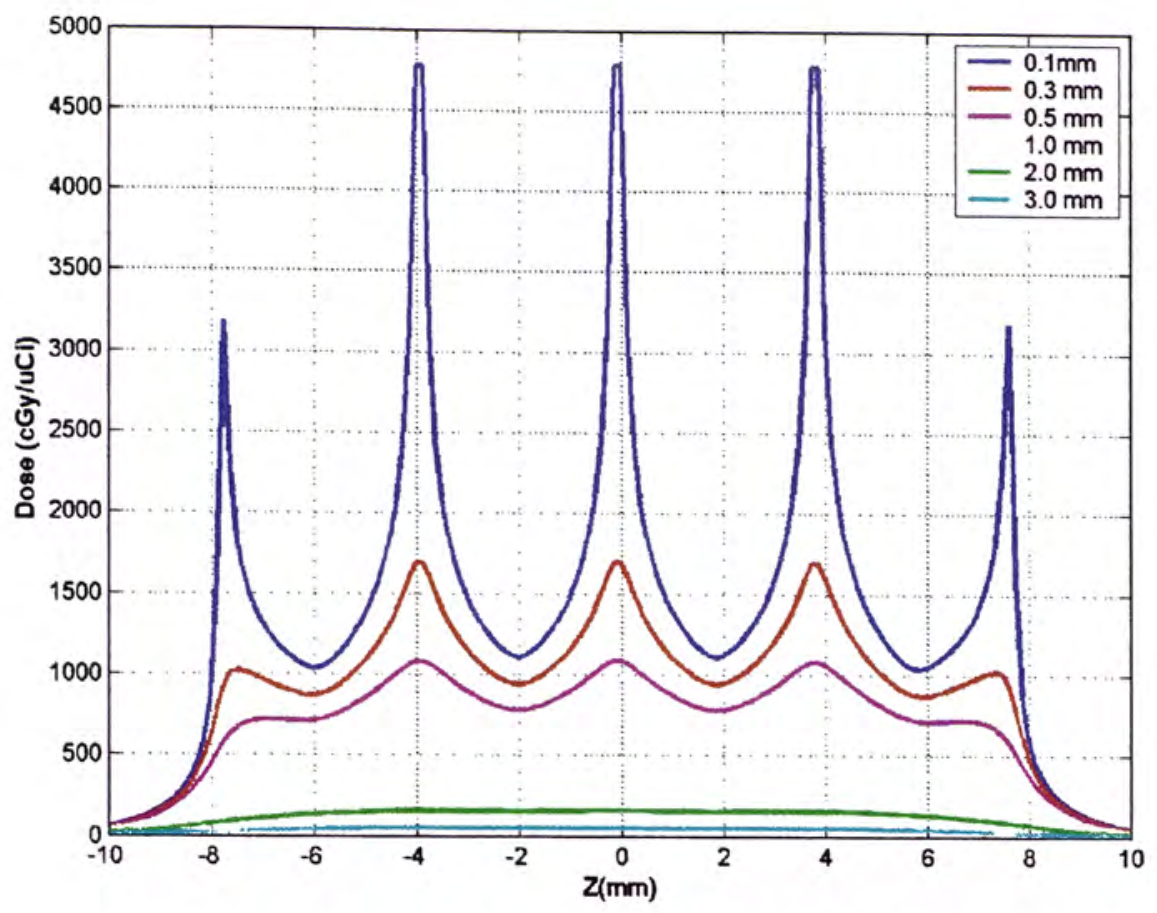

Figure 4-1. 2D plot of dose distribution of a ${ }^{32} \mathrm{P}$ stent

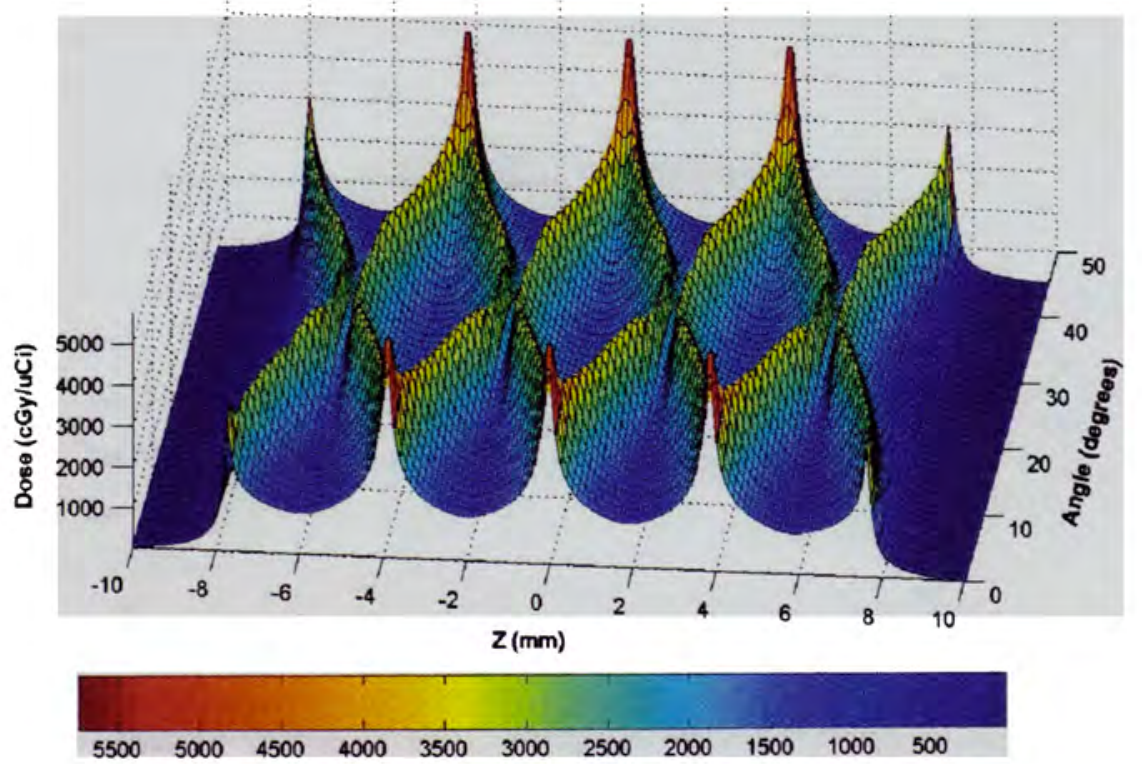

Figure 4-2. 3D map of dose to tissue after total decay of ${ }^{32} \mathrm{P}$ stent at $0.1 \mathrm{~mm}$ exterior to the stent surface. 


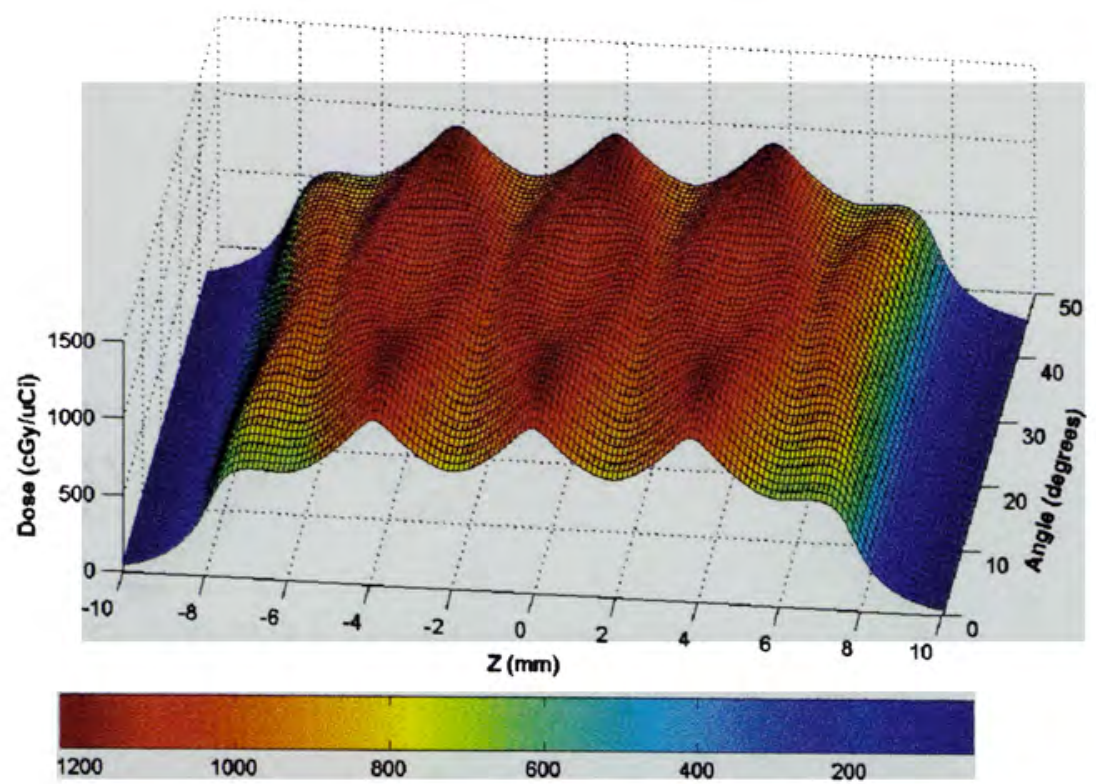

Figure 4-3. 3D map of dose to tissue after total decay of a ${ }^{32} \mathrm{P}$ stent at $0.5 \mathrm{~mm}$ exterior to the stent surface.

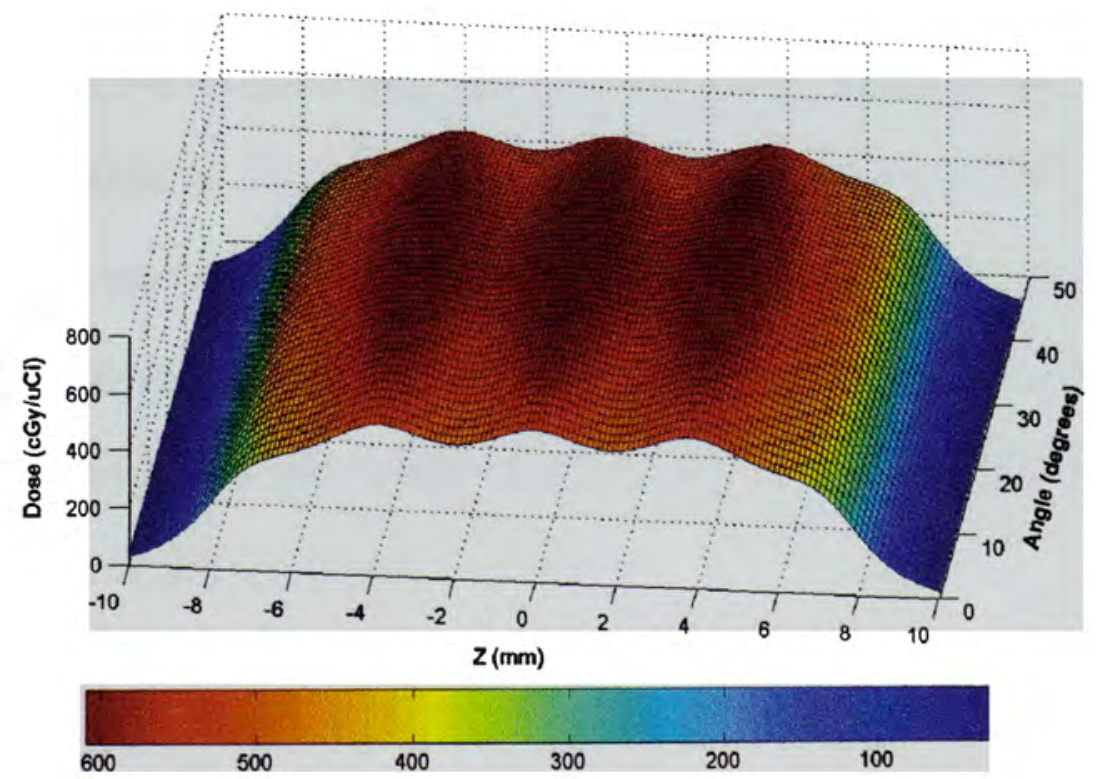

Figure 4-4. 3D map of dose to tissue after total decay of a ${ }^{32} \mathrm{P}$ stent at $1.0 \mathrm{~mm}$ exterior to the stent surface. 


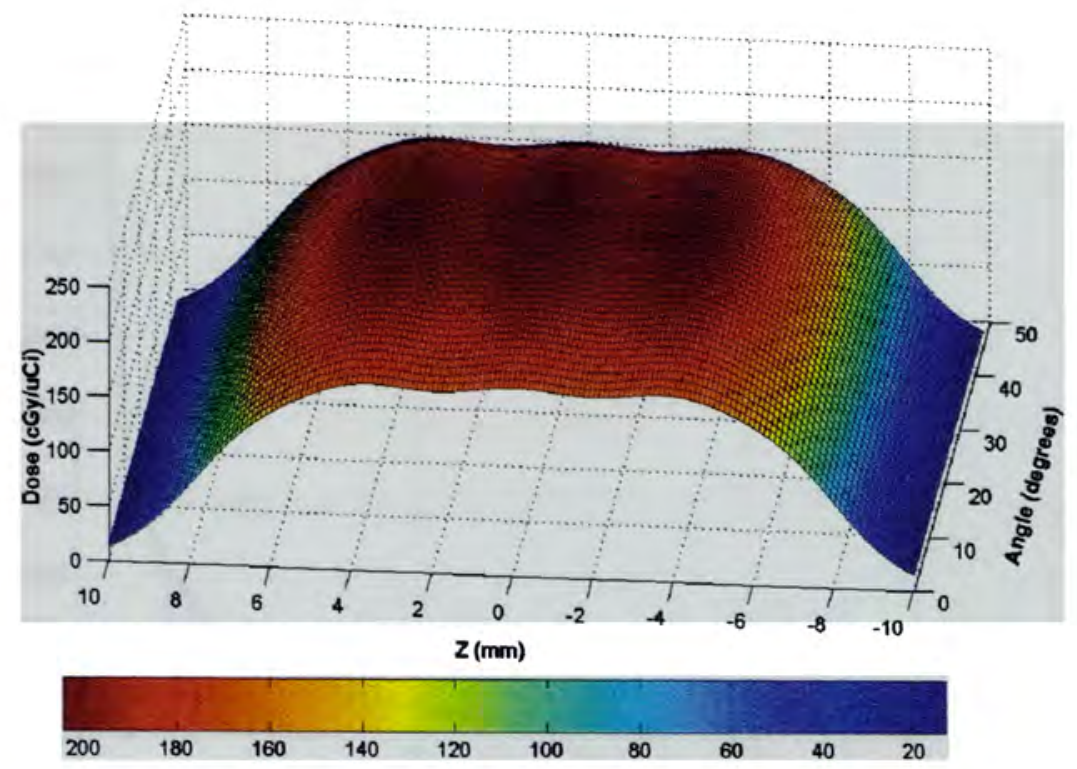

Figure 4-5. 3D map of dose to tissue after total decay of a ${ }^{32} \mathrm{P}$ stent at $2.0 \mathrm{~mm}$ exterior to the stent surface.

Figure 4-6 represents the dose as a function of radial distance up to $5 \mathrm{~mm}$ into the arterial wall calculated at the stent midplane or $z=0$. For ${ }^{32} \mathrm{P}$, the dose delivered at $0.1 \mathrm{~mm}$ is $4797 \mathrm{cGy} / \mu \mathrm{Ci}$, while at $1.0 \mathrm{~mm}$ it falls off by $88 \%$ to $531.84 \mathrm{cGy} / \mu \mathrm{Ci}$. At a target distance of $2 \mathrm{~mm}$, the dose is $172.26 \mathrm{cGy} / \mu \mathrm{Ci}$, or $3.7 \%$ of the dose at $0.1 \mathrm{~mm}$. The dose delivered to the arterial wall at a fixed radial distance of $2.0 \mathrm{~mm}$ along the axis of the stent is shown in Figure 4-7 for half a stent from 0 to $12 \mathrm{~mm}$. At the stent ends, the dose is $88.78 \mathrm{cGy} / \mu \mathrm{Ci}$ or $51.54 \%$ of the dose at $\mathrm{z}=0$. 


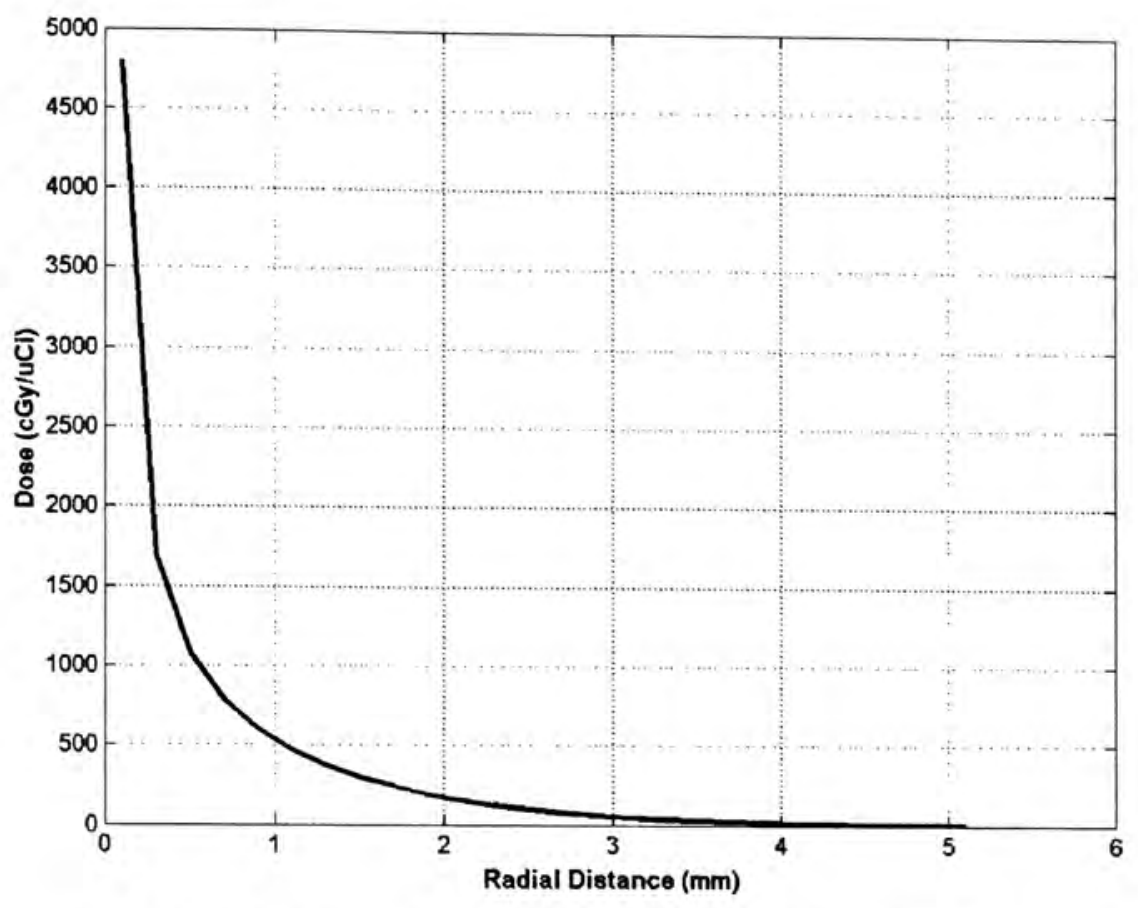

Figure 4-6. The variation of dose with radial distance of a ${ }^{32} \mathrm{P}$ stent

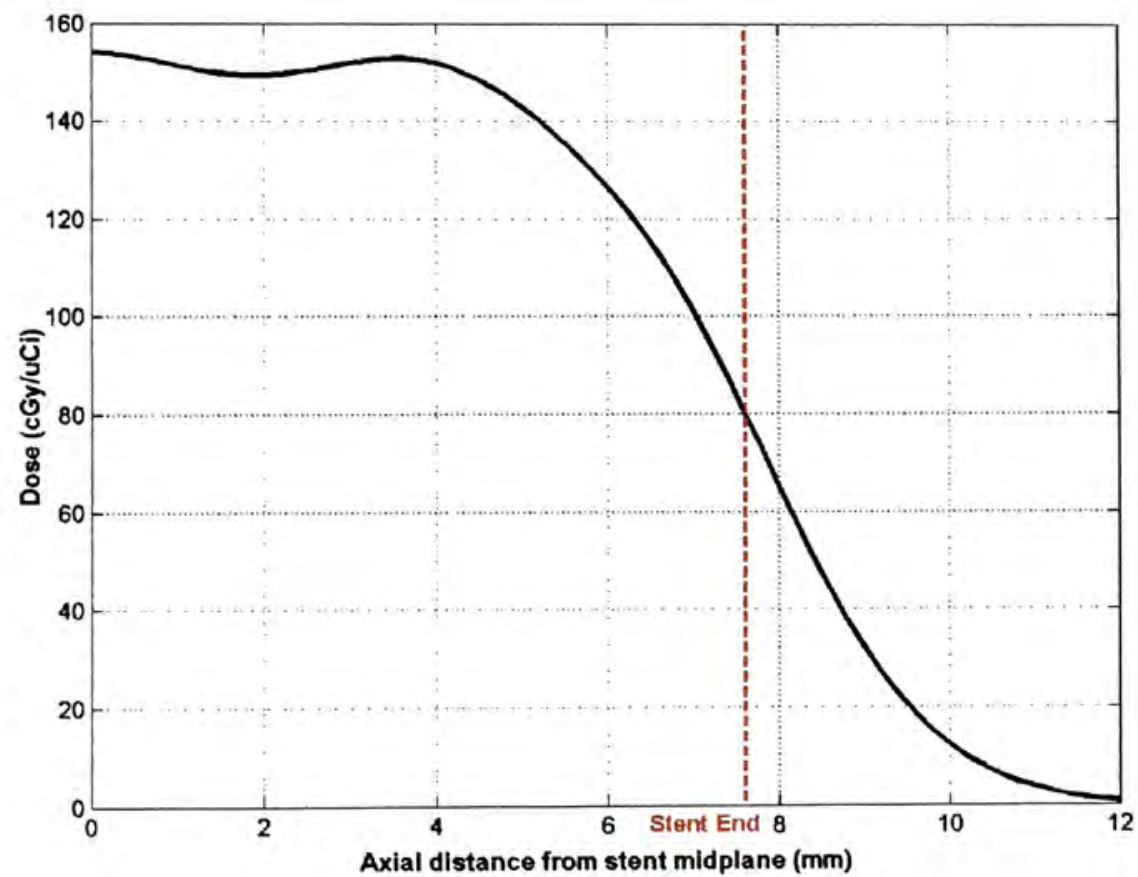

Figure 4-7. The variation of dose with axial distance of a ${ }^{32} \mathrm{P}$ stent 


\subsection{Dosimetry of a ${ }^{90} \mathrm{Y}$ stent}

Figure 4-8 represents a 2D dosimetry plot for a stent coated with ${ }^{90} \mathrm{Y}$ as a function of increasing radial distance along the entire axis of the stent. The different curves are for doses at different depths into the arterial wall. At $0.1 \mathrm{~mm}$ from the surface of the stent, the dose varies from 900 to $600 \mathrm{cGy} / \mu \mathrm{Ci}$ at close proximity to the stent strut wires to $\sim 200 \mathrm{cGy} / \mu \mathrm{Ci}$ in the areas between struts. At a distance of $1.0 \mathrm{~mm}$, dose delivery is more homogenous with a cumulative dose of $\sim 100 \mathrm{cGy} / \mu \mathrm{Ci}$. At 2.0 and $3.0 \mathrm{~mm}$, the dose is completely uniform, although it has fallen to less than $5 \%$ of the dose at $0.1 \mathrm{~mm}$.

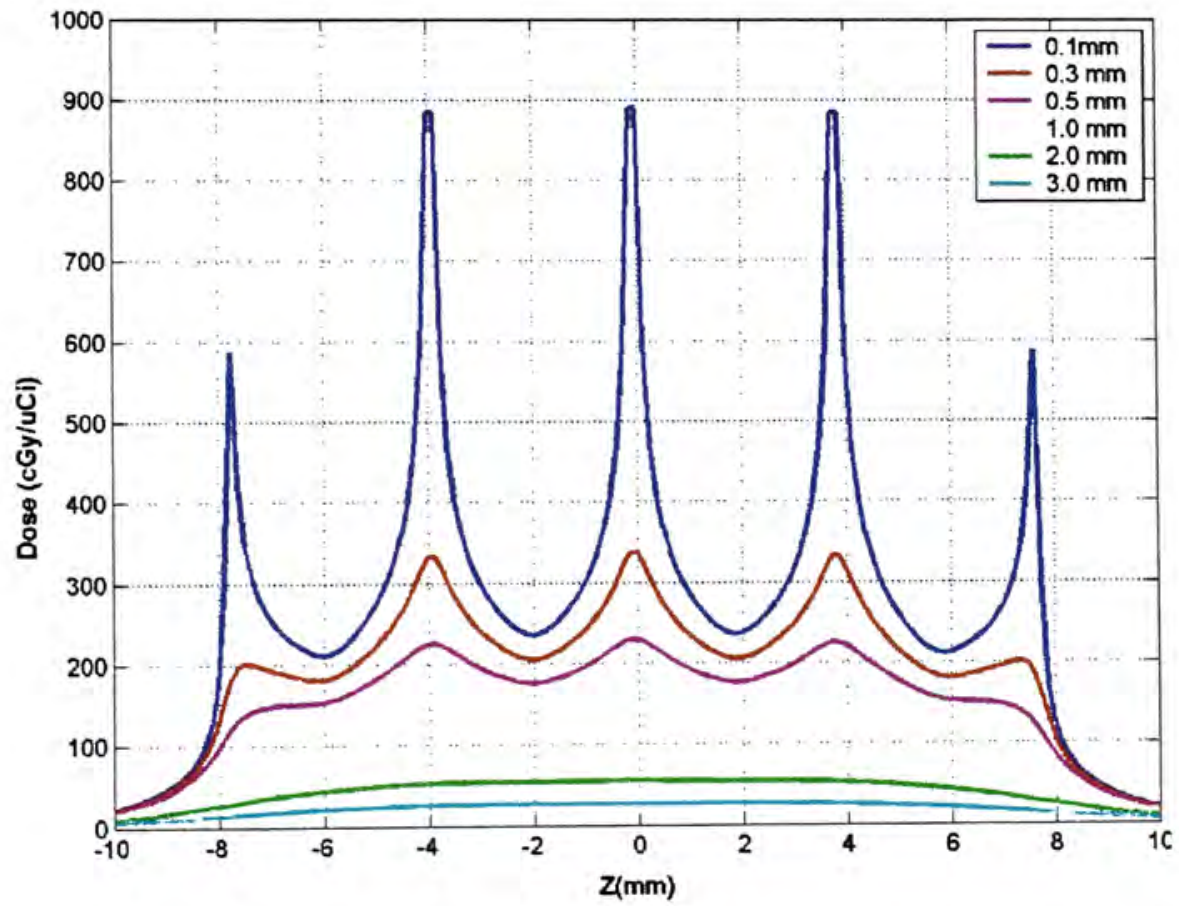

Figure 4-8. 2D plot of dose distribution of a ${ }^{90} \mathrm{Y}$ stent 
Figures 4-9 to $4-5$ represent $3 \mathrm{D}$ dose maps extending from $-10 \mathrm{~mm} \leq \mathrm{z} \leq 10 \mathrm{~mm}$ at distances $\mathrm{d}=0.1,0.5,1.0$ and $2.0 \mathrm{~mm}$ from the stent surface. These plots are projections over the stent in the $(\theta, z)$ plane shown in Figure 3-6 (Chapter 3). Shown is the dose for a segment over the stent between 0 and 45 degrees of the total stent circumference. At a distance of $0.1 \mathrm{~mm}$, the effect of the stent wires is pronounced. This effect is reduced significantly at distances of 1.0 and $2.0 \mathrm{~mm}$ as seen in Figures 4-11 and 4-12.

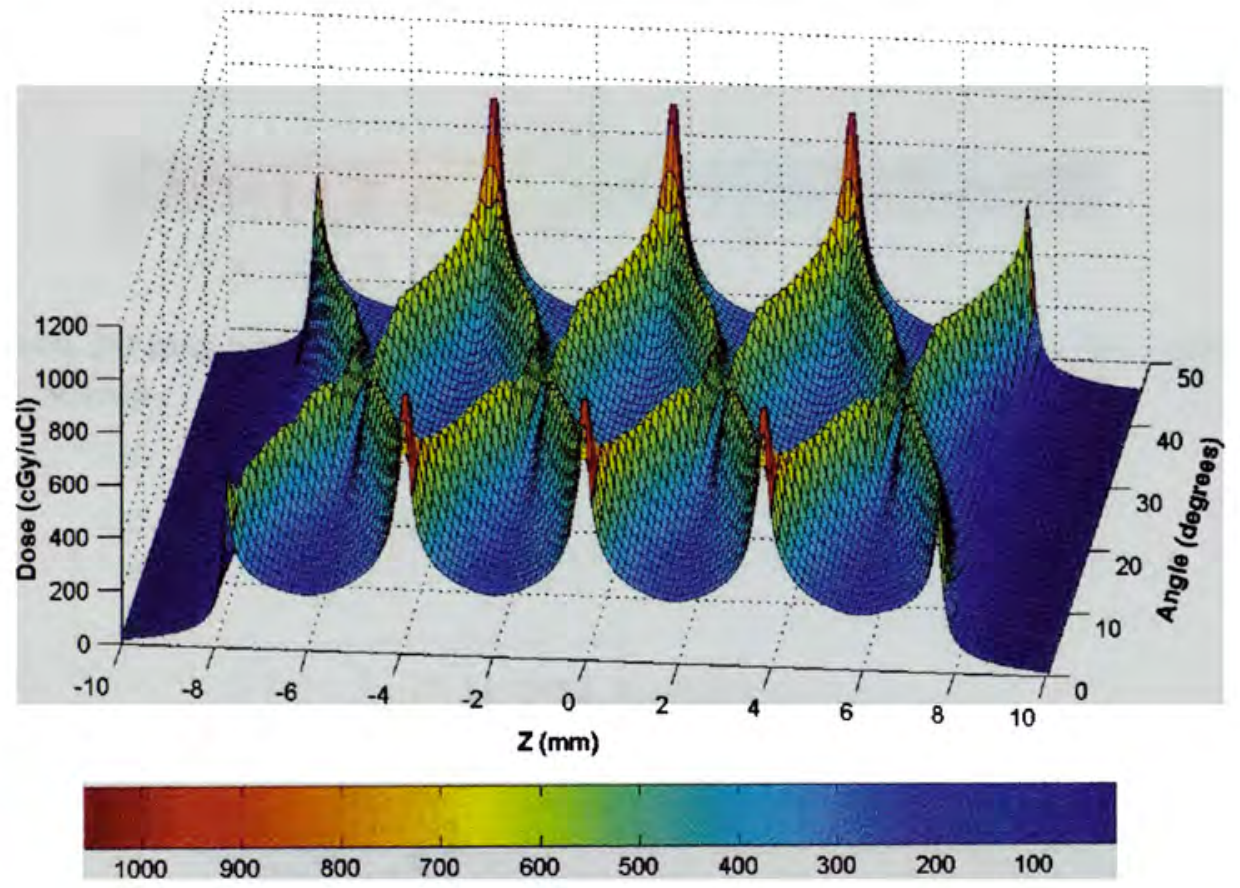

Figure 4-9. 3D map of dose to tissue after total decay of a ${ }^{90} \mathrm{Y}$ stent at $0.1 \mathrm{~mm}$ exterior to the stent surface. 


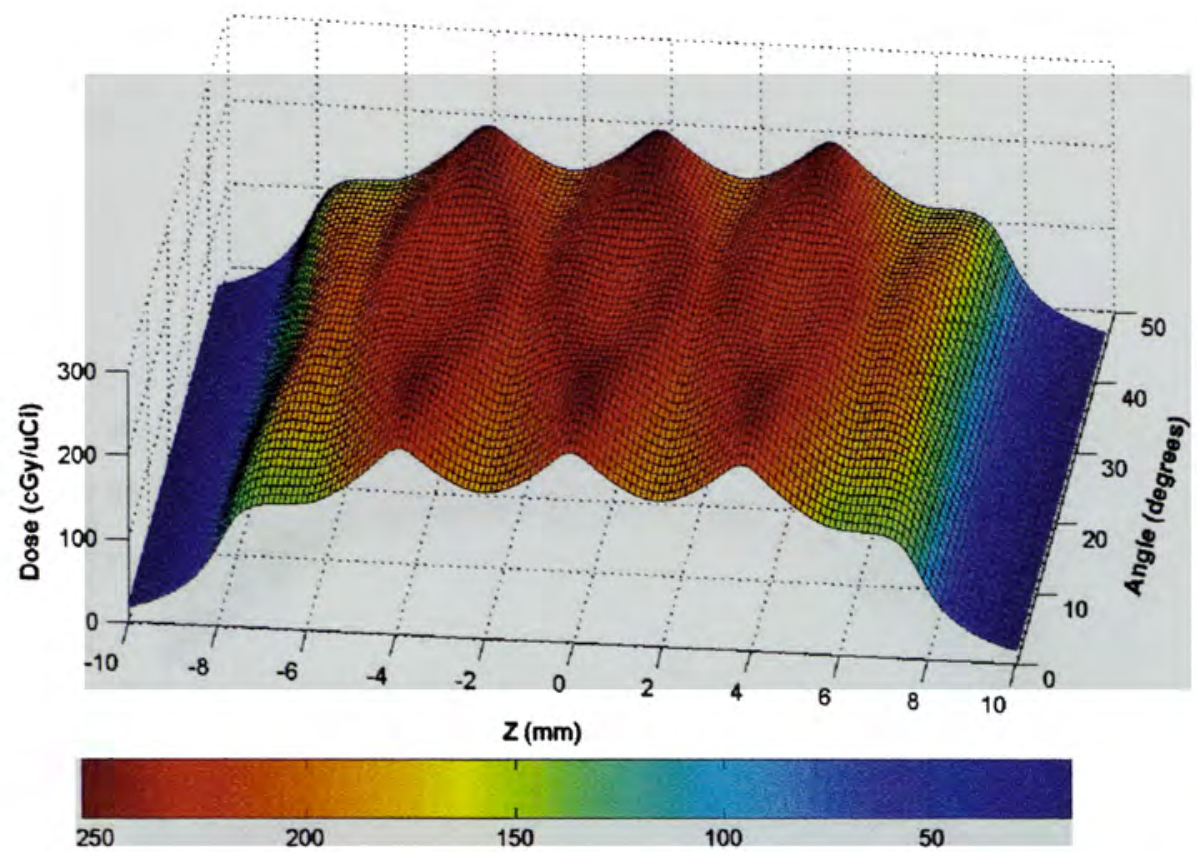

Figure 4-10. 3D map of dose to tissue after total decay of a ${ }^{90} \mathrm{Y}$ stent at $0.5 \mathrm{~mm}$ exterior to the stent surface.

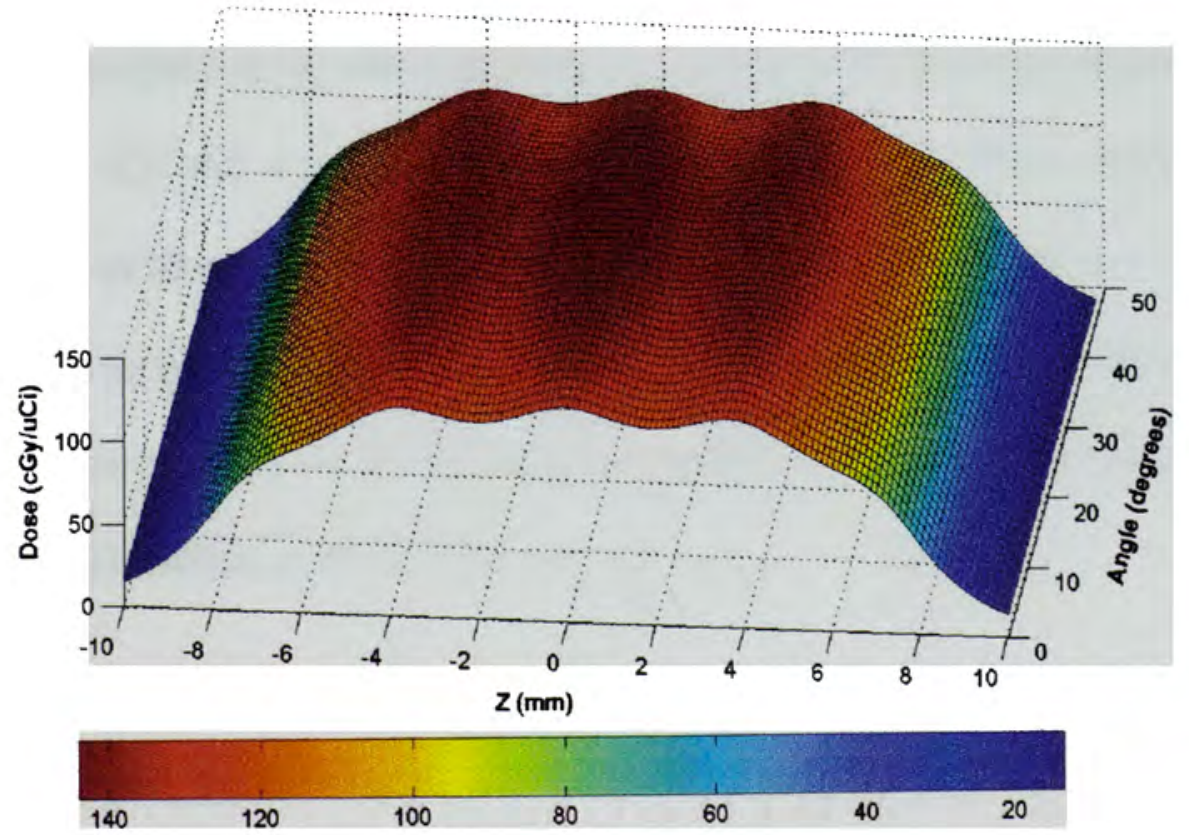

Figure 4-11. 3D map of dose to tissue after total decay of a ${ }^{90} \mathrm{Y}$ stent at $1.0 \mathrm{~mm}$ exterior to the stent surface. 


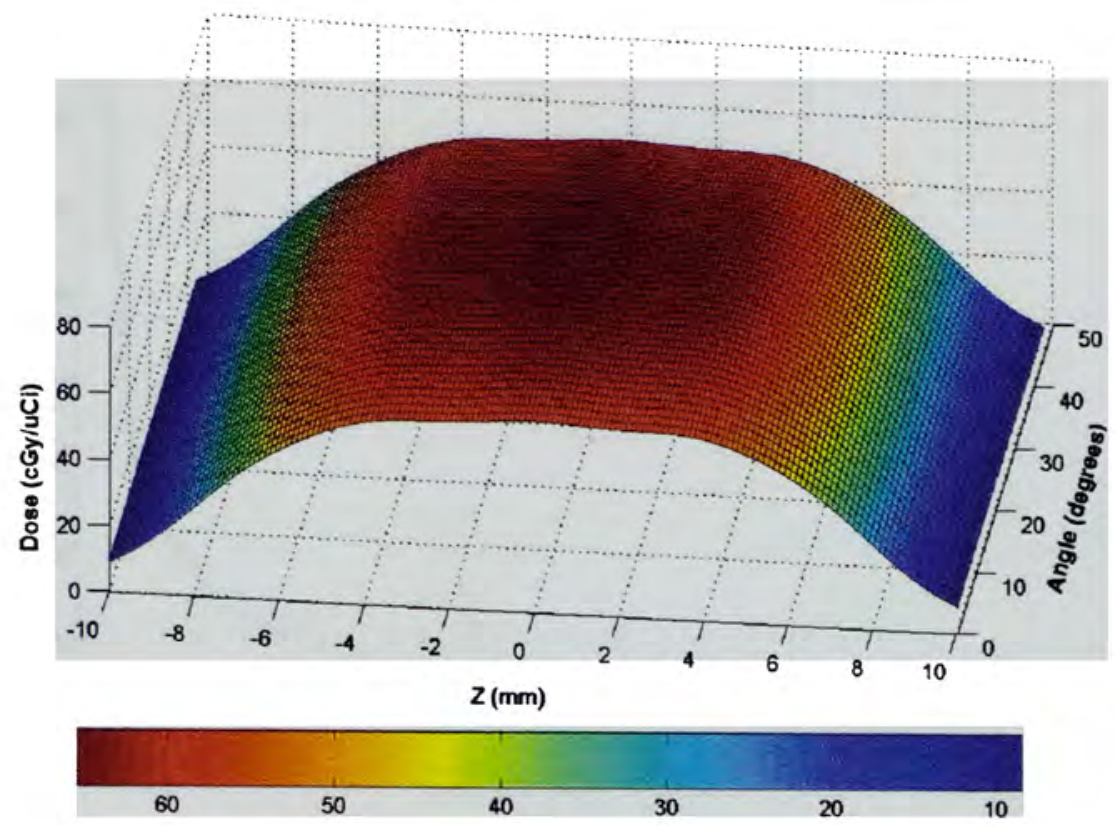

Figure 4-12. 3D map of dose to tissue after total decay of a ${ }^{90} \mathrm{Y}$ stent at $2.0 \mathrm{~mm}$ exterior to the stent surface.

Figure 4-13 represents the dose as a function of radial distance up to $5 \mathrm{~mm}$ into the arterial wall calculated at the stent midplane or $\mathrm{z}=0$. For ${ }^{90} \mathrm{Y}$, the dose delivered at 0.1 $\mathrm{mm}$ is $888.81 \mathrm{cGy} / \mu \mathrm{Ci}$, while at $1.0 \mathrm{~mm}$ it falls by $85.42 \%$ to $129.60 \mathrm{cGy} / \mu \mathrm{Ci}$. At a target distance of $2 \mathrm{~mm}$, the dose is $58.19 \mathrm{cGy} / \mu \mathrm{Ci}$, or $6.5 \%$ of the dose at $0.1 \mathrm{~mm}$. The dose delivered to the arterial wall at a fixed radial distance of $2.0 \mathrm{~mm}$ along the axis of the stent is shown in Figure 4-14 for half a stent from 0 to $12 \mathrm{~mm}$. At the stent ends, the dose is $29.89 \mathrm{cGy} / \mu \mathrm{Ci}$ or $51.38 \%$ of the dose at $\mathrm{z}=0$. 


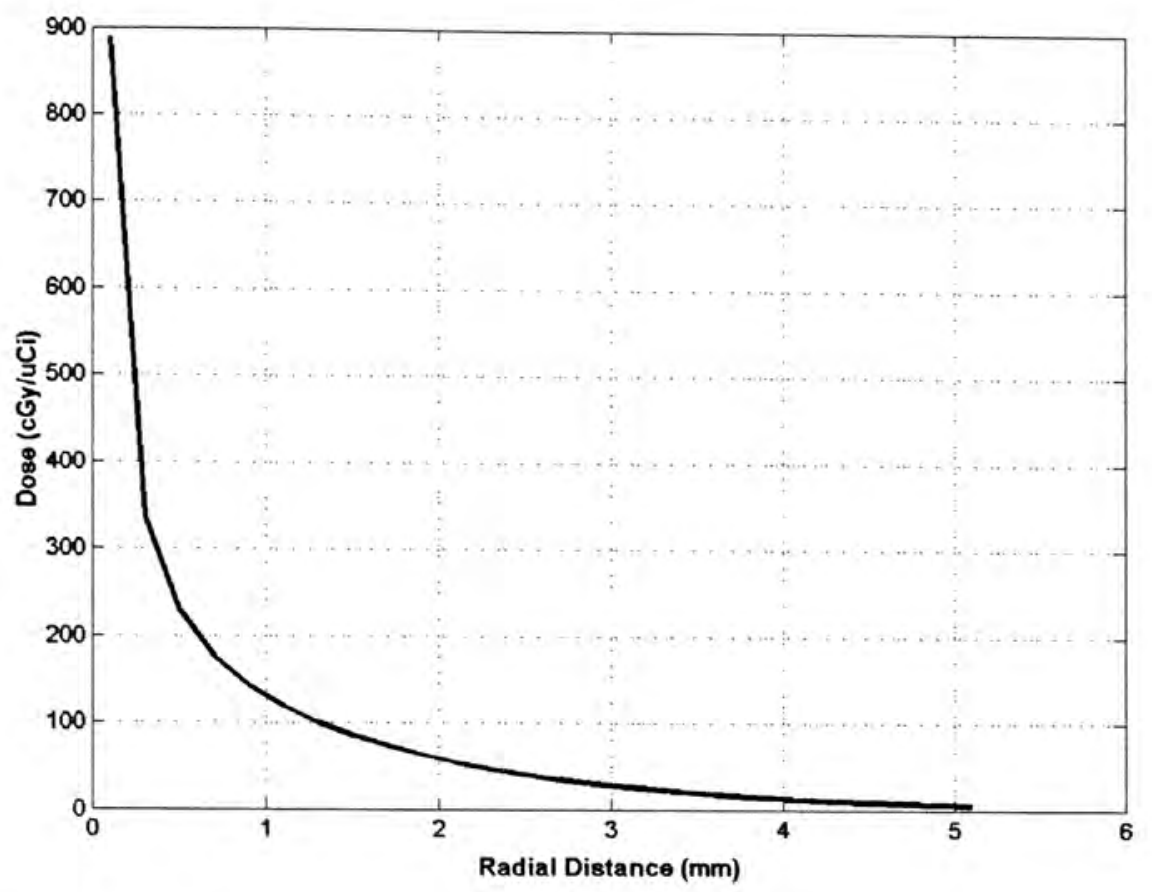

Figure 4-13. The variation of dose with radial distance of a ${ }^{90} \mathrm{Y}$ stent

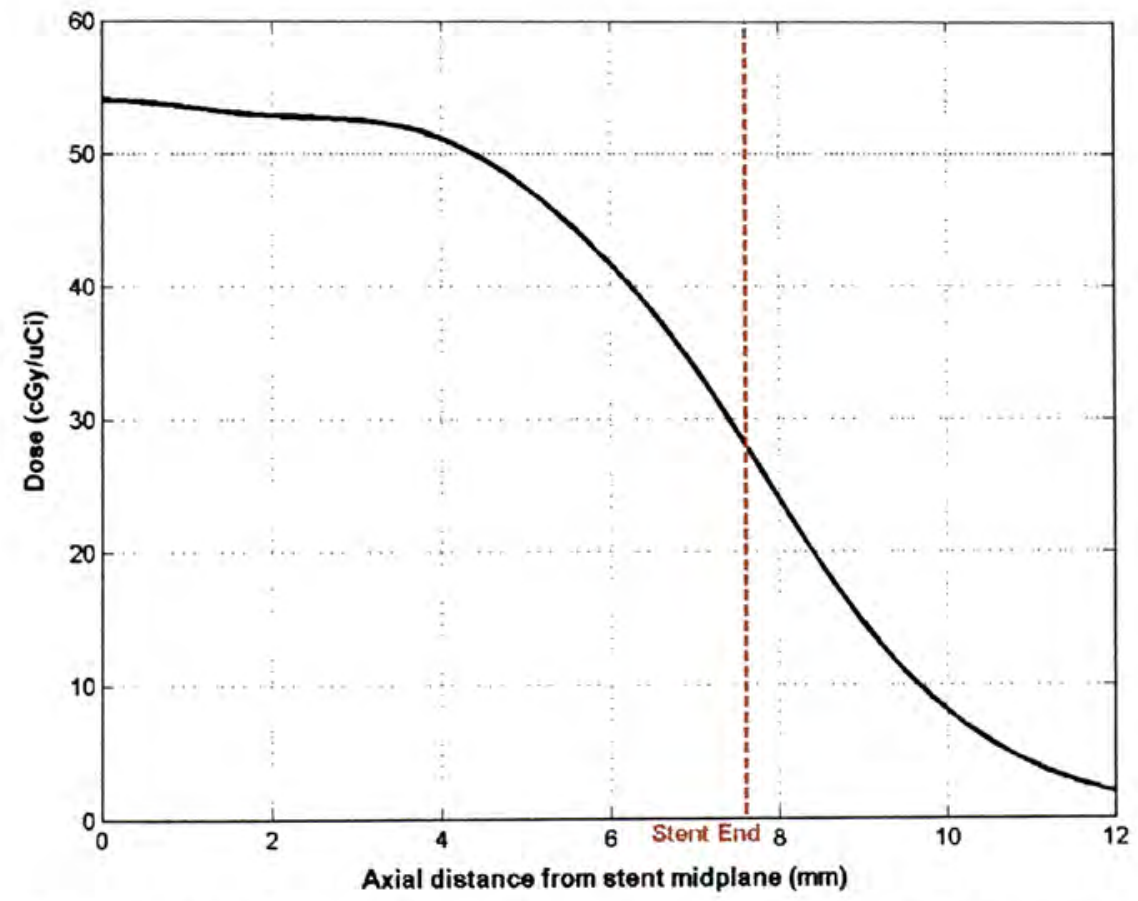

Figure 4-14. The variation of dose with axial distance of $a^{90} \mathrm{Y}$ stent 


\subsection{Dosimetry of a ${ }^{188}$ Re stent}

Figure 4-15 represents the $2 \mathrm{D}$ dosimetry plot for a stent coated with ${ }^{188} \mathrm{Re}$ as a function of increasing radial distance along the entire axis of the stent. The different curves are for doses at different depths into the arterial wall. At $0.1 \mathrm{~mm}$ from the surface of the stent, the dose varies from 290 to $195 \mathrm{cGy} / \mu \mathrm{Ci}$ at close proximity to the stent strut wires down to $\sim 60 \mathrm{cGy} / \mu \mathrm{Ci}$ in the areas between struts. At a distance of $1.0 \mathrm{~mm}$, dose delivery is more homogenous with a cumulative dose of $\sim 30 \mathrm{cGy} / \mu \mathrm{Ci}$. At 2.0 and $3.0 \mathrm{~mm}$, the dose is completely uniform, although it has fallen to about $6 \%$ of the dose at $0.1 \mathrm{~mm}$.

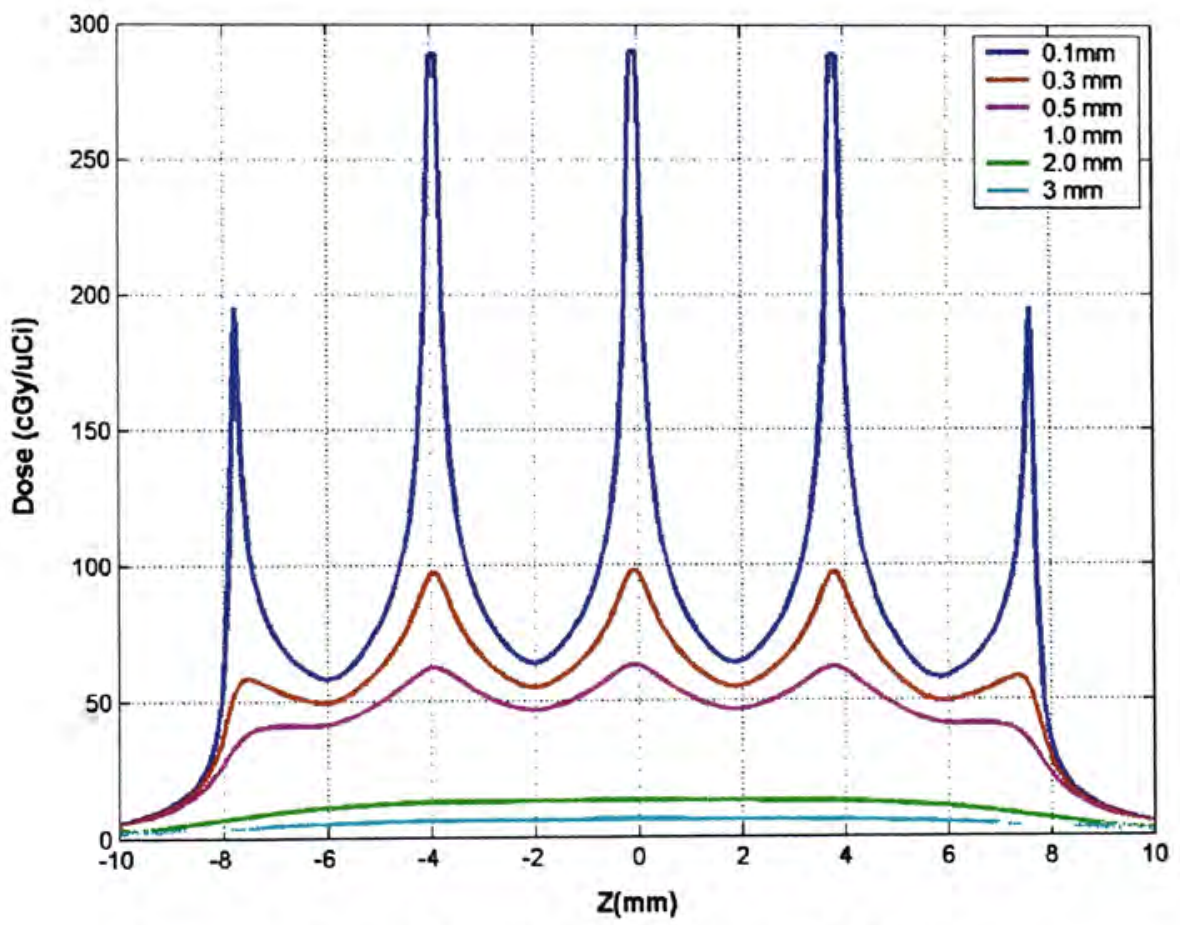

Figure 4-15. 2D plot of dose distribution of a ${ }^{188} \operatorname{Re}$ stent

Figures 4-16 to 4-19 provide a view of $3 \mathrm{D}$ dose maps extending from $-10 \mathrm{~mm} \leq \mathrm{z} \leq 10$ $\mathrm{mm}$ at distances $\mathrm{d}=0.1,0.5,1.0$ and $2.0 \mathrm{~mm}$ from the stent surface. These plots are 
projections over the stent in the $(\theta, z)$ plane shown in Figure 3-6 (Chapter 3). Shown is the dose for a segment over the stent between 0 and 45 degrees of the total stent circumference. At a distance of $0.1 \mathrm{~mm}$, the effect of the stent wires is very pronounced, indicating the nonuniformity of dose. This effect is significantly reduced at distances of 1.0 and $2.0 \mathrm{~mm}$ as seen in Figures 4-18 and 4-19.

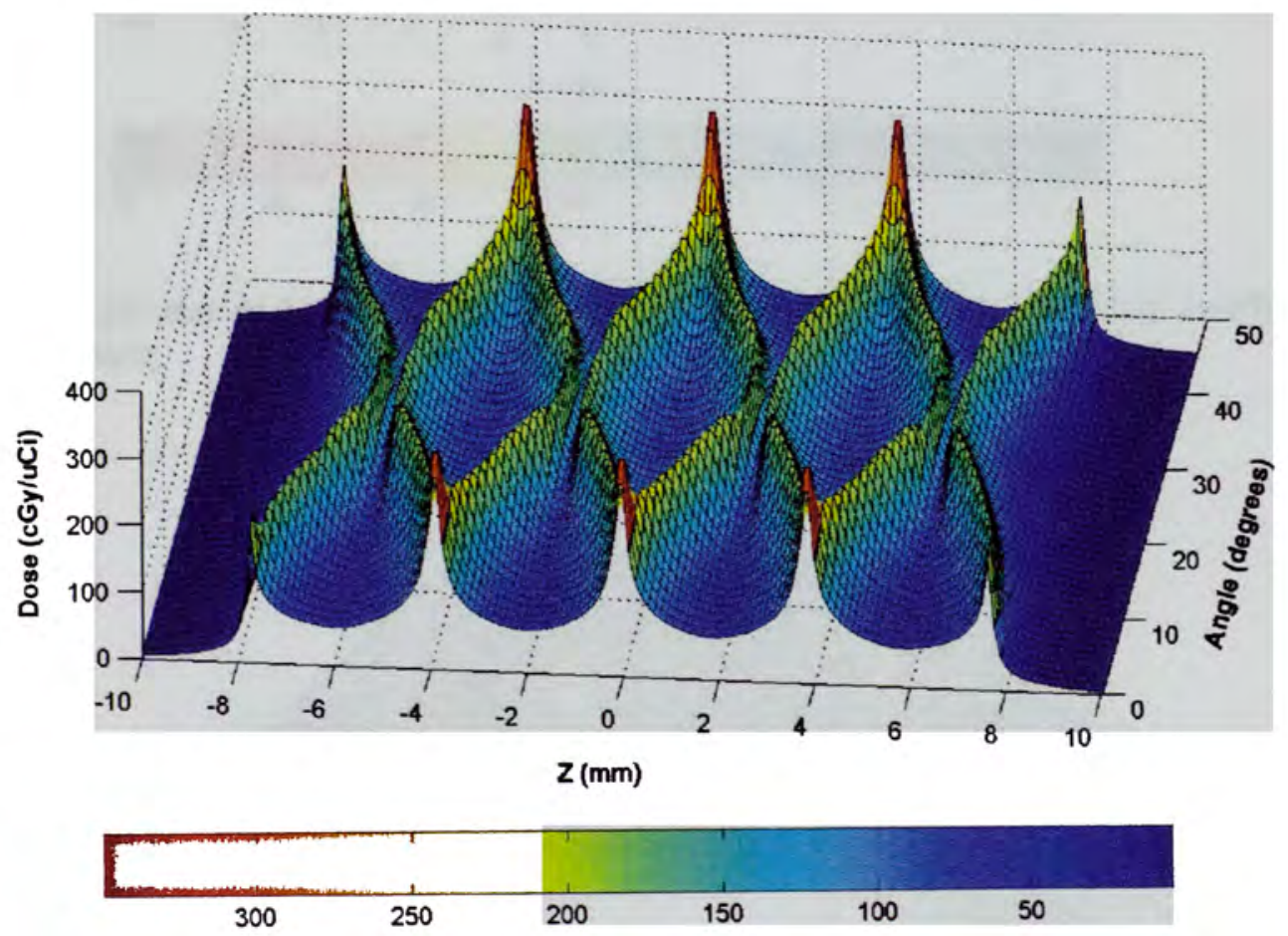

Figure 4-16. 3D map of dose to tissue after total decay of $a{ }^{188} \mathrm{Re}$ stent at $0.1 \mathrm{~mm}$ exterior to the stent surface. 


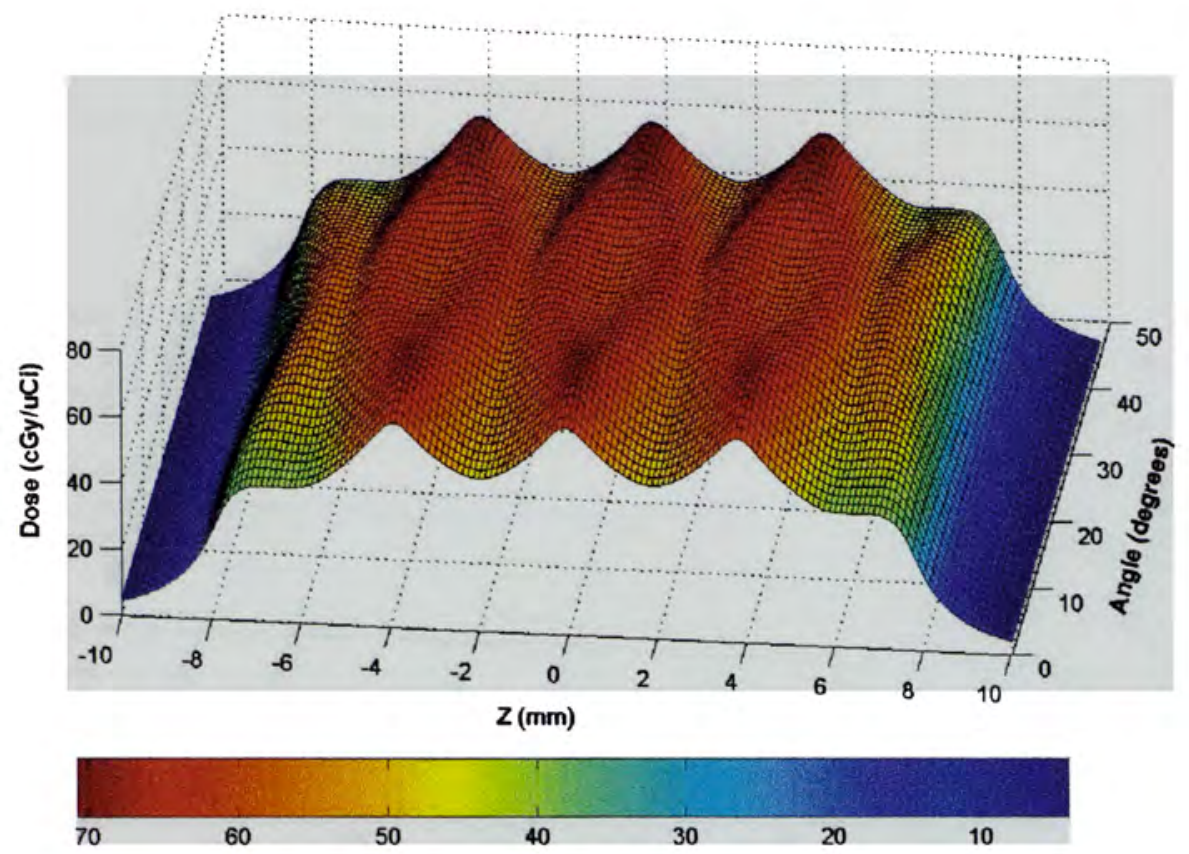

Figure 4-17. 3D map of dose to tissue after total decay of a ${ }^{188} \mathrm{Re}$ stent at $0.5 \mathrm{~mm}$ exterior to the stent surface.

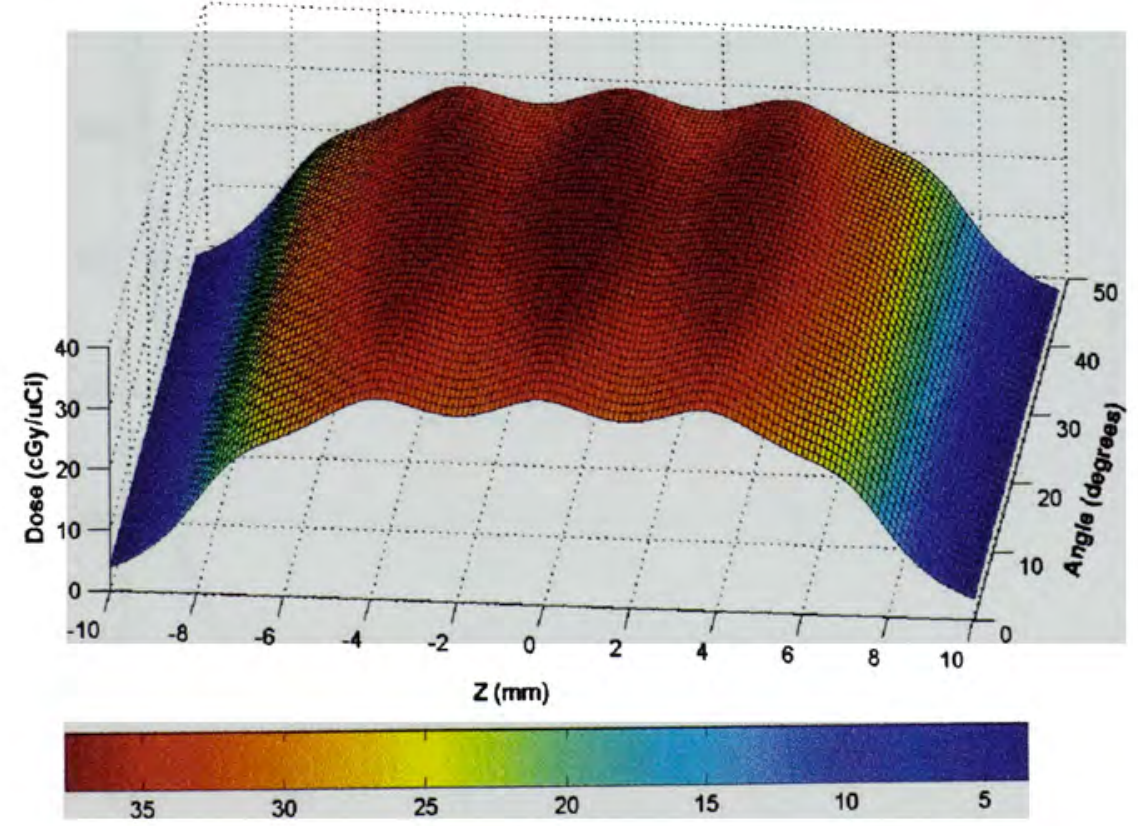

Figure 4-18. 3D map of dose to tissue after total decay of $a^{188} \mathrm{Re}$ stent at $1.0 \mathrm{~mm}$ exterior to the stent surface. 


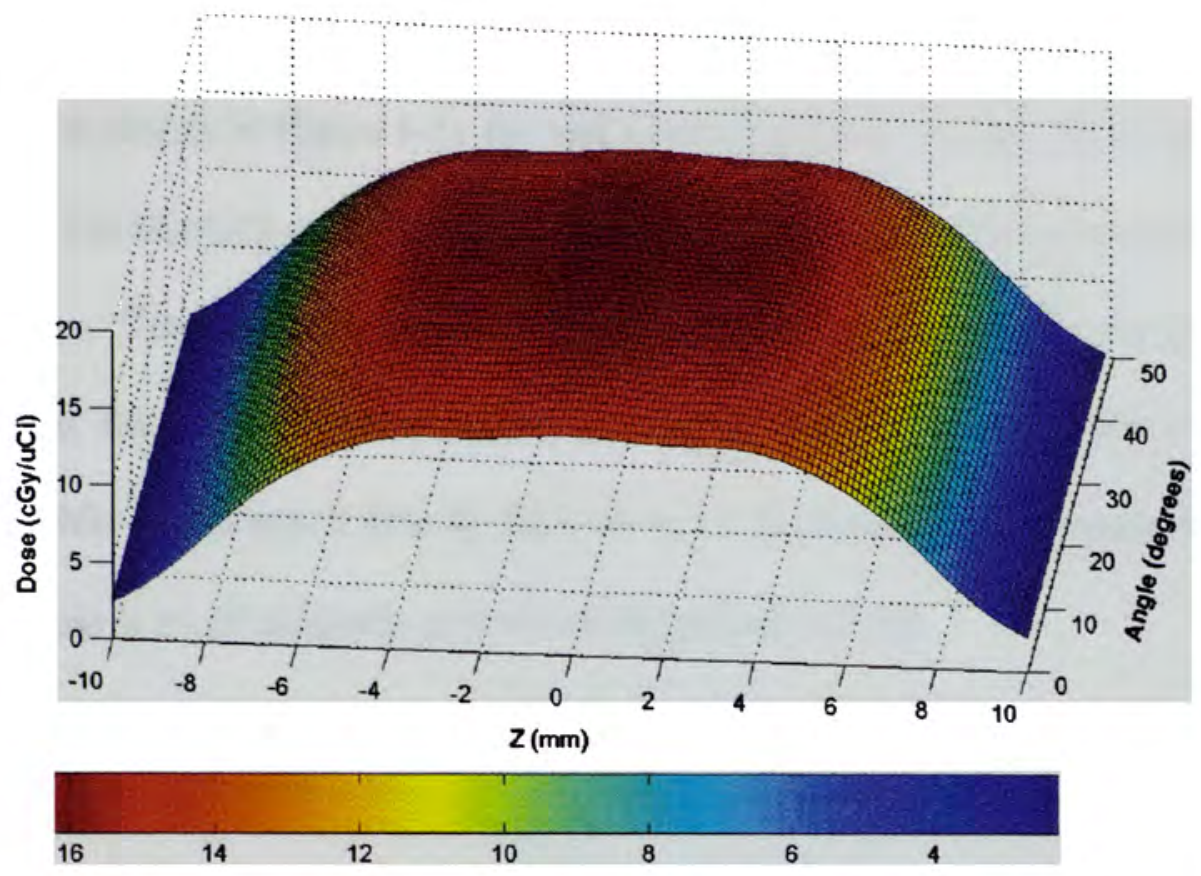

Figure 4-19. 3D map of dose to tissue after total decay of a ${ }^{188} \mathrm{Re}$ stent at $2.0 \mathrm{~mm}$ exterior to the stent surface.

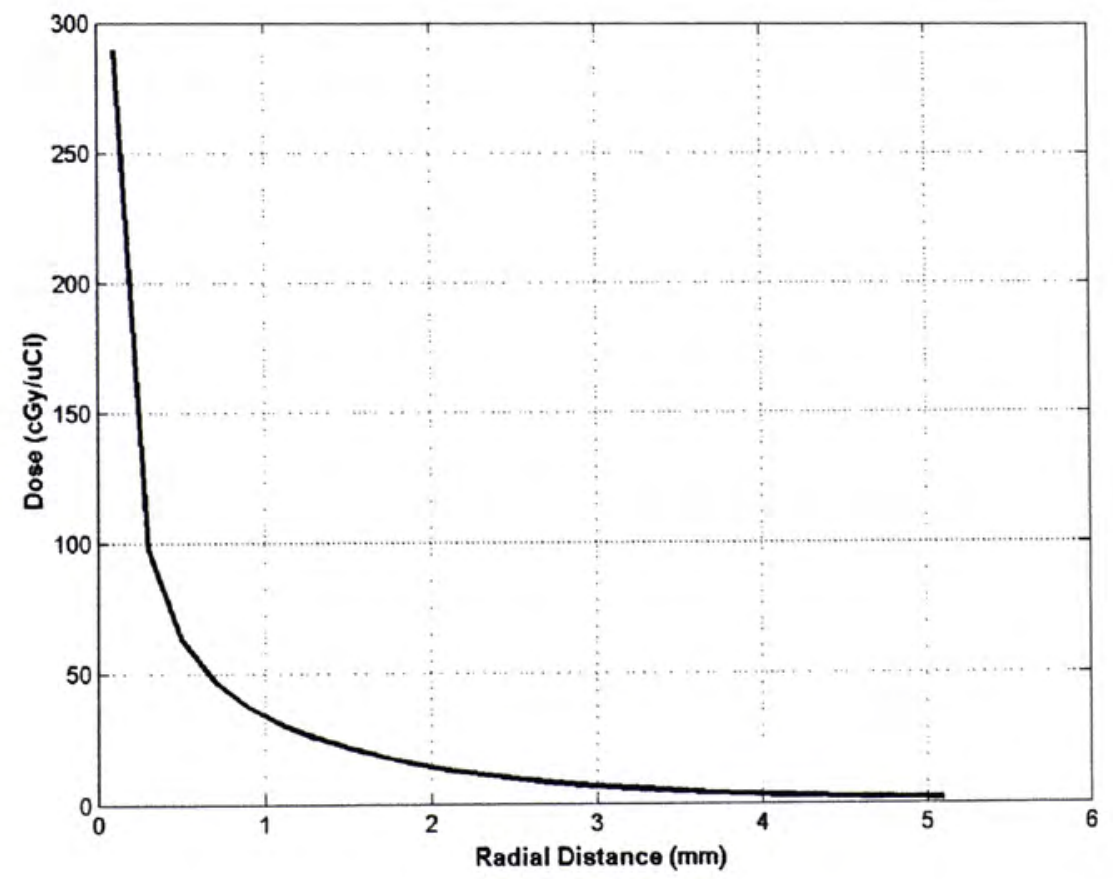

Figure 4-20. The variation of dose with radial distance of a ${ }^{188} \operatorname{Re}$ stent 
The dose delivered to the arterial wall at a fixed radial distance of $2.0 \mathrm{~mm}$ along the axis of the stent is shown in Figure 4-21 for half a stent from 0 to $12 \mathrm{~mm}$. At the stent edge, the dose is $7.6 \mathrm{cGy} / \mu \mathrm{Ci}$ or $53 \%$ of the dose at $\mathrm{z}=0$. Figure $4-20$ represents the dose delivered by a ${ }^{188} \mathrm{Re}$ stent as a function of radial distance up to $5 \mathrm{~mm}$ into the arterial wall calculated at the stent midplane or $\mathrm{z}=0$. At $0.1 \mathrm{~mm}$, the dose delivered is 289.75 $\mathrm{cGy} / \mu \mathrm{Ci}$, while at $1.0 \mathrm{~mm}$ it falls by $88.35 \%$ to $33.76 \mathrm{cGy} / \mu \mathrm{Ci}$. At a target distance of $2 \mathrm{~mm}$, the dose is $14.30 \mathrm{cGy} / \mu \mathrm{Ci}$, or $4.9 \%$ of the dose at $0.1 \mathrm{~mm}$.

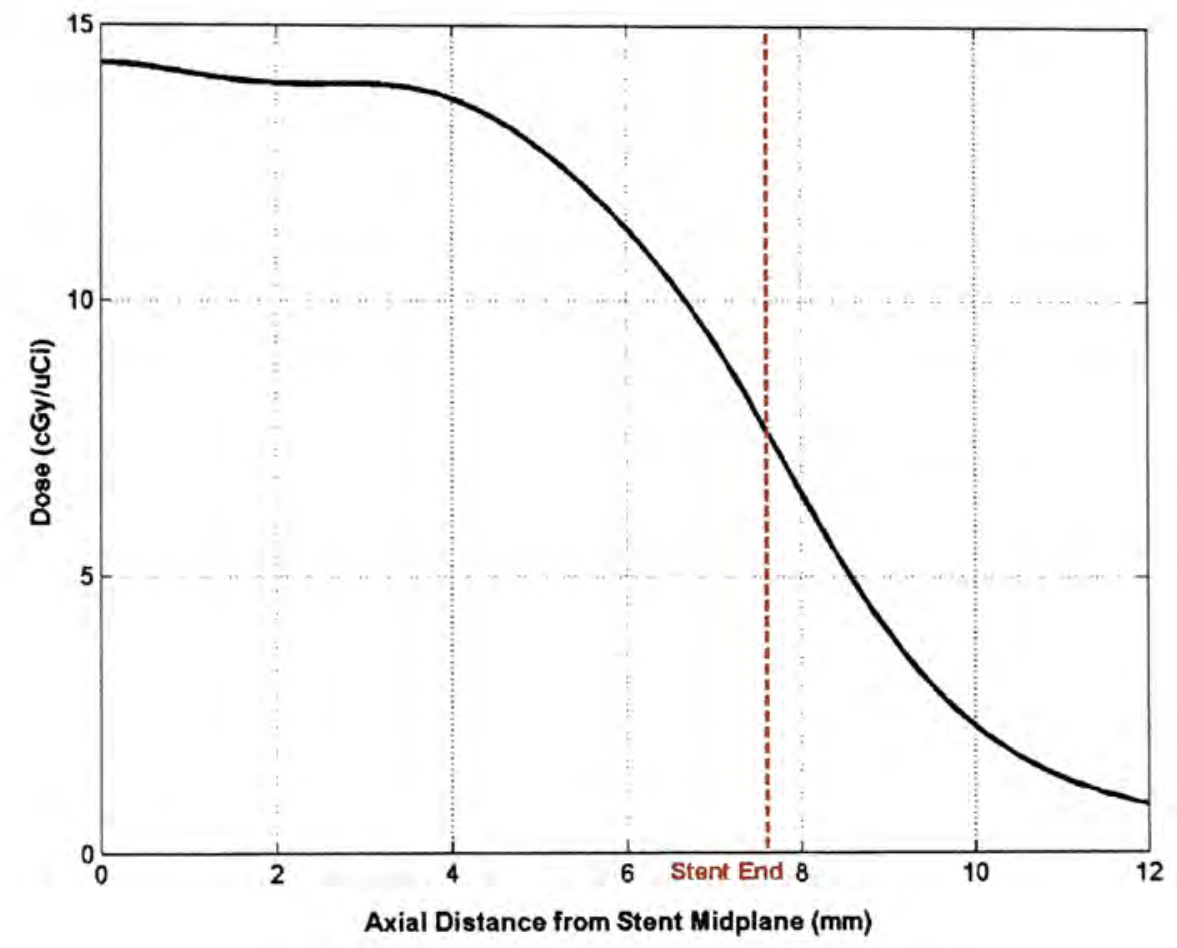

Figure 4-21. The variation of dose with axial distance for $a{ }^{188} \operatorname{Re}$ stent

${ }^{188} \operatorname{Re}$ decays by both beta and gamma emissions. Although its highest energy is provided by beta decay, it has gamma decay of $0.155 \mathrm{MeV}$ at $14.9 \%, 0.633 \mathrm{MeV}$ at $1.25 \%$ and 0.478 at $1.01 \%$. The relative percentage of this gamma decay to the total dose delivered by $a{ }^{188} \mathrm{Re}$ stent as a function of radial distance is shown in Figure 4-22. The beta DPK of 
${ }^{188} \mathrm{Re}$ has a maximum range of $8.7 \mathrm{~mm}$, at which point the dose is composed of gamma emissions entirely. At the target distance of $2 \mathrm{~mm}$, gamma emissions contribute about a $20 \%$ to the total dose.

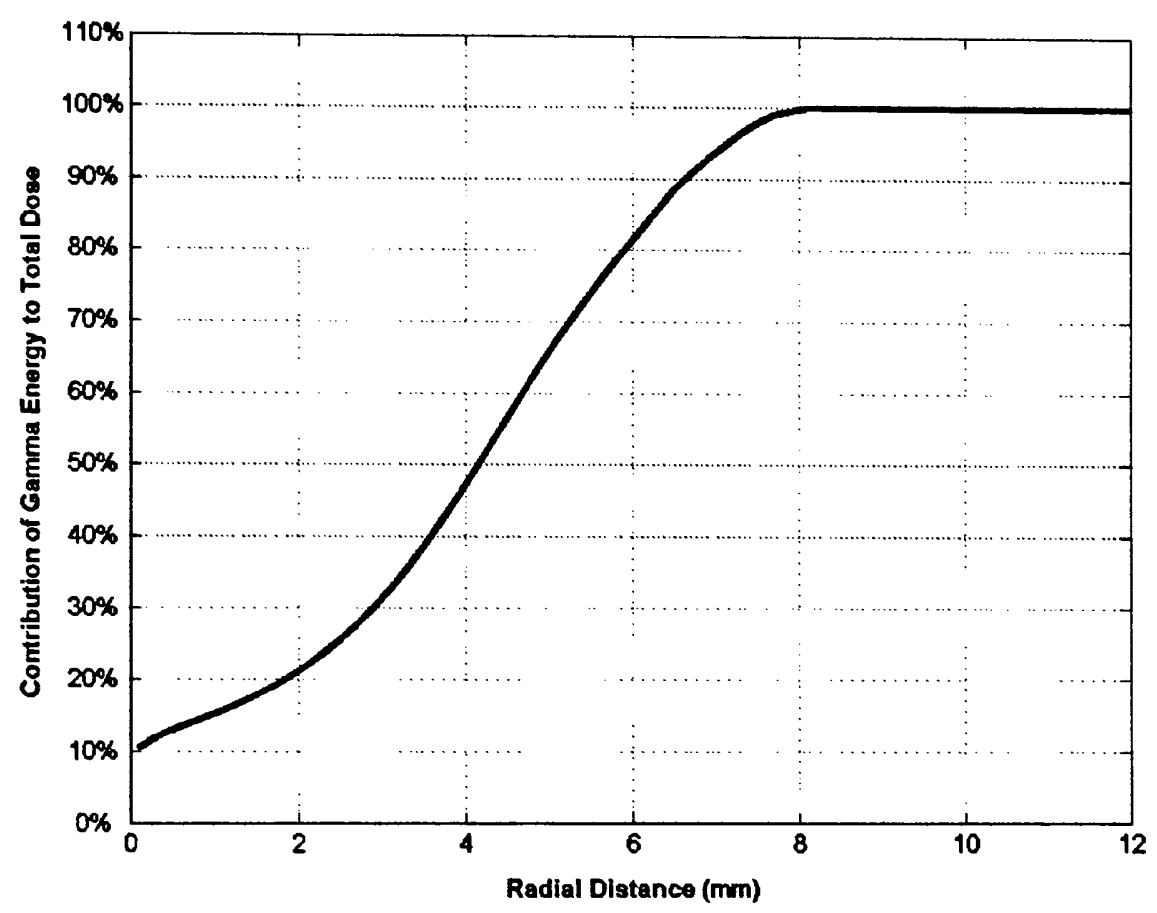

Figure 4-22. Contribution of gamma energy to total dose of a ${ }^{188} \operatorname{Re}$ stent

Figure 4-23 provides a view of the total dose as a function of radial distance and the contributions of both beta and gamma emissions. From a distance of $4.0 \mathrm{~mm}$ the greatest contribution is provided by the gamma emissions. Note that the dose from beta emissions falls off more quickly than that of gamma emissions, which is of a much smaller magnitude, but with a less steep dose gradient. Numerical values are presented in Table 4-1. 


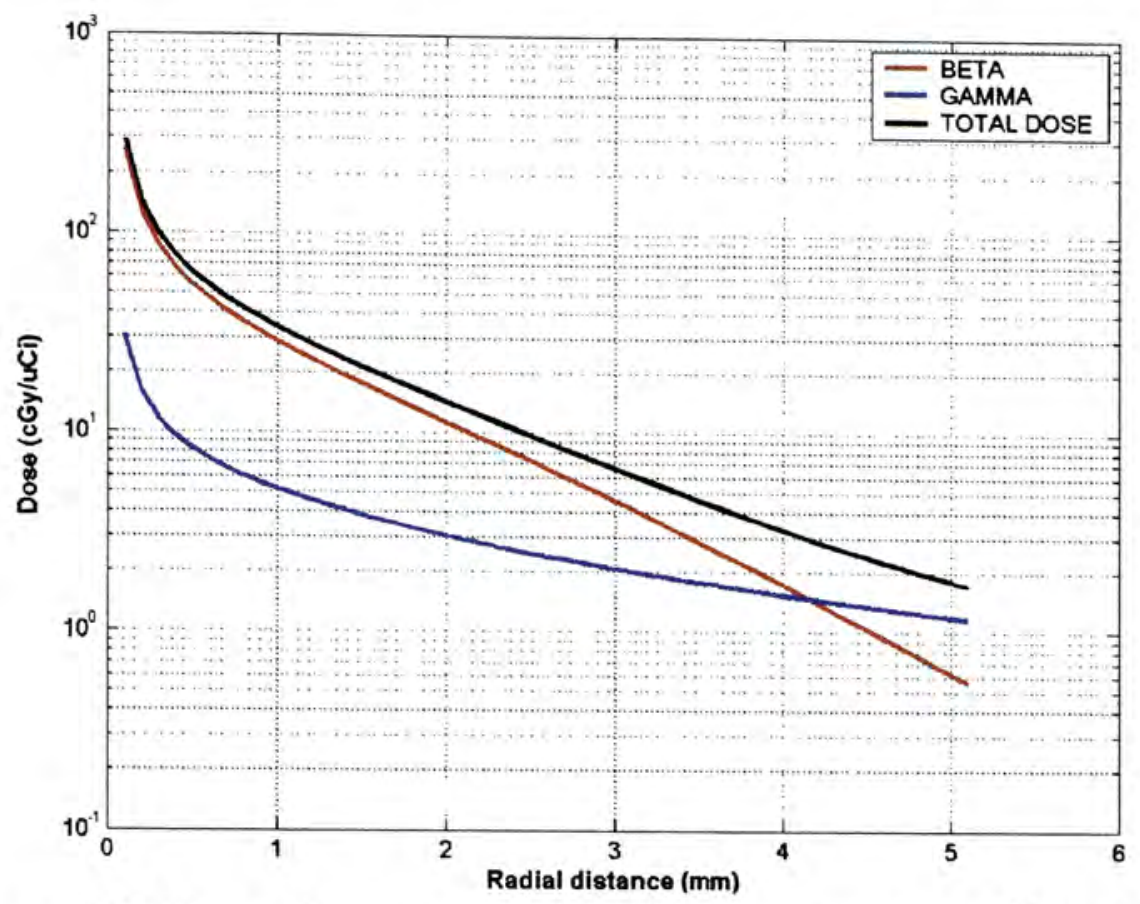

Figure 4-23. Beta and gamma components of dose delivered by a ${ }^{188}$ Re stent

Table 4-1. Beta and gamma components of total dose of a ${ }^{188}$ Re stent

\begin{tabular}{|c|c|c|c|}
\hline $\begin{array}{c}\text { Radial } \\
\text { distance }(\mathbf{m m})\end{array}$ & $\begin{array}{c}\text { BETA } \\
(\mathbf{c G y} / \boldsymbol{\mu} \mathbf{C i})\end{array}$ & $\begin{array}{c}\text { GAMMA } \\
(\mathbf{c G y} / \boldsymbol{\mu C} \mathbf{C})\end{array}$ & $\begin{array}{c}\text { TOTAL DOSE } \\
(\mathbf{c G y} / \boldsymbol{\mu C} \mathbf{)})\end{array}$ \\
\hline 0.1 & 259.68 & 30.07 & 289.75 \\
\hline 0.5 & 54.81 & 8.19 & 63.00 \\
\hline 1.0 & 28.61 & 5.14 & 33.76 \\
\hline 1.5 & 17.65 & 3.82 & 21.47 \\
\hline 2.0 & 11.28 & 3.02 & 14.30 \\
\hline 2.5 & 7.22 & 2.48 & 9.70 \\
\hline 3.0 & 4.56 & 2.08 & 6.64 \\
\hline 3.5 & 2.83 & 1.77 & 4.61 \\
\hline 4.0 & 1.72 & 1.54 & 3.26 \\
\hline 4.5 & 1.04 & 1.34 & 2.38 \\
\hline 5.0 & 0.62 & 1.19 & 1.80 \\
\hline
\end{tabular}




\subsection{Self-Attenuation Correction Factor for DPK Calculation of a ${ }^{177}$ Lu stent}

The ${ }^{177} \mathrm{Lu}$ stent, unlike all others simulated in this work has the radioactivity embedded within the volume of the stent. This required the calculation of an attenuation correction factor of the beta and gamma emissions as they travel from the inside of the material to the target distances. The self-attenuation factor for both beta and gamma emissions was calculated according to equations 18 and 19 in (Chapter 3). Selfattenuation factors were 0.28 for beta emissions and 0.991 for gamma emissions. The final dose results obtained from the dosimetry model was then multiplied by these factors for beta and gamma emissions respectively. Figure 4-24 shows a comparison of the dose delivered from the midstent, or $z=0$, to target points ranging from 0.1 to $5 \mathrm{~mm}$ from the stent. The dose from the beta emissions is significantly attenuated with only $28 \%$ of the dose reaching the target tissue. As the distance increases from the stent surface, the dose from beta emissions becomes negligible and the dose is composed entirely of gamma emissions. At these points the dose with and without attenuation correction is almost identical, because for gamma energy the self-attenuation is negligible. Table 4-2 shows

numerical values of the components of the dose delivered by ${ }^{177} \mathrm{Lu}$ at increasing radial distances from the surface of the stent. 


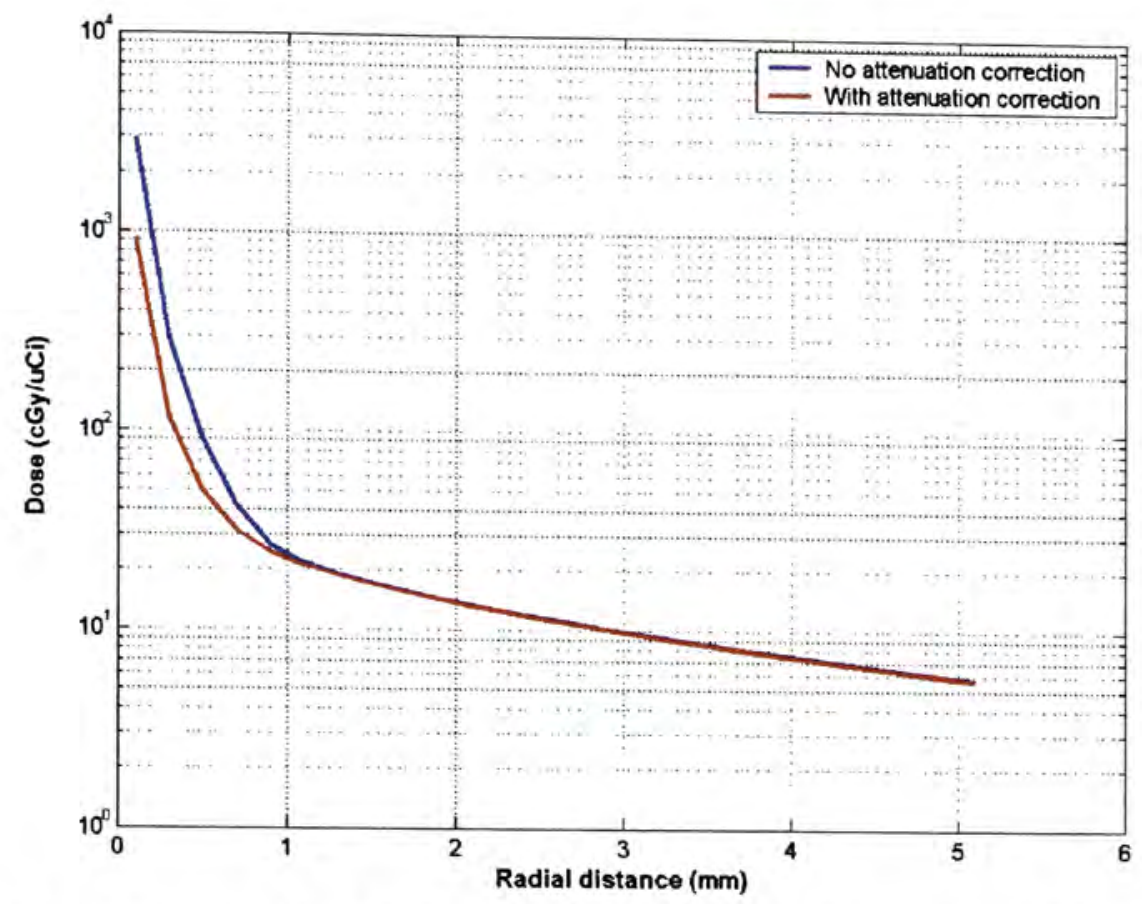

Figure 4-24. Comparison of dose with and without attenuation correction for a ${ }^{177} \mathrm{Lu}$ stent.

Table 4-2. Comparison of dose with and without self-attenuation correction factors for dose delivered by a ${ }^{177} \mathrm{Lu}$ stent.

\begin{tabular}{|c|c|c|c|c|c|c|}
\hline $\begin{array}{c}\text { Radial } \\
\text { distance } \\
\text { (mm) }\end{array}$ & Beta & $\begin{array}{c}\text { Beta (with } \\
\text { attenuation } \\
\text { correction) }\end{array}$ & Gamma & $\begin{array}{c}\text { Gamma } \\
\text { (with } \\
\text { attenuation } \\
\text { correction) }\end{array}$ & $\begin{array}{c}\text { Total } \\
\text { dose }\end{array}$ & $\begin{array}{c}\text { Total dose } \\
\text { (with } \\
\text { attenuation } \\
\text { correction) }\end{array}$ \\
\hline 0.1 & $2,774.4$ & 776.8 & 142.42 & 141.14 & $2,916.80$ & 917.96 \\
\hline 0.5 & 55.7 & 15.6 & 33.91 & 33.61 & 89.61 & 49.20 \\
\hline 1.0 & 0.4914 & 0.1376 & 20.99 & 20.81 & 21.49 & 20.94 \\
\hline 1.5 & 0.0123 & 0.0035 & 17.10 & 16.95 & 17.11 & 16.95 \\
\hline 2.0 & 0.0000 & 0.0000 & 13.34 & 13.22 & 13.34 & 13.22 \\
\hline 2.5 & 0.0000 & 0.0000 & 11.56 & 11.46 & 11.56 & 11.46 \\
\hline 3.0 & 0.0000 & 0.0000 & 9.55 & 9.46 & 9.55 & 9.46 \\
\hline 3.5 & 0.0000 & 0.0000 & 8.50 & 8.42 & 8.50 & 8.42 \\
\hline 4.0 & 0.0000 & 0.0000 & 7.23 & 7.17 & 7.23 & 7.17 \\
\hline 4.5 & 0.0000 & 0.0000 & 6.54 & 6.48 & 6.54 & 6.48 \\
\hline 5.0 & 0.0000 & 0.0000 & 5.68 & 5.63 & 5.68 & 5.63 \\
\hline
\end{tabular}




\subsection{Dosimetry of a ${ }^{177} \mathrm{Lu}$ stent}

Figure 4-25 shows the 2D dose distribution of ${ }^{177}$ Lu emitting stent along the entire axis of the stent with distances ranging from 0.1 to $2.0 \mathrm{~mm}$ from the stent surface. Due to the steep dose gradient of ${ }^{177} \mathrm{Lu}$, the dose delivered at a distance of $0.1 \mathrm{~mm}$ ranges between $\sim 900 \mathrm{cGy} / \mu \mathrm{Ci}$ at points in close proximity to the stent struts and $\sim 50 \mathrm{cGy} / \mu \mathrm{Ci}$ in areas between the struts. As the distance from the stent increases, the dose uniformity increases, although the dose delivered decreases dramatically up to insignificant values with $1.4 \%$ of the dose at $0.1 \mathrm{~mm}$, at a target distance of $2.0 \mathrm{~mm}$ into the artery wall.

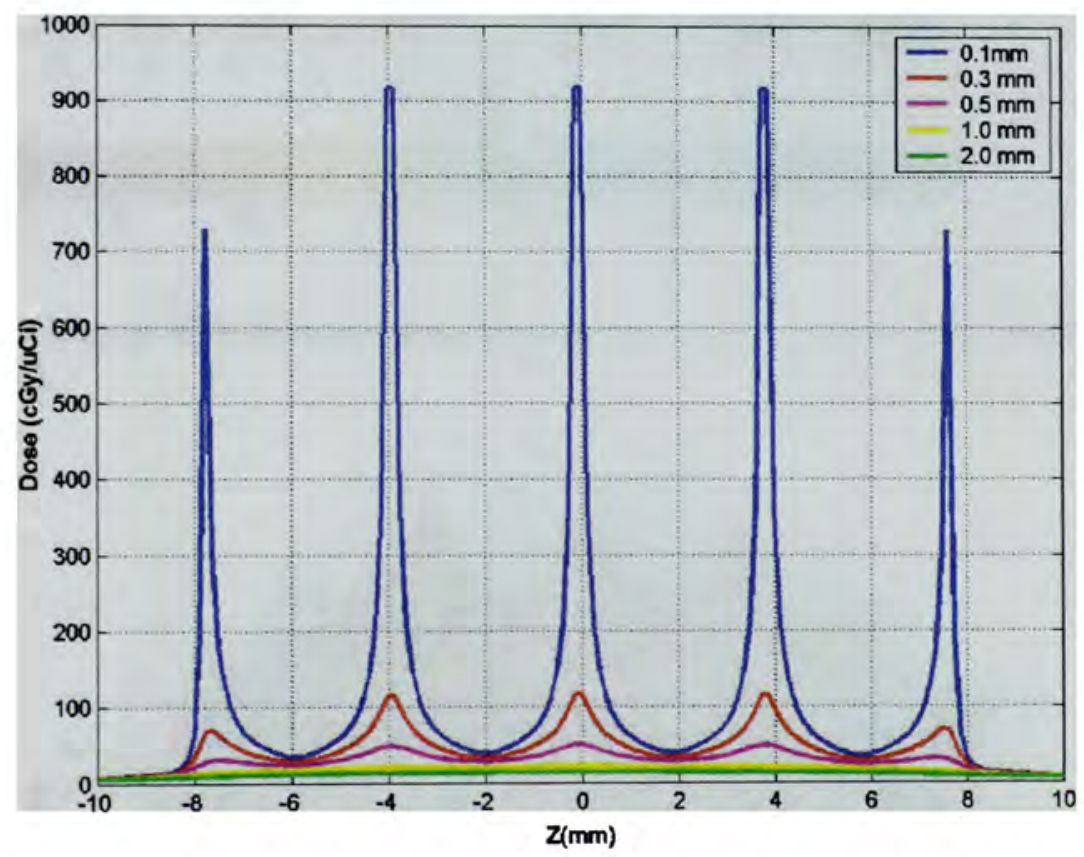

Figure 4-25. 2D plot of dose distribution of a ${ }^{177} \mathrm{Lu}$ stent

Figures 4-26 to 4-29 provide a view of $3 \mathrm{D}$ dose maps extending from $-10 \mathrm{~mm} \leq \mathrm{z} \leq 10$ $\mathrm{mm}$ at distances $\mathrm{d}=0.1,0.5,1.0$ and $2.0 \mathrm{~mm}$ from the stent surface. These plots are projections over the stent in the $(\theta, z)$ plane shown in Figure 3-6 (Chapter 3). Shown is the dose for a segment over the stent between 0 and 45 degrees of the total stent 
circumference. At a distance of $0.1 \mathrm{~mm}$, the effect of the stent wires is very pronounced, indicating the nonuniformity of dose. This effect is significantly reduced at distances of 1.0 and $2.0 \mathrm{~mm}$ as seen in Figures 4-28 and 4-29.

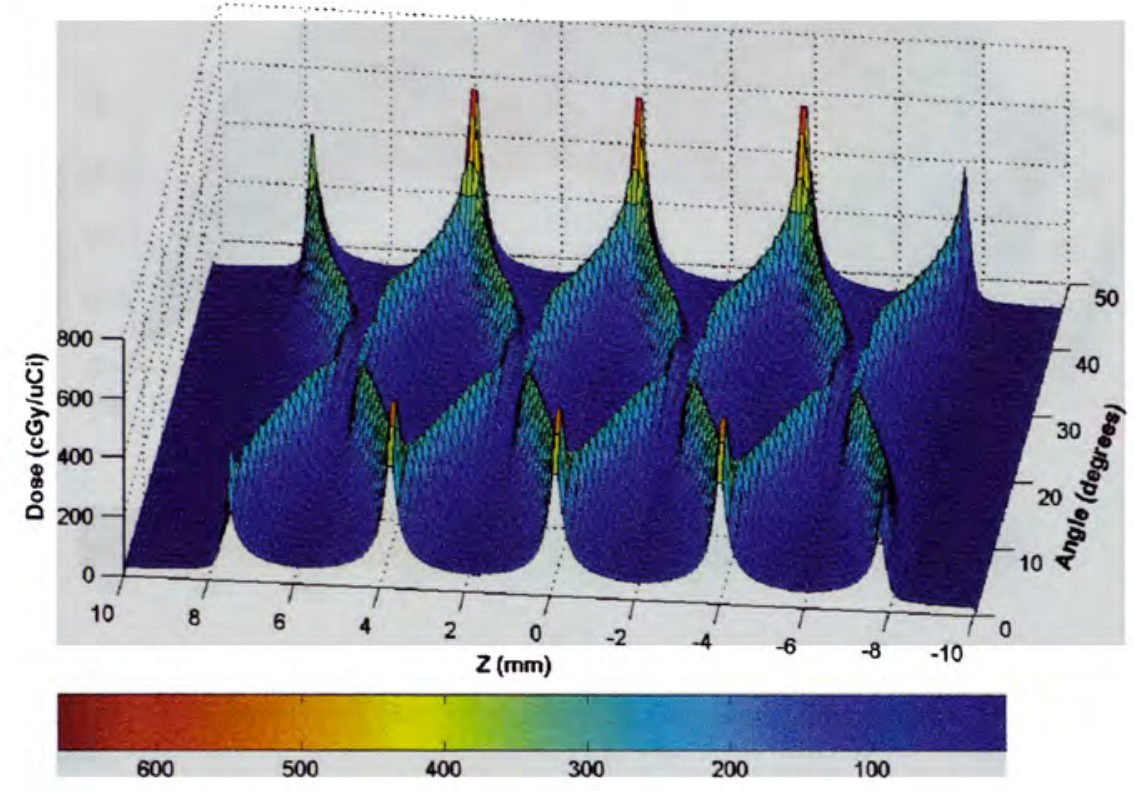

Figure 4-26. 3D map of dose to tissue after total decay of a ${ }^{177} \mathrm{Lu}$ stent at $0.1 \mathrm{~mm}$ exterior to the stent surface.

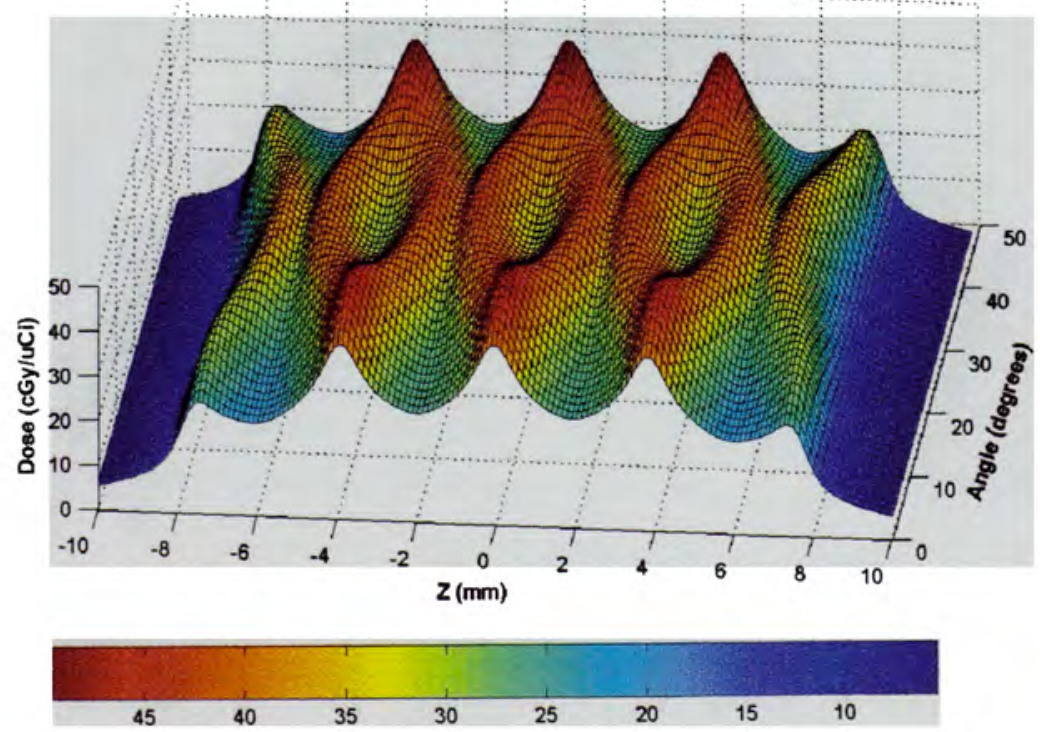

Figure 4-27. 3D map of dose to tissue after total decay of a ${ }^{177} \mathrm{Lu}$ stent at $0.5 \mathrm{~mm}$ exterior to the stent surface. 


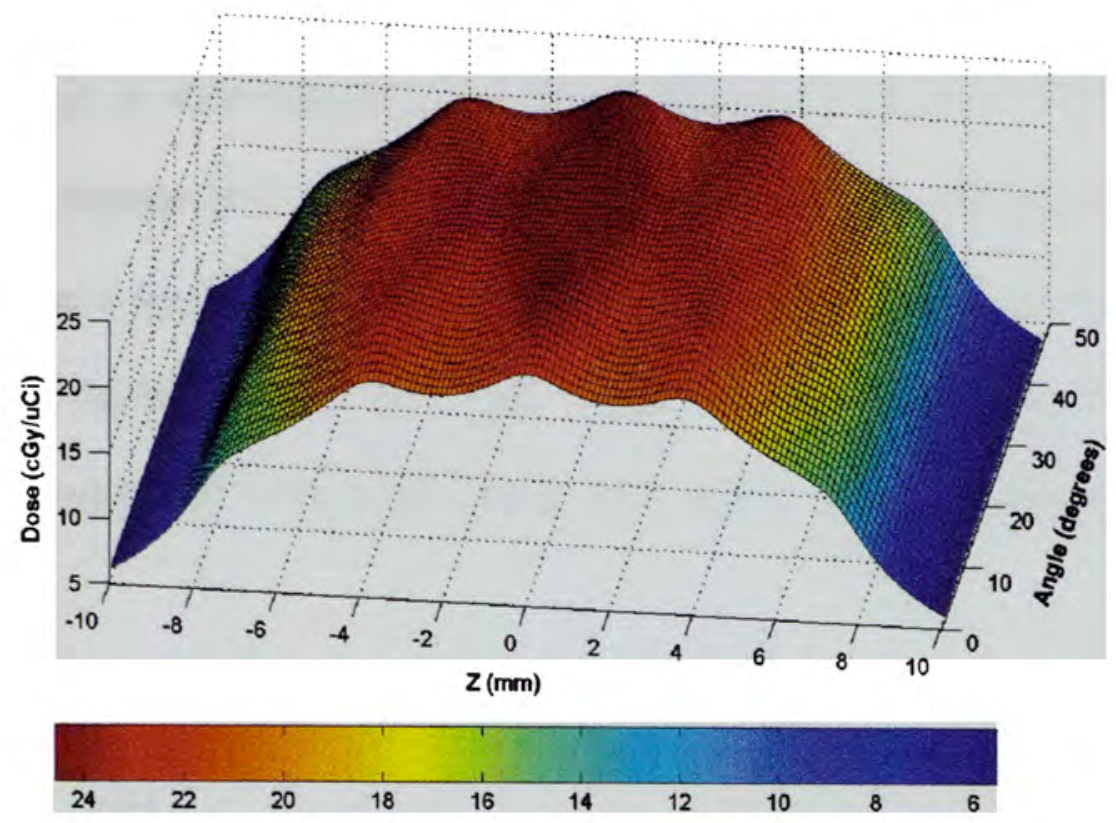

Figure 4-28. 3D map of dose to tissue after total decay of $\mathrm{a}^{177} \mathrm{Lu}$ stent at $1.0 \mathrm{~mm}$ exterior to the stent surface.

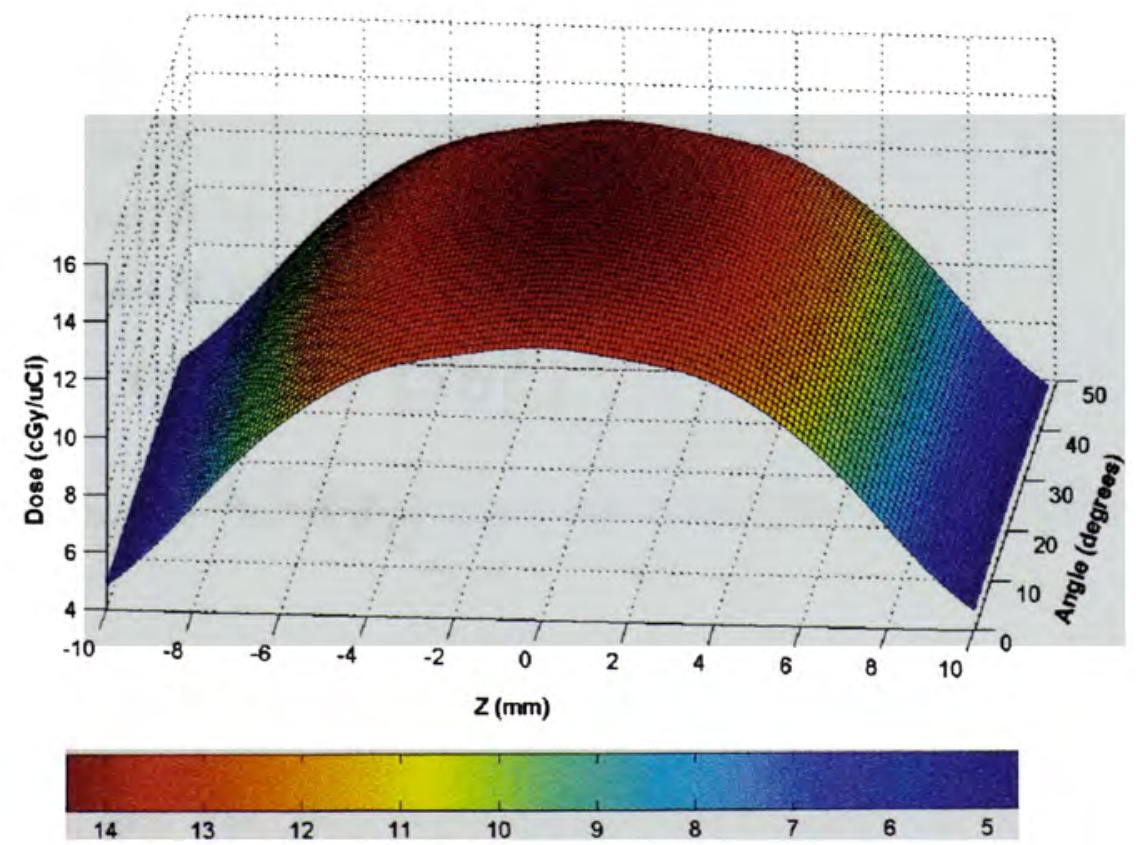

Figure 4-29. 3D map of dose to tissue after total decay of a ${ }^{177} \mathrm{Lu}$ stent at $2.0 \mathrm{~mm}$ exterior to the stent surface. 
Figure 4-30 shows the variation of dose as a function of radial distance delivered by a ${ }^{177} \mathrm{Lu}$ calculated at stent midplane $\mathrm{z}=0$. A maximum dose of $917.96 \mathrm{cGy} / \mu \mathrm{Ci}$ is delivered at a distance of $0.1 \mathrm{~mm}$ from the stent, however it falls off steeply by $95 \%$ to $49.2 \mathrm{cGy} / \mu \mathrm{Ci}$ at a distance of $0.5 \mathrm{~mm}$. The high energy delivered at such short distances is the result of the beta energy. At a target distance of $2 \mathrm{~mm}$ from the stent, the dose is only $13.73 \mathrm{cGy} / \mu \mathrm{Ci}$, or $1.5 \%$ of the initial dose, and is composed entirely of gamma energy.

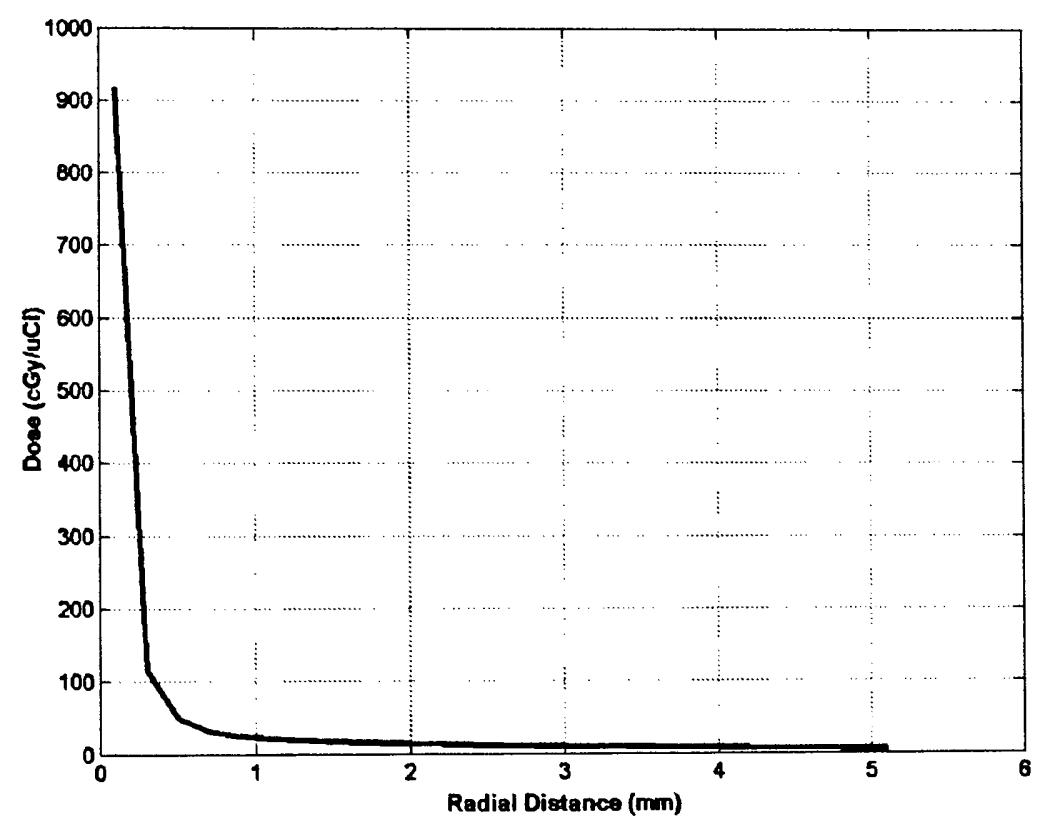

Figure 4-30. The variation of dose with radial distance of $a^{177} \mathbf{L u}$ stent

Figure 4-31 shows the variation of dose with axial displacement for a fixed radial distance of $2.0 \mathrm{~mm}$. The graph shows only half the stent as the dose distribution is symmetrical on the negative $\mathrm{z}$ axis of the stent. The dose tends to drop gradually at the 
edges of the stent and beyond. At the stent edge, the dose is $8.1562 \mathrm{cGy} / \mu \mathrm{Ci}$ or $60 \%$ of the dose at $z=0$. The contribution to this dose is made solely by gamma emissions of ${ }^{177} \mathrm{Lu}$.

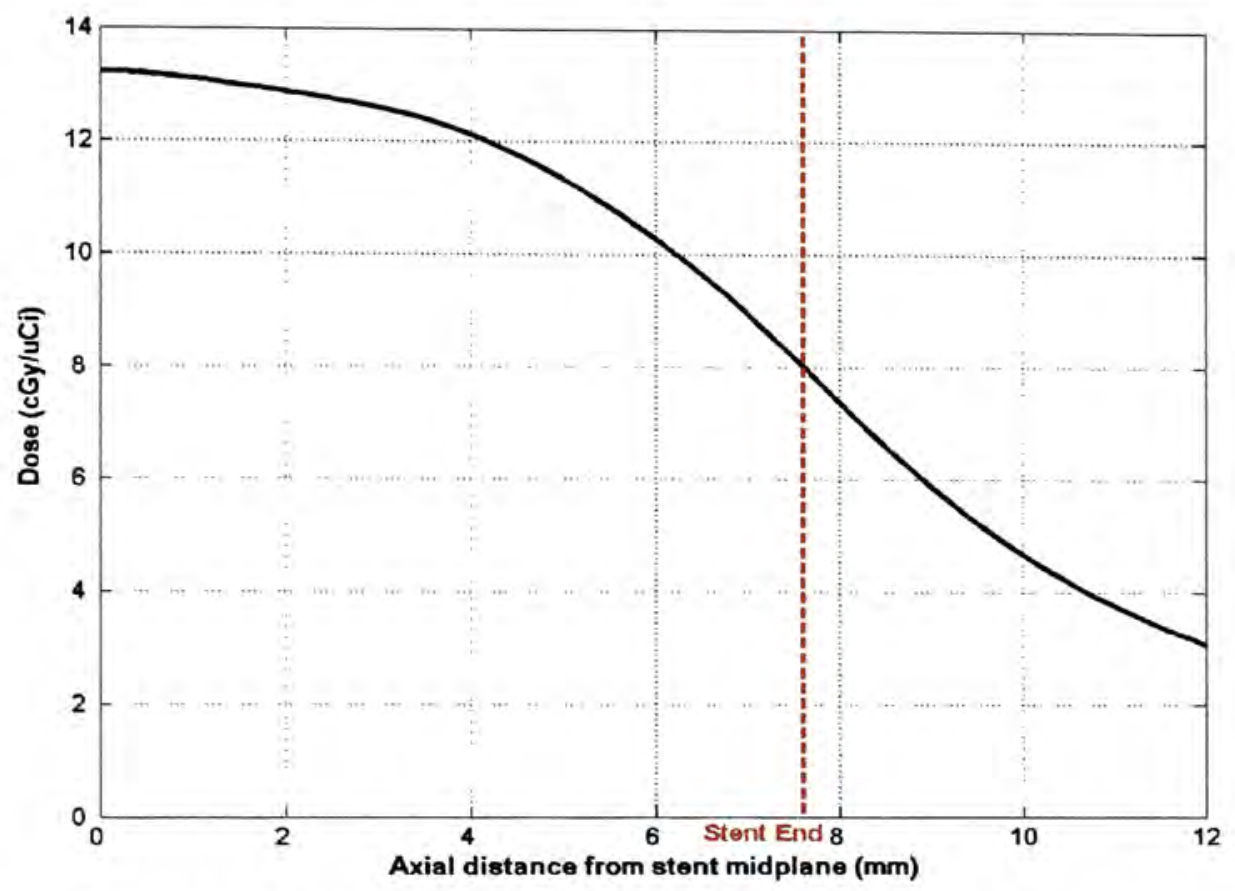

Figure 4-31. The variation of dose with axial distance of $a^{177} \mathrm{Lu}$ stent

Like ${ }^{188} \mathrm{Re},{ }^{177} \mathrm{Lu}$ decays by both beta and gamma emissions. Figure 4-32 shows the percentage of contribution of gamma energy to total dose delivered by the ${ }^{177} \mathrm{Lu}$ as a function of radial distance from the stent surface. At a radial distance greater than $1 \mathrm{~mm}$ the contribution of gamma to total dose is $100 \%$. Figure 4-33 shows the breakdown of the dose into beta and gamma components. It is clear that the dose by beta energy falls off significantly and makes very little contribution to the total dose at a radial distance greater than $1.0 \mathrm{~mm}$. Specific values are shown in Table 4-3. 


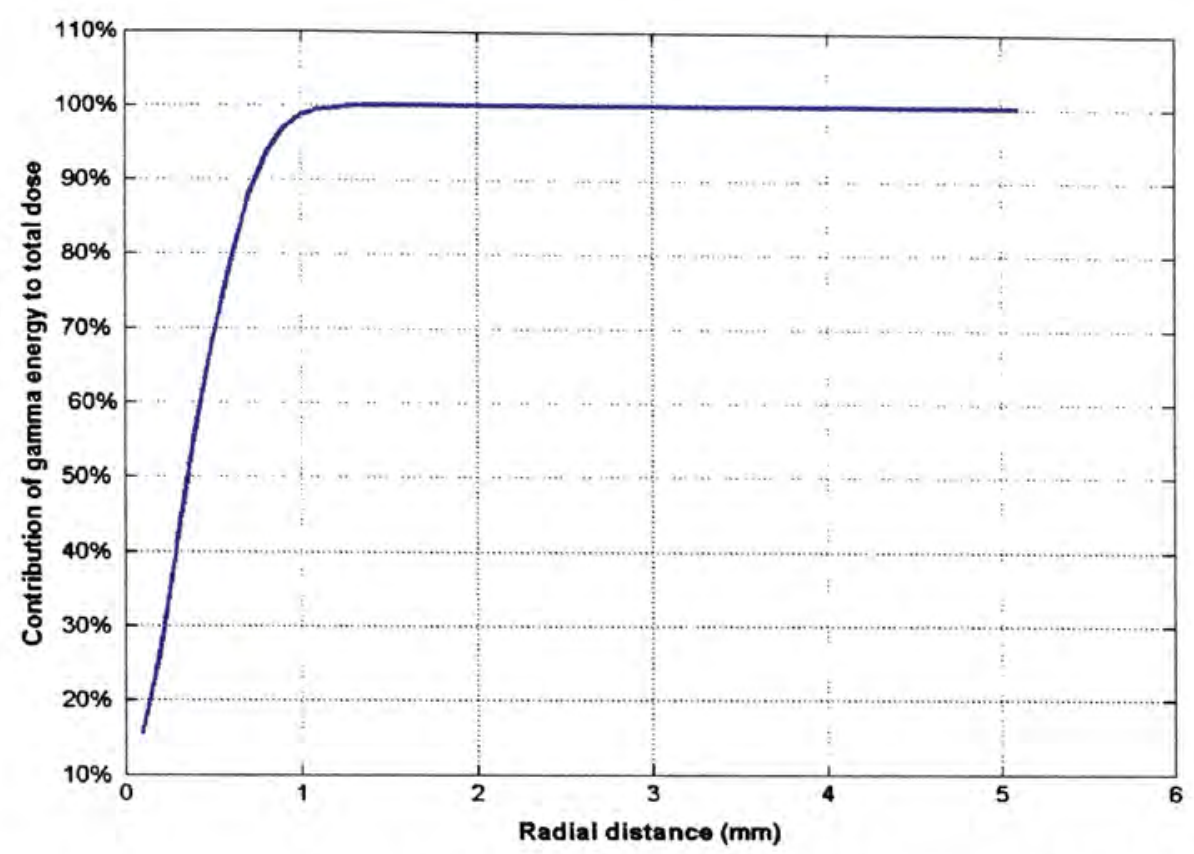

Figure 4-32. Contribution of gamma energy to total dose delivered by a ${ }^{177} \mathrm{Lu}$ stent.

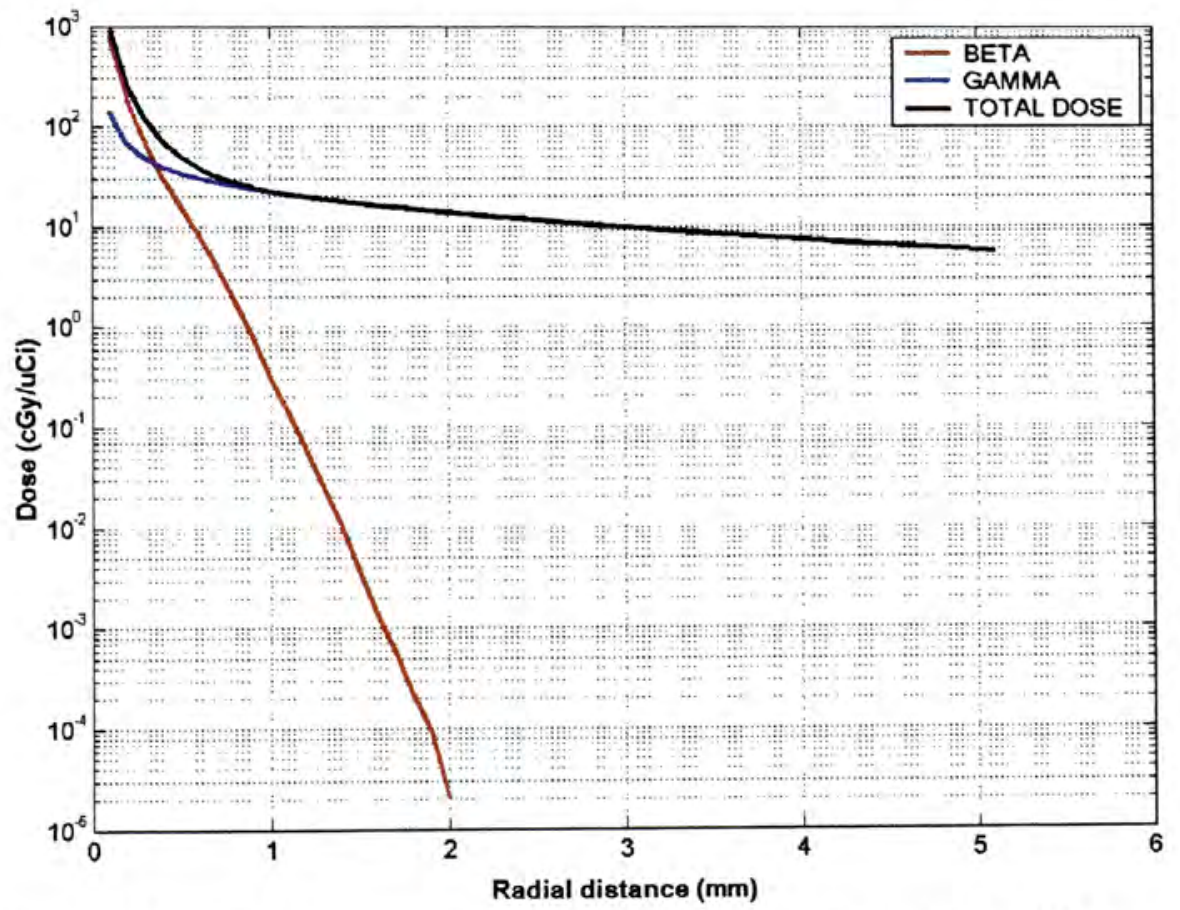

Figure 4-33. Beta and gamma components of dose delivered by a ${ }^{177} \mathrm{Lu}$ stent 
Table 4-3. Beta and gamma components of total dose of a ${ }^{177} \mathrm{Lu}$ stent

\begin{tabular}{|c|c|c|c|}
\hline $\begin{array}{c}\text { Radial } \\
\text { distance }(\mathbf{m m})\end{array}$ & $\begin{array}{c}\text { BETA } \\
(\mathbf{c G y} / \boldsymbol{\mu} \mathbf{C i})\end{array}$ & $\begin{array}{c}\text { GAMMA } \\
(\mathbf{c G y} / \boldsymbol{\mu} \mathbf{C i})\end{array}$ & $\begin{array}{c}\text { TOTAL DOSE } \\
(\mathbf{c G y} / \boldsymbol{\mu} \mathbf{C i})\end{array}$ \\
\hline 0.1 & 776.83 & 141.14 & 917.96 \\
\hline 0.5 & 15.59 & 33.61 & 49.20 \\
\hline 1.0 & 0.31 & 22.08 & 22.40 \\
\hline 1.5 & 0.0035 & 16.95 & 16.95 \\
\hline 2.0 & 0.00 & 13.73 & 13.73 \\
\hline 2.5 & 0.00 & 11.46 & 11.46 \\
\hline 3.0 & 0.00 & 9.75 & 9.75 \\
\hline 3.5 & 0.00 & 8.42 & 8.42 \\
\hline 4.0 & 0.00 & 7.36 & 7.36 \\
\hline 4.5 & 0.00 & 6.48 & 6.48 \\
\hline 5.0 & 0.00 & 5.76 & 5.76 \\
\hline
\end{tabular}

\subsection{Dosimetry Comparison of ${ }^{32} \mathrm{P},{ }^{90} \mathrm{Y},{ }^{188} \mathrm{Re}$, and ${ }^{177} \mathrm{Lu}$ stents}

Figures 4-34 shows a comparison of the dose distribution of the four radioisotope stents as a function of radial distance. Figure 4-35 represents the ratio of the dose at the point of interest to the dose at the middle of the stent along the stents axis for a fixed radial distance of $2.0 \mathrm{~mm}$ for each of the radioisotope stents.

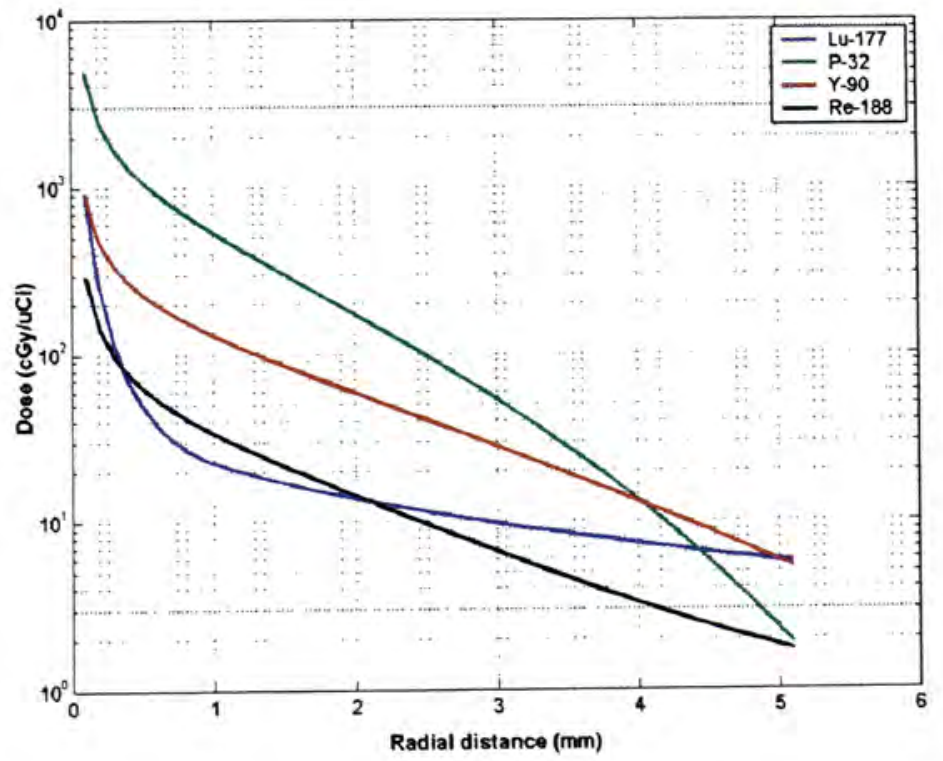

Figure 4-34. Comparison of radial dose distribution of four radioisotopes. 


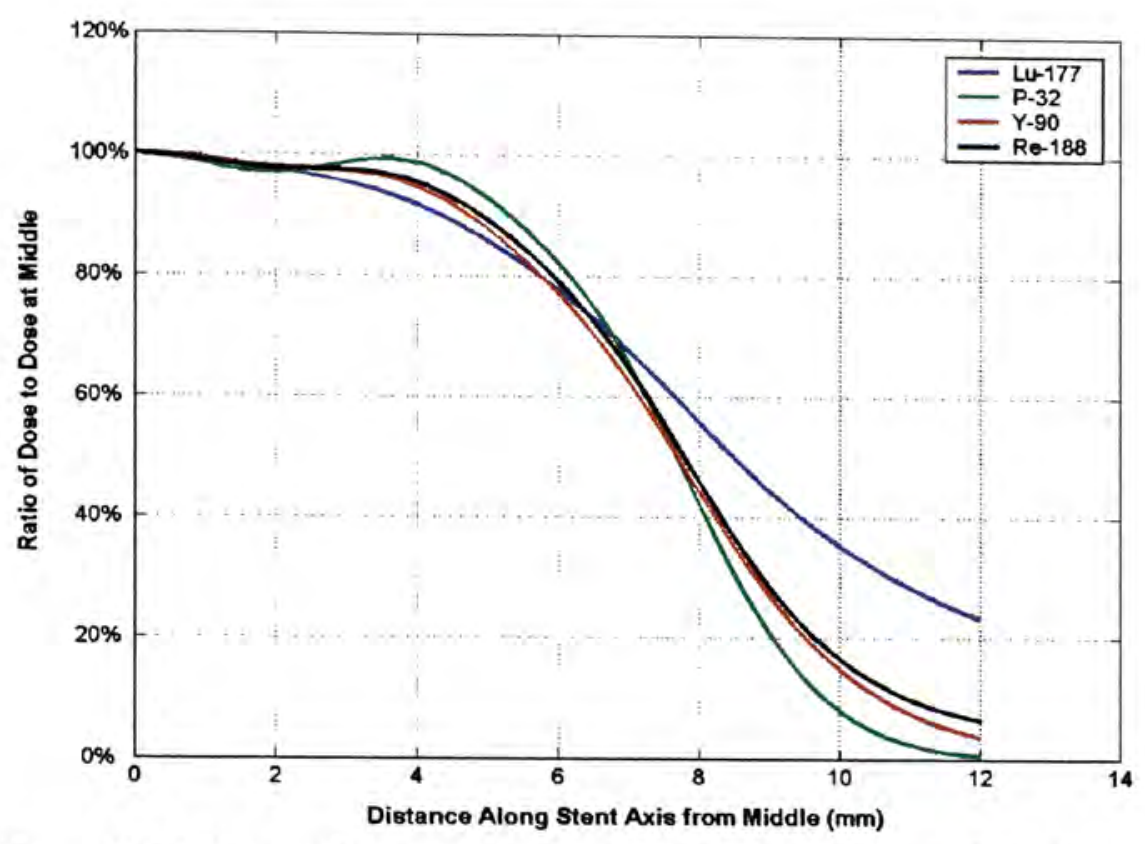

Figure 4-35. Comparison of axial dose distribution of four radioisotopes

\subsection{Radiobiological Modeling for ${ }^{32} \mathrm{P},{ }^{90} \mathrm{Y},{ }^{188} \mathrm{Re}$, and ${ }^{177}$ Lu Stents}

The purpose of the radiobiological model was to establish a comparison between the physical absorbed dose and the biological equivalent dose (BED) at the same target point. This was done by employing equations 13 and 15 (Chapter 3). Figures 4-36 to 4-39 represent this comparison taken as a function of radial distance from the stent midplane $\mathbf{z}$ $=0$ for ${ }^{32} \mathrm{P},{ }^{90} \mathrm{Y},{ }^{188} \mathrm{Re}$, and ${ }^{177} \mathrm{Lu}$ stents respectively. In all cases, it is clear that the BED is always higher than the physical dose. Tables $4-4$ to $4-7$ provide the values for dose rate, physical absorbed dose, relative effectiveness (RE) and BED for a set of radial distances ranging from 0.1 to $5.0 \mathrm{~mm}$ in intervals of $0.5 \mathrm{~mm}$. 


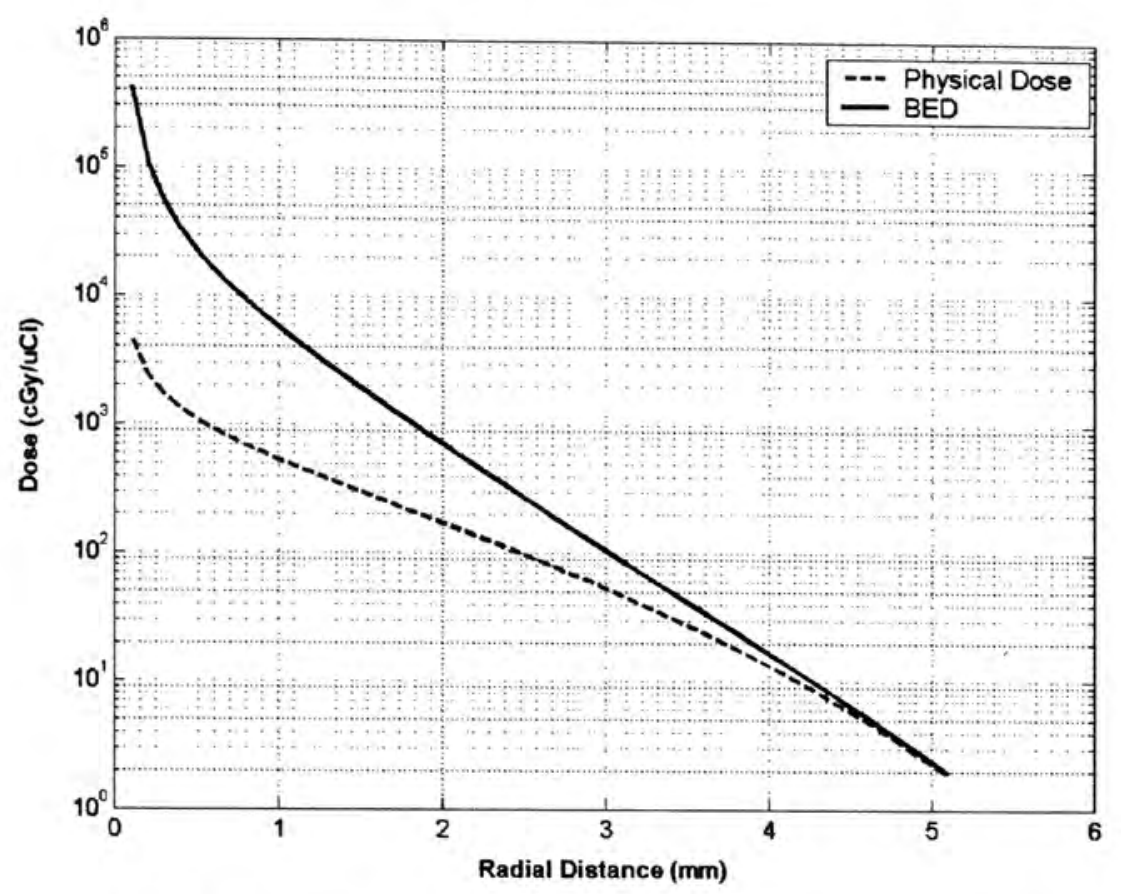

Figure 4-36. Comparison of BED and physical absorbed dose of a ${ }^{32} \mathrm{P}$ stent

Table 4-4. Calculation of BED for ${ }^{32} \mathrm{P}$ stent at increasing radial distance

\begin{tabular}{|c|c|c|c|c|}
\hline $\begin{array}{c}\text { Radial } \\
\text { distance } \\
(\mathbf{m m})\end{array}$ & $\begin{array}{c}\text { Dose rate } \\
\text { (cGy/h) }\end{array}$ & $\begin{array}{c}\text { Physical } \\
\text { Absorbed } \\
\text { dose (cGy) }\end{array}$ & $\begin{array}{c}\text { Relative } \\
\text { Effectiveness }\end{array}$ & $\begin{array}{c}\text { Biological } \\
\text { equivalent } \\
\text { dose }\end{array}$ \\
\hline 0.1 & 9.69 & $4,797.60$ & 88.28 & 424,000 \\
\hline 0.5 & 2.19 & $1,082.10$ & 20.68 & 22,382 \\
\hline 1.0 & 1.07 & 531.84 & 10.68 & $5,677.30$ \\
\hline 1.5 & 0.60516 & 299.58 & 6.45 & $1,932.30$ \\
\hline 2.0 & 0.34796 & 172.26 & 4.13 & 712.04 \\
\hline 2.5 & 0.1971 & 97.58 & 2.78 & 270.78 \\
\hline 3.0 & 0.10762 & 53.28 & 1.97 & 104.91 \\
\hline 3.5 & 0.055711 & 27.58 & 1.50 & 41.42 \\
\hline 4.0 & 0.02689 & 13.31 & 1.24 & 16.54 \\
\hline 4.5 & 0.011789 & 5.84 & 1.11 & 6.46 \\
\hline 5.0 & 0.0046097 & 2.28 & 1.04 & 2.38 \\
\hline
\end{tabular}




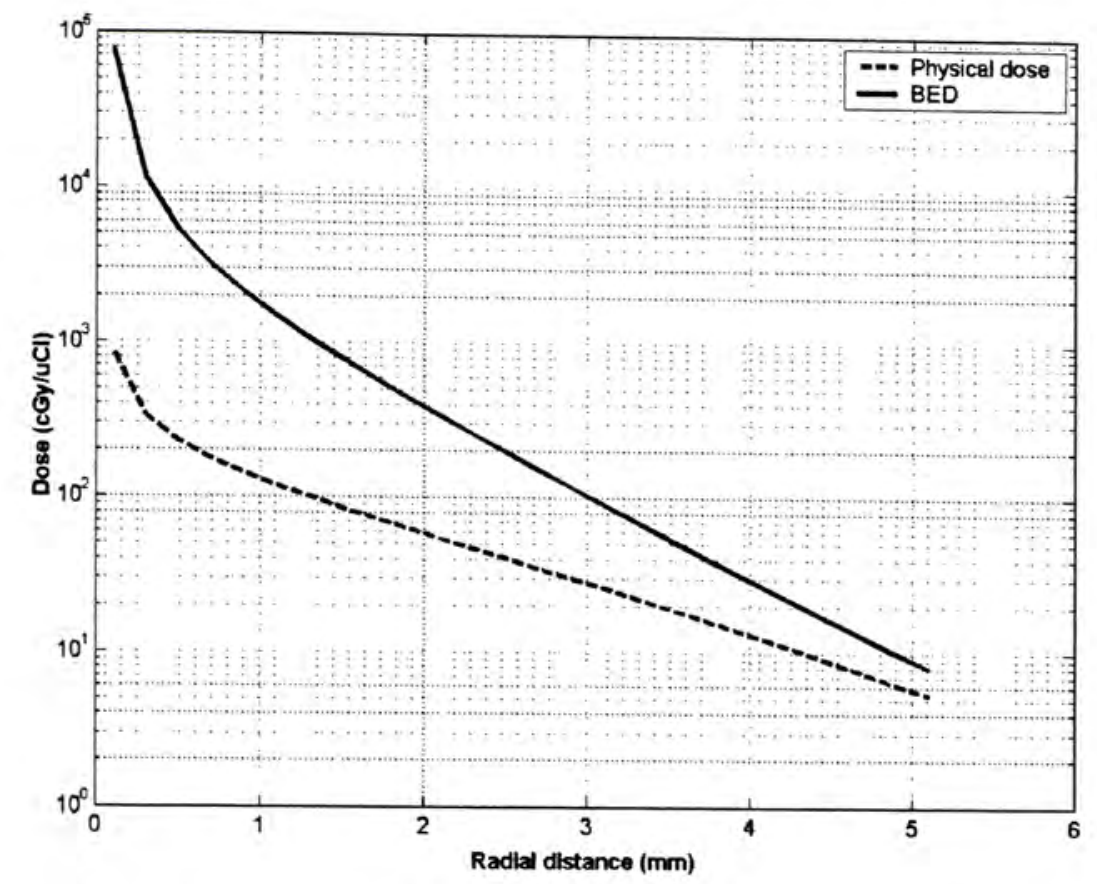

Figure 4-37. Comparison of BED and physical absorbed dose of a ${ }^{90} \mathrm{Y}$ stent

Table 4-5. Calculation of BED for a ${ }^{90} \mathrm{Y}$ stent at increasing radial distance

\begin{tabular}{|c|c|c|c|c|}
\hline $\begin{array}{c}\text { Radial } \\
\text { distance } \\
(\mathbf{m m})\end{array}$ & $\begin{array}{c}\text { Dose rate } \\
\mathbf{( c G y / h )}\end{array}$ & $\begin{array}{c}\text { Absorbed } \\
\text { dose (cGy) }\end{array}$ & $\begin{array}{c}\text { Relative } \\
\text { Effectiveness }\end{array}$ & $\begin{array}{c}\text { Biological } \\
\text { equivalent } \\
\text { dose }\end{array}$ \\
\hline 0.1 & 9.62 & 888.81 & 87.06 & $77,381.13$ \\
\hline 0.5 & 2.47 & 228.36 & 23.11 & $5,277.61$ \\
\hline 1.0 & 1.40 & 129.60 & 13.55 & $1,755.93$ \\
\hline 1.5 & 0.9209 & 85.11 & 9.24 & 786.44 \\
\hline 2.0 & 0.6296 & 58.19 & 6.63 & 386.08 \\
\hline 2.5 & 0.4359 & 40.29 & 4.90 & 197.43 \\
\hline 3.0 & 0.3017 & 27.89 & 3.70 & 103.19 \\
\hline 3.5 & 0.2074 & 19.17 & 2.86 & 54.74 \\
\hline 4.0 & 0.1409 & 13.02 & 2.26 & 29.45 \\
\hline 4.5 & 0.0945 & 8.73 & 1.85 & 16.11 \\
\hline 5.0 & 0.0624 & 5.77 & 1.56 & 8.98 \\
\hline
\end{tabular}




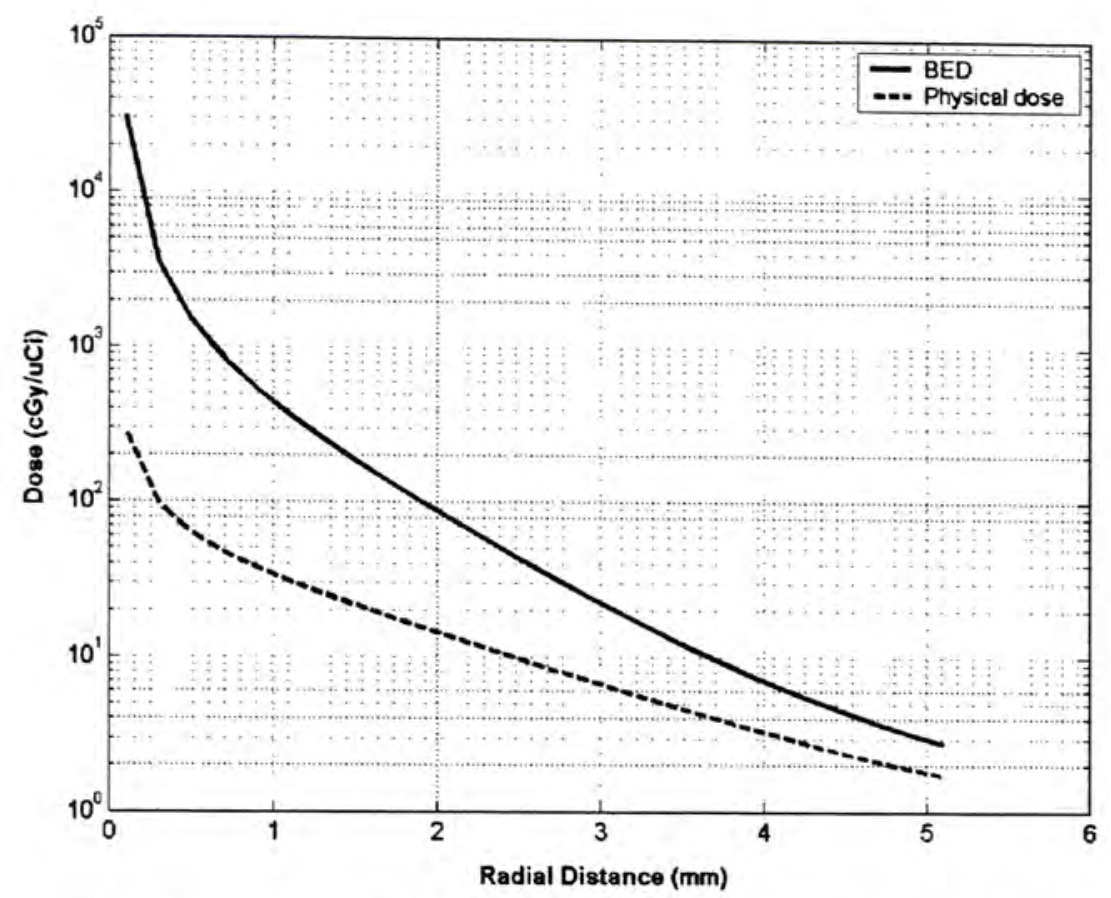

Figure 4-38. Comparison of BED and physical absorbed dose of a ${ }^{188} \operatorname{Re}$ stent

Table 4-6. Calculation of BED for ${ }^{188}$ Re stent at increasing radial distance

\begin{tabular}{|c|c|c|c|c|}
\hline $\begin{array}{c}\text { Radial } \\
\text { distance } \\
\text { (mm) }\end{array}$ & $\begin{array}{c}\text { Dose rate } \\
\text { (cGy/h) }\end{array}$ & $\begin{array}{c}\text { Absorbed } \\
\text { dose (cGy) }\end{array}$ & $\begin{array}{c}\text { Relative } \\
\text { Effectiveness }\end{array}$ & $\begin{array}{c}\text { Biological } \\
\text { equivalent } \\
\text { dose }\end{array}$ \\
\hline 0.1 & 11.85 & 289.75 & 104.81 & 30369.83 \\
\hline 0.5 & 2.57 & 63.00 & 23.57 & 1485.20 \\
\hline 1.0 & 1.38 & 33.76 & 13.10 & 442.05 \\
\hline 1.5 & 0.8782 & 21.47 & 8.69 & 186.65 \\
\hline 2.0 & 0.5850 & 14.30 & 6.12 & 87.60 \\
\hline 2.5 & 0.3966 & 9.70 & 4.47 & 43.38 \\
\hline 3.0 & 0.2717 & 6.64 & 3.38 & 22.45 \\
\hline 3.5 & 0.1884 & 4.61 & 2.65 & 12.21 \\
\hline 4.0 & 0.1334 & 3.26 & 2.17 & 7.07 \\
\hline 4.5 & 0.0974 & 2.38 & 1.85 & 4.41 \\
\hline 5.0 & 0.0738 & 1.80 & 1.65 & 2.97 \\
\hline
\end{tabular}




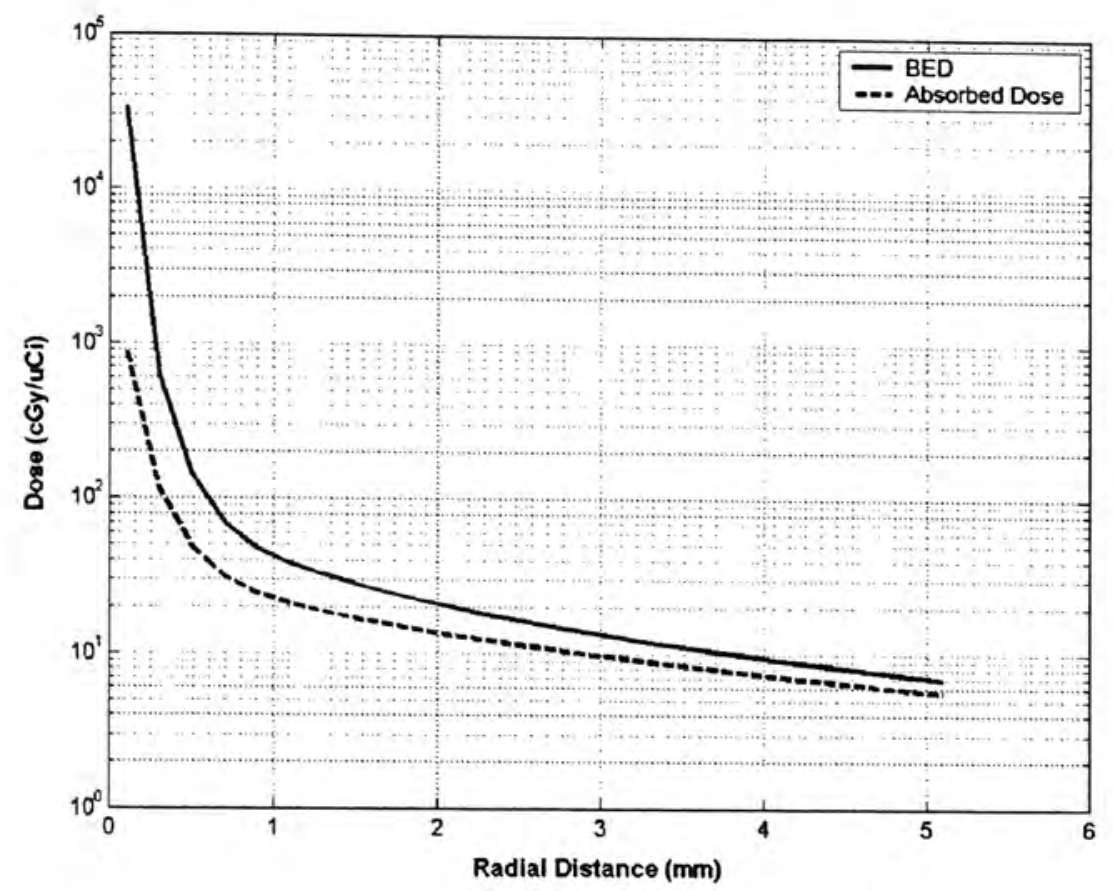

Figure 4-39. Comparison of BED and physical absorbed dose of a ${ }^{177} \mathrm{Lu}$ stent

Table 4-7. Calculation of BED for a ${ }^{177} \mathrm{Lu}$ stent at increasing radial distance

\begin{tabular}{|c|c|c|c|c|}
\hline $\begin{array}{c}\text { Radial } \\
\text { distance } \\
\text { (mm) }\end{array}$ & $\begin{array}{c}\text { Dose rate } \\
\text { (cGy/h) }\end{array}$ & $\begin{array}{c}\text { Absorbed } \\
\text { dose (cGy) }\end{array}$ & $\begin{array}{c}\text { Relative } \\
\text { Effectiveness }\end{array}$ & $\begin{array}{c}\text { Biological } \\
\text { equivalent } \\
\text { dose }\end{array}$ \\
\hline 0.1 & 3.95 & 917.96 & 36.49 & $33,495.70$ \\
\hline 0.5 & 0.21 & 49.20 & 2.90 & 142.79 \\
\hline 1.0 & 0.10 & 22.40 & 1.87 & 41.79 \\
\hline 1.5 & 0.07 & 16.95 & 1.66 & 28.06 \\
\hline 2.0 & 0.06 & 13.73 & 1.53 & 21.02 \\
\hline 2.5 & 0.05 & 11.46 & 1.44 & 16.53 \\
\hline 3.0 & 0.04 & 9.75 & 1.38 & 13.43 \\
\hline 3.5 & 0.04 & 8.42 & 1.33 & 11.17 \\
\hline 4.0 & 0.03 & 7.36 & 1.28 & 9.45 \\
\hline 4.5 & 0.03 & 6.48 & 1.25 & 8.11 \\
\hline 5.0 & 0.02 & 5.76 & 1.22 & 7.04 \\
\hline
\end{tabular}


The rate at which the dose is delivered is a very important factor in IVBT. Figure 4-40 shows a comparison of the dose rates of the four radioisotope stents. The curves represent the initial dose rate as a function of radial distance from the stent midplane $z=0$. This is important in the resulting BED for each of the radioisotopes.

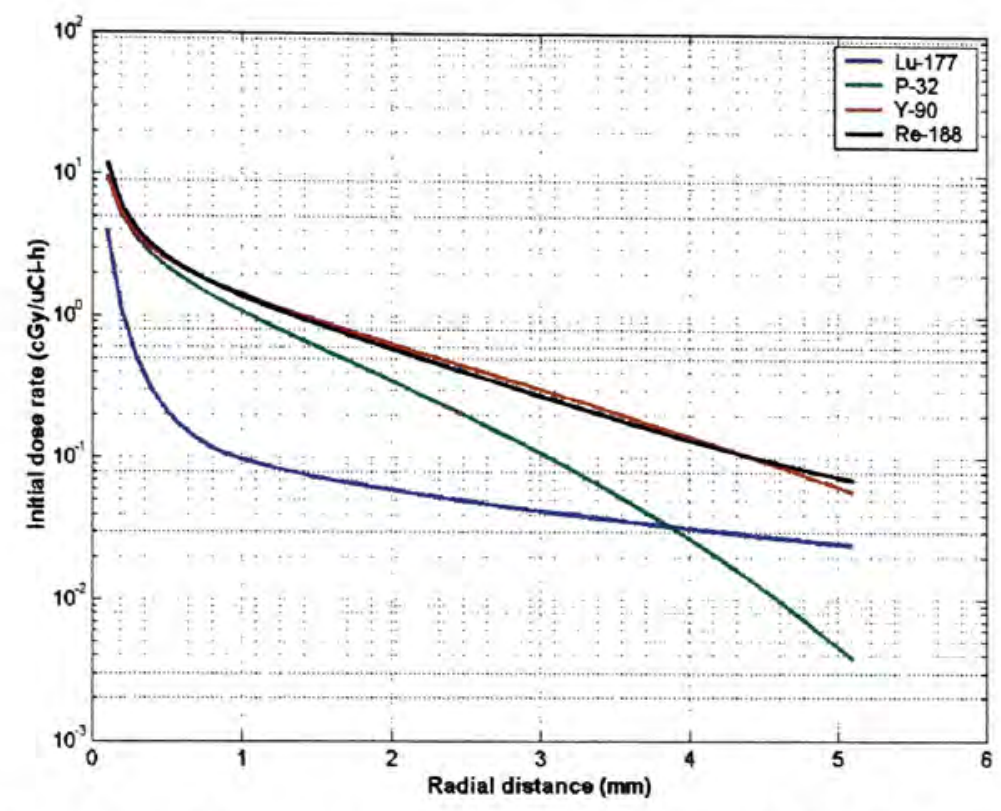

Figure 4-40. Variation of dose rate with radial distance for ${ }^{32} \mathrm{P},{ }^{90} \mathrm{Y},{ }^{188} \mathrm{Re}$, and ${ }^{177} \mathrm{Lu}$ stents

BED serves an important function in comparing different treatments. Table 4-8 shows the calculation of BED for ${ }^{32} \mathrm{P},{ }^{90} \mathrm{Y},{ }^{188} \mathrm{Re}$ and ${ }^{177} \mathrm{Lu}$ stents delivered to the same target point of $2.0 \mathrm{~mm}$ into the arterial wall. The third column represents the value of the dose at 2 $\mathrm{mm}$, while the fourth column is the activity required for each to reach a therapeutically significant dose of $2000 \mathrm{cGy}$ or $20 \mathrm{~Gy}$. This calculation of BED shows how for a same physical dose, the BED can vary greatly, with that of ${ }^{188}$ Re being 20 times the value of BED of ${ }^{32} \mathrm{P}$. 
Table 4-8. Calculation of BED of each radioisotope for the same physical dose of $20 \mathrm{~Gy}$

\begin{tabular}{|c|c|c|c|c|c|c|}
\hline $\begin{array}{c}\text { Radio- } \\
\text { isotope }\end{array}$ & Half-life & $\begin{array}{c}\text { Physical } \\
\text { Absorbed } \\
\text { Dose } \\
\text { at 2 mm } \\
(\mathbf{c G y} / \mu \mathrm{Ci})\end{array}$ & $\begin{array}{c}\text { Activity } \\
(\boldsymbol{\mu C} \mathbf{C})\end{array}$ & $\begin{array}{c}\text { Dose } \\
\text { Rate } \\
(\mathbf{c G y} / \mathbf{h})\end{array}$ & RE & BED \\
\hline${ }^{32} \mathrm{P}$ & $14.28 \mathrm{~d}$ & 172.26 & 11.6 & 4.036 & 37.35 & 74,631 \\
\hline${ }^{90} \mathrm{Y}$ & $2.67 \mathrm{~d}$ & 58.19 & 34.4 & 21.66 & 194.83 & 390,010 \\
\hline${ }^{188} \mathrm{Re}$ & $16.94 \mathrm{~h}$ & 14.30 & 139.8 & 81.781 & 717.42 & $1,434,500$ \\
\hline${ }^{177} \mathrm{Lu}$ & $6.734 \mathrm{~d}$ & 13.73 & 145.7 & 8.601 & 78.33 & 156,685 \\
\hline
\end{tabular}

\subsection{Combinations of Isotopes within the Same Stent}

The following results describe the dosimetry of a radioactive stent containing two radioisotopes. Figures 4-41, 4-43, and 4-45 show the $2 \mathrm{D}$ dose distribution of a ${ }^{177} \mathrm{Lu}$ stent combined with ${ }^{32} \mathrm{P},{ }^{90} \mathrm{Y}$ and ${ }^{188} \mathrm{Re}$ respectively along the entire axis of the stent with distances ranging from 0.1 to $2.0 \mathrm{~mm}$ from the stent surface. Figures $4-42,4-44$ and 4-46 represent a comparison of the physical absorbed dose and the biological equivalent dose (BED) for each of the combinations with ${ }^{177} \mathrm{Lu}$ at increasing radial distance from the stents midplane. Tables 4-9 to 4-11 present the results of the radiobiological modeling according to equation 16 (Chapter 3). The values of RE and BED are for the effects of the combined radioisotopes. 


\subsubsection{Uniform distribution of ${ }^{177} \mathrm{Lu}$ and ${ }^{32} \mathrm{P}$}

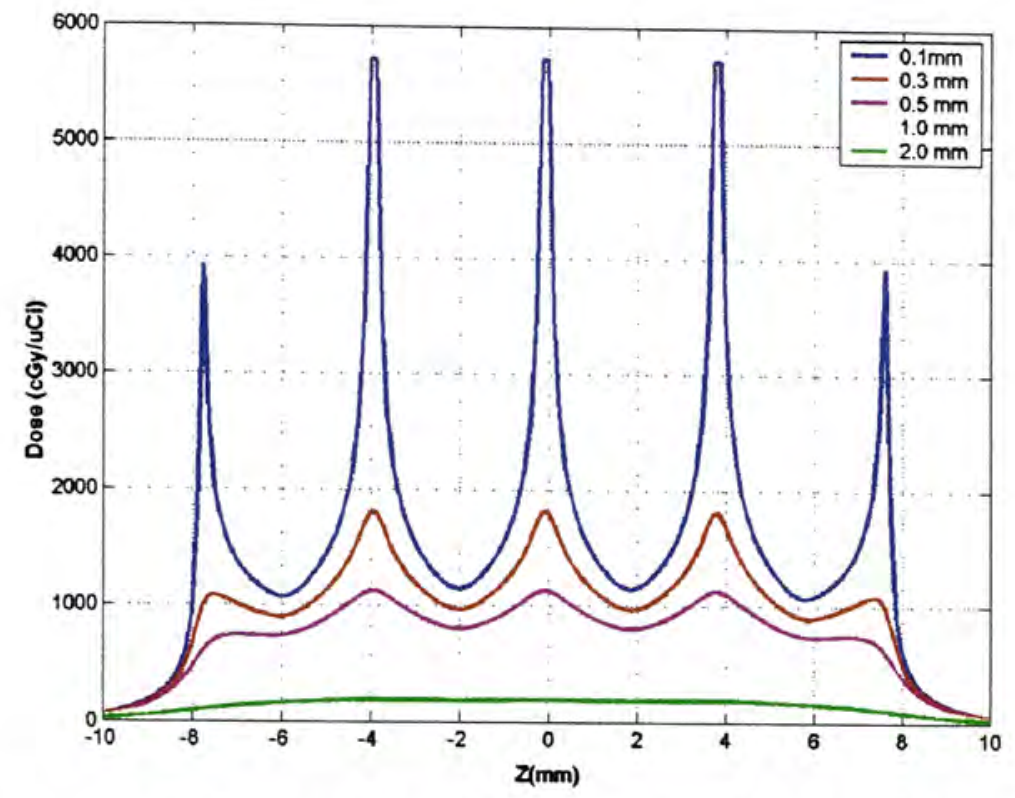

Figure 4-41. 2D plot of dose from a combined ${ }^{177} \mathrm{Lu}$ and ${ }^{32} \mathrm{P}$ stent

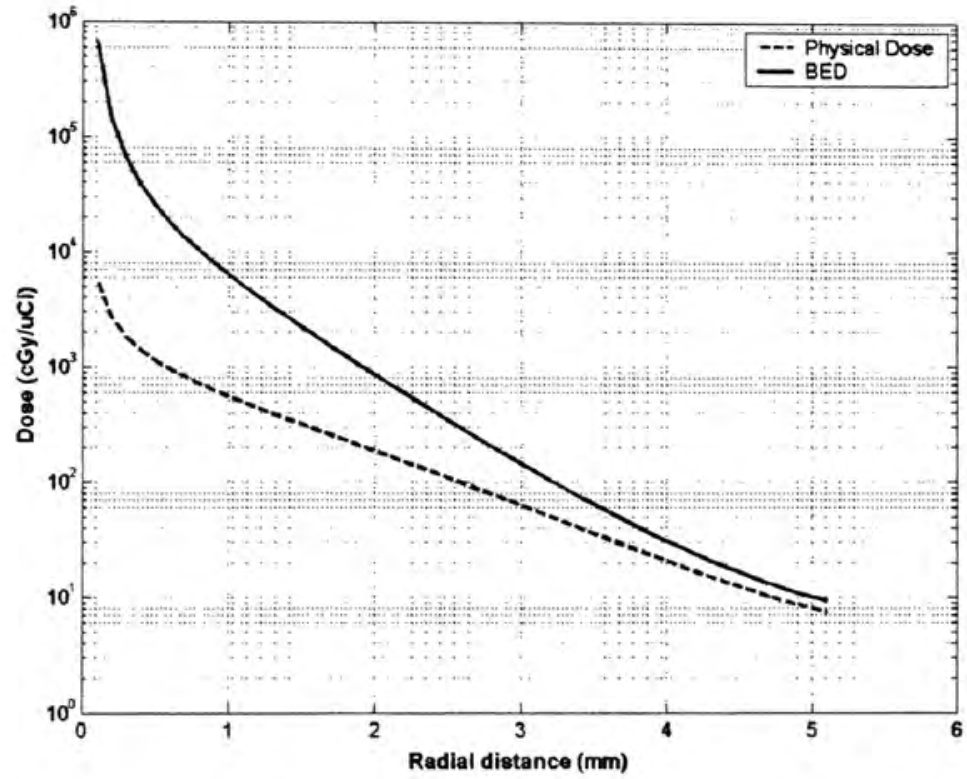

Figure 4-42. Comparison of BED and physical absorbed dose of a combined ${ }^{177} \mathrm{Lu}$ and ${ }^{32} \mathrm{P}$ stent. 
Table 4-9. Calculation of BED for a combined ${ }^{177} \mathrm{Lu}$ and ${ }^{32} \mathrm{P}$ stent at increasing radial distance

\begin{tabular}{|c|c|c|c|c|c|c|}
\hline $\begin{array}{c}\text { Radial } \\
\text { distance } \\
\text { (mm) }\end{array}$ & $\begin{array}{c}\text { Dose } \\
\text { rate } \\
(\mathrm{cGy/h}) \\
{ }_{177} \mathbf{L u}\end{array}$ & $\begin{array}{c}\text { Dose } \\
\text { rate } \\
\left(\mathrm{cGy}^{32} / \mathrm{h}\right)\end{array}$ & $\begin{array}{c}\text { Total } \\
\text { dose } \\
\text { rate } \\
(c \mathbf{G y} / \mathbf{h})\end{array}$ & $\begin{array}{c}\text { Absorbed } \\
\text { dose } \\
\text { (cGy) }\end{array}$ & $\begin{array}{c}\text { Relative } \\
\text { Effectiveness }\end{array}$ & $\begin{array}{c}\text { Biological } \\
\text { equivalent } \\
\text { dose }\end{array}$ \\
\hline 0.1 & 3.947 & 9.691 & 13.638 & $5,715.60$ & 118.07 & $675,000.00$ \\
\hline 0.5 & 0.212 & 2.186 & 2.397 & $1,131.30$ & 22.24 & $25,158.00$ \\
\hline 1.0 & 0.096 & 1.074 & 1.171 & 554.23 & 11.38 & $6,308.20$ \\
\hline 1.5 & 0.073 & 0.605 & 0.678 & 316.53 & 6.99 & $2,211.50$ \\
\hline 2.0 & 0.059 & 0.348 & 0.407 & 185.99 & 4.57 & 850.04 \\
\hline 2.5 & 0.049 & 0.197 & 0.246 & 109.03 & 3.14 & 342.61 \\
\hline 3.0 & 0.042 & 0.108 & 0.150 & 63.03 & 2.29 & 144.05 \\
\hline 3.5 & 0.036 & 0.056 & 0.092 & 36.00 & 1.78 & 64.07 \\
\hline 4.0 & 0.032 & 0.027 & 0.059 & 20.67 & 1.49 & 30.83 \\
\hline 4.5 & 0.028 & 0.012 & 0.040 & 12.32 & 1.33 & 16.44 \\
\hline 5.0 & 0.025 & 0.005 & 0.029 & 8.04 & 1.25 & 10.07 \\
\hline
\end{tabular}

\subsubsection{Uniform Distribution of ${ }^{177} \mathrm{Lu}$ and ${ }^{90} \mathrm{Y}$}

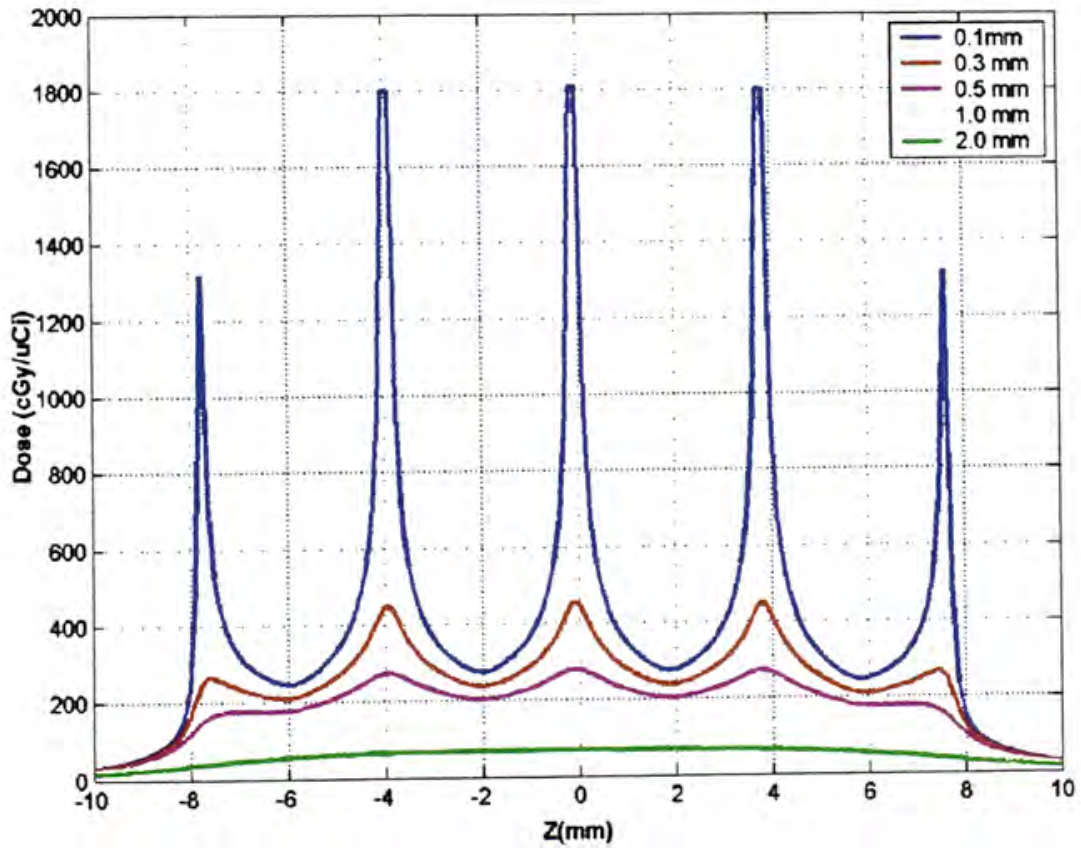

Figure 4-43. 2D plot of dose distribution of a combined ${ }^{177} \mathrm{Lu}$ and ${ }^{90} \mathrm{Y}$ stent 


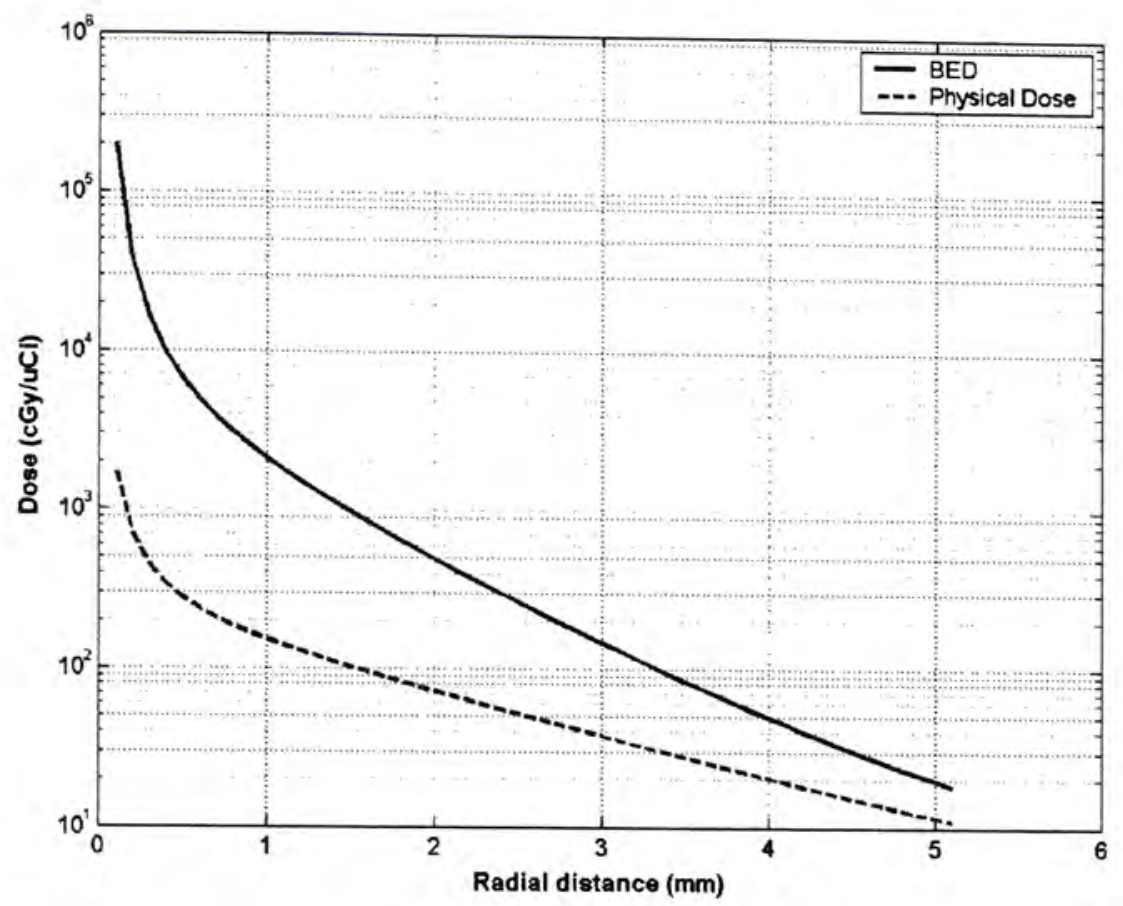

Figure 4-44. Comparison of BED and physical absorbed dose of a combined ${ }^{177} \mathrm{Lu}$ and ${ }^{90} \mathrm{Y}$ stent.

Table 4-10. Calculation of BED for a combined ${ }^{177} \mathrm{Lu}$ and ${ }^{90} \mathrm{Y}$ stent at increasing radial distance

\begin{tabular}{|c|c|c|c|c|c|c|}
\hline $\begin{array}{c}\text { Radial } \\
\text { distance } \\
(\mathrm{mm})\end{array}$ & $\begin{array}{c}\text { Dose } \\
\text { rate } \\
(\mathbf{c G y / h}) \\
{ }_{177} \mathbf{L u}\end{array}$ & $\begin{array}{c}\text { Dose } \\
\text { rate } \\
\left(c_{90 y / h)}\right)\end{array}$ & $\begin{array}{c}\text { Total } \\
\text { dose } \\
\text { rate } \\
(c G y / h)\end{array}$ & $\begin{array}{c}\text { Absorbed } \\
\text { dose } \\
\text { (cGy) }\end{array}$ & $\begin{array}{c}\text { Relative } \\
\text { Effectiveness }\end{array}$ & $\begin{array}{c}\text { Biological } \\
\text { equivalent } \\
\text { dose }\end{array}$ \\
\hline 0.1 & 3.947 & 9.617 & 13.564 & $1,806.80$ & 111.22 & 201,000 \\
\hline 0.5 & 0.212 & 2.471 & 2.682 & 277.56 & 24.00 & $6,660.80$ \\
\hline 1.0 & 0.0963 & 1.4023 & 1.4986 & 152.00 & 13.94 & $2,118.20$ \\
\hline 1.5 & 0.0729 & 0.9209 & 0.9937 & 102.06 & 9.54 & 973.77 \\
\hline 2.0 & 0.0590 & 0.6296 & 0.6887 & 71.92 & 6.89 & 495.30 \\
\hline 2.5 & 0.0493 & 0.4359 & 0.4852 & 51.74 & 5.12 & 264.92 \\
\hline 3.0 & 0.0419 & 0.3017 & 0.3437 & 37.64 & 3.90 & 146.65 \\
\hline 3.5 & 0.0362 & 0.2074 & 0.2436 & 27.59 & 3.03 & 83.73 \\
\hline 4.0 & 0.0316 & 0.1409 & 0.1726 & 20.38 & 2.43 & 49.48 \\
\hline 4.5 & 0.0279 & 0.0945 & 0.1224 & 15.22 & 2.00 & 30.47 \\
\hline 5.0 & 0.0248 & 0.0624 & 0.0872 & 11.53 & 1.71 & 19.69 \\
\hline
\end{tabular}


4.8.3 Uniform distribution of ${ }^{177} \mathrm{Lu}$ and ${ }^{188} \mathrm{Re}$

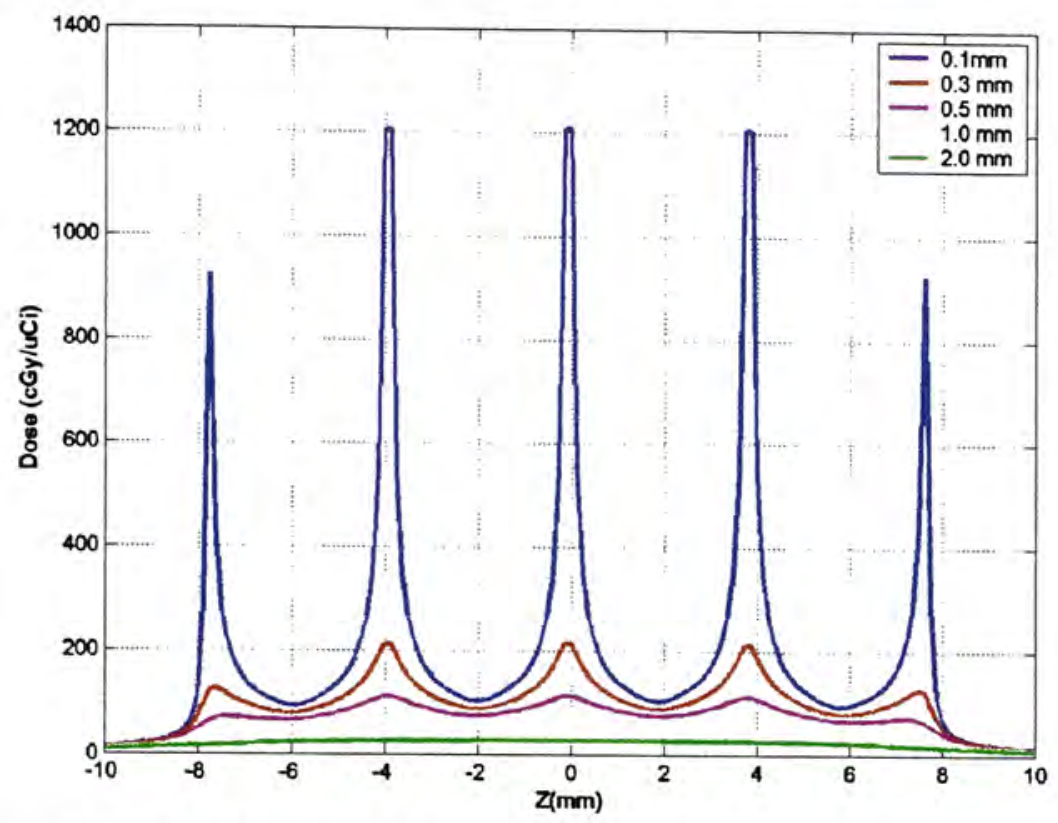

Figure 4-45. 2D plot of dose distribution of a combined ${ }^{177} \mathrm{Lu}$ and ${ }^{188} \mathrm{Re}$ stent

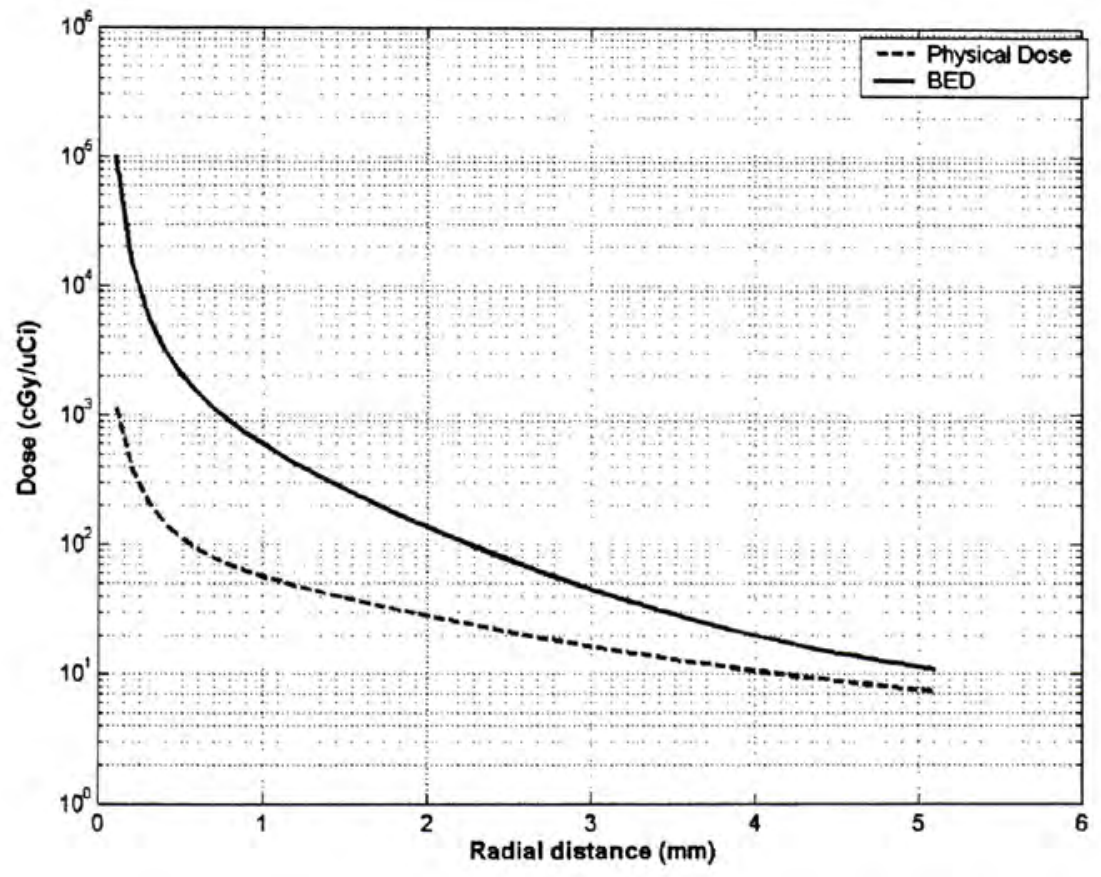

Figure 4-46. Comparison of BED and physical absorbed dose of a combined ${ }^{177} \mathrm{Lu}$ and ${ }^{188} \mathrm{Re}$ stent. 
Table 4-11. Calculation of BED for a combined ${ }^{177} \mathrm{Lu}$ and ${ }^{188} \mathrm{Re}$ stent at increasing radial distance

\begin{tabular}{|c|c|c|c|c|c|c|}
\hline $\begin{array}{c}\text { Radial } \\
\text { distance } \\
\text { (mm) }\end{array}$ & $\begin{array}{c}\text { Dose } \\
\text { rate } \\
(\mathbf{c G y / h )} \\
\mathbf{1 7 7} \mathbf{L u}\end{array}$ & $\begin{array}{c}\text { Dose } \\
\text { rate } \\
(\mathbf{c G y / h )} \\
\mathbf{1 8 8} \mathbf{R e}\end{array}$ & $\begin{array}{c}\text { Total } \\
\text { dose } \\
\text { rate } \\
\text { (cGy/h) }\end{array}$ & $\begin{array}{c}\text { Absorbed } \\
\text { dose } \\
\text { (cGy) }\end{array}$ & $\begin{array}{c}\text { Relative } \\
\text { Effectiveness }\end{array}$ & $\begin{array}{c}\text { Biological } \\
\text { equivalent } \\
\text { dose }\end{array}$ \\
\hline 0.1 & 3.95 & 11.85 & 15.80 & $1,207.70$ & 83.30 & 101,000 \\
\hline 0.5 & 0.21 & 2.58 & 2.79 & 112.20 & 18.33 & $2,056.20$ \\
\hline 1.0 & 0.096 & 1.381 & 1.477 & 56.15 & 10.48 & 588.27 \\
\hline 1.5 & 0.073 & 0.878 & 0.951 & 38.42 & 6.90 & 264.99 \\
\hline 2.0 & 0.059 & 0.585 & 0.644 & 28.03 & 4.84 & 135.74 \\
\hline 2.5 & 0.049 & 0.397 & 0.446 & 21.15 & 3.56 & 75.26 \\
\hline 3.0 & 0.042 & 0.272 & 0.314 & 16.40 & 2.73 & 44.83 \\
\hline 3.5 & 0.036 & 0.188 & 0.225 & 13.03 & 2.21 & 28.74 \\
\hline 4.0 & 0.032 & 0.133 & 0.165 & 10.62 & 1.87 & 19.83 \\
\hline 4.5 & 0.028 & 0.097 & 0.125 & 8.86 & 1.65 & 14.65 \\
\hline 5.0 & 0.025 & 0.074 & 0.099 & 7.56 & 1.51 & 11.45 \\
\hline
\end{tabular}

\subsection{Modification of Radioisotope Distribution at Stent Edges}

The problem of edge restenosis is the results of underdosing at the stent edges as a result of excessive barotraumas during the angioplasty procedure as well as the radiation dose fall-off at the edges. Figures 4-7, 4-14, 4-21 and 4-31 show that the dose at the stent edges is roughly $50 \%$ of that in the center of the stent for ${ }^{32} \mathrm{P},{ }^{90} \mathrm{Y},{ }^{188} \mathrm{Re}$ and ${ }^{177} \mathrm{Lu}$ respectively. The dosimetry model developed in this work was used to modify the radioactivity at the stent edges in order to increase the dose to greater than $50 \%$. This modification was done at the $3 \mathrm{~mm}$ proximal and distal segments along the $\mathrm{z}$ axis of the stent.

\subsubsection{Different radioisotopes at stent edges}

One alternative is that of combining different radioisotopes at the stent edges. The simulated stents consisted of uniform ${ }^{32} \mathrm{P}$ with added ${ }^{188} \mathrm{Re}$ and ${ }^{90} \mathrm{Y}$ at $3 \mathrm{~mm}$ in the edges. 
These isotopes were chosen because of their higher energy compared to ${ }^{32} \mathrm{P}$ alone. Figure 4-47 shows this comparison as a function of axial distance from the stent midplane at a fixed radial distance of $2 \mathrm{~mm}$. Figure 4-48 shows the same information but with the values normalized at the stent edge of $7.625 \mathrm{~mm}$ in order to observe the dose gradient extending beyond the stent edge. The effect of incorporating different radioisotopes at the stent edges can be further amplified by increasing the activity of the radioisotopes at the stent edges. Figure 4-49 shows the results of increasing the activity of ${ }^{188} \mathrm{Re}$ and ${ }^{90} \mathrm{Y}$ to 10 $\mu \mathrm{Ci}$ at the stent edges. For $\mathrm{a}^{32} \mathrm{P}$ stent, the dose at the edge is $52 \%$ of that in the center. For the stent with uniform ${ }^{32} \mathrm{P}$ with $10 \mu \mathrm{Ci}$ of ${ }^{188} \mathrm{Re}$ at the edges, the dose at the edges is $83 \%$ higher than the dose at the stent center. In the case of ${ }^{90} \mathrm{Y}$, the dose at the edges is $168 \%$ higher than the dose at the center.

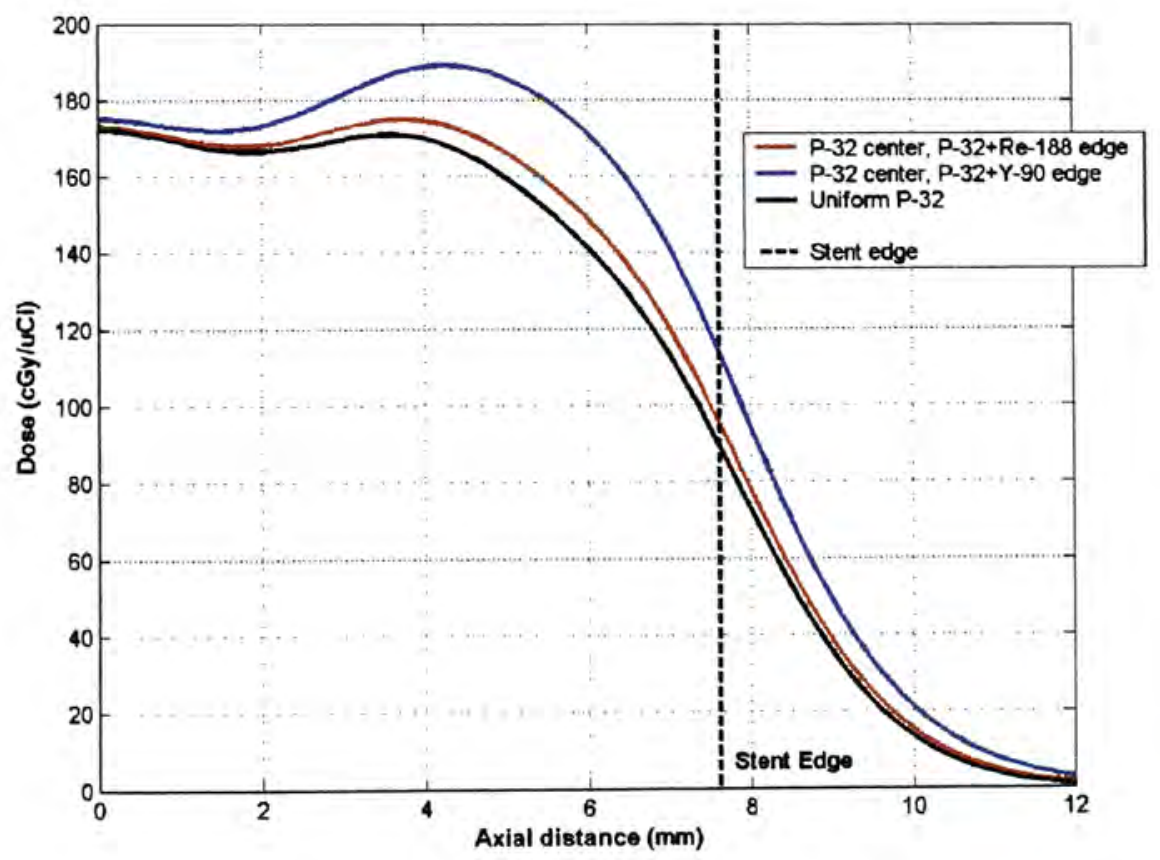

Figure 4-47. Comparison of a ${ }^{32} \mathrm{P}$ stent with ${ }^{188} \mathrm{Re}$ and ${ }^{90} \mathrm{Y}$ at stent edges 


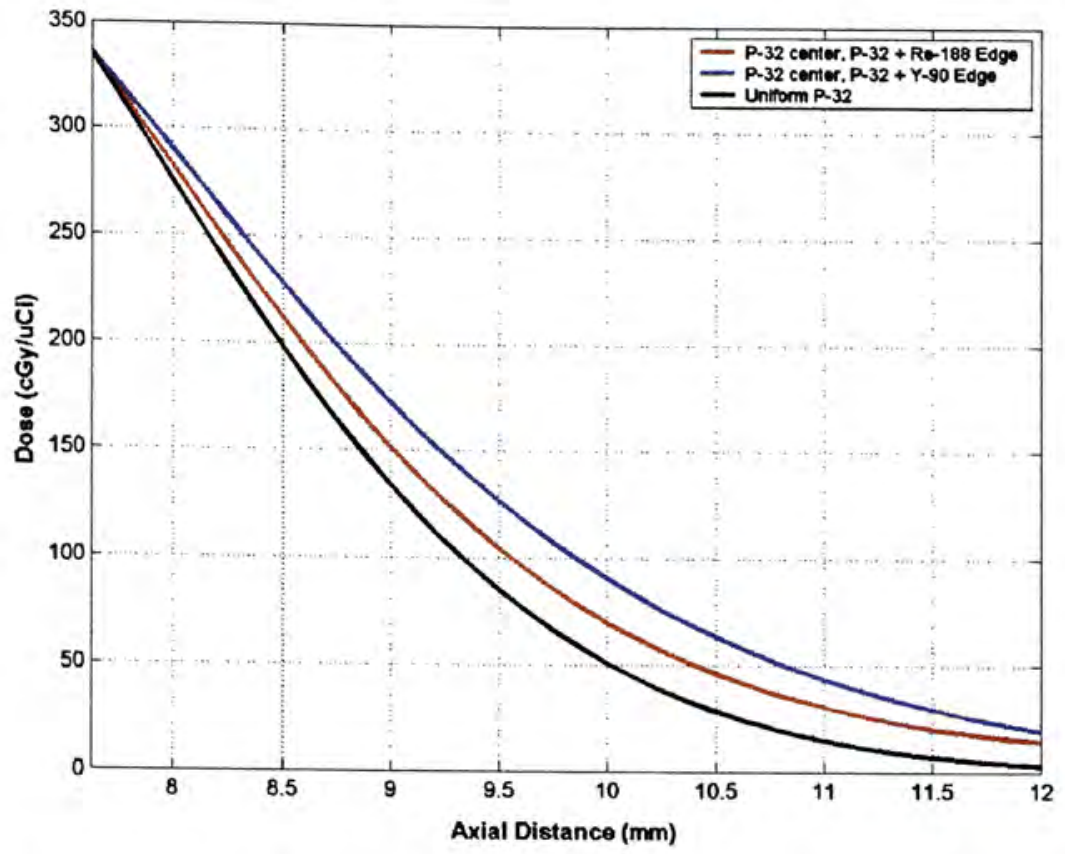

Figure 4-48. Comparison of a ${ }^{32} \mathrm{P}$ stent with ${ }^{188} \mathrm{Re}$ and ${ }^{90} \mathrm{Y}$ at stent edges normalized to the stent edge

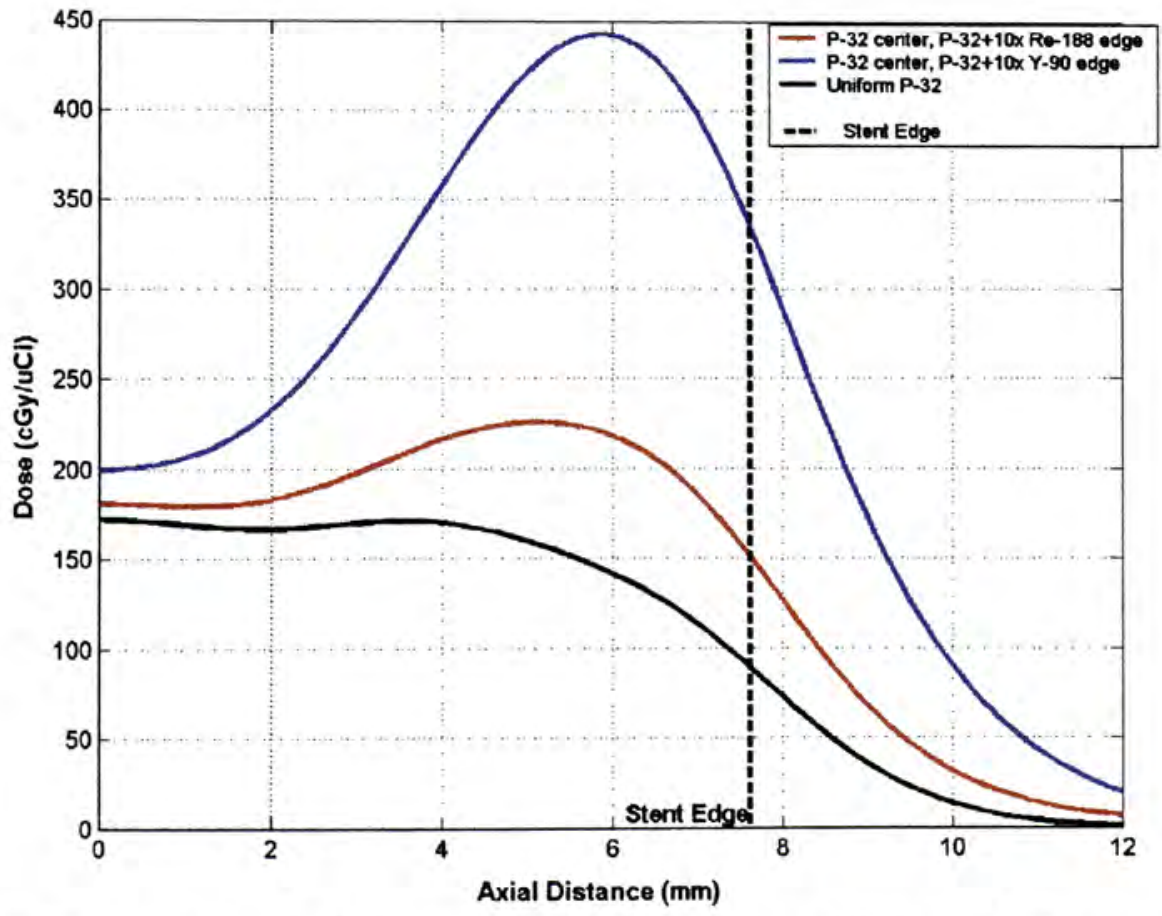

Figure 4-49. Comparison of a ${ }^{32} \mathrm{P}$ stent with $10 \mathrm{x}$ the activity of ${ }^{188} \mathrm{Re}$ and ${ }^{90} \mathrm{Y}$ at stent edges 


\subsubsection{Increase of activity at stent edges (“dumbbell effect”)}

Another way of increasing the dose at the stent edges was by increasing the activity of at the edges of the same radioisotope in order to achieve the "dumbbell effect". For ${ }^{32} \mathrm{P}$, ${ }^{90} \mathrm{Y},{ }^{188} \mathrm{Re}$ and ${ }^{177} \mathrm{Lu}$ stents the activity at the stent edges was increased by an order of three. Therefore the stent edges had $3 \mu \mathrm{Ci}$ of activity.

\subsubsection{1 ${ }^{32} \mathrm{P}$ stent with $3 \mathrm{x}$ the activity at the stent edges}

Figure 4-50 shows the $2 \mathrm{D}$ dose distribution of $\mathrm{a}^{32} \mathrm{P}$ stent with weighted activity at the edges $(3 \mathrm{~mm})$ along the entire axis of the stent with distances ranging from 0.1 to $2.0 \mathrm{~mm}$ from the stent surface. The dose is higher at the stent ends compared to the stent center.

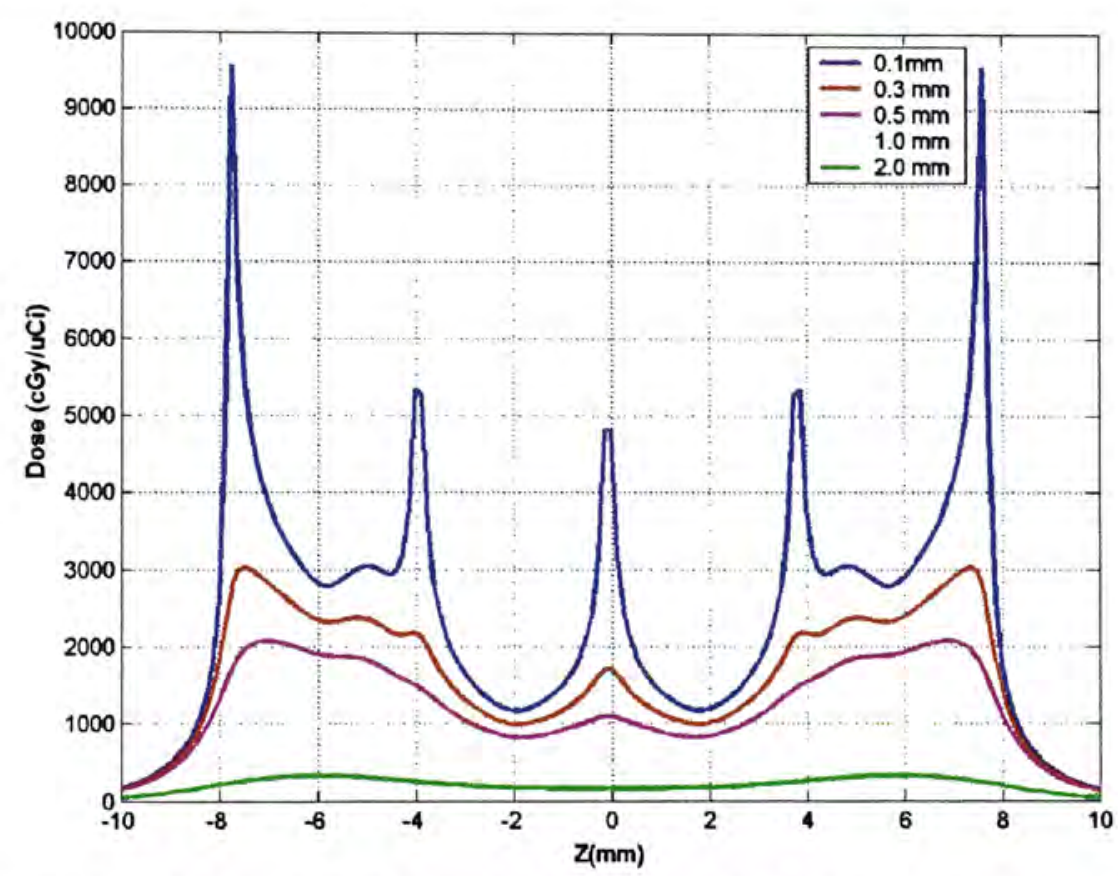

Figure 4-50. 2D plot of dose distribution of a ${ }^{32} \mathrm{P}$ stent with $3 \mathrm{x}$ the activity on the stent edges.

Figure 4-51 shows a comparison of a uniform ${ }^{32} \mathrm{P}$ stent with a ${ }^{32} \mathrm{P}$ stent with 3 times the activity at the edges. The graph shows the curves as the ratio of the dose at a particular 
point to the dose at the stent center for a fixed radial distance of $2 \mathrm{~mm}$. At the stent edge, the dose delivered by the stent with the weighted activity is $150 \%$ of the dose at the stent center, compared to $50 \%$ with a uniform ${ }^{32} \mathrm{P}$ stent.

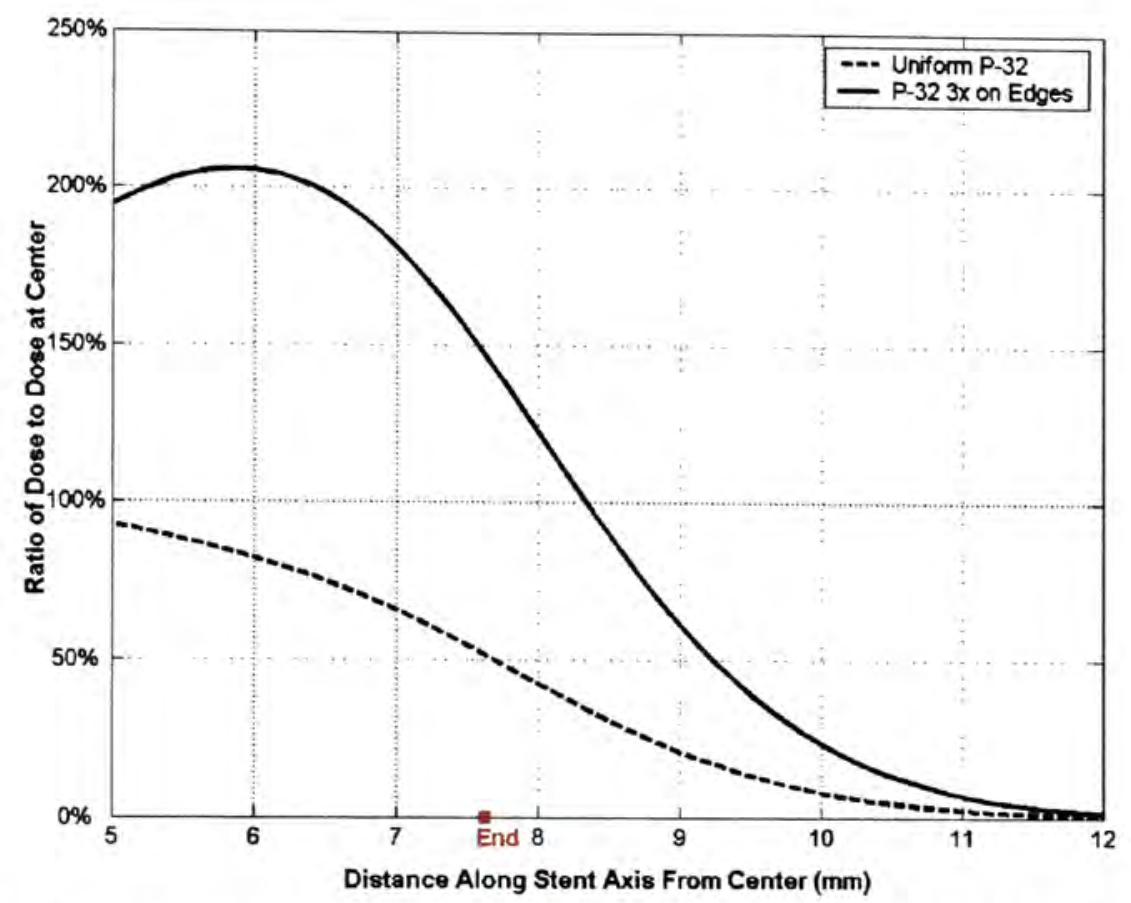

Figure 4-51. Comparison of dose as a function of axial distance from a uniform ${ }^{32} \mathrm{P}$ stent and one with $3 x$ the activity at the stent edges.

Table 4-12. Dose calculation of a ${ }^{32} \mathrm{P}$ stent with variation in activity at stent edges

\begin{tabular}{|c|c|c|c|c|c|c|}
\hline \multirow{2}{*}{$\begin{array}{c}\text { Radial } \\
\text { Distance } \\
\text { from Stent } \\
\text { Surface }\end{array}$} & Stent & $\begin{array}{c}\text { Stent } \\
\text { Center }\end{array}$ & $\begin{array}{c}\text { Stent } \\
\text { Edge }\end{array}$ & $\begin{array}{c}\mathbf{1 . 0} \mathbf{~ m m} \\
\text { Distal }\end{array}$ & $\begin{array}{c}\mathbf{2 . 0} \mathbf{~ m m} \\
\text { Distal }\end{array}$ & $\begin{array}{c}\mathbf{3 . 0} \mathbf{~ m m} \\
\text { distal }\end{array}$ \\
\hline \multirow{2}{*}{$0.5 \mathrm{~mm}$} & ${ }^{32} \mathrm{P}$ & $1,082.00$ & 573.24 & 177.33 & 58.30 & 17.50 \\
\cline { 2 - 7 } & $3 \mathrm{x}^{32} \mathrm{P}$ & $1,086.80$ & $1,689.50$ & 525.11 & 173.87 & 52.45 \\
\hline \multirow{2}{*}{$1.0 \mathrm{~mm}$} & ${ }^{32} \mathrm{P}$ & 531.79 & 276.52 & 121.52 & 13.47 & 13.47 \\
\cline { 2 - 7 } & $3 \mathrm{x}^{32} \mathrm{P}$ & 535.42 & 806.28 & 359.27 & 40.36 & 40.36 \\
\hline \multirow{2}{*}{$2.0 \mathrm{~mm}$} & ${ }^{32} \mathrm{P}$ & 154.04 & 79.38 & 43.19 & 18.11 & 5.86 \\
\cline { 2 - 7 } & $3 \mathrm{x}^{32} \mathrm{P}$ & 155.53 & 227.93 & 127.31 & 54.01 & 17.58 \\
\hline
\end{tabular}

$3 \mathrm{x}^{32} \mathrm{P}$ indicates nonuniform activity (three times the activity at the stent edges) 
Table 4-12 shows the dose delivered from a uniform ${ }^{32} \mathrm{P}$ stent and one with 3 times the activity at the stent edges for radial distances of $0.5,1$ and $2 \mathrm{~mm}$ from the surface of the stent. The values of dose are taken for points at the stent center, or midplane, at the stent edge, and 1,2 and $3 \mathrm{~mm}$ distal to the edge of the stent.

\subsubsection{2. ${ }^{90} \mathrm{Y}$ stent with $3 \mathrm{x}$ the activity at the stent edges}

Figure 4-52 shows the $2 \mathrm{D}$ dose distribution of $\mathrm{a}^{90} \mathrm{Y}$ stent with weighted activity at the edges along the entire axis of the stent with distances ranging from 0.1 to $2.0 \mathrm{~mm}$ from the stent surface.

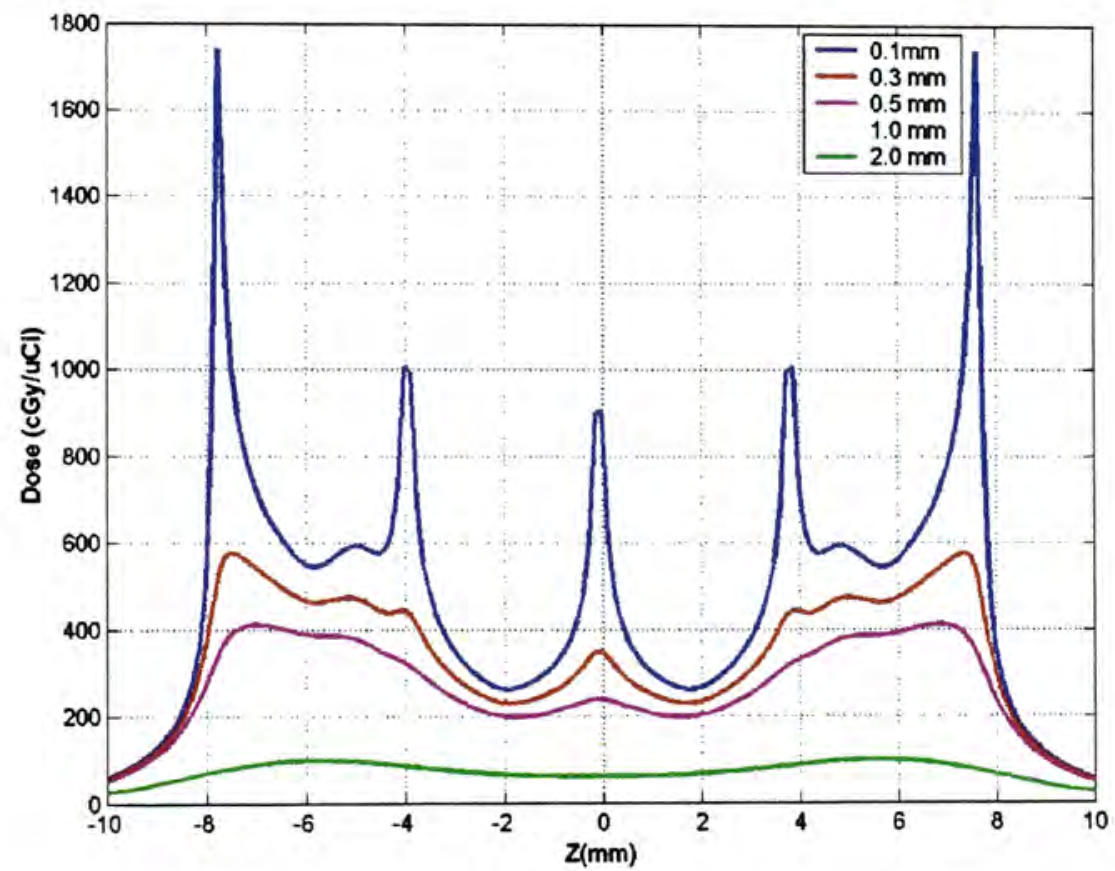

Figure 4-52. 2D plot of dose distribution of a ${ }^{90} \mathrm{Y}$ stent with $3 \mathrm{x}$ the activity at the stents edges

Figure 4-53 shows a comparison of a uniform ${ }^{90} \mathrm{Y}$ stent with a ${ }^{90} \mathrm{Y}$ stent with 3 times the activity at the edges. The graph shows the curves as the ratio of the dose at a particular point to the dose at the stent center for a fixed radial distance of $2 \mathrm{~mm}$. At the stent edge, 
the dose delivered by the stent with the weighted activity is $130 \%$ of the dose at the stent center, compared to $50 \%$ with a uniform ${ }^{90} \mathrm{Y}$ stent.

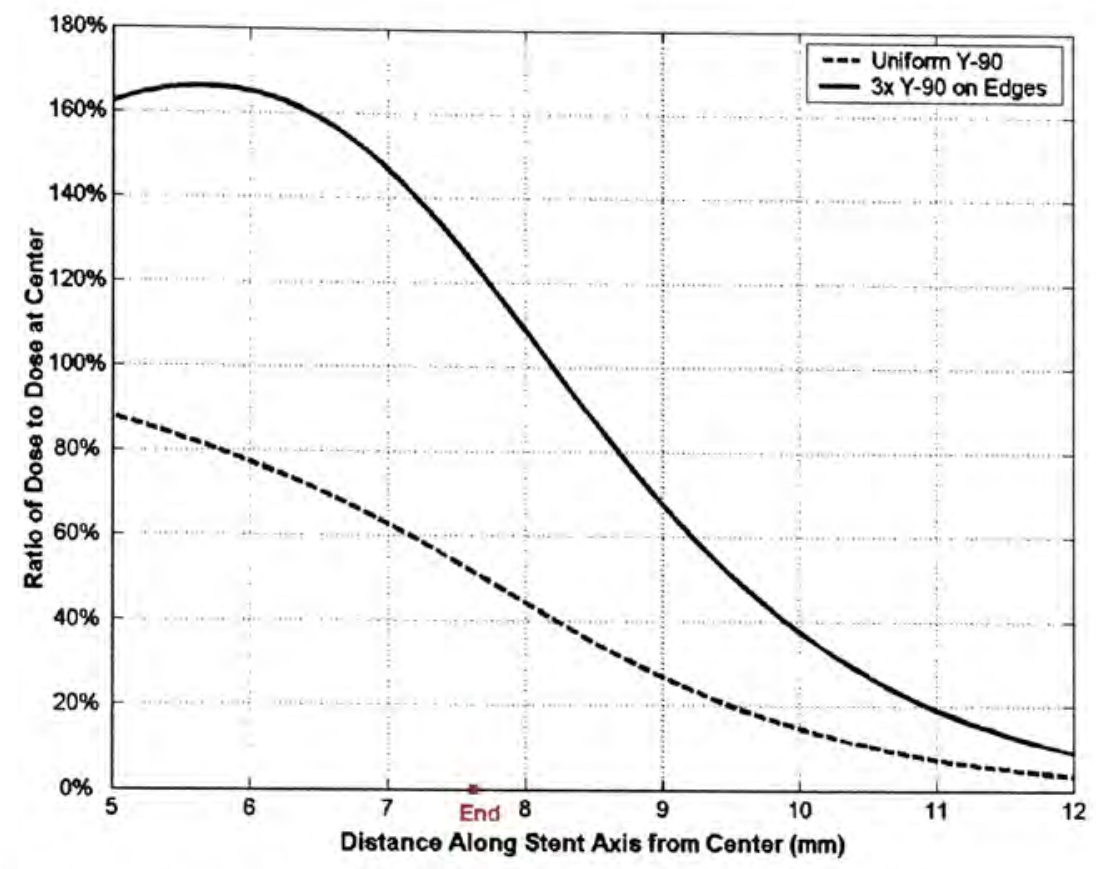

Figure 4-53. Comparison of dose as a function of axial distance from a uniform ${ }^{90} \mathrm{Y}$ stent and $a^{90} Y$ stent with 3 times the activity at the stent edges.

Table 4-13 shows the dose delivered from a uniform ${ }^{90} \mathrm{Y}$ stent and one with 3 times the activity at the stent edges for radial distances of $0.5,1$ and $2 \mathrm{~mm}$ from the surface of the stent. The values of dose are taken for points at the stent center, or midplane, at the stent edge, and 1,2 and $3 \mathrm{~mm}$ distal to the stent edge. 
Table 4-13. Dose calculation of $a^{90} \mathbf{Y}$ stent with variation in activity at stent edges

\begin{tabular}{|c|c|c|c|c|c|c|}
\hline \multirow{2}{*}{$\begin{array}{c}\text { Radial } \\
\text { Distance } \\
\text { from Stent } \\
\text { Surface }\end{array}$} & \multirow[b]{2}{*}{ Stent } & \multicolumn{5}{|c|}{ Position Along Stent Axis } \\
\hline & & $\begin{array}{c}\text { Stent } \\
\text { Center }\end{array}$ & $\begin{array}{l}\text { Stent } \\
\text { Edge }\end{array}$ & $\begin{array}{c}1.0 \mathrm{~mm} \\
\text { Distal }\end{array}$ & $\begin{array}{c}2.0 \mathrm{~mm} \\
\text { Distal }\end{array}$ & $\begin{array}{c}3.0 \mathrm{~mm} \\
\text { distal }\end{array}$ \\
\hline \multirow{2}{*}{$0.5 \mathrm{~mm}$} & ${ }^{90} \mathrm{Y}$ & 228.34 & 120.19 & 47.21 & 21.78 & 10.34 \\
\hline & $3 \mathrm{x}^{90} \mathrm{Y}$ & 237.90 & 341.30 & 132.88 & 61.64 & 29.57 \\
\hline \multirow{2}{*}{$1.0 \mathrm{~mm}$} & ${ }^{90} \mathrm{Y}$ & 129.59 & 67.06 & 35.77 & 17.85 & 8.70 \\
\hline & $3 x^{90} Y$ & 137.75 & 184.92 & 99.83 & 50.36 & 24.83 \\
\hline \multirow{2}{*}{$2.0 \mathrm{~mm}$} & ${ }^{90} \mathrm{Y}$ & 58.19 & 29.90 & 19.07 & 10.77 & 5.59 \\
\hline & $3 x^{90} Y$ & 63.66 & 79.19 & 52.23 & 30.12 & 15.84 \\
\hline
\end{tabular}

$3 \mathrm{x}^{90} \mathrm{Y}$ indicates nonuniform activity (three times the activity at the stent edges)

\subsubsection{3 ${ }^{188}$ Re stent with $3 x$ the activity at the stent edges}

Figure 4-54 shows the 2D dose distribution of $a{ }^{188} \mathrm{Re}$ stent with weighted activity at the edges along the entire axis of the stent with distances ranging from 0.1 to $2.0 \mathrm{~mm}$ from the stent surface.

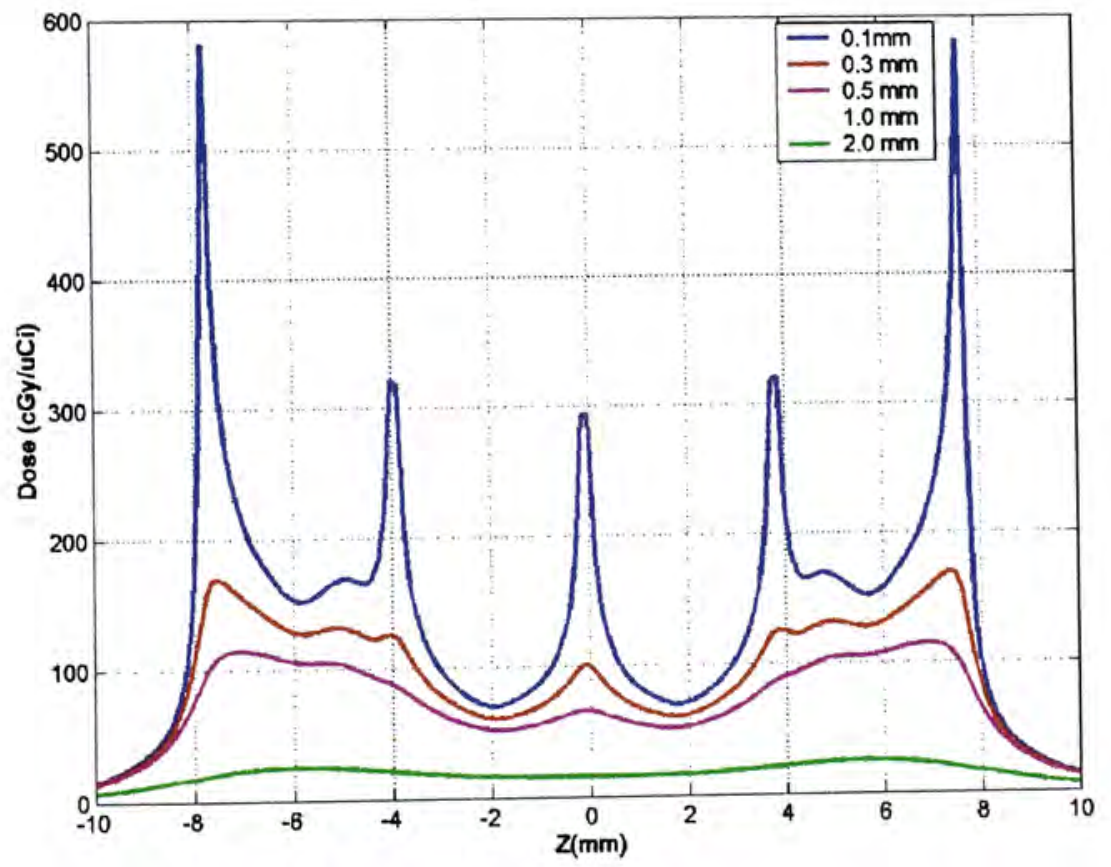

Figure 4-54. 2D plot of dose distribution of a ${ }^{188} \mathrm{Re}$ stent with $3 \mathrm{x}$ the activity at the stent edges. 
Figure 4-55 shows a comparison of a uniform ${ }^{188} \operatorname{Re}$ stent with a ${ }^{188} \operatorname{Re}$ stent with 3 times the activity at the edges. The graph shows the curves as the ratio of the dose at a particular point to the dose at the stent center for a fixed radial distance of $2 \mathrm{~mm}$. At the stent edge, the dose delivered by the stent with the weighted activity is $125 \%$ of the dose at the stent center, compared to $50 \%$ with a uniform ${ }^{188} \mathrm{Re}$ stent.

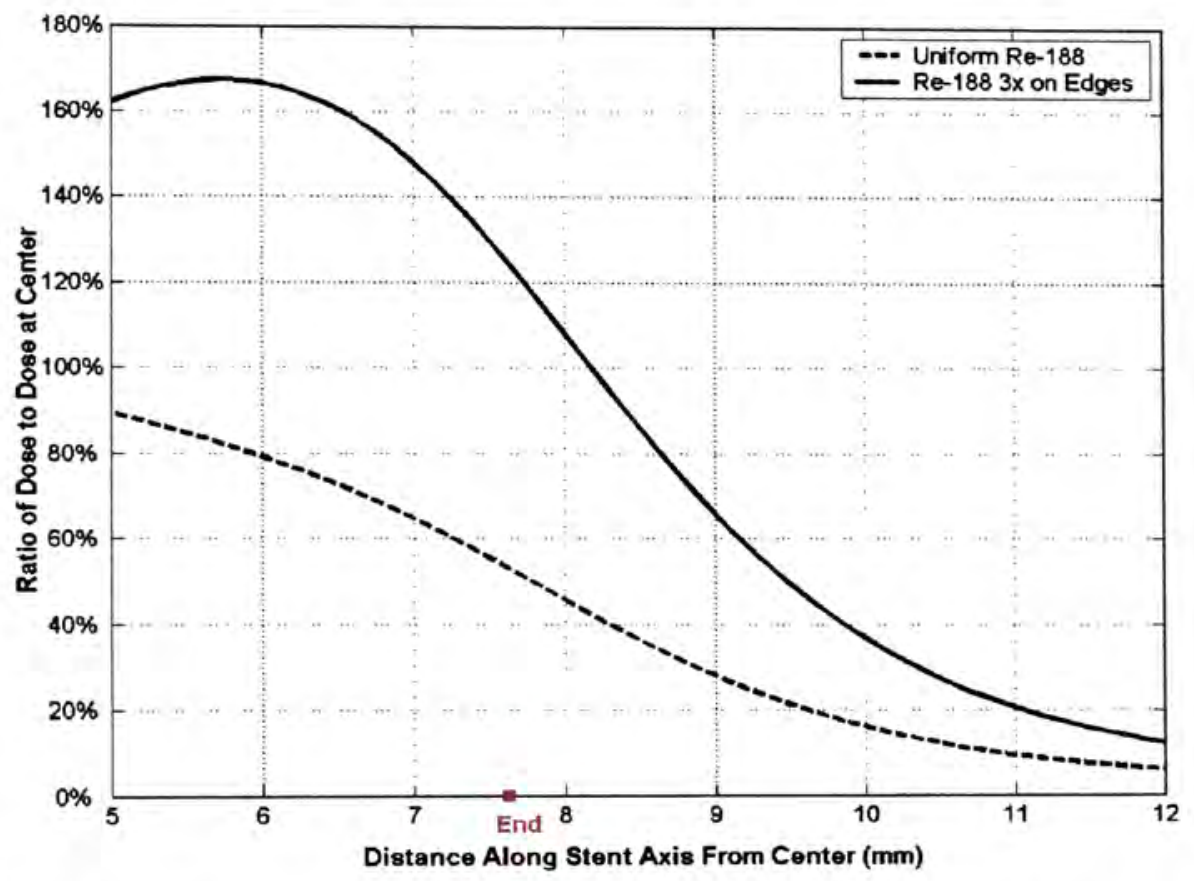

Figure 4-55. Comparison of dose as a function of axial distance from a uniform ${ }^{188}$ Re stent and a ${ }^{188} \mathrm{Re}$ stent with 3 times the activity at the stent edges.

Table 4-14 shows the dose delivered from a uniform ${ }^{188}$ Re stent and one with 3 times the activity at the stent edges for radial distances of $0.5,1$ and $2 \mathrm{~mm}$ from the surface of the stent. The values of dose are taken for points at the stent center, or midplane, at the stent edge, and 1, 2 and $3 \mathrm{~mm}$ distal to the stent edge. 
Table 4-14. Dose calculation of a ${ }^{188}$ Re stent with variation in activity at stent edges

\begin{tabular}{|c|c|c|c|c|c|c|}
\hline \multirow{2}{*}{$\begin{array}{c}\text { Radial } \\
\text { Distance } \\
\text { from Stent } \\
\text { Surface }\end{array}$} & \multirow[b]{2}{*}{ Stent } & \multicolumn{5}{|c|}{ Position Along Stent Axis } \\
\hline & & $\begin{array}{l}\text { Stent } \\
\text { Center }\end{array}$ & $\begin{array}{l}\text { Stent } \\
\text { Edge }\end{array}$ & $\begin{array}{c}1.0 \mathrm{~mm} \\
\text { Distal }\end{array}$ & $\begin{array}{c}2.0 \mathrm{~mm} \\
\text { Distal }\end{array}$ & $\begin{array}{c}3.0 \mathrm{~mm} \\
\text { Distal }\end{array}$ \\
\hline \multirow{2}{*}{$0.5 \mathrm{~mm}$} & ${ }^{188} \mathrm{Re}$ & 63.00 & 33.52 & 12.30 & 5.50 & 2.66 \\
\hline & $3 x^{188} \mathrm{Re}$ & 65.45 & 95.84 & 34.45 & 15.04 & 7.00 \\
\hline \multirow{2}{*}{$1.0 \mathrm{~mm}$} & ${ }^{188} \mathrm{Re}$ & 33.76 & 17.74 & 9.21 & 2.30 & 1.28 \\
\hline & $3 x^{188} \mathrm{Re}$ & 35.95 & 49.13 & 25.43 & 5.98 & 3.12 \\
\hline \multirow{2}{*}{$2.0 \mathrm{~mm}$} & ${ }^{188} \mathrm{Re}$ & 14.30 & 7.59 & 4.86 & 2.83 & 1.63 \\
\hline & $3 x^{188} \mathrm{Re}$ & 15.98 & 19.91 & 12.86 & 7.33 & 4.06 \\
\hline
\end{tabular}

$3 \mathrm{x}^{188} \mathrm{Re}$ indicates nonuniform activity (three times the activity at the stent edges)

\subsubsection{4. ${ }^{177} \mathrm{Lu}$ with $3 \mathrm{x}$ the activity at the stent edges}

Figure 4-56 shows the $2 \mathrm{D}$ dose distribution of a ${ }^{177} \mathrm{Lu}$ stent with weighted activity at the edges along the entire axis of the stent with distances ranging from 0.1 to $2.0 \mathrm{~mm}$ from the stent surface.

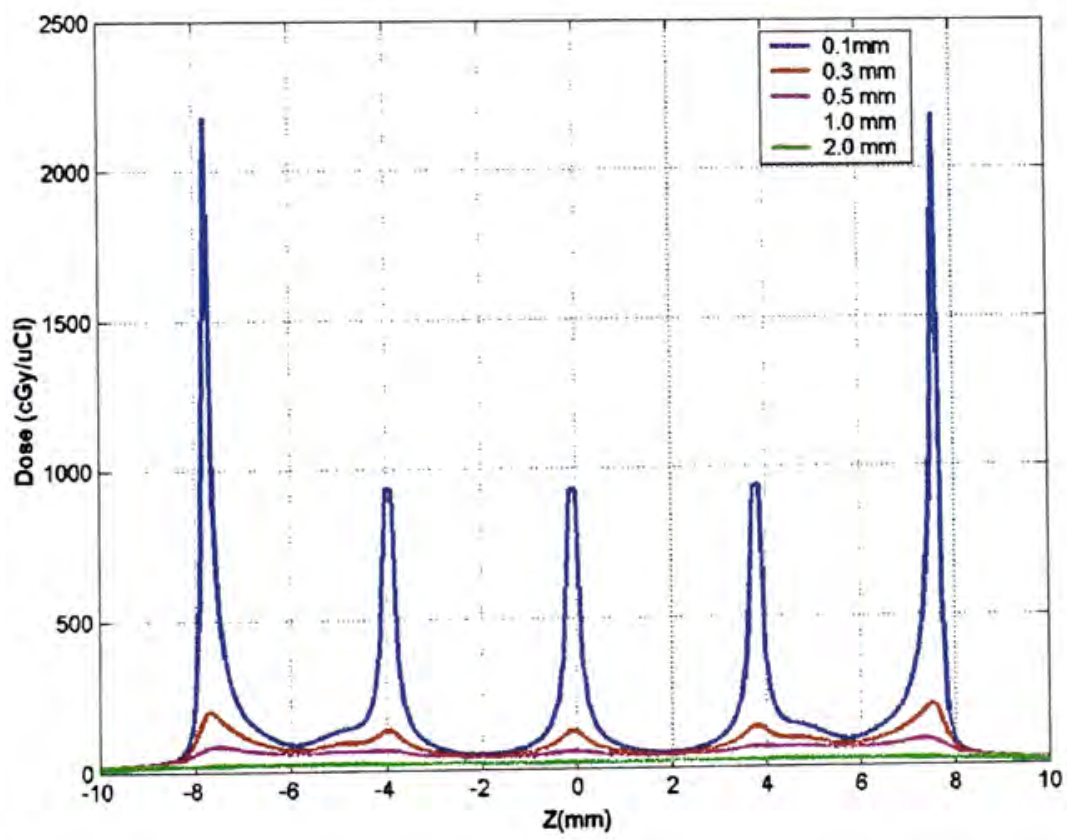

Figure 4-56. 2D plot of dose distribution of a ${ }^{177} \mathrm{Lu}$ emitting stent with $3 \mathrm{x}$ the activity at the stent ends. 
Figure 4-57 shows a comparison of a uniform ${ }^{177} \mathrm{Lu}$ stent with a ${ }^{177} \mathrm{Lu}$ stent with 3 times the activity at the edges. The graph shows the curves as the ratio of the dose at a particular point to the dose at the stent center for a fixed radial distance of $2 \mathrm{~mm}$. At the stent edge, the dose delivered by the stent with the weighted activity is $67 \%$ of the dose at the stent center, compared to $50 \%$ with a uniform ${ }^{177} \mathrm{Lu}$ stent.

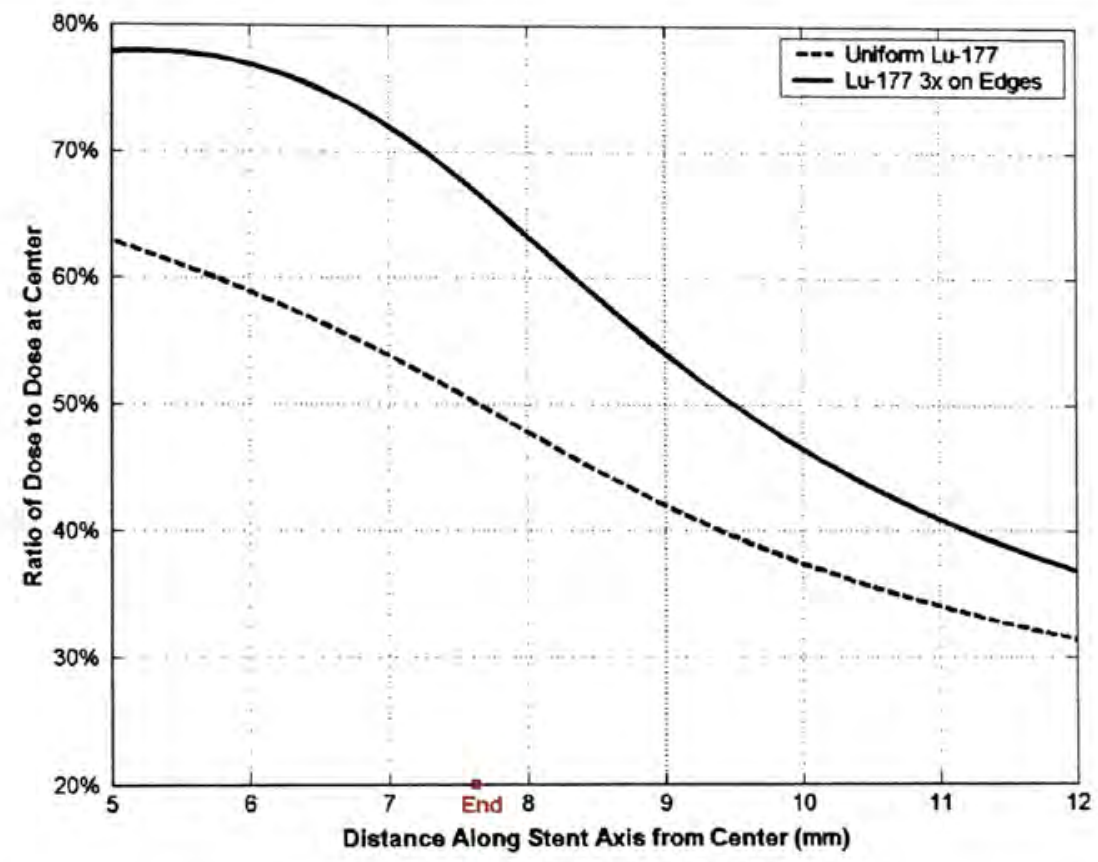

Figure 4-57. Comparison of dose as a function of axial distance from a uniform ${ }^{177} \mathrm{Lu}$ stent and $a{ }^{177} \mathrm{Lu}$ stent with 3 times the activity at the stent edges.

Table 4-15 shows the dose delivered from a uniform ${ }^{177}$ Lu stent and one with 3 times the activity at the stent edges for radial distances of $0.5,1$ and $2 \mathrm{~mm}$ from the surface of the stent. The values of dose are taken for points at the stent center, or midplane, at the stent edge, and 1,2 and $3 \mathrm{~mm}$ distal to the stent edge. 
Table 4-15. Dose calculation of a ${ }^{177}$ Lu stent with variation in activity at stent edges

\begin{tabular}{|c|c|c|c|c|c|c|}
\hline \multirow{2}{*}{$\begin{array}{c}\text { Radial } \\
\text { Distance } \\
\text { from Stent } \\
\text { Surface }\end{array}$} & Stent & $\begin{array}{c}\text { Stent } \\
\text { Center }\end{array}$ & $\begin{array}{c}\text { Stent } \\
\text { Edge }\end{array}$ & $\begin{array}{c}\mathbf{1 . 0} \mathbf{~ m m} \\
\text { Distal }\end{array}$ & $\begin{array}{c}\mathbf{2 . 0} \mathbf{~ m m} \\
\text { Distal }\end{array}$ & $\begin{array}{c}\mathbf{3 . 0} \mathbf{~ m m} \\
\text { Distal }\end{array}$ \\
\hline \multirow{2}{*}{$0.5 \mathrm{~mm}$} & ${ }^{177} \mathrm{Lu}$ & 49.10 & 27.66 & 10.05 & 6.74 & 4.97 \\
\cline { 2 - 7 } & $3 \mathrm{x}^{177} \mathrm{Lu}$ & 55.29 & 74.43 & 23.62 & 15.05 & 10.73 \\
\hline \multirow{2}{*}{$1.0 \mathrm{~mm}$} & ${ }^{177} \mathrm{Lu}$ & 21.71 & 12.47 & 8.57 & 6.16 & 4.67 \\
\cline { 2 - 7 } & $3 \mathrm{x}^{177} \mathrm{Lu}$ & 27.55 & 29.42 & 19.51 & 13.52 & 9.96 \\
\hline \multirow{2}{*}{$2.0 \mathrm{~mm}$} & ${ }^{177} \mathrm{Lu}$ & 13.50 & 8.14 & 6.50 & 5.13 & 4.10 \\
\cline { 2 - 7 } & $3 \mathrm{x}^{177} \mathrm{Lu}$ & 18.66 & 17.48 & 13.94 & 10.85 & 8.51 \\
\hline
\end{tabular}

$3 \mathrm{x}^{177}$ Lu indicates nonuniform activity (three times the activity at the stent edges)

\subsection{Validation of DPK convolution method with Monte Carlo simulation of a ${ }^{32} \mathbf{P}$ Cylinder}

The validation of the DPK convolution used in the radiation dosimetry model was done for the dose emitted by a cylinder of ${ }^{32} \mathrm{P}$ as a function of radial distance from the surface of the cylinder. Table 4-16 summarizes the parameters that were needed for the calculation of the attenuation correction factor $\mathrm{AF}$ for the radioactivity of the ${ }^{32} \mathrm{P}$ within the volume of the cylinder.

Table 4-16. Tabulated parameters for calculation of attenuation correction factor for ${ }^{32} \mathbf{P}$ cylinder used in validation of DPK convolution.

\begin{tabular}{|c|c|c|c|c|}
\hline $\mathbf{r}(\mathbf{m m})$ & $\bar{d} \mathbf{( m m )}$ & $\Delta \mathbf{x}(\mathbf{m m})$ & $\frac{1}{\mathrm{~T}} \rho \frac{\mathrm{dT}}{\mathrm{dx}} \Delta \mathbf{x}$ & $\mathbf{A F}$ \\
\hline 0.01 & 0.489 & 0.479 & 0.609 & 0.391 \\
\hline 0.2 & 0.629 & 0.429 & 0.55 & 0.45 \\
\hline 0.5 & 0.888 & 0.388 & 0.494 & 0.506 \\
\hline 0.7 & 1.07 & 0.37 & 0.471 & 0.529 \\
\hline 1.0 & 1.36 & 0.36 & 0.458 & 0.542 \\
\hline 2.0 & 2.33 & 0.33 & 0.4201 & 0.5799 \\
\hline 4.0 & 4.32 & 0.32 & 0.407 & 0.593 \\
\hline
\end{tabular}

The Monte Carlo simulation of the ${ }^{32} \mathrm{P}$ cylinder was done by Dr. Michael Stabin of Vanderbilt University. Table 4-17 shows the dose values at specific target points obtained 
from Monte Carlo and DPK methods as well as the \% error. This data is plotted in Figure 4-58.

Table 4-17. Comparison between Monte Carlo and DPK dose values for increasing radial distance.

\begin{tabular}{|c|c|c|c|}
\hline $\mathbf{r}(\mathbf{m m})$ & Monte Carlo & DPK & \% Error \\
\hline $\mathbf{0 . 0 1}$ & 10,400 & $10,699.7$ & 2.88 \\
\hline $\mathbf{0 . 2}$ & 6,000 & $6,297.9$ & 4.96 \\
\hline $\mathbf{0 . 5}$ & 3,680 & $3,276.4$ & 10.97 \\
\hline $\mathbf{0 . 7}$ & 2,580 & $2,276.6$ & 11.76 \\
\hline $\mathbf{1 . 0}$ & 1,900 & $1,907.3$ & 0.38 \\
\hline $\mathbf{2 . 0}$ & 514 & 371.4 & 27.74 \\
\hline $\mathbf{4 . 0}$ & 35.2 & 27.8 & 21.02 \\
\hline
\end{tabular}

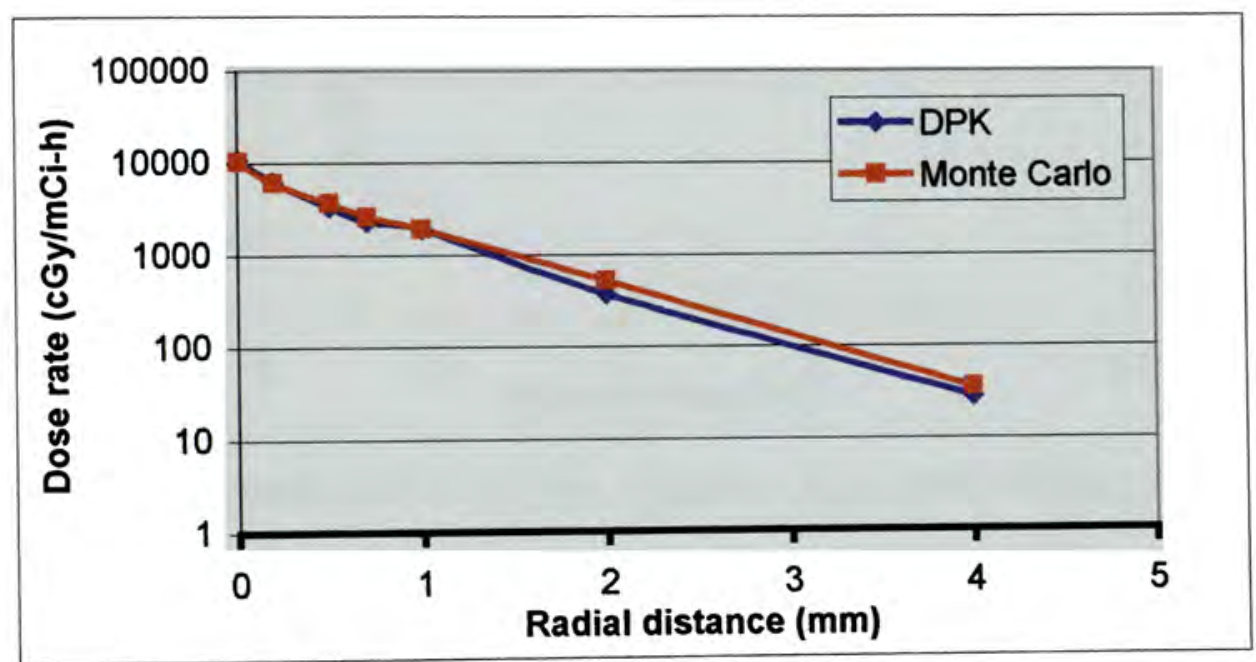

Figure 4-58. Monte Carlo versus DPK convolution method for dose calculation as a function of radial distance from surface of cylinder.

The dose emitted from a ${ }^{32} \mathrm{P}$ stent was also compared to the dose calculated by Janicki et al. (1997), which was also based on a DPK convolution model. The dose was calculated for increasing radial distance $\mathrm{r}$ up to $2 \mathrm{~mm}$ from the surface of the stent. The stent used by Janicki et al. (1997) was a Palmaz-Schatz stent with expanded dimensions of $5 \mathrm{~mm}$ in diameter and $13 \mathrm{~mm}$ in length. The sample stent used in the radiation dosimetry model 
developed in this work had deployed dimensions of $4 \mathrm{~mm}$ in diameter and $15 \mathrm{~mm}$ in length. Dose was calculated for stents with an initial activity of $1 \mu \mathrm{Ci}$ cumulated over a one half-life time interval of 14.28 days for ${ }^{32} \mathrm{P}$. Figure 4-59 shows the comparison of the radial dose distribution curves obtained from the DPK radiation dosimetry model developed in this work and the results presented by Janicki et al. (1997). Table 4-18 provides tabulated values of these results.

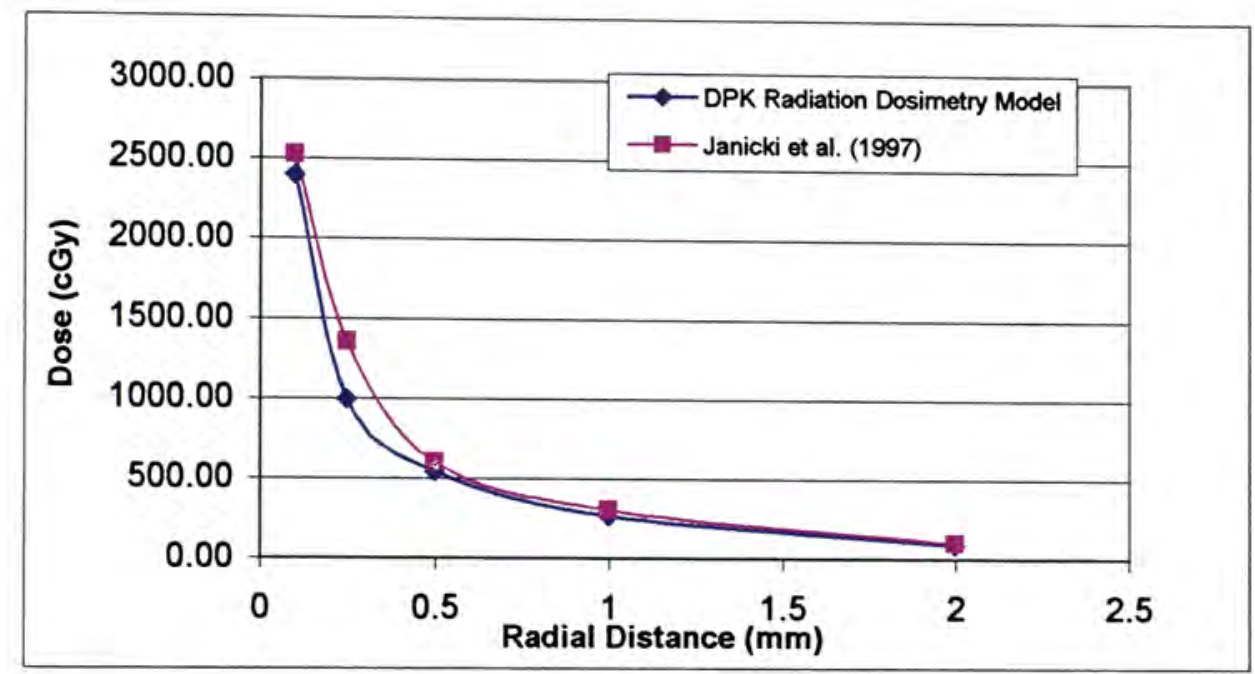

Figure 4-59. Comparison of DPK radiation dosimetry model with published results (Janicki et al. (1997)).

Table 4-18. Dose at increasing radial distance for DPK radiation dosimetry model and published results from Janicki et al. (1997)

\begin{tabular}{|c|c|c|c|}
\hline r (mm) & $\begin{array}{c}\text { DPK Radiation } \\
\text { Dosimetry Model }\end{array}$ & $\begin{array}{c}\text { Janicki et al. } \\
(\mathbf{1 9 9 7})\end{array}$ & \% Error \\
\hline 0.1 & $2,398.82$ & 2,520 & 4.81 \\
\hline 0.25 & 994.47 & 1,350 & 26.34 \\
\hline 0.5 & 541.03 & 600 & 9.83 \\
\hline 1.0 & 265.92 & 300 & 11.36 \\
\hline 2.0 & 86.13 & 100 & 13.87 \\
\hline
\end{tabular}




\section{CHAPTER 5 \\ DISCUSSION}

The results from the DPK radiation dosimetry model of the ${ }^{32} \mathrm{P},{ }^{90} \mathrm{Y},{ }^{188} \mathrm{Re}$ and ${ }^{177} \mathrm{Lu}$ stents reveal several important findings. These radioisotopes are commonly used in IVBT, with the exception of ${ }^{177} \mathrm{Lu}$, and are examples of the different radioisotopes that can be used in the radiation dosimetry model. Relevant to all is the nonuniformity of the dose at close proximity to the stent struts. There is a great variation of the dose at areas immediately adjacent to the struts and that between the struts, resulting in the peaks and valleys of the curves at distances of $0.1 \mathrm{~mm}$ shown in Figures 4-1, 4-8, 4-15 and 4-25. This effect is also evident in the 3D dose maps for each of the stents. At distances of 1-2 $\mathrm{mm}$ from the stent surface, the dose distribution becomes more homogenous, although falling to very low, almost negligible doses. It is believed that a dose in the range of 15$30 \mathrm{~Gy}$ is significant in the treatment and prevention of neointimal hyperplasia. Dose is expressed per unit of activity so to obtain a desired dose it is necessary to multiply by a factor of activity. However, to deliver dose in this range to the adventitial layer at a depth of $2 \mathrm{~mm}$ into the arterial wall, the dose at closer proximities to the stent surface will be massive.

This pronounced nonuniformity of dose at such close distances is more evident with ${ }^{177} \mathrm{Lu}$ than with other isotopes investigated, and quite unfavorable. Because the beta energy of ${ }^{177} \mathrm{Lu}$ is so low and falls off so steeply to negligible doses at $\sim 2.0 \mathrm{~mm}$, the dose at distances greater than $2.0 \mathrm{~mm}$ results mostly from gamma emissions. The dose from gamma energy is very low, and not enough to produce any significant effect on its own. 
The lutetium is embedded within the volume of the stent and a self-attenuation correction factor of 0.28 was calculated for the beta emissions of this radioisotope. The self-attenuation correction factor for gamma emissions was 0.991 . This means that only $28 \%$ of the beta emissions will reach the target point, while most of the gamma energy will be accounted for. Furthermore, in the presence of plaque, the dose will be attenuated even further. This is not the most favorable radioisotope for IVBT, even less so for incorporation into the NiTi alloy of the stent.

The radiation dosimetry model also allows the modification of dose distribution at the stent edges. The problem of edge restenosis has prompted the investigation of other alternatives within the radioactive stent. One such alternative is the increase of activity at the stent ends. As can be seen from the results obtained for the uniform stents, the dose at the stent ends is roughly $50 \%$ of that at the center of the stent. This is because the center of the stent receives dose from the center as well as from the stent segment on either side. At the stent ends, the dose is delivered by only half of a stent, as there is no source of radiation in the areas proximal and distal from the stent ends. Figures 4-50, 4-52, 4-54, and 4-6 illustrate 2D axial dose plots for ${ }^{32} \mathrm{P},{ }^{90} \mathrm{Y},{ }^{188} \mathrm{Re}$ and ${ }^{177} \mathrm{Lu}$ stents respectively with 3 times the activity at the stent ends. This did increase the percentage of the dose at the stent ends compared to the dose in the center of the stent as well as for $3 \mathrm{~mm}$ distal to the stent edges. However, the dose at the stent ends and beyond will never be the same as that in the center because of the dose fall-off particularly in the case of beta emitters. Even though clinical trials using these modifications have given unsatisfactory results, self-expanding radioactive stents, as well as radioactive angioplasty balloons could help 
improve these efforts by reducing barotraumas at the stent edges (Serruys and Kay, 2000; Hehrlein and Fischell, 2002).

Along with increasing the activity at the stent ends, different radioisotopes were also simulated. A uniform ${ }^{32} \mathrm{P}$ stent was reinforced with ${ }^{90} \mathrm{Y}$ and ${ }^{188} \mathrm{Re}$. The selection of these radioisotopes at the stent edges was based on their higher energy. Figures 4-46 and 4-47 show the results of this simulation and reveal that the dose is slightly increased at the stent ends. This effect is amplified by increasing the activity of ${ }^{90} \mathrm{Y}$ and ${ }^{188} \mathrm{Re}$ yielding $162 \%$ and $83 \%$ higher dose at the ends respectively. The dosimetry of the ${ }^{177} \mathrm{Lu}$ stent established in this work has demonstrated that ${ }^{177} \mathrm{Lu}$ is a poor candidate for IVBT due to its rapid fall-off dose and extremely low beta energy that is almost entirely attenuated when incorporated into the metal alloy of the stent. As previously stated, the gamma energy of ${ }^{177} \mathrm{Lu}$ is attenuated by only $0.01 \%$, and at distances greater than $2 \mathrm{~mm}$ from the stent, the dose is composed in its entirety of gamma emissions. Figure 4-35 shows a comparison of the axial dose distribution of the ${ }^{32} \mathrm{P},{ }^{90} \mathrm{Y},{ }^{188} \mathrm{Re}$ and ${ }^{177} \mathrm{Lu}$ calculated at a fixed radial distance of $2 \mathrm{~mm}$ from the surface of the stent and measured as the ratio of the dose to the dose at the center of the stent. Of the four radioisotopes, ${ }^{177} \mathrm{Lu}$ has the smoothest dose fall-off at the stent edges, with over $60 \%$ of the dose at the center at the edge of the stent, compared to values of $50 \%$ and below for the other radioisotopes. At this distance, the smoothness of the curve of ${ }^{177} \mathrm{Lu}$ is a result of the gamma emissions. The low gamma energy of ${ }^{177} \mathrm{Lu}$ produces a smooth reduction in the dose fall-off at the edges of the stent. This effect, which could in theory reduce the candy wrapper effect, makes ${ }^{177} \mathrm{Lu}$ a potentially useful candidate for use at the stent edges. 
The concept of BED is very important in radiotherapy treatment planning and is widely used in the treatment of cancerous tumors (Dale, 1985,1993; Giap et al., 1999). BED is more complete than physical absorbed dose in that it takes into account the repair capability of the tissue, half-life and dose rate, all of which are not included in the physical dose. Even though establishing a treatment based on BED is difficult due to limited experimental data, it is physiologically more relevant. The results of the radiobiological model for the four radioactive stents modeled in this project reveal that the BED is much higher than the physical absorbed dose, ranging from 100 times higher in the case of ${ }^{188} \mathrm{Re}$ to 36 times higher in the case of ${ }^{177} \mathrm{Lu}$. This can be explained by the much higher energy and shorter half-life of ${ }^{188} \mathrm{Re}$. Furthermore, it is interesting to note that the relative effectiveness (RE) and hence the BED vary greatly as a function of radial distance. At a smaller radial distance, the dose rate is much higher, resulting in a higher value of RE. At a distance of $5.0 \mathrm{~mm}$, the dose rate has decreased significantly and $R E$ is close to unity, therefore there is not much difference between the physical absorbed dose and the BED. Table 4-8 offers an interesting analysis of BED for the same physical dose delivered by the four radioisotope stents. The underlying premise is that for the same physical dose delivered by different radioisotopes, the biological equivalent dose BED is much different, because of the difference in dose rates, and half-lives of the radioisotopes. These results illustrate the importance of this type of calculation and provide an insight on the actual effect of this dose on the tissue. The goal is to irradiate target tissue without causing significant damage to healthy tissue.

In the case of IVBT, the concept of BED may be even more important. Unlike the treatment of cancer, where the interest is in irradiating and killing the tumor, in restenosis 
it is only necessary to irradiate a given population of cells so as to limit their proliferative potential. Also, the range of target tissue is very small, only in the order of a few millimeters thick. In the case of cancer, a higher BED is more favorable. In IVBT applications, this is not as clear. Radiotherapy treatments are not an exact science. Even today, dose prescription is done rather empirically. Because there is a lack of information in the subject of BED related to IVBT and restenosis, the theoretical calculation of BED is not widely used. It is not clear up to what point is a high BED desirable, and what are the dose thresholds for BED that would prove effective in the prevention of restenosis. The practical consequences of BED are unknown and worthy of further experimental investigation.

An attempt was made in this work to investigate the radiobiological effects of the uniform combination of radioisotopes in one stent. Figures 4-41, 4-43 and 4-45 show the dose distribution of a ${ }^{177} \mathrm{Lu}$ stent combined with ${ }^{32} \mathrm{P},{ }^{90} \mathrm{Y}$ and ${ }^{188} \mathrm{Re}$ respectively. This results in an increase in the total dose than what would be delivered by ${ }^{177} \mathrm{Lu}$ alone. A radiobiological modeling was done for each case as well, and is illustrated in figures 4$42,4-44$ and $4-46$. Similar to the simulation of a one-radioisotope stent, the BED is greater than the physical dose. The dose rate is also increased. Unfortunately, the advantage of incorporating more than one radioisotope in a stent is unknown and the radiobiological data obtained from this analysis does not provide much enlightenment. The use of multiple radioisotopes in a permanent implant has been used in radioactive seeds for use in head and neck cancer and prostate carcinomas. For tumors containing both fast growing and slow growing cells, the use of different radioisotopes with different half-lives is advantageous (Chen et al., 2003). The details of the radiobiology and cellular 
kinetics in IVBT is not as clear, and therefore, conclusions that are made in the use of radiation for treatment of cancer cannot be extended to IVBT with the same conviction. This area is worthy of further experimental study. Nevertheless, the DPK radiation dosimetry model has demonstrated to have the versatility of allowing the calculation of dose and radiobiological equivalent dose of a stent containing more than one radioisotope with similar ease and dexterity.

The validation of the DPK convolution method was done for the dose emitted from a cylinder of ${ }^{32} \mathrm{P}$ as a function of radial distance from the midplane of the cylinder and compared to the results obtained from a Monte Carlo simulation done by Dr. Michael Stabin of Vanderbilt University. Figure 4-57 shows that the curves for DPK and Monte Carlo are in close agreement. The percentage error between the two ranges between $2.88 \%$ at the points closest to the surface of the cylinder to $21.02 \%$ at the furthest distance of $4.0 \mathrm{~mm}$. The error is greater at larger distances because the number of radiations reaching the target point is considerably less. In addition there is a statistical difference between the dose calculated from DPK and Monte Carlo methods, as the DPK relies on the CSDA range and Monte Carlo follows the trajectory of each individual electron and its respective attenuation along path length. Nevertheless, the correlation between the two methods is most important at smaller distances, which are of greatest significance in IVBT dosimetry.

In addition, the results of the DPK convolution method used in the radiation dosimetry model in this work was also compared with the results of a paper published by Janicki et al. (1997) which calculated dosimetry of a ${ }^{32} \mathrm{P}$ Palmaz-Schatz stent using the DPK. Figure 4-58 shows the comparison of these two methods for increasing radial 
distance calculated from the center of the stent. Dose was calculated from stents with an initial activity of $1 \mu \mathrm{Ci}$ cumulated at one half life interval of 14.28 days for ${ }^{32} \mathrm{P}$. Table 418 provides the tabulated data of these results. This table, as well as figure $4-58$, shows that the dose values obtained in the radiation dosimetry model developed in this work are comparable to those obtained by Janicki et al. (1997). The error percentage between the two can be explained by the different stent geometries and stent dimensions that were used in each respective dose calculation. Additionally, the surface area or surface area units in the convolution equation represented by the number of stent struts or coordinates could be quite different for each stent.

The use of the dose point kernel is attractive because it is relatively simple to accommodate different stent geometries, radioisotopes and activities, a task that is more difficult and time consuming with Monte Carlo simulations. The calculation of dose distribution of a radioactive stent in this project revealed fast computation times of less than 15 minutes. Determination of the dose distribution around a radioactive source simply requires inputting radiation source coordinates, initial activity, and the analytical expression for a specific DPK, or a lookup table. Even the combination of isotopes is done quickly and easily. Even though the Monte Carlo method can be very accurate, it is generally not used for radiotherapy treatment planning because of the amount of time required. Instead, most dose calculations rely on the use of tabulated data or dose point kernel tables generated from Monte Carlo radiation transport simulations in water to perform a very fast and generally accurate assessment of the dose distribution.

Monte Carlo simulations do hold some advantages over DPK methods. Monte Carlo simulations can take into account different densities and materials, such as the 
presence of plaque to simulate more closely a realistic diseased artery. With DPK, this becomes much more difficult, as the DPK describes the dose emitted by an isotropic point source in water. However, calculations have been done using a scaling factor of DPK that takes into account different densities such as that of plaque surrounding an artery (Janicki et al., 1999).

The most important disadvantage of the DPK convolution method relevant in this study is the problem of self-attenuation when radioactive material is embedded within the NiTi material of the stent, such as the case of the ${ }^{177} \mathrm{Lu}$ stent. In this case, the lutetium is an integral part of the nickel-titanium alloy prior to its activation; therefore problems of leaching, flaking or peeling of the radioactive coatings of the stent are essentially eliminated (Satz, 2001). As a result, a more uniform distribution of the dose is expected. However, attenuation is a big problem with beta particle irradiation, particularly in the case of ${ }^{177} \mathrm{Lu}$, which has a very low energy and range. It is recommended that if a stent is to be made in this manner that the radioactive material is of much higher beta energy, or a low gamma energy, so that it is still capable of delivering significant dose to the target tissue without being completely attenuated within the stent. In the case of ${ }^{177} \mathrm{Lu}$, only $28 \%$ of the dose from the beta energy is actually delivered to the target tissue. Even by increasing the activity of ${ }^{177} \mathrm{Lu}$, the dose still would not be optimal, as there would have to be an enormous dose at close proximity to the stent struts in order to deliver a therapeutically significant dose to tissue at a target distance of $2 \mathrm{~mm}$. Furthermore, increasing the initial activity would also prove problematic since the cost of irradiation would increase significantly, and there is a limit as to how much the stent can be activated. The attenuation factor calculated in this work was based on approximations 
and average values. This issue of attenuation correction could be more exact and tractable through Monte Carlo simulations.

Calculation of the dose within a specified volume is a standard means employed by radiation oncologists/radiation physicists for planning brachytherapy treatments (Fox, 1999). These dose calculation methods provide clinicians with a tool to make pretreatment evaluations of the dose distribution and customize the treatment for the individual patient. Treatment planning in IVBT poses some difficulty because the distances of interest are so small. In conventional brachytherapy applications, distances are usually in a much greater range. Furthermore, there are many uncertainties related to the optimal dose, radiation source, activity, and target tissue to be irradiated. In vascular brachytherapy, the use of dose calculation methods for pre-treatment evaluation is not widely carried out.

Even though radioactive stents have had their share of problems, particularly edge effects, IVBT is considered a promising and effective anti-restenosis therapy (Kuntz and Baim, 2000; Sims et al., 2002; Fox, 2002). In 2002, IVBT was the standard of care for the treatment of in-stent restenosis, and is currently in practice in over 500 catheterization labs in the United States (Waksman, 2002b). Catheter-based systems such as the Guidant Galileo $^{T M}$, Cordis Checkmate ${ }^{T M}$ and Novoste Beta-Cath ${ }^{T M}$ systems are all implemented clinically with much success. The radioactive stent as a delivery platform does need much improvement, but a device that is so efficient in inhibiting in-stent neointimal hyperplasia, with such a low incidence of thrombosis and simple in terms of delivery technique should not be abandoned (Colombo, 2000). 
Improvement of stent design is a viable option, as well as a radioactive stent specifically tailored for radiation delivery. Stents with fewer, thicker struts make poor radiation delivery systems because of the accentuated difference of dose delivery between the areas adjacent to the struts and the areas between the struts (Amols, 1999b). This can be improved by decreasing stent strut thickness, increasing the number of struts, and placing them closer together in order to deliver a more uniform dose at closer proximities to the stent. It is possible to incorporate radiation considerations into stent design but perhaps not without compromising mechanical properties. A stent with more struts placed closer together could inhibit re-endothelialization that is an important healing process necessary to minimize stent thrombosis. Nevertheless, it is questionable if such a stent design would comply with the mechanical properties of the stent.

Radioisotope selection could also further improve the dose delivery of radioactive stents. Some uncertainty exists as to whether ${ }^{32} \mathrm{P}$, the most commonly used radioisotope in radioactive stents, which has a maximum energy of $1.71 \mathrm{MeV}$, provides sufficient penetration to deliver adequate amounts of radiation to the media and adventitia (Amols, 1999a). Doses from all radioactive sources decrease by at least $30-50 \%$ per millimeter, with the dose being very high near the source, but rapidly decreasing with increasing distance. The dose fall-off rate exceeds $70 \%$ per millimeter for ${ }^{32} \mathrm{P}$ (Amols, 1999a) If an adequate dose is delivered to the media, the adventitia will receive a negligible dose. On the other hand, for an adequate dose to be delivered to the adventitia, the dose to the intima may be excessive (Amols, 1999a; Fischell et al., 2000). Other radioisotopes such as positron emitter ${ }^{48} \mathrm{~V}$, and gamma emitters ${ }^{103} \mathrm{Pd}$ and ${ }^{131} \mathrm{Cs}$ have received some attention as candidates for use in radioactive stents (Hehrlein and Fischell, 2002). However, these 
gamma emitters are of relatively low energies and would require higher activities to deliver therapeutically effective doses. There also exists the concern of irradiating healthy tissue as a result of the more penetrating gamma rays. Still, there is uncertainty as to the optimal activity of the radioisotope, dose and dose rate to be delivered to the tissue, as well as the half-life that best matches the growth rates of the tissues involved in neointimal hyperplasia and restenosis.

Drug-eluting stents have been acclaimed by many to be one of the greatest breakthroughs in interventional cardiology (Waksman, 2002a; Indolfi et al., 2003). With the advent of drug-eluting stent technology and the reported lower restenosis rates, it would appear that the future of intravascular brachytherapy (IVBT) would be in jeopardy, particularly in the case of radioactive stents. Despite the fact that radioactive stents need much improvement, IVBT of a catheter-based nature is used clinically with much success. After redilatation of in-stent restenosis, brachytherapy reduces the risk of subsequent recurrence by over 50\% (Teirstein and King, 2003). While IVBT has proven to be an effective treatment in cases of in-stent restenosis, its fate in the drug-eluting stent world appears to be uncertain.

At present, there is sufficient data from numerous trials including SCORES, ELUTES, FIM, RAVEL, SIRIUS, TAXUS I, and TAXUS II to convincingly indicate the promise and effectiveness of drug-eluting stents in reducing restenosis rates to single digit percentages. A target lesion restenosis rate of only 5.5\% was observed in the Boston Scientific TAXUS II trial with a slow-release paclitaxel stent. In the Cordis SIRIUS trial where sirolimus-eluting stents were compared to bare stents, restenosis of the target lesion was observed in only $8.9 \%$ of treated patients compared with $36.6 \%$ of placebo 
patients (Teirstein and King, 2003). Moreover, the Cordis CYPHER drug-eluting stent received FDA approval in April 2003, and the Boston Scientific TAXUS drug-eluting stent has been given an expedited review status by the FDA (Endovascular Today, May/June 2003).

Despite the enthusiasm surrounding drug-eluting stents, the technology is still not perfect. The overall success of drug-eluting stents relies on inconsistent results between animal and clinical trials. The animal models have generally yielded positive results, although it is important to note that the atherosclerotic and healing processes in animals and humans are quite different, with the healing process in humans being much longer and complex. In addition, cases of edge restenosis in drug eluting stents, as well as thrombosis, polymer-induced inflammation, drug-leaching and toxicity, nonabsorbable polymers, and late stent malapposition have been reported (Waksman, 2002a, Indolfi et al., 2003). Late malapposition, or separation of the stent from the vessel wall, has been observed in both the RAVEL and the multi-center SIRIUS BX Velocity sirolimus coated stent trials in a small cohort of patients that were subject to intravascular ultrasound analysis (Indolfi et al., 2003). Other problems could emerge in the long-term results of clinical trials.

A major shortcoming of drug-eluting stents is the cost. At present, drug-eluting stents are costly, which might have a negative impact on their widespread applicability (Waksman, 2002a). Each drug-eluting stent costs more than twice as much as a bare metal stent. In Europe, where drug-eluting stents have been approved since 2002, the use of drug-eluting stents ranged between 5 and $10 \%$ of cases, mainly for economic reasons. Adequate reimbursement could also be a problem (Waksman, 2002a). For hospitals 
receiving a budget on drug-eluting stents, not all patients and all lesions can be treated with this technology.

Clinical trials have confirmed the benefit and efficacy of IVBT in treatment of instent restenosis lesions of varying lengths and vessel diameters, native artery and aortocoronary saphenous vein graft targets, bifurcation lesions, and/or the presence of diabetes (Waksman and Weinberger, 2003). Recent trials have provided excellent-quality data supporting the effectiveness of $\gamma$-radiation for the treatment of saphenous vein graft in-stent restenosis, superficial femoral artery obstructions, and diseased dialysis grafts. Results from the SVG BRITE (Saphenous Vein Graft Beta Radiation to Prevent In-Stent Restenosis) study with the use of $\mathrm{a}^{32} \mathrm{P}$ source train are encouraging, with a $0 \%$ restenosis rate (Waskman, 2002b). In the majority of clinical trials, drug-eluting stents have been used mostly for smaller and simpler lesions. In the SIRIUS study, a 35\% restenosis rate was reported in insulin-dependent diabetic patients, despite the sirolimus-eluting stent. Similarly, rates between 16 and $18 \%$ were observed in patients with long lesions and small vessels (Waksman, 2002a). The risk of restenosis is much higher in longer and complex lesions, and the initial data on drug-eluting stents is not very encouraging with higher rates of restenosis in this group of patients (Massat, 2002; Waksman, 2002a; Yajnik et al., 2003). Additionally, there exists no data regarding the effectiveness of drug-eluting stents for saphenous vein graft stenoses (Yajnik et al., 2003).

It is the opinion of some experts that drug-eluting stents will more than double the current number of patients undergoing stent implantation to approximately 2 million a year by 2005 (Yajnik et al., 2003). If this is the case, even a very small rate of failure such as $5 \%$ will translate into a considerable number of candidates for IVBT, up to 
100,000 per year, even in a drug-eluting stent era (Yajnik et al., 2003). Even though drugeluting stents might become the treatment of choice for in-stent restenosis, restenotic lesions in a more difficult subset of patients with diabetes, long lesions and smaller vessels, and restenosis in peripheral vessels will likely benefit from IVBT therapy. Intravascular brachytherapy should not be dismissed completely as it has proven to be an effective means of treating restenosis and may be needed for the treatment of in-stent restenosis due to drug-eluting stent failures (Waksman, 2002a). A randomized study of IVBT vs. drug-eluting stents in peripheral and more complex lesions is warranted and might provide more conclusive information on this subject.

Experimental work using radiochromic film as well as complete Monte Carlo simulations is recommended for further characterization of the ${ }^{177} \mathrm{Lu}$ stent. In addition, the calculation of self-attenuation correction factor by experimental means might also be useful and could be a more accurate than theoretical approximations. This is specifically significant for the cases in which the radioisotope is embedded within the volume of the stent. The design of the experiment would consist of measuring the stent activity in a radioisotope calibrator. This activity would be for the radiations emitted from the whole stent and designated as $\mathrm{A}_{\mathrm{SA}}$, or the activity of the self-attenuated radiations. The stent would then be pulverized and its activity measured in a beta liquid scintillator with a photomultiplier tube, and corrected for the time decay. This activity, $A_{0}$, is the actual activity of the stent. The self-attenuation correction factor would be given by the quotient of the two measured activities or $\mathrm{A}_{\mathrm{SA}} / \mathrm{A}_{0}$. Once determined, this self-attenuation correction factor would be multiplied by the dose calculated from the stent. This is the 
experimental method used by NIST (National Institute of Standards and Technology) for determining the activity of any material. 


\section{CHAPTER 6 \\ CONCLUSIONS}

The DPK method developed in this work proved to be a fast, easy and versatile way to estimate the $3 \mathrm{D}$ distribution of the dose emitted from radioactive stents. The radiation dosimetry model developed in this work has the versatility to accommodate different radioisotopes, stent geometries and activities. This model has fast computation times of 15 minutes or less per simulation. It characterized the dose at different distances into the target tissue in both radial and axial directions. The dosimetry of ${ }^{32} \mathrm{P},{ }^{90} \mathrm{Y},{ }^{188} \mathrm{Re}$ and ${ }^{177} \mathrm{Lu}$ was investigated. Of the four, ${ }^{32} \mathrm{P}$ delivers the highest dose, while ${ }^{90} \mathrm{Y},{ }^{188} \mathrm{Re}$ and ${ }^{177} \mathrm{Lu}$ require high levels of activity to deliver a significant therapeutic dose in the range of 15-30 Gy. At very short distances from the stent, the dose is highly nonuniform. This nonuniformity decreases with increasing distance, although the dose falls off significantly.

Two different kinds of stents were simulated in this study. The radioactivity was assumed on the stent surface for ${ }^{32} \mathrm{P},{ }^{90} \mathrm{Y}$ and ${ }^{188} \mathrm{Re}$. In the case of ${ }^{177} \mathrm{Lu}$, the radioactivity was embedded within the volume of the stent. This required the calculation of selfattenuation correction factors for both beta and gamma emissions of ${ }^{177} \mathrm{Lu}$. The total dose delivered by ${ }^{177} \mathrm{Lu}$ was attenuated by $72 \%$ for beta emissions and $0.9 \%$ for gamma emissions. Even though the gamma emissions were hardly attenuated, the energy is too low to be significant. In addition, the self-attenuation of beta particles by the stent when the ${ }^{177} \mathrm{Lu}$ is incorporated into the alloy, make this radioisotope a poor candidate for intravascular brachytherapy. For a radioactive stent in which the radioactive material is 
an integral part of the metal alloy of the stent, a radioisotope with a much higher energy should be used for a significant dose to be delivered to the target tissue. The main limitation of the DPK model is the calculation of the self-attenuation of the beta emissions when the radioisotope is incorporated into the volume of the stent. This particular case could require the experimental determination of a self-attenuation factor.

The rapid fall-off dose of beta particles of radioisotopes used in this work results in the dose at the stent edges being about fifty percent less than the dose at the center of the stent. The low energy of the beta emissions does not allow adequate delivery of radiation dose to the critical targets. Nevertheless, the low gamma energy of ${ }^{177} \mathrm{Lu}$ produces a smooth reduction in the dose at the edges of the stent compared to the other radioisotopes studied. This effect, which in theory could reduce the candy wrapper effect, makes ${ }^{177} \mathrm{Lu}$ a potentially useful radioisotope to be incorporated at the edges of the stent. This also implies that the use of a gamma emitter at the stent edges could also be favorable.

A radiobiological assessment provides interesting insights on the dose delivered at a particular target point by different radioisotopes. It was shown that for the same physical dose delivered by ${ }^{32} \mathrm{P},{ }^{90} \mathrm{Y},{ }^{188} \mathrm{Re}$ and ${ }^{177} \mathrm{Lu}$ stents, the BED is quite different. Physical absorbed dose does not say much about the quality and characteristics of the dose. However, BED takes into account the rate at which the dose is delivered, the halflife of the radioisotope and the repair capability of the tissue. BED can be up to 100 times higher than physical absorbed dose. Results of the radiobiological model demonstrated that the same physical dose delivered by different radioisotopes could produce 
significantly different biological effects. The practical consequence of this effect is unknown and is worthy of further experimental investigation.

The dosimetry and radiobiological models developed in this work serve as a tool to characterize the dosimetry of a radioactive stent, and give an idea of the radiobiological effect. This type of theoretical dose calculation can be useful for the development of new stent designs in efforts to improve the radioactive stent technology, and in the planning of animal studies and clinical trials. 


\section{LIST OF REFERENCES}

American Heart Association. Heart Disease and Stroke Statistics - 2003 Update. Dallas, Texas: American Heart Association; 2002. [Online] Available: http://www. americanheart.org/ [3/10/2003].

Albeiro R., Adamian M., Kobayashi N., et al. (2000a). "Short and Intermediate-term results of ${ }^{32} \mathrm{P}$ radioactive $\beta$-emitting stent implantation in patients with coronary artery disease: the Milan dose-response study." Circulation 101:18-26.

Albeiro R., Nishida T., Adamian M., Amato A., Vaghetti M., Corvaja N., Di Mario C., and Colombo A., (2000b). "Edge restenosis after implantation of high activity ${ }^{32} \mathrm{P}$ radioactive $\beta$-emitting stents." Circulation 101: 2454-2457.

Amols HI, Zaider M, Weinberger J, Ennis R, Schiff PB, and Reinstein LE. (1996). "Dosimetric considerations for catheter-based beta and gamma emitters in the therapy of neointimal hyperplasia in human coronary arteries." Intl J. Rad. Oncol. Biol. Phy 36(4): 913-921.

Amols, Howard I. (1999a). "Review of endovascular brachytherapy physics for prevention of restenosis." Cardiovascular Radiation Medicine 1(1): 270-277.

Amols, Howard I. (1999b). "Methods to improve dose uniformity for radioactive stents in endovascular brachytherapy." Cardiovascular Radiation Medicine 1(3): 64-71.

Apple M. and Waksman R. "Xenon-133 Gas-Filled Balloon", From Waksman R (ed.). Vascular Brachytherapy, Third Edition. Armonk, NY: Futura Publishing Co., Inc 2002.

Attix, Frank H. (1986). Introduction to Radiological Physics and Radiation Dosimetry. John Wiley \& Sons, Inc.

Berger M.J.(1971). "Distribution of absorbed dose around point sources of electrons in water and other media." MIRD phamplet No. 7, J Nucl Med 12(suppl.5): 7-23.

Berger M.J., Coursey J.S., and Zucker M.A. (2000). "Stopping Power and Range Tables for Electrons, Protons and Helium Ions." [Online] Available: http://physics.nist.gov/PhysRefData/Star/Text/ESTAR.html. [6/30/2003].

Brenner D.J., Miller R.C., and Hall, E.J. (1996). "The Radiobiology of Intravascular Irradiation." International Journal of Radiation Oncology and Biological Physics 36(4): 805-810.

Brenner D.J. (1997). "Radiation Biology in Brachytherapy." Journal of Surgical Oncology 65:66-70. 
Brenner D.J. and Hall E.J. (2001). "Dose rate does matter in endovascular brachytherapy." Cardiovascular Radiation Medicine 2: 254-255.

Carter A.J. and Laird J.R. (1996). "Experimental results with endovascular irradiation via a radioactive stent." International Journal of Radiation Oncology and Biological Physics 36(4): 797-803.

Carter A.J., Jenkins S., Sweet W., Bailey L., Jones R., Fischell T.A., and Virmani R. (1999). "Dose and dose rate effects of beta-particle emitting radioactive stents in a porcine model of restenosis." Cardiovascular Radiation Medicine 1(4): 327-335.

Chantler, C.T., Olsen, K., Dragoset, R.A., Kishore, A.R., Kotochigova, S.A., and Zucker, D.S. (2003), X-Ray Form Factor, Attenuation and Scattering Table(version 2.0). [Online] Available: http://physics.nist.gov/ffast [7/3/2003]. National Institute of Standards and Technology, Gaithersburg, MD. Originally published as Chantler, C.T., J. Phys. Chem. Ref. Data 29(4), 597-1048 (2000); and Chantler, C.T., J. Phys. Chem. Ref. Data 24, 71-643 (1995).

Chen Z. and Nath R. (2003). "Biological effective dose (BED) for interstitial seed implants containing a mixture of radionuclides with different half-lives." International Journal of Radiation Oncology and Biological Physics 55(3): 825-834.

Coffey C.W and Duggan D.M. "The calculation and measurement of radiation dose surrounding radioactive stents: the effects of radionuclide selection and stent design on dosimetric results", From Waksman R (ed.). Vascular Brachytherapy, Third Edition. Armonk, NY: Futura Publishing Co., Inc 2002.

Colombo A. (2000). "Radioactive stents - A Dead End?" Current Interventional Cardiology Reports 2:87-88.

Cross W.G., Freedman N.O., and Wong, P.Y. (1992). "Tables of Beta-Ray Dose Distributions in Water" Atomic Energy of Canada, Ltd., Report No. AECL-10521, Ontario, Canada.

Dale, R.G., (1993). "Radiobiological assessment of non-standard and novel radiotherapy treatments using the linear-quadratic model," Med. \& Biol. Eng. \& Comput. 31: 53-57.

Dale, R.G., (1985). "The application of the linear-quadratic dose-effect equation to fractionated and protracted radiotherapy," British Journal of Radiology, 58: 515-528.

Dillman, L.T. (1969). "Radionuclide Decay Schemes and Nuclear Parameters for use in Radiation-Dose estimation." Journal of Nuclear Medicine 10 (Suppl. 2):29. 
Duggan C., Coffey C.W. and Levit S. (1998). "Dose Distribution for a ${ }^{32}$ P-Impregnated Coronary Stent: Comparison of Theoretical Calculations and Measurements with Radiochromic Film." International Journal of Radiation Oncology and Biological Physics 40(3): 713-720.

Endovascular Today May/June (2003). [Online] Available:

http://www.evtoday.com/etart/et0503/et0503 deschart.pdf [7/30/2003].

Evans, Robley D. (1982). The Atomic Nucleus. Robert E. Krieger Publishing Company Inc., Malabar, FL.

Fischell T.A., Kharma B.K., Fischell D.R, et al.. (1994). "Low-dose, beta-particle emission from stent wire results in complete, localized inhibition of smooth muscle cell proliferation." Circulation 90: 2956-2963.

Fischell, T.A., (1998) "Radioactive Stents," Semin. Intervent. Cardiol, 3:51-56.

Fischell T.A., Hehrlein C., Fischell R.E, and Fischell D.R. (2000). "The Impact of Stent Design and Delivery Upon the Long-Term Efficacy of the Radioisotope Stent", J. Invas. Cardiol., 12: 162-167.

Fischman D.L., Leon M.B., Schatz R.A., Savage M.P., Penn I., Detre K., Veltri, L., Ricci D., and Nobuyoshi, M., (1993). "A randomized comparison of coronary stent placement and balloon angioplasty in the treatment of coronary artery disease. Stent Restenosis Study Investigators." New England Journal of Medicine 331(8): 496-501.

Fox, Tim (1999). "Treatment Planning for IVBT: Clinically desirable radiation dose distributions and evaluation of competing dose distributions." President's Symposium Lecture 1999 Annual AAPM Meeting Nashville, TN.

Fox, R.A. (2000). "The dosimetry for a coronary stent coated with radioactive ${ }^{188} \operatorname{Re}$ and ${ }^{32}$ P." Phys. Med. Biol., 45: 3643-3655.

Fox, R.A., (2002). "Intravascular brachytherapy of the coronary arteries," Phys. Med. Biol., 47: 1-30.

Furhang E., Sgouros G., and Chui, C. (1996). "Radionuclide photon dose kernels for internal emitter dosimetry." Medical Physics 23: 759-764.

Giap H., Tripuraneni P., Teirstein P., and Massulo V. (1999). "Theoretical assessment of dose-rate effect in endovascular brachytherapy." Cardiovascular Radiation Medicine 1(3): 227-232.

Hall E.J., Marchese M., Rubin J., and Zaider M. (1988). "Low dose-rate irradiation." Front. Radiat. Ther. Onc. 22: 19-29. 
Hall, E.J., Miller, R.C., and Brenner, D.J. (1999). "Radiobiological Principles in Intravascular Irradiation.” Cardiovascular Radiation Medicine 1(1): 42-47.

Hehrlein C., Gollan C., Donges K., Metz J., Riessen R., Fehsenfeld P., von Hodenberg E., and Kubler W. (1995). "Low-dose Radioactive Endovascular Stents Prevent Smooth Muscle Cell Proliferation and Neointimal Hyperplasia in Rabbits." Circulation 92(6): 1570-1575.

Hehrlein C. and Kubler W. (1997). "Advantages and Limitations of radioactive stents." Semin Intervent Cardiol 2: 109-113.

Hehrlein C. and Fischell T. "New concepts for radioactive stents", From Waksman R (ed.). Vascular Brachytherapy, Third Edition. Armonk, NY: Futura Publishing Co., Inc 2002.

Indolfi C., Mongiardo A., Curcio A., and Torella D. (2003). "Molecular Mechanisms of In-Stent Restenosis and Approach to Therapy with Eluting Stents." Trends Cardiovasc Med 13:142:148.

Jani S.K., Chu G.L., Huppe G.B. Massullo V., Tripuraneni P. and Teirstein P. "Cordis Checkmate $^{\mathrm{TM}}$ : Manually loaded Iridium 192 ribbon", From Waksman R (ed.). Vascular Brachytherapy, Third Edition. Armonk, NY: Futura Publishing Co., Inc 2002.

Janicki C., Duggan D.M., Coffey C.W., Fischell D.R., and Fischell T.A.(1997). "Radiation Dose from a phosphorous-32 impregnated wire mesh vascular stent." Medical Physics 24: 437-445.

Janicki C., Duggan D.M., Gonzalez A., Coffey C.W., and Rahdert, D. (1999). "Dose model for a beta-emitting stent in a realistic artery consisting of soft tissue and plaque." Medical Physics 26: 2451-2460.

Janicki C., Duggan D., and Rahdert D. (2001). “A dose point kernel model for a low energy gamma emitting stent in a heterogeneous medium." Medical Physics 28: 13971405 .

John M., Shroff, S., Farb, A., and Virmani, R. (2001). "Local arterial responses to $32 \mathrm{P}$ beta-emitting stents." Cardiovascular Radiation Medicine 2: 143-150.

King S.B. "Restenosis following angioplasty", From Waksman R (ed.). Vascular Brachytherapy, Third Edition. Armonk, NY: Futura Publishing Co., Inc 2002.

Kuntz R.E. and Baim D.S. (2000). "Prevention of Coronary Restenosis: The Evolving Evidence Base fro Radiation Therapy." Circulation 101:2130-2133. 
Li A.N., Eigler N.L., Livack F., and Whiting J.S. (1998). "Characterization of a positron emitting V48 nitinol stent for intracoronary brachytherapy." Medical Physics 25(1): $20: 28$.

Luxton G., and Jozsef G. (1999). "Radial dose distribution, dose to water and dose rate constant for monoenergetic photon point sources from $10 \mathrm{keV}$ to $2 \mathrm{MeV}$ : EGS4 Monte Carlo calculation." Medical Physics 26(12): 2531:2538.

Massat, Mary Beth (2002). "Drug Eluting Stents vs. Vascular Brachytherapy: Hype or Hope?" [Online] Available: http://www.reillycomm.com/di archive/di to 1102 1.htm [7/28/2003].

Mintz G.S., Popma J.J., Pichard A.D., et al. (1996). "Arterial remodeling after coronary angioplasty: A serial intravascular ultrasound study." Circulation 94:35-43.

Mitchell J.B. "Radiation biology concepts for the use of radiation to prevent restenosis", From Waksman R (ed.). Vascular Brachytherapy, Third Edition. Armonk, NY: Futura Publishing Co., Inc 2002.

Nath R., Amols H., Coffey C., Duggan D., Jani S., Li Z., Schell M., Soares C., Whitling J., Cole P., Crocker I., and Schwarz R. (1999). "Intravascular brachytherapy physics: Report of the AAPM Radiation Therapy Committee Task Group No. 60." Medical Physics 26(2): 119-152.

Pasterkamp G., de Kleijn D.P. and Borst C. (2000). "Arterial remodeling in atherosclerosis, restenosis and after alteration of blood flow: potential mechanisms and implications." Cardiovascular Research 45: 843-852.

Prestwich W.V., Nunes J., and Kwok, C.S. (1989). "Beta dose point kernels for radionuclides of potential use in radioimmunotherapy." J Nucl Med 30:1036-1046.

Prestwich W.V., Kennett T.J., and Kus F.W. (1995). "The dose distribution produced by a ${ }^{32}$ P-coated stent." Medical Physics 22(3): 313-320.

Raizner A.E, Kaluza G.L. Calfee R.V. and Bradshaw A.J. "The Guidant Coronary Source Wire System", From Waksman R (ed.). Vascular Brachytherapy, Third Edition. Armonk, NY: Futura Publishing Co., Inc 2002.

Reynaert N., Verhaegen F., Taeymans Y., van Eijkeren M., and Thierens H. (1999). "Monte Carlo calculations of dose distributions around 32P and $198 \mathrm{Au}$ stents for intravascular brachytherapy." Medical Physics 26(8): 1484-1491.

Rubin P., Williams J.P. and Okunieff P. "A paradigm shift for the radiation prophylaxis of arterial restenosis", From Waksman R (ed.). Vascular Brachytherapy, Third Edition. Armonk, NY: Futura Publishing Co., Inc 2002. 
Rubin P., Williams J.P., Riggs P.N., et al.(1998). "Cellular and molecular mechanisms of radiation inhibition of restenosis. Part I: Role of the macrophage and platelet-derived growth factor." Int J Radiat Oncol Biol Phys 40:929-941.

Satz S. (2001). Metal Stent Containing Radioactive Isotope and Method of making the Same. USA.

Schwartz R.S. and Holmes D.R. "Restenosis and Remodeling", From Waksman R (ed.). Vascular Brachytherapy, Third Edition. Armonk, NY: Futura Publishing Co., Inc 2002.

Scott N.A., Ross C.E., Dunn B., et al. (1996). "Identification of a potential role for the adventitia in vascular lesion formation after balloon overstretch injury of porcine coronary arteries." Circulation 93:2178-2187.

Serruys P.W., de Jaegere P., Kiemeneij F., Macaya C., Rutsch W., Heyndrickx G., Emanuelsson H., Marco J., Lengrand V., and Materne P. (1994). "A comparison of balloon-expandable-stent implantation with balloon angioplasty in patients with coronary artery disease. Benestent Study Group." New England Journal of Medicine 331(8): 48995.

Serruys P.W. and Kay I.P. (2000). "I like the candy, I hate the wrapper: The ${ }^{32} \mathbf{P}$ radioactive stent." Circulation 101:3-7.

Silverberg G.D., Britt R.H., and Goffinet D.R. (1978). "Radiation-induced carotid artery disease." Cancer 41: 130-137.

Sims E.C., Rothman M.T., Warner T.D. and Powell M.E. (2002). "Coronary Artery Brachytherapy." Clinical Oncology 14:313-326.

Stewart J.R., Fajardo L.F., Gillette S.M., and Constine L.S. (1995). "Radiation Injury to the heart." Intl J. Rad. Oncol. Biol. Phy. 31:1205-1211.

Teirstein P. and King S. (2003). "Vascular Radiation in a Drug-Eluting Stent World: It's Not Over Till It's Over." Circulation 108:384-385.

van der Giessen W., Regar E., Harteveld M., Coen V., Bhagwandien R., Au A., Levendag P., et al. (2001). "Edge Effect of ${ }^{32} \mathrm{P}$ Radioactive Stents Is Caused by the Combination of Chronic Stent Injury and Radioactive Dose Falloff." Circulation 104: 2236-2241.

Virmani R., Farb A., John M., and Taylor A.J. "Pathology of Radioactive Stents." From Waksman R (ed.). Vascular Brachytherapy, Third Edition. Aramonk, NY: Futura Publishing Co., Inc; 2002. 
Waksman, R. (2002a). "Drug-eluting stents: From bench to bed." Cardiovascular Radiation Medicine 3:226-241.

Waksman, R. (2002b). "Vascular Brachytherapy: Applications in the Era of Drug-Eluting Stents." Reviews in Cardiovascular Medicine 3(suppl 5):S23-S30.

Waksman R. and Weinberger J. (2003). "Coronary Brachytherapy in the Drug-Eluting Stent Era: Don't Bury It Alive." Circulation 108:386-388.

Wienberger J. and Knapp F. "Liquid-filled balloons for coronary brachytherapy." From Waksman R (ed.). Vascular Brachytherapy, Third Edition. Aramonk, NY: Futura Publishing Co., Inc; 2002.

Wilcox, J.N., Waksman, R., King, S.B., and Scott, N.A., (1996). "The role of the adventitia in the arterial response to angioplasty: the effect of intravascular radiation," Int J Radiation Oncology Biol Phys, 36(4): 789-796.

Wilcox J.N. and Scott N.A. "Adventitial remodeling associated with postangioplasty restenosis", From Waksman R (ed.). Vascular Brachytherapy, Third Edition. Armonk, NY: Futura Publishing Co., Inc 2002.

Yajnik S., Brunton E., and Tripuraneni P. (2003). "Vascular Brachytherapy: The Standard of Care for Patients with Coronary In-stent Restenosis."

The Journal of Imaging Technology Management. [Online] Available: http://www.imagingeconomics.com/library/200305-11.asp [7/28/2003]. 
APPENDIX A

Determination of the Spectrum of Beta Emissions of ${ }^{177} \mathrm{Lu}$ 
The beta spectrum of ${ }^{177} \mathrm{Lu}$ was determined according to the formalism of Dillman et al. (1969) and Prestwich et al. (1989). The disintegration of ${ }^{177} \mathrm{Lu}$ includes three beta emissions (Table A.1).

Table A.1. Nuclear Properties of ${ }^{177} \mathrm{Lu}$

\begin{tabular}{|l|c|}
\hline Atomic Mass & 177 \\
\hline Atomic Number & 71 \\
\hline Beta Decay & $0.498 \mathrm{MeV} \mathrm{(79 \% )}$ \\
\hline & $0.385 \mathrm{MeV}(9.1 \%)$ \\
\hline & $0.177 \mathrm{MeV}(12 \%)$ \\
\hline Gamma Decay & $0.208 \mathrm{MeV}(11 \%)$ \\
\hline & $1.113 \mathrm{MeV}(6.4 \%)$ \\
\hline
\end{tabular}

For each emission an individual spectrum was calculated by using the following equation (Prestwich et al., 1989):

$$
n\left(E_{i}\right)=C F\left(Z, W_{i}\right) P_{i} W_{i}\left(E_{M}-E_{i}\right)^{2}
$$

where $\mathrm{E}_{\mathrm{i}}$ is the energy bin, $n\left(E_{i}\right)$ is the relative number of beta emissions corresponding to the energy $E_{i}$. $E_{M}$ is the maximum energy of the beta emission.

$$
W_{i}=E_{i}+m_{o} c^{2}-V_{o}
$$

in which $m_{o} c^{2}$ is the electron rest mass expressed in energy units $(0.511 \mathrm{MeV})$ and $V_{o}$ is the screened potential, given by:

$$
V_{o}=\frac{1,131|Z|^{413}}{\alpha^{2}}=0.0092 \mathrm{MeV}
$$

where $\mathrm{Z}$ is the atomic number of daughter nucleus $(Z=72)$ and $\alpha$ is the fine structure constant $(\alpha=1 / 137)$ (Evans, p. 601, 1982). 
$P_{i}$ is the screened momentum given by :

$$
P_{i}=\sqrt{W_{i}^{2}-m_{o} c^{4}}
$$

$\mathrm{F}\left(\mathrm{Z}, \mathrm{W}_{\mathrm{i}}\right)$ is the Fermi function (Evans, p.548, 1982) expressed by:

$$
F\left(Z, W_{i}\right)=F_{N}\left(Z, W_{i}\right) \times F_{2}
$$

in which $F_{2}$ is given by:

$$
\begin{gathered}
\left(\frac{\alpha^{2} Z^{2} w_{i}^{2}+\left(w_{i}^{2}-1\right)}{4}\right)^{s}, \\
F_{N}\left(Z, W_{i}\right)=\frac{2 \pi v_{i}}{\left(1-e^{-2 \pi v_{i}}\right)}, \\
v_{i}=\frac{\alpha Z w_{i}}{\eta_{i}}, \\
w_{i}=\frac{W_{i}}{m_{o} c^{2}} \\
\eta_{i}=\frac{P_{i}}{m_{o} c^{2}} \\
\text { and } S=\sqrt{1-\alpha^{2} Z^{2}}-1=-0.1492
\end{gathered}
$$

$\mathrm{C}$ is a correction factor (Prestwich et al., 1989) given by:

$$
C=1+\left\lfloor a(Z-50)+b[Z-50]^{2}\right\rfloor \times\left(1-e^{-k v_{i}}\right),
$$

where $a=4.05 \times 10^{-4}$

$$
\begin{gathered}
b=2.23 \times 10^{-5} \\
k=1.26 .
\end{gathered}
$$


For calculating the beta spectrum, the maximum energy was divided into 100 energy bins. The relative number of emissions was determined for the average energy of each energy bin. Tables A.2, A.3 and A.4 show the calculations for each beta disintegration of ${ }^{177} \mathrm{Lu}$. The graphs of the beta spectra are shown in Figures A.1, A.2 and A.3.

Table A.2. Spectrum calculation and distribution of the beta emission with maximum energy of $0.498 \mathrm{MeV}(79 \%)$

\begin{tabular}{|c|c|c|c|c|c|c|c|c|c|c|}
\hline $\begin{array}{c}\text { Energy } \\
\text { bin } \\
\text { number }\end{array}$ & $\mathrm{E}(\mathrm{MeV})$ & $\mathbf{W}$ & $\mathbf{P}$ & $\mathbf{w}$ & $\eta$ & $v$ & $F_{n}$ & $\mathbf{F}_{\mathbf{2}}$ & $\mathbf{C}$ & $\mathbf{n}(\mathbf{E})$ \\
\hline 0 & 0.00249 & 511.0 & 3.20 & 1.0000 & 0.0063 & 84.0067 & 527.8307 & 1.2119 & 1.0197 & 0.02998 \\
\hline 1 & 0.00747 & 511.1 & 9.04 & 1.0002 & 0.0177 & 29.7039 & 186.6355 & 1.2118 & 1.0197 & 0.02938 \\
\hline 2 & 0.01245 & 514.3 & 57.77 & 1.0064 & 0.1131 & 4.6779 & 29.3923 & 1.2076 & 1.0169 & 0.02897 \\
\hline 3 & 0.01743 & 519.2 & 92.11 & 1.0161 & 0.1803 & 2.9625 & 18.6140 & 1.2011 & 0.9953 & 0.02816 \\
\hline 4 & 0.02241 & 524.2 & 117.0 & 1.0259 & 0.2289 & 2.3554 & 14.7993 & 1.1948 & 0.9673 & 0.02718 \\
\hline 5 & 0.02739 & 529.2 & 137.6 & 1.0356 & 0.2692 & 2.0216 & 12.7019 & 1.1887 & 0.9399 & 0.02622 \\
\hline 6 & 0.03237 & 534.2 & 155.6 & 1.0454 & 0.3046 & 1.8038 & 11.3337 & 1.1828 & 0.9146 & 0.02532 \\
\hline 7 & 0.03735 & 539.2 & 172.0 & 1.0551 & 0.3365 & 1.6478 & 10.3541 & 1.1771 & 0.8918 & 0.02450 \\
\hline 8 & 0.04233 & 544.1 & 187.0 & 1.0648 & 0.3659 & 1.5294 & 9.6101 & 1.1715 & 0.8713 & 0.02374 \\
\hline 9 & 0.04731 & 549.1 & 201.0 & 1.0746 & 0.3934 & 1.4356 & 9.0215 & 1.1661 & 0.8526 & 0.02304 \\
\hline 10 & 0.05229 & 554.1 & 214.2 & 1.0843 & 0.4193 & 1.3592 & 8.5418 & 1.1608 & 0.8358 & 0.02239 \\
\hline 11 & $\mathbf{0 . 0 5 7 2 7}$ & 559.1 & 226.8 & 1.0941 & 0.4439 & 1.2954 & 8.1418 & 1.1556 & 0.8204 & 0.02178 \\
\hline 12 & 0.06225 & 564.1 & 238.8 & 1.1038 & 0.4674 & 1.2412 & 7.8021 & 1.1506 & 0.8063 & 0.02121 \\
\hline 13 & 0.06723 & 569.0 & 250.4 & 1.1136 & 0.4899 & 1.1945 & 7.5094 & 1.1456 & 0.7933 & 0.02067 \\
\hline 14 & 0.07221 & 574.0 & 261.5 & 1.1233 & 0.5117 & 1.1537 & 7.2541 & 1.1408 & 0.7814 & 0.02016 \\
\hline 15 & 0.07719 & 579.0 & 272.2 & 1.1331 & 0.5328 & 1.1177 & 7.0291 & 1.1361 & 0.7703 & $\mathbf{0 . 0 1 9 6 8}$ \\
\hline 16 & 0.08217 & 584.0 & 282.7 & 1.1428 & 0.5532 & 1.0857 & 6.8292 & 1.1316 & 0.7601 & 0.01921 \\
\hline 17 & $\mathbf{0 . 0 8 7 1 5}$ & 589.0 & 292.8 & 1.1526 & 0.5730 & 1.0570 & 6.6501 & 1.1271 & 0.7505 & 0.01876 \\
\hline 18 & 0.09213 & 593.9 & 302.7 & 1.1623 & 0.5924 & 1.0311 & 6.4887 & 1.1227 & 0.7416 & 0.01833 \\
\hline 19 & 0.09711 & 598.9 & 312.4 & 1.1720 & 0.6113 & 1.0076 & 6.3424 & 1.1184 & 0.7332 & 0.01792 \\
\hline 20 & 0.10209 & 603.9 & 321.8 & 1.1818 & 0.6298 & 0.9862 & 6.2091 & 1.1142 & 0.7254 & 0.01752 \\
\hline 21 & 0.10707 & 608.9 & 331.1 & 1.1915 & 0.6479 & 0.9665 & 6.0870 & 1.1101 & 0.7180 & 0.01713 \\
\hline 22 & 0.11205 & 613.9 & 340.1 & 1.2013 & 0.6656 & 0.9485 & 5.9747 & 1.1060 & 0.7111 & 0.01675 \\
\hline 23 & 0.11703 & 618.8 & 349.1 & 1.2110 & 0.6831 & 0.9317 & 5.8712 & 1.1021 & 0.7045 & 0.01637 \\
\hline 24 & 0.12201 & 623.8 & 357.8 & 1.2208 & 0.7002 & 0.9163 & 5.7753 & 1.0982 & 0.6983 & 0.01601 \\
\hline 25 & 0.12699 & 628.8 & 366.4 & 1.2305 & 0.7171 & 0.9019 & 5.6863 & 1.0944 & 0.6924 & 0.01566 \\
\hline 26 & 0.13197 & 633.8 & 374.9 & 1.2403 & 0.7337 & 0.8884 & 5.6034 & 1.0907 & 0.6868 & 0.01531 \\
\hline 27 & 0.13695 & 638.8 & 383.3 & 1.2500 & 0.7500 & 0.8759 & 5.5260 & 1.0870 & 0.6815 & 0.01497 \\
\hline 28 & 0.14193 & 643.7 & 391.5 & 1.2598 & 0.7662 & 0.8641 & 5.4535 & 1.0834 & 0.6765 & 0.01463 \\
\hline 29 & 0.14691 & 648.7 & 399.6 & 1.2695 & 0.7821 & 0.8531 & 5.3855 & 1.0798 & 0.6716 & 0.01430 \\
\hline 30 & 0.15189 & 653.7 & 407.7 & 1.2792 & 0.7978 & 0.8427 & 5.3216 & 1.0763 & 0.6671 & 0.01398 \\
\hline 31 & 0.15687 & 658.7 & 415.6 & 1.2890 & 0.8133 & 0.8329 & 5.2614 & 1.0729 & 0.6627 & 0.01365 \\
\hline
\end{tabular}




\begin{tabular}{|c|c|c|c|c|c|c|c|c|c|c|}
\hline 32 & 0.16185 & 663.7 & 423.5 & 1.2987 & 0.8287 & 0.8237 & 5.2046 & 1.0696 & 0.6585 & 0.01334 \\
\hline 33 & 0.16683 & 668.6 & 431.2 & 1.3085 & 0.8439 & 0.8149 & 5.1509 & 1.0662 & 0.6545 & 0.01302 \\
\hline 34 & 0.17181 & 673.6 & 438.9 & 1.3182 & 0.8589 & 0.8066 & 5.1001 & 1.0630 & 0.6506 & 0.01271 \\
\hline 35 & 0.17679 & 678.6 & 446.5 & 1.3280 & 0.8738 & 0.7987 & 5.0519 & 1.0598 & 0.6470 & 0.01241 \\
\hline 36 & 0.18177 & 683.6 & 454.0 & 1.3377 & 0.8885 & 0.7912 & 5.0062 & 1.0566 & 0.6434 & 0.01210 \\
\hline 37 & 0.18675 & 688.6 & 461.5 & 1.3475 & 0.9031 & 0.7841 & 4.9627 & 1.0535 & 0.6400 & 0.01180 \\
\hline 38 & 0.19173 & 693.5 & 468.9 & 1.3572 & 0.9176 & 0.7773 & 4.9213 & 1.0505 & 0.6368 & 0.01151 \\
\hline 39 & 0.19671 & 698.5 & 476.2 & 1.3670 & 0.9320 & 0.7708 & 4.8818 & 1.0474 & 0.6336 & 0.01121 \\
\hline 40 & 0.20169 & 703.5 & 483.5 & 1.3767 & 0.9462 & 0.7647 & 4.8442 & 1.0445 & 0.6306 & 0.01092 \\
\hline 41 & 0.20667 & 708.5 & 490.7 & 1.3864 & 0.9603 & 0.7587 & 4.8082 & 1.0415 & 0.6277 & 0.01063 \\
\hline 42 & 0.21165 & 713.5 & 497.9 & 1.3962 & 0.9744 & 0.7531 & 4.7738 & 1.0387 & 0.6249 & 0.01034 \\
\hline 43 & 0.21663 & 718.4 & 505.0 & 1.4059 & 0.9883 & 0.7477 & 4.7409 & 1.0358 & 0.6222 & 0.01006 \\
\hline 44 & 0.22161 & 723.4 & 512.1 & 1.4157 & 1.0021 & 0.7425 & 4.7094 & 1.0330 & 0.6196 & 0.00977 \\
\hline 45 & 0.22659 & 728.4 & 519.1 & 1.4254 & 1.0158 & 0.7375 & 4.6792 & 1.0302 & 0.6171 & 0.00949 \\
\hline 46 & 0.23157 & 733.4 & 526.0 & 1.4352 & 1.0294 & 0.7327 & 4.6502 & 1.0275 & 0.6146 & 0.00921 \\
\hline 47 & 0.23655 & 738.4 & 533.0 & 1.4449 & 1.0430 & 0.7281 & 4.6224 & 1.0248 & 0.6123 & 0.00894 \\
\hline 48 & 0.24153 & 743.3 & 539.8 & 1.4547 & 1.0564 & 0.7237 & 4.5956 & 1.0222 & 0.6100 & .00867 \\
\hline 49 & 0.24651 & 748.3 & 546.7 & 1.4644 & 1.0698 & 0.7194 & 4.5698 & 1.0196 & 0.6078 & .00840 \\
\hline 50 & 0.25149 & 753.3 & 553.5 & 1.4742 & 1.0831 & 0.7153 & 4.5451 & 1.0170 & 0.6056 & .00813 \\
\hline 51 & 0.25647 & 758.3 & 560.2 & 1.4839 & 1.0963 & 0.7113 & 4.5212 & 1.0144 & 0.6036 & .00786 \\
\hline 52 & 0.26145 & 763.3 & 567.0 & 1.4937 & 1.1095 & 0.7075 & 4.4982 & 1.0119 & 0.6016 & 0.00760 \\
\hline 53 & 0.26643 & 768.2 & 573.6 & 1.5034 & 1.1226 & 0.7038 & 4.4760 & 1.0094 & 0.5996 & .00734 \\
\hline 54 & 0.27141 & 773.2 & 580.3 & 1.5131 & 1.1356 & 0.7003 & 4.4546 & 1.0069 & 0.5977 & 0.00708 \\
\hline 55 & 0.27639 & 778.2 & 586.9 & 1.5229 & 1.1486 & 0.6968 & 4.4340 & 1.0045 & 0.5959 & .00682 \\
\hline 56 & 0.28137 & 783.2 & 593.5 & 1.5326 & 1.1614 & 0.6935 & 4.4140 & 1.0021 & 0.5941 & .00657 \\
\hline 57 & 0.28635 & 788.2 & 600.1 & 1.5424 & 1.1743 & 0.6903 & 4.3947 & 0.9997 & 0.5924 & .00632 \\
\hline 58 & 0.29133 & 793.1 & 606.6 & 1.5521 & 1.1871 & 0.6872 & 4.3760 & 0.9974 & 0.5907 & .00607 \\
\hline 59 & 0.29631 & 798.1 & 613.1 & 1.5619 & 1.1998 & 0.6842 & 4.3579 & 0.9951 & 5891 & 00583 \\
\hline 60 & 0.30129 & 803.1 & 619.5 & 1.5716 & 1.2124 & 0.6812 & 4.3405 & 0.9928 & 0.5875 & 0.00558 \\
\hline 61 & 0.30627 & 808.1 & 626.0 & 1.5814 & 1.2250 & 0.6784 & 4.3235 & 0.9905 & .5860 & .00535 \\
\hline 62 & 0.31125 & 813.1 & 632.4 & 1.5911 & 1.2376 & 0.6757 & 4.3071 & 0.9883 & 0.5845 & .00511 \\
\hline 63 & 0.31623 & 818.0 & 638.8 & 1.6009 & 1.2501 & 0.6730 & 4.2912 & 0.9861 & 0.5830 & 00488 \\
\hline 64 & 0.32121 & 823.0 & 645.2 & 1.6106 & 1.2625 & 0.6704 & 4.2758 & 0.9839 & 0.5816 & .00465 \\
\hline 65 & 0.32619 & 828.0 & 651.5 & 1.6203 & 1.2750 & 0.6679 & 4.2608 & 0.9817 & 0.5802 & .00443 \\
\hline 66 & 0.33117 & 833.0 & 657.8 & 1.6301 & 1.2873 & 0.6655 & 4.2462 & 0.9796 & 0.5788 & .00421 \\
\hline 67 & 3615 & 838.0 & 664.1 & 1.6398 & 1.2996 & 0.6631 & 4.2321 & 0.9774 & 0.5775 & .00399 \\
\hline 68 & 0.34113 & 842.9 & 670.4 & 1.6496 & 1.3119 & 0.6608 & 4.2184 & 0.9753 & 0.5762 & .00378 \\
\hline 69 & 0.34611 & 847.9 & 676.6 & 1.6593 & 1.3241 & 0.6586 & 4.2051 & 0.9733 & 0.5750 & .00357 \\
\hline 70 & 0.35109 & 852.9 & 682.9 & 1.6691 & 1.3363 & 0.6564 & 4.1921 & 0.9712 & 0.5738 & .00336 \\
\hline 71 & 0.35607 & 857.9 & 689.1 & 1.6788 & 1.3485 & 0.6543 & 4.1795 & 0.9692 & 0.5726 & 0.00316 \\
\hline 72 & 0.36105 & 862.9 & 695.3 & 1.6886 & 1.3606 & 0.6522 & 4.1673 & 0.9672 & 0.5714 & 0.00297 \\
\hline 73 & 0.36603 & 867.8 & 701.4 & 1.6983 & 1.3727 & 0.6502 & 4.1553 & 0.9652 & 0.5703 & 0.00278 \\
\hline 74 & 0.37101 & 872.8 & 707.6 & 1.7081 & 1.3847 & 0.6483 & 4.1437 & 0.9632 & 0.5692 & 0.00259 \\
\hline 75 & 0.37599 & 877.8 & 713.7 & 1.7178 & 1.3967 & 0.6464 & 4.1324 & 0.9613 & 0.5681 & 0.00241 \\
\hline 76 & 0.38097 & 882.8 & 719.8 & 1.7275 & 1.4087 & 0.6445 & 4.1214 & 0.9593 & 0.5670 & 0.00224 \\
\hline 77 & 0.38595 & 887.8 & 725.9 & 1.7373 & 1.4206 & 0.6427 & 4.1106 & 0.9574 & 0.5660 & 0.00207 \\
\hline 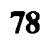 & 0.39093 & 892.7 & 732.0 & 1.7470 & 1.4325 & 0.6409 & 4.1002 & 0.9555 & 0.5650 & 0.00190 \\
\hline 79 & 0.39591 & 897.7 & 738.1 & 1.7568 & 1.4444 & 0.6392 & 4.0900 & 0.9536 & 0.5640 & 0.00174 \\
\hline & 0.40089 & 902.7 & 744.1 & 1.7665 & 1.4562 & 0.6375 & 4.0800 & 0.9518 & 0.5630 & 0.00159 \\
\hline
\end{tabular}




\begin{tabular}{|l|l|l|l|l|l|l|l|l|l|l|}
$\mathbf{8 1}$ & $\mathbf{0 . 4 0 5 8 7}$ & 907.7 & 750.2 & 1.7763 & 1.4680 & 0.6359 & 4.0703 & 0.9499 & 0.5621 & $\mathbf{0 . 0 0 1 4 4}$ \\
$\mathbf{8 2}$ & $\mathbf{0 . 4 1 0 8 5}$ & 912.7 & 756.2 & 1.7860 & 1.4798 & 0.6343 & 4.0609 & 0.9481 & 0.5612 & $\mathbf{0 . 0 0 1 3 0}$ \\
$\mathbf{8 3}$ & $\mathbf{0 . 4 1 5 8 3}$ & 917.6 & 762.2 & 1.7958 & 1.4916 & 0.6327 & 4.0516 & 0.9463 & 0.5603 & $\mathbf{0 . 0 0 1 1 6}$ \\
$\mathbf{8 4}$ & $\mathbf{0 . 4 2 0 8 1}$ & 922.6 & 768.2 & 1.8055 & 1.5033 & 0.6312 & 4.0426 & 0.9445 & 0.5594 & $\mathbf{0 . 0 0 1 0 3}$ \\
$\mathbf{8 5}$ & $\mathbf{0 . 4 2 5 7 9}$ & 927.6 & 774.2 & 1.8153 & 1.5150 & 0.6297 & 4.0338 & 0.9427 & 0.5585 & $\mathbf{0 . 0 0 0 9 1}$ \\
$\mathbf{8 6}$ & $\mathbf{0 . 4 3 0 7 7}$ & 932.6 & 780.1 & 1.8250 & 1.5266 & 0.6283 & 4.0252 & 0.9410 & 0.5577 & $\mathbf{0 . 0 0 0 8 0}$ \\
$\mathbf{8 7}$ & $\mathbf{0 . 4 3 5 7 5}$ & 937.6 & 786.1 & 1.8347 & 1.5383 & 0.6268 & 4.0168 & 0.9392 & 0.5568 & $\mathbf{0 . 0 0 0 6 9}$ \\
$\mathbf{8 8}$ & $\mathbf{0 . 4 4 0 7 3}$ & 942.5 & 792.0 & 1.8445 & 1.5499 & 0.6254 & 4.0085 & 0.9375 & 0.5560 & $\mathbf{0 . 0 0 0 5 9}$ \\
$\mathbf{8 9}$ & $\mathbf{0 . 4 4 5 7 1}$ & 947.5 & 797.9 & 1.8542 & 1.5615 & 0.6241 & 4.0005 & 0.9358 & 0.5552 & $\mathbf{0 . 0 0 0 4 9}$ \\
$\mathbf{9 0}$ & $\mathbf{0 . 4 5 0 6 9}$ & 952.5 & 803.8 & 1.8640 & 1.5730 & 0.6228 & 3.9927 & 0.9341 & 0.5544 & $\mathbf{0 . 0 0 0 4 1}$ \\
$\mathbf{9 1}$ & $\mathbf{0 . 4 5 5 6 7}$ & 957.5 & 809.7 & 1.8737 & 1.5846 & 0.6215 & 3.9850 & 0.9324 & 0.5537 & $\mathbf{0 . 0 0 0 3 3}$ \\
$\mathbf{9 2}$ & $\mathbf{0 . 4 6 0 6 5}$ & 962.5 & 815.6 & 1.8835 & 1.5961 & 0.6202 & 3.9775 & 0.9307 & 0.5529 & $\mathbf{0 . 0 0 0 2 6}$ \\
$\mathbf{9 3}$ & $\mathbf{0 . 4 6 5 6 3}$ & 967.4 & 821.5 & 1.8932 & 1.6076 & 0.6189 & 3.9701 & 0.9291 & 0.5522 & $\mathbf{0 . 0 0 0 1 9}$ \\
$\mathbf{9 4}$ & $\mathbf{0 . 4 7 0 6 1}$ & 972.4 & 827.3 & 1.9030 & 1.6190 & 0.6177 & 3.9629 & 0.9275 & 0.5515 & $\mathbf{0 . 0 0 0 1 4}$ \\
$\mathbf{9 5}$ & $\mathbf{0 . 4 7 5 5 9}$ & 977.4 & 833.2 & 1.9127 & 1.6305 & 0.6165 & 3.9559 & 0.9258 & 0.5508 & $\mathbf{0 . 0 0 0 0 9 5}$ \\
$\mathbf{9 6}$ & $\mathbf{0 . 4 8 0 5 7}$ & 982.4 & 839.0 & 1.9225 & 1.6419 & 0.6153 & 3.9490 & 0.9242 & 0.5501 & $\mathbf{0 . 0 0 0 0 5 8}$ \\
$\mathbf{9 7}$ & $\mathbf{0 . 4 8 5 5 5}$ & 987.4 & 844.8 & 1.9322 & 1.6533 & 0.6142 & 3.9423 & 0.9226 & 0.5494 & $\mathbf{0 . 0 0 0 0 3 0}$ \\
$\mathbf{9 8}$ & $\mathbf{0 . 4 9 0 5 3}$ & 992.3 & 850.7 & 1.9419 & 1.6647 & 0.6131 & 3.9357 & 0.9210 & 0.5487 & $\mathbf{0 . 0 0 0 0 1 1}$ \\
$\mathbf{9 9}$ & $\mathbf{0 . 4 9 5 5 1}$ & 997.3 & 856.5 & 1.9517 & 1.6760 & 0.6120 & 3.9292 & 0.9195 & 0.5481 & $\mathbf{0 . 0 0 0 0 0 1}$ \\
\hline
\end{tabular}

Figure A.1 Beta Spectrum of ${ }^{177}$ Lu with Maximum Energy of $0.498 \mathrm{MeV}(79 \%)$

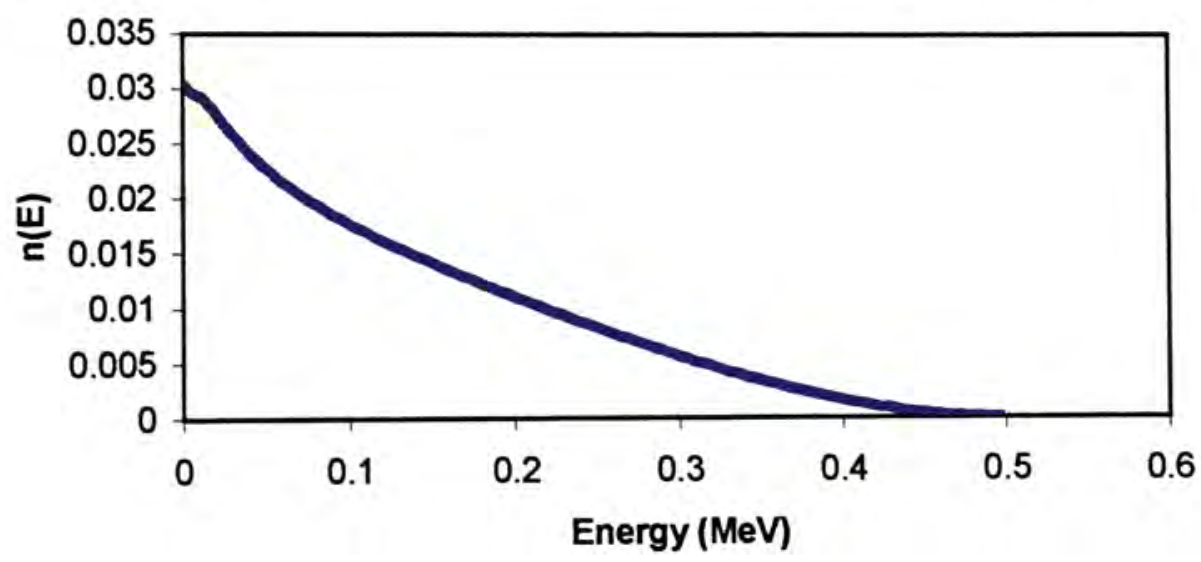


Table A.3. Spectrum calculation and distribution of the beta emission with maximum energy of $0.385 \mathrm{MeV}(9.1 \%)$

\begin{tabular}{|c|c|c|c|c|c|c|c|c|c|c|}
\hline $\begin{array}{c}\begin{array}{c}\text { Energy } \\
\text { bin } \\
\text { number }\end{array} \\
\end{array}$ & $\mathrm{E}(\mathrm{MeV})$ & $\mathbf{W}$ & $\mathbf{P}$ & $\mathbf{w}$ & $\eta$ & $v$ & $\mathbf{F}_{\mathbf{n}}$ & $\mathbf{F}_{2}$ & C & $\mathbf{n}(\mathbf{E})$ \\
\hline $\mathbf{0}$ & 0.00249 & 511.0 & 3.20 & 1.0000 & 0.0063 & 84.0067 & 527.8307 & 1.2119 & 1.0197 & 0.03951 \\
\hline 1 & 0.00747 & 511.1 & 9.04 & 1.0002 & 0.0177 & 29.7039 & 186.6355 & 1.2118 & 1.0197 & 0.03849 \\
\hline 2 & 0.01245 & 514.3 & 57.77 & 1.0064 & 0.1131 & 4.6779 & 29.3923 & 1.2076 & 1.0169 & 0.03772 \\
\hline 3 & 0.01743 & 519.2 & 92.11 & 1.0161 & 0.1803 & 2.9625 & 18.6140 & 1.2011 & 0.9953 & 0.03644 \\
\hline 4 & 0.02241 & 524.2 & 117.0 & 1.0259 & 0.2289 & 2.3554 & 14.7993 & 1.1948 & 0.9673 & 0.03494 \\
\hline 5 & 0.02739 & 529.2 & 137.6 & 1.0356 & 0.2692 & 2.0216 & 12.7019 & 1.1887 & 0.9399 & 0.03349 \\
\hline 6 & 0.03237 & 534.2 & 155.6 & 1.0454 & 0.3046 & 1.8038 & 11.3337 & 1.1828 & 0.9146 & 0.03213 \\
\hline 7 & 0.03735 & 539.2 & 172.0 & 1.0551 & 0.3365 & 1.6478 & 10.3541 & 1.1771 & 0.8918 & 0.03087 \\
\hline 8 & 0.04233 & 544.1 & 187.0 & 1.0648 & 0.3659 & 1.5294 & 9.6101 & 1.1715 & 0.8713 & 0.02970 \\
\hline 9 & 0.04731 & 549.1 & 201.0 & 1.0746 & 0.3934 & 1.4356 & 9.0215 & 1.1661 & 0.8526 & 0.02862 \\
\hline 10 & 0.05229 & 554.1 & 214.2 & 1.0843 & 0.4193 & 1.3592 & 8.5418 & 1.1608 & 0.8358 & 0.02760 \\
\hline 11 & 0.05727 & 559.1 & 226.8 & 1.0941 & 0.4439 & 1.2954 & 8.1418 & 1.1556 & 0.8204 & 0.02665 \\
\hline 12 & 0.06225 & 564.1 & 238.8 & 1.1038 & 0.4674 & 1.2412 & 7.8021 & 1.1506 & 0.8063 & 0.02575 \\
\hline 13 & 0.06723 & 569.0 & 250.4 & 1.1136 & 0.4899 & 1.1945 & 7.5094 & 1.1456 & 0.7933 & 0.02489 \\
\hline 14 & 0.07221 & 574.0 & 261.5 & 1.1233 & 0.5117 & 1.1537 & 7.2541 & 1.1408 & 0.7814 & 0.02407 \\
\hline 15 & 0.07719 & 579.0 & 272.2 & 1.1331 & 0.5328 & 1.1177 & 7.0291 & 1.1361 & 0.7703 & 0.02329 \\
\hline 16 & 0.08217 & 584.0 & 282.7 & 1.1428 & 0.5532 & 1.0857 & 6.8292 & 1.1316 & 0.7601 & 0.02254 \\
\hline 17 & 0.08715 & 589.0 & 292.8 & 1.1526 & 0.5730 & 1.0570 & 6.6501 & 1.1271 & 0.7505 & 0.02182 \\
\hline 18 & 0.09213 & 593.9 & 302.7 & 1.1623 & 0.5924 & 1.0311 & 6.4887 & 1.1227 & 0.7416 & 0.02112 \\
\hline 19 & 0.09711 & 598.9 & 312.4 & 1.1720 & 0.6113 & 1.0076 & 6.3424 & 1.1184 & 0.7332 & 0.02045 \\
\hline 20 & 0.10209 & 603.9 & 321.8 & 1.1818 & 0.6298 & 0.9862 & 6.2091 & 1.1142 & 0.7254 & 0.01979 \\
\hline 21 & 0.10707 & 608.9 & 331.1 & 1.1915 & 0.6479 & 0.9665 & 6.0870 & 1.1101 & 0.7180 & 0.01916 \\
\hline 22 & 0.11205 & 613.9 & 340.1 & 1.2013 & 0.6656 & 0.9485 & 5.9747 & 1.1060 & 0.7111 & 0.01854 \\
\hline 23 & 0.11703 & 618.8 & 349.1 & 1.2110 & 0.6831 & 0.9317 & 5.8712 & 1.1021 & 0.7045 & 0.01793 \\
\hline 24 & 0.12201 & 623.8 & 357.8 & 1.2208 & 0.7002 & 0.9163 & 5.7753 & 1.0982 & 0.6983 & 0.01734 \\
\hline 25 & 0.12699 & 628.8 & 366.4 & 1.2305 & 0.7171 & 0.9019 & 5.6863 & 1.0944 & 0.6924 & 0.01676 \\
\hline 26 & 0.13197 & 633.8 & 374.9 & 1.2403 & 0.7337 & 0.8884 & 5.6034 & 1.0907 & 0.6868 & 0.01620 \\
\hline 27 & 0.13695 & 638.8 & 383.3 & 1.2500 & 0.7500 & 0.8759 & 5.5260 & 1.0870 & 0.6815 & 0.01564 \\
\hline 28 & 0.14193 & 643.7 & 391.5 & 1.2598 & 0.7662 & 0.8641 & 5.4535 & 1.0834 & 0.6765 & 0.01510 \\
\hline 29 & 0.14691 & 648.7 & 399.6 & 1.2695 & 0.7821 & 0.8531 & 5.3855 & 1.0798 & 0.6716 & 0.01456 \\
\hline 30 & 0.15189 & 653.7 & 407.7 & 1.2792 & 0.7978 & 0.8427 & 5.3216 & 1.0763 & 0.6671 & 0.01404 \\
\hline 31 & 0.15687 & 658.7 & 415.6 & 1.2890 & 0.8133 & 0.8329 & 5.2614 & 1.0729 & 0.6627 & 0.01352 \\
\hline 32 & 0.16185 & 663.7 & 423.5 & 1.2987 & 0.8287 & 0.8237 & 5.2046 & 1.0696 & 0.6585 & 0.01302 \\
\hline 33 & 0.16683 & 668.6 & 431.2 & 1.3085 & 0.8439 & 0.8149 & 5.1509 & 1.0662 & 0.6545 & 0.01252 \\
\hline 34 & 0.17181 & 673.6 & 438.9 & 1.3182 & 0.8589 & 0.8066 & 5.1001 & 1.0630 & 0.6506 & 0.01203 \\
\hline 35 & 0.17679 & 678.6 & 446.5 & 1.3280 & 0.8738 & 0.7987 & 5.0519 & 1.0598 & 0.6470 & 0.01155 \\
\hline 36 & 0.18177 & 683.6 & 454.0 & 1.3377 & 0.8885 & 0.7912 & 5.0062 & 1.0566 & 0.6434 & 0.01108 \\
\hline 37 & 0.18675 & 688.6 & 461.5 & 1.3475 & 0.9031 & 0.7841 & 4.9627 & 1.0535 & $0.6400 \mid$ & 0.01061 \\
\hline 38 & 0.19173 & 693.5 & 468.9 & 1.3572 & 0.9176 & 0.7773 & 4.9213 & 1.0505 & 0.6368 & 0.01015 \\
\hline 39 & 0.19671 & 698.5 & 476.2 & 1.3670 & 0.9320 & 0.7708 & 4.8818 & 1.0474 & 0.6336 & 0.00970 \\
\hline 40 & 0.20169 & 703.5 & 483.5 & 1.3767 & 0.9462 & 0.7647 & 4.8442 & 1.0445 & 0.6306 & 0.00926 \\
\hline 41 & 0.20667 & 708.5 & 490.7 & 1.3864 & 0.9603 & 0.7587 & 4.8082 & 1.0415 & 0.6277 & 0.00883 \\
\hline 42 & $|0.21165|$ & 713.5 & 497.9 & 1.3962 & 0.9744 & 0.7531 & 4.7738 & 1.0387 & $|0.6249|$ & $\mid 0.00840$ \\
\hline
\end{tabular}




\begin{tabular}{|c|c|c|c|c|c|c|c|c|c|c|}
\hline 43 & 0.21663 & 718.4 & 505.0 & 1.4059 & 0.9883 & 0.7477 & 4.7409 & 1.0358 & 0.6222 & 0.00798 \\
\hline 44 & 0.22161 & 723.4 & 512.1 & 1.4157 & 1.0021 & 0.7425 & 4.7094 & 1.0330 & 0.6196 & 0.00757 \\
\hline 45 & 0.22659 & 728.4 & 519.1 & 1.4254 & 1.0158 & 0.7375 & 4.6792 & 1.0302 & 0.6171 & 0.00717 \\
\hline 46 & 0.23157 & 733.4 & 526.0 & 1.4352 & 1.0294 & 0.7327 & 4.6502 & 1.0275 & 0.6146 & 0.00678 \\
\hline 47 & 0.23655 & 738.4 & 533.0 & 1.4449 & 1.0430 & 0.7281 & 4.6224 & 1.0248 & 0.6123 & 0.00639 \\
\hline 48 & 0.24153 & 743.3 & 539.8 & 1.4547 & 1.0564 & 0.7237 & 4.5956 & 1.0222 & 0.6100 & 0.00602 \\
\hline 49 & 0.24651 & 748.3 & 546.7 & 1.4644 & 1.0698 & 0.7194 & 4.5698 & 1.0196 & 0.6078 & 0.00565 \\
\hline 50 & 0.25149 & 753.3 & 553.5 & 1.4742 & 1.0831 & 0.7153 & 4.5451 & 1.0170 & 0.6056 & 0.00529 \\
\hline 51 & 0.25647 & 758.3 & 560.2 & 1.4839 & 1.0963 & 0.7113 & 4.5212 & 1.0144 & 0.6036 & 0.00494 \\
\hline 52 & 0.26145 & 763.3 & 567.0 & 1.4937 & 1.1095 & 0.7075 & 4.4982 & 1.0119 & 0.6016 & 0.00460 \\
\hline 53 & 0.26643 & 768.2 & 573.6 & 1.5034 & 1.1226 & 0.7038 & 4.4760 & 1.0094 & 0.5996 & 0.00427 \\
\hline 54 & 0.27141 & 773.2 & 580.3 & 1.5131 & 1.1356 & 0.7003 & 4.4546 & 1.0069 & 0.5977 & 0.00395 \\
\hline 55 & 0.27639 & 778.2 & 586.9 & 1.5229 & 1.1486 & 0.6968 & 4.4340 & 1.0045 & 0.5959 & 0.00364 \\
\hline 56 & 0.28137 & 783.2 & 593.5 & 1.5326 & 1.1614 & 0.6935 & 4.4140 & 1.0021 & 0.5941 & 0.00334 \\
\hline 57 & 0.28635 & 788.2 & 600.1 & 1.5424 & 1.1743 & 0.6903 & 4.3947 & 0.9997 & 0.5924 & 0.00305 \\
\hline 58 & 0.29133 & 793.1 & 606.6 & 1.5521 & 1.1871 & 0.6872 & 4.3760 & 0.9974 & 0.5907 & 0.00278 \\
\hline 59 & 0.29631 & 798.1 & 613.1 & 1.5619 & 1.1998 & 0.6842 & 4.3579 & 0.9951 & 0.5891 & 0.00251 \\
\hline 60 & 0.30129 & 803.1 & 619.5 & 1.5716 & 1.2124 & 0.6812 & 4.3405 & 0.9928 & 0.5875 & 0.00225 \\
\hline 61 & 0.30627 & 808.1 & 626.0 & 1.5814 & 1.2250 & 0.6784 & 4.3235 & 0.9905 & 0.5860 & 0.00201 \\
\hline 62 & 0.31125 & 813.1 & 632.4 & 1.5911 & 1.2376 & 0.6757 & 4.3071 & 0.9883 & 0.5845 & 0.00178 \\
\hline 63 & 0.31623 & 818.0 & 638.8 & 1.6009 & 1.2501 & 0.6730 & 4.2912 & 0.9861 & 0.5830 & 0.00156 \\
\hline 64 & 0.32121 & 823.0 & 645.2 & 1.6106 & 1.2625 & 0.6704 & 4.2758 & 0.9839 & 0.5816 & 0.00135 \\
\hline 65 & 0.32619 & 828.0 & 651.5 & 1.6203 & 1.2750 & 0.6679 & 4.2608 & 0.9817 & 0.5802 & 0.00116 \\
\hline 66 & 0.33117 & 833.0 & 657.8 & 1.6301 & 1.2873 & 0.6655 & 4.2462 & 0.9796 & 0.5788 & 0.00098 \\
\hline 67 & 0.33615 & 838.0 & 664.1 & 1.6398 & 1.2996 & 0.6631 & 4.2321 & 0.9774 & 0.5775 & 0.00082 \\
\hline 68 & 0.34113 & 842.9 & 670.4 & 1.6496 & 1.3119 & 0.6608 & 4.2184 & 0.9753 & 0.5762 & 0.00066 \\
\hline 69 & 0.34611 & 847.9 & 676.6 & 1.6593 & 1.3241 & 0.6586 & 4.2051 & 0.9733 & 0.5750 & 0.00053 \\
\hline 70 & 0.35109 & 852.9 & 682.9 & 1.6691 & 1.3363 & 0.6564 & 4.1921 & 0.9712 & 0.5738 & 0.00040 \\
\hline 71 & 0.35607 & 857.9 & 689.1 & 1.6788 & 1.3485 & 0.6543 & 4.1795 & 0.9692 & 0.5726 & 0.00030 \\
\hline 72 & 0.36105 & 862.9 & 695.3 & 1.6886 & 1.3606 & 0.6522 & 4.1673 & 0.9672 & 0.5714 & 0.00021 \\
\hline 73 & 0.36603 & 867.8 & 701.4 & 1.6983 & 1.3727 & 0.6502 & 4.1553 & 0.9652 & 0.5703 & 0.00013 \\
\hline 74 & 0.37101 & 872.8 & 707.6 & 1.7081 & 1.3847 & 0.6483 & 4.1437 & 0.9632 & 0.5692 & 7.3E-05 \\
\hline 75 & 0.37599 & 877.8 & 713.7 & 1.7178 & 1.3967 & 0.6464 & 4.1324 & 0.9613 & 0.5681 & 3.2E-05 \\
\hline 76 & 0.38097 & 882.8 & 719.8 & 1.7275 & 1.4087 & 0.6445 & 4.1214 & 0.9593 & 0.5670 & $7.1 \mathrm{E}-06$ \\
\hline
\end{tabular}


Figure A.2 Beta Spectrum of ${ }^{177} \mathrm{Lu}$ with Maximum Energy of $0.385 \mathrm{MeV}(9.1 \%)$

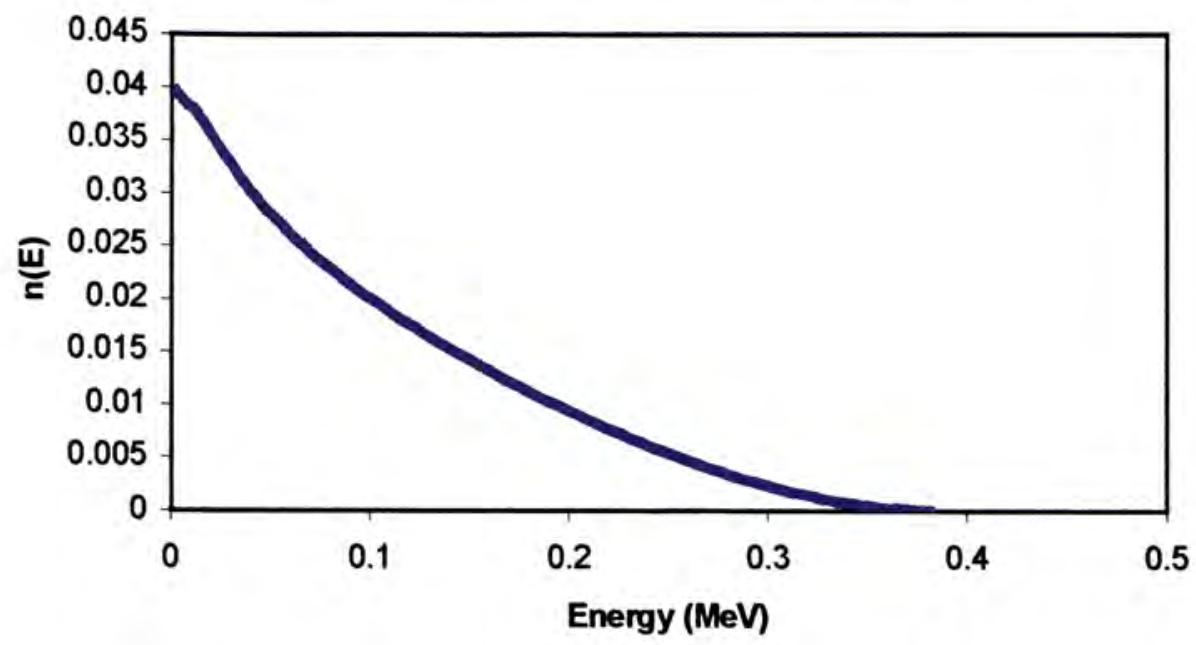

Table A.4. Spectrum calculation and distribution of the beta emission with maximum energy of $0.177 \mathrm{MeV}(12.0 \%)$

\begin{tabular}{|c|c|c|c|c|c|c|c|c|c|c|}
\hline $\begin{array}{c}\text { Energy } \\
\text { bin } \\
\text { number }\end{array}$ & $\mathrm{E}(\mathrm{MeV})$ & $\mathbf{W}$ & $\mathbf{P}$ & $\mathbf{w}$ & $\eta$ & $v$ & $F_{n}$ & $\mathbf{F}_{\mathbf{2}}$ & $\mathbf{C}$ & $\mathbf{n}(\mathbf{E})$ \\
\hline 0 & 0.00249 & 511.0 & 3.20 & 1.0000 & 0.0063 & 84.0067 & 527.8307 & 1.2119 & 1.0197 & 0.08591 \\
\hline 1 & 0.00747 & 511.1 & 9.04 & 1.0002 & 0.0177 & 29.7039 & 186.6355 & 1.2118 & 1.0197 & 0.08109 \\
\hline 2 & 0.01245 & 514.3 & 57.77 & 1.0064 & 0.1131 & 4.6779 & 29.3923 & 1.2076 & 1.0169 & 0.07687 \\
\hline 3 & 0.01743 & 519.2 & 92.11 & 1.0161 & 0.1803 & 2.9625 & 18.6140 & 1.2011 & 0.9953 & 0.07174 \\
\hline 4 & 0.02241 & 524.2 & 117.0 & 1.0259 & 0.2289 & 2.3554 & 14.7993 & 1.1948 & 0.9673 & 0.06635 \\
\hline 5 & 0.02739 & 529.2 & 137.6 & 1.0356 & 0.2692 & 2.0216 & 12.7019 & 1.1887 & 0.9399 & 0.06122 \\
\hline 6 & 0.03237 & 534.2 & 155.6 & 1.0454 & 0.3046 & 1.8038 & 11.3337 & 1.1828 & 0.9146 & 0.05645 \\
\hline 7 & 0.03735 & 539.2 & 172.0 & 1.0551 & 0.3365 & 1.6478 & 10.3541 & 1.1771 & 0.8918 & 0.05203 \\
\hline 8 & 0.04233 & 544.1 & 187.0 & 1.0648 & 0.3659 & 1.5294 & 9.6101 & 1.1715 & 0.8713 & 0.04791 \\
\hline 9 & 0.04731 & 549.1 & 201.0 & 1.0746 & 0.3934 & 1.4356 & 9.0215 & 1.1661 & 0.8526 & 0.04408 \\
\hline 10 & 0.05229 & 554.1 & 214.2 & 1.0843 & 0.4193 & 1.3592 & 8.5418 & 1.1608 & 0.8358 & 0.04050 \\
\hline 11 & 0.05727 & 559.1 & 226.8 & 1.0941 & 0.4439 & 1.2954 & 8.1418 & 1.1556 & 0.8204 & 0.03714 \\
\hline 12 & 0.06225 & 564.1 & 238.8 & 1.1038 & 0.4674 & 1.2412 & 7.8021 & 1.1506 & 0.8063 & 0.03399 \\
\hline 13 & 0.06723 & 569.0 & 250.4 & 1.1136 & 0.4899 & 1.1945 & 7.5094 & 1.1456 & 0.7933 & 0.03102 \\
\hline 14 & 0.07221 & 574.0 & 261.5 & 1.1233 & 0.5117 & 1.1537 & 7.2541 & 1.1408 & 0.7814 & 0.02822 \\
\hline 15 & 0.07719 & 579.0 & 272.2 & 1.1331 & 0.5328 & 1.1177 & 7.0291 & 1.1361 & 0.7703 & 0.02557 \\
\hline 16 & 0.08217 & 584.0 & 282.7 & 1.1428 & 0.5532 & 1.0857 & 6.8292 & 1.1316 & 0.7601 & 0.02308 \\
\hline 17 & 0.08715 & 589.0 & 292.8 & 1.1526 & 0.5730 & 1.0570 & 6.6501 & 1.1271 & 0.7505 & 0.02073 \\
\hline 18 & 0.09213 & 593.9 & 302.7 & 1.1623 & 0.5924 & 1.0311 & 6.4887 & 1.1227 & 0.7416 & 0.01852 \\
\hline 19 & 0.09711 & 598.9 & 312.4 & 1.1720 & 0.6113 & 1.0076 & 6.3424 & 1.1184 & 0.7332 & 0.01644 \\
\hline 20 & 0.10209 & 603.9 & 321.8 & 1.1818 & 0.6298 & 0.9862 & 6.2091 & 1.1142 & 0.7254 & 0.01449 \\
\hline 21 & 0.10707 & 608.9 & 331.1 & 1.1915 & 0.6479 & 0.9665 & 6.0870 & 1,1101 & 0.7180 & 0.01266 \\
\hline 22 & 0.11205 & 613.9 & 340.1 & 1.2013 & 0.6656 & 0.9485 & 5.9747 & 1.1060 & 0.7111 & 0.01096 \\
\hline 23 & $|0.11703|$ & 618.8 & 349.1 & 1.2110 & 0.6831 & 0.9317 & 5.8712 & 1.1021 & 0.7045 & 0.00937 \\
\hline
\end{tabular}




\begin{tabular}{|l|l|l|l|l|l|l|l|l|l|l|}
$\mathbf{2 4}$ & $\mathbf{0 . 1 2 2 0 1}$ & 623.8 & 357.8 & 1.2208 & 0.7002 & 0.9163 & 5.7753 & 1.0982 & 0.6983 & $\mathbf{0 . 0 0 7 9 1}$ \\
$\mathbf{2 5}$ & $\mathbf{0 . 1 2 6 9 9}$ & 628.8 & 366.4 & 1.2305 & 0.7171 & 0.9019 & 5.6863 & 1.0944 & 0.6924 & $\mathbf{0 . 0 0 6 5 7}$ \\
$\mathbf{2 6}$ & $\mathbf{0 . 1 3 1 9 7}$ & 633.8 & 374.9 & 1.2403 & 0.7337 & 0.8884 & 5.6034 & 1.0907 & 0.6868 & $\mathbf{0 . 0 0 5 3 5}$ \\
$\mathbf{2 7}$ & $\mathbf{0 . 1 3 6 9 5}$ & 638.8 & 383.3 & 1.2500 & 0.7500 & 0.8759 & 5.5260 & 1.0870 & 0.6815 & $\mathbf{0 . 0 0 4 2 6}$ \\
$\mathbf{2 8}$ & $\mathbf{0 . 1 4 1 9 3}$ & 643.7 & 391.5 & 1.2598 & 0.7662 & 0.8641 & 5.4535 & 1.0834 & 0.6765 & $\mathbf{0 . 0 0 3 2 8}$ \\
$\mathbf{2 9}$ & $\mathbf{0 . 1 4 6 9 1}$ & 648.7 & 399.6 & 1.2695 & 0.7821 & 0.8531 & 5.3855 & 1.0798 & 0.6716 & $\mathbf{0 . 0 0 2 4 3}$ \\
$\mathbf{3 0}$ & $\mathbf{0 . 1 5 1 8 9}$ & 653.7 & 407.7 & 1.2792 & 0.7978 & 0.8427 & 5.3216 & 1.0763 & 0.6671 & $\mathbf{0 . 0 0 1 7 0}$ \\
$\mathbf{3 1}$ & $\mathbf{0 . 1 5 6 8 7}$ & 658.7 & 415.6 & 1.2890 & 0.8133 & 0.8329 & 5.2614 & 1.0729 & 0.6627 & $\mathbf{0 . 0 0 1 1 0}$ \\
$\mathbf{3 2}$ & $\mathbf{0 . 1 6 1 8 5}$ & 663.7 & 423.5 & 1.2987 & 0.8287 & 0.8237 & 5.2046 & 1.0696 & 0.6585 & $\mathbf{0 . 0 0 0 6 3}$ \\
$\mathbf{3 3}$ & $\mathbf{0 . 1 6 6 8 3}$ & 668.6 & 431.2 & 1.3085 & 0.8439 & 0.8149 & 5.1509 & 1.0662 & 0.6545 & $\mathbf{0 . 0 0 0 2 8}$ \\
$\mathbf{3 4}$ & $\mathbf{0 . 1 7 1 8 1}$ & 673.6 & 438.9 & 1.3182 & 0.8589 & 0.8066 & 5.1001 & 1.0630 & 0.6506 & $\mathbf{7 . 4 E - 0 5}$ \\
$\mathbf{3 5}$ & $\mathbf{0 . 1 7 6 7 9}$ & 678.6 & 446.5 & 1.3280 & 0.8738 & 0.7987 & 5.0519 & 1.0598 & 0.6470 & $\mathbf{1 . 2 E}-\mathbf{0 7}$ \\
\hline
\end{tabular}

Figure A.3 Beta Spectrum of ${ }^{177}$ Lu with Maximum Energy of $0.177 \mathrm{MeV}(12.0 \%)$

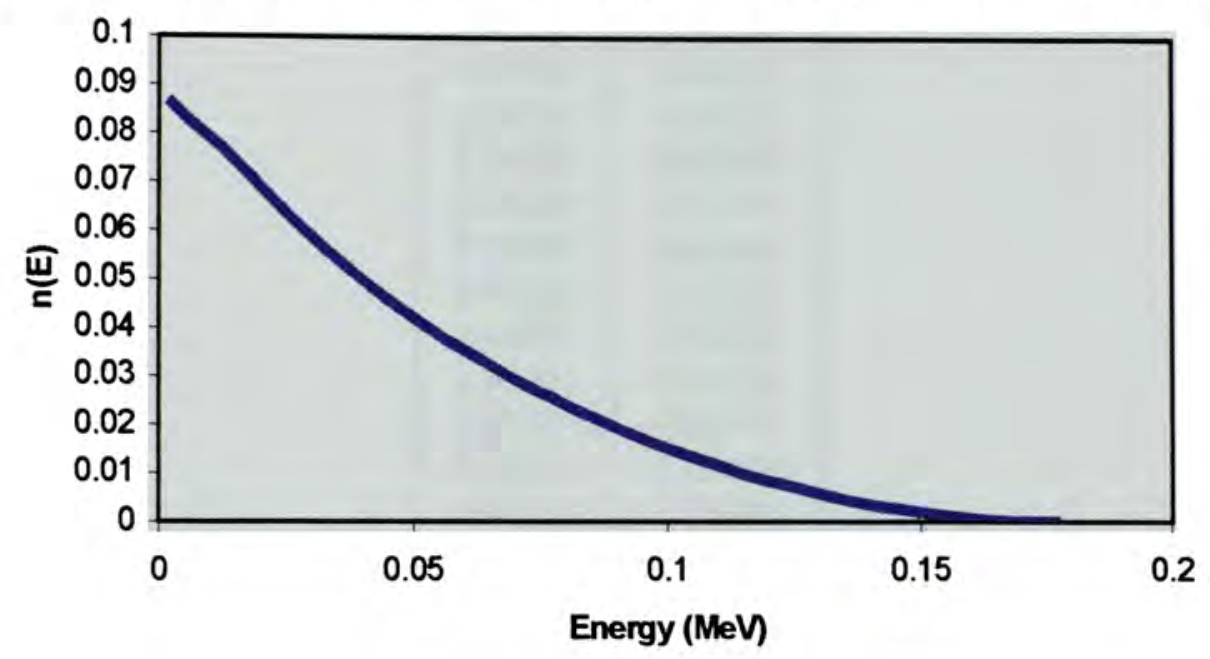

The complete spectrum including the three beta emissions was determined by adding the individual contributions of each beta emission according to the following equation:

$$
n\left(E_{i}\right)=0.79 n_{1}\left(E_{i}\right)+0.091 n_{2}\left(E_{i}\right)+0.12 n_{3}\left(E_{i}\right),
$$

where $n_{1}\left(E_{i}\right), n_{2}\left(E_{i}\right)$ and $n_{3}\left(E_{i}\right)$ correspond to the spectrum emissions of the maximum energies of $0.498 \mathrm{MeV}, 0.385 \mathrm{MeV}$ and $0.177 \mathrm{MeV}$ respectively. Table A.5 shows the 
numerical data of the complete beta energy spectrum of ${ }^{177} \mathrm{Lu}$. Figure A.4 shows the graph of the complete spectrum.

Table A.5. Complete beta energy spectrum of ${ }^{177} \mathrm{Lu}$

\begin{tabular}{|c|c|}
\hline $\mathbf{E}(\mathbf{M e V})$ & $\mathbf{n}(\mathbf{E})$ \\
\hline 0.00249 & 0.03759 \\
0.00747 & 0.03645 \\
0.01245 & 0.03554 \\
0.01743 & 0.03417 \\
0.02241 & 0.03261 \\
0.02739 & 0.03111 \\
0.03237 & 0.02970 \\
0.03735 & 0.02841 \\
0.04233 & 0.02721 \\
0.04731 & 0.02610 \\
0.05229 & 0.02506 \\
0.05727 & 0.02409 \\
0.06225 & 0.02318 \\
0.06723 & 0.02232 \\
0.07221 & 0.02150 \\
0.07719 & 0.02073 \\
0.08217 & 0.02000 \\
0.08715 & 0.01930 \\
0.09213 & 0.01863 \\
0.09711 & 0.01799 \\
0.10209 & 0.01738 \\
0.10707 & 0.01679 \\
0.11205 & 0.01623 \\
0.11703 & 0.01569 \\
0.12201 & 0.01518 \\
0.12699 & 0.01468 \\
0.13197 & 0.01421 \\
0.13695 & 0.01376 \\
0.14193 & 0.01333 \\
0.14691 & 0.01291 \\
0.15189 & 0.01252 \\
0.15687 & 0.01215 \\
0.16185 & 0.01180 \\
0.16683 & 0.01146 \\
0.17181 & 0.01115 \\
0.17679 & 0.01085 \\
0.18177 & 0.01057 \\
0.18675 & 0.01029 \\
0.19173 & 0.01001 \\
\hline
\end{tabular}




\begin{tabular}{|c|c|}
\hline $\mathbf{E}(\mathbf{M e V})$ & $\mathbf{n}(\mathbf{E})$ \\
\hline 0.19671 & 0.00974 \\
0.20169 & 0.00947 \\
0.20667 & 0.00920 \\
0.21165 & 0.00893 \\
0.21663 & 0.00867 \\
0.22161 & 0.00841 \\
0.22659 & 0.00815 \\
0.23157 & 0.00790 \\
0.23655 & 0.00764 \\
0.24153 & 0.00739 \\
0.24651 & 0.00715 \\
0.25149 & 0.00690 \\
0.25647 & 0.00666 \\
0.26145 & 0.00642 \\
0.26643 & 0.00618 \\
0.27141 & 0.00595 \\
0.27639 & 0.00572 \\
0.28137 & 0.00549 \\
0.28635 & 0.00527 \\
0.29133 & 0.00505 \\
0.29631 & 0.00483 \\
0.30129 & 0.00462 \\
0.30627 & 0.00441 \\
0.31125 & 0.00420 \\
0.31623 & 0.00400 \\
0.32121 & 0.00380 \\
0.32619 & 0.00360 \\
0.33117 & 0.00341 \\
0.33615 & 0.00323 \\
0.34113 & 0.00304 \\
0.34611 & 0.00287 \\
0.35109 & 0.00269 \\
0.35607 & 0.00253 \\
0.36105 & 0.00236 \\
0.36603 & 0.00221 \\
0.37101 & 0.00205 \\
0.37599 & 0.00191 \\
0.38097 & 0.00177 \\
0.38595 & 0.00163 \\
0.39093 & 0.00150 \\
0.39591 & 0.00138 \\
0.40089 & 0.00125 \\
0.40587 & 0.00114 \\
0.41085 & 0.00103 \\
0.41583 & 0.00092 \\
0.42081 & 0.00082 \\
0.42579 & 0.00072 \\
0.43077 & 0.00063 \\
\hline
\end{tabular}




\begin{tabular}{|c|c|}
\hline $\mathbf{E}(\mathbf{M e V})$ & $\mathbf{n}(\mathbf{E})$ \\
\hline 0.43575 & 0.00054 \\
0.44073 & 0.00046 \\
0.44571 & 0.00039 \\
0.45069 & 0.00032 \\
0.45567 & 0.00026 \\
0.46065 & 0.00020 \\
0.46563 & 0.00015 \\
0.47061 & 0.00011 \\
0.47559 & 0.00007 \\
0.48057 & 0.00005 \\
0.48555 & 0.00002 \\
0.49053 & 0.00001 \\
0.49551 & 0.00000 \\
\hline
\end{tabular}

Figure A.4 Beta Energy Spectrum of ${ }^{177} \mathrm{Lu}$

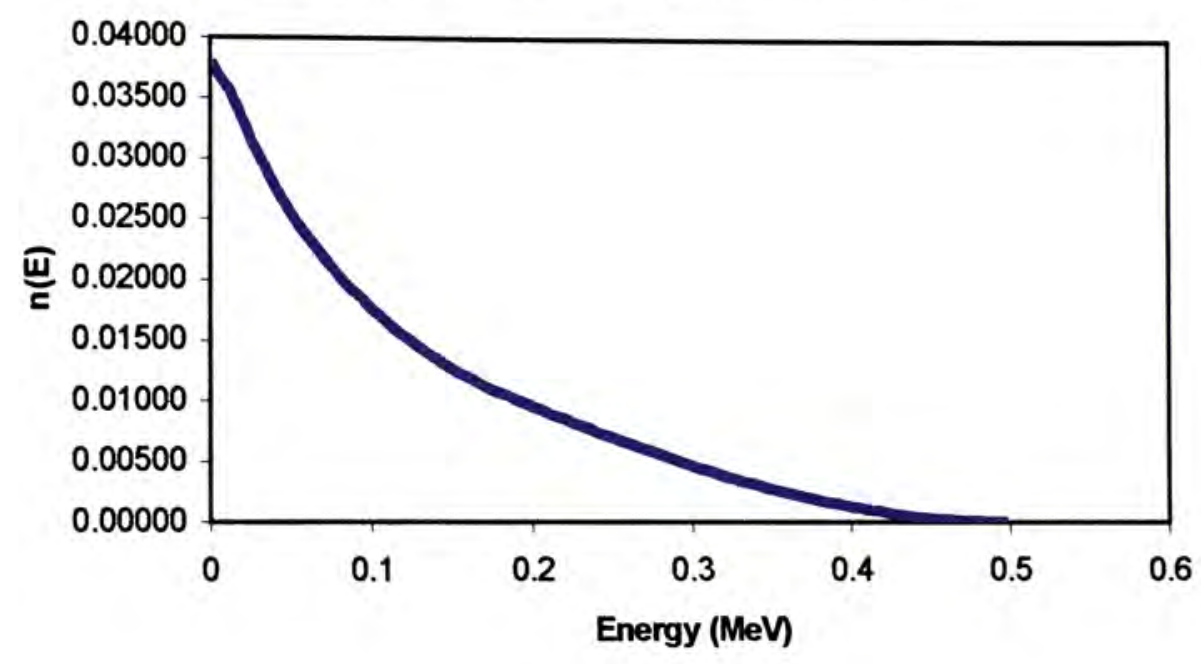




\section{APPENDIX B \\ Calculation of Beta Dose Point Kernel of ${ }^{177} \mathrm{Lu}$}


The DPK for ${ }^{177} \mathrm{Lu}$ was calculated according to equation 9 (Chapter 3 , p. ). The DPK of beta particles was derived from the dimensionless dose distribution $j(r / R, E)$ tabulated by Cross et al. (1992), where:

$$
j(r / R, E)=4 \pi \rho r^{2} \times D P K(r, E) \times R / E,
$$

in which $\rho$ is the density of water equal to $1 \mathrm{~g} / \mathrm{cm}^{2}, \mathrm{r}^{2}$ is the distance from the point source to the target point and $R$ is the range of beta particles in water for a specific energy $E$. The DPK was calculated from the following equation:

$$
D P K(r, E)=\frac{j(r / R, E)}{4 \pi \rho r^{2} R} \times E
$$

The range $\mathrm{R}$ was determined from the beta range tables in water (Attix, Appendix E, p. 575, 1986). DPK was determined at intervals of $25 \mathrm{keV}$. Those values of $\mathrm{j}(\mathrm{r}, \mathrm{E})$ or range $\mathrm{R}$, which were not available in the tables, were calculated by logarithmic linear interpolation. Table B-1 shows the contribution to the DPK of each energy bin at intervals of $25 \mathrm{keV}$. Table B-2 shows the value of the DPK of ${ }^{177} \mathrm{Lu}$ at distances ranging up to $2 \mathrm{~mm}$. 
Table B-1. Contribution of each energy bin to DPK of ${ }^{177} \mathrm{Lu}$ for distances ranging from 0.01 to $0.2 \mathrm{~cm}$

\begin{tabular}{|c|c|c|}
\hline & 00000000000000000 岁 & \\
\hline & 0000000000000000 总 常 & \\
\hline & 000000000000000 䓌茹莒 & $=$ \\
\hline & 000000000000 吉芯总总总宫 & 형 \\
\hline & 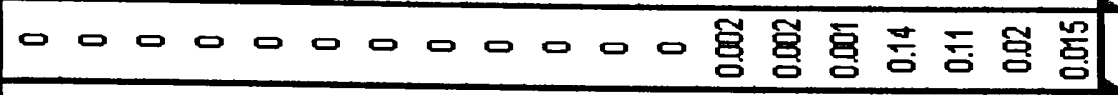 & 7 \\
\hline & 00000000000 兽罟 & 焉 \\
\hline & 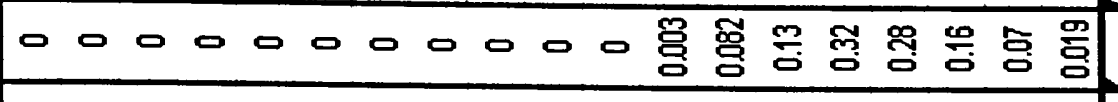 & \\
\hline & 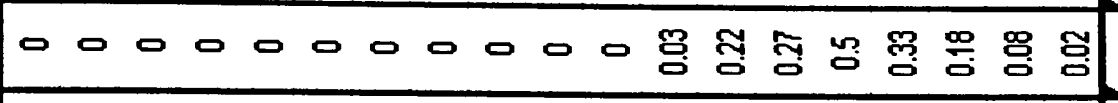 & \\
\hline & 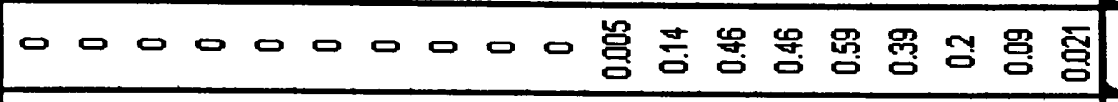 & 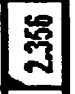 \\
\hline & 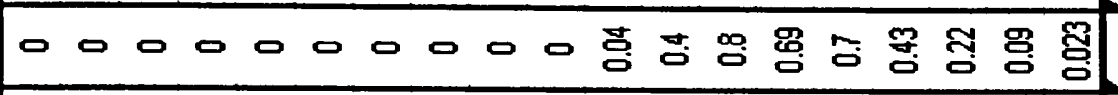 & 鹿 \\
\hline & 00000000 Б영 & \& \\
\hline & 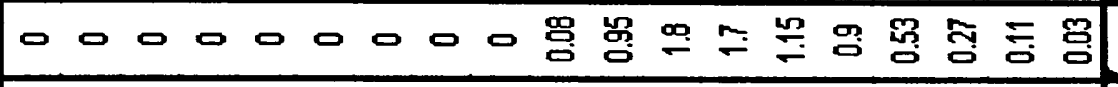 & 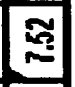 \\
\hline & 00000000 舫采采 & 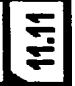 \\
\hline & 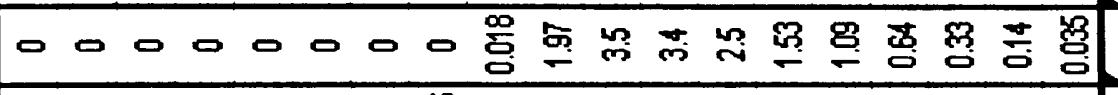 & 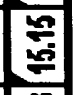 \\
\hline & 000000悬 & $\pi$ \\
\hline & 000000 हु용 & בֶ \\
\hline 莺 & 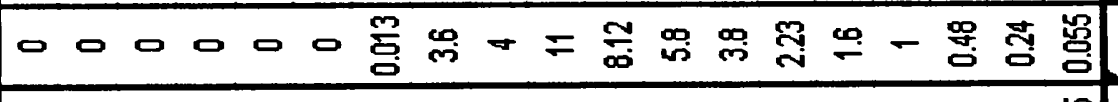 & $\bar{z}$ \\
\hline & 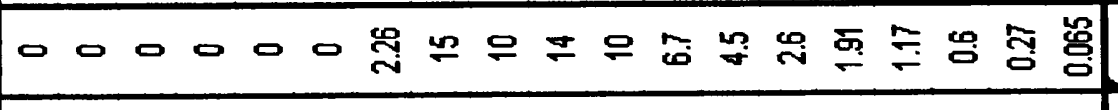 & 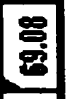 \\
\hline : & 00000 뉴 & $\neq$ \\
\hline 总 & o & 8 \\
\hline$\simeq$ & 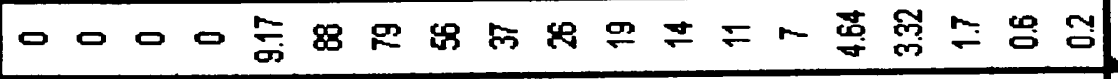 & 5 \\
\hline 7 & 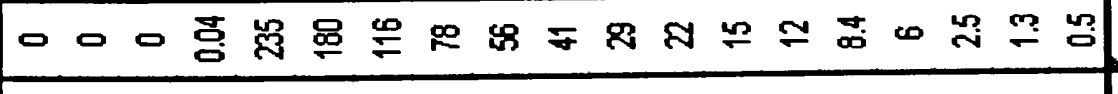 & $\approx$ \\
\hline & ณ & \\
\hline & $\infty$ & \\
\hline
\end{tabular}


Table B-2. Beta DPK of ${ }^{177}$ Lu

\begin{tabular}{|c|c|c|c|}
\hline $\mathbf{r}(\mathrm{cm})$ & $\mathrm{MeV} / \mathrm{g}$ & nGy/Bq-h & $\begin{array}{c}\mathrm{nGy}-\mathrm{cm}^{2} / \\
\mathrm{Bq}-\mathrm{h}\end{array}$ \\
\hline 0 & $\sum<$ & $3<$ & 212.51 \\
\hline 0.01 & 1465.6 & 845240.8 & 84.52408 \\
\hline 0.015 & 802.7 & 462933.1 & 104.16 \\
\hline 0.02 & 356.63 & 205675.7 & 82.27026 \\
\hline 0.025 & 198.5 & 114478.9 & 71.54933 \\
\hline 0.03 & 111.83 & 64494.6 & 58.04514 \\
\hline 0.035 & 69.1 & 39851.35 & 48.81791 \\
\hline 0.04 & 41.9 & 24164.57 & 38.66331 \\
\hline 0.045 & 29.3 & 16897.9 & 34.21824 \\
\hline 0.05 & 20.9 & 12053.45 & 3362 \\
\hline 0.055 & 15.2 & 8766.144 & 26.51759 \\
\hline 0.06 & 11.11 & 6407.359 & 23.06649 \\
\hline 0.065 & 7.52 & 4336.934 & 2355 \\
\hline 0.07 & 5.18 & 2987.41 & 831 \\
\hline 0.075 & 3.39 & 1955.081 & 10.99733 \\
\hline 0.08 & 2.36 & 059 & 8.710779 \\
\hline 0.085 & 1.63 & 940. & 1887 \\
\hline 0.09 & 1.064 & 613.6301 & 4.970404 \\
\hline 0.095 & 0.606 & 349.4923 & 3.154168 \\
\hline 0.1 & & 167.2488 & 1.672488 \\
\hline 0.125 & 0.0356 & 20.53123 & 0.320801 \\
\hline 0.15 & 0.00245 & 1.412964 & 0.031792 \\
\hline 0.175 & 0.00028 & 0.161482 & 0.004945 \\
\hline 0.2 & 0.00004 & 0.023069 & 0.000923 \\
\hline
\end{tabular}


Appendix C

Calculation of Gamma DPK of ${ }^{177} \mathrm{Lu}$ 
Tables C-1 and C-2 present the results of the logarithmic linear interpolation that was done to obtain the DPK values for gamma emissions of ${ }^{177} \mathrm{Lu}$ with energies of $.208 \mathrm{MeV}$ and $0.113 \mathrm{MeV}$ for a given distance $\mathrm{d}$. The interpolation was done using the values provided in the tables by Luxton and Jozsef (1999). Table C-3 provides the final DPK of ${ }^{177} \mathrm{Lu}$ obtain by summing up the DPK for both energies multiplied by the fraction of emissions according to equation 11 (Chapter 3).

Table C-1. Dose to water per gamma ray emission from a point source (nGycm $/ \mathrm{Bq}-\mathrm{hr}$ ) for gamma energy $0.208 \mathrm{MeV}(11.0 \%)$

\begin{tabular}{|c|c|c|c|}
\hline $\mathbf{d}(\mathbf{c m})$ & $\begin{array}{c}\mathbf{0 . 2 0 0} \\
\mathbf{M e V}\end{array}$ & $\begin{array}{c}\mathbf{0 . 2 5 0} \\
\mathbf{M e V}\end{array}$ & $\begin{array}{c}\mathbf{0 . 2 0 8} \\
\mathbf{M e V}\end{array}$ \\
\hline 0.05 & 0.2852 & 0.3648 & 0.296657 \\
0.1 & 0.28 & 0.3629 & 0.291863 \\
0.2 & 0.2736 & 0.357 & 0.285499 \\
0.24 & 0.2743 & 0.3545 & 0.285791 \\
0.3 & 0.2693 & 0.3626 & 0.282428 \\
0.4 & 0.2779 & 0.3699 & 0.290911 \\
0.5 & 0.2719 & 0.361 & 0.284515 \\
0.6 & 0.2803 & 0.3598 & 0.291725 \\
0.8 & 0.2811 & 0.363 & 0.292838 \\
0.9 & 0.2861 & 0.3648 & 0.297443 \\
1 & 0.286 & 0.364 & 0.297251 \\
1.11 & 0.2883 & 0.3688 & 0.299886 \\
1.2 & 0.2875 & 0.3745 & 0.299922 \\
1.5 & 0.2925 & 0.3706 & 0.303788 \\
2 & 0.2985 & 0.3763 & 0.30977 \\
\hline
\end{tabular}


Table C-2. Dose to water per gamma ray emission from a point source $\left(\mathrm{nGycm}^{2} / \mathrm{Bq}-\mathrm{hr}\right)$ for gamma energy $0.113 \mathrm{MeV}(6.4 \%)$

\begin{tabular}{|c|c|c|c|}
\hline $\mathbf{d}(\mathbf{c m})$ & $\begin{array}{c}\mathbf{0 . 1 0 0} \\
\mathbf{M e V}\end{array}$ & $\begin{array}{c}\mathbf{0 . 1 2 5} \\
\mathbf{M e V}\end{array}$ & $\begin{array}{c}\mathbf{0 . 1 1 3} \\
\mathbf{M e V}\end{array}$ \\
\hline 0.05 & 0.126 & 0.1559 & 0.140753 \\
0.1 & 0.1231 & 0.1514 & 0.137085 \\
0.2 & 0.1226 & 0.1519 & 0.137052 \\
0.24 & 0.1206 & 0.1584 & 0.138969 \\
0.3 & 0.1226 & 0.1563 & 0.139102 \\
0.4 & 0.1244 & 0.161 & 0.142254 \\
0.5 & 0.1223 & 0.1602 & 0.140731 \\
0.6 & 0.1344 & 0.1574 & 0.145906 \\
0.8 & 0.1313 & 0.1671 & 0.148838 \\
0.9 & 0.1344 & 0.1675 & 0.150702 \\
1.0 & 0.1347 & 0.1674 & 0.150817 \\
1.11 & 0.1367 & 0.1708 & 0.153484 \\
1.2 & 0.1371 & 0.175 & 0.155653 \\
1.5 & 0.1418 & 0.1786 & 0.159876 \\
2.0 & 0.152 & 0.1823 & 0.167068 \\
\hline
\end{tabular}

Table C-3. Gamma DPK of ${ }^{177} \mathrm{Lu}$

\begin{tabular}{|c|c|}
\hline $\mathbf{d}(\mathbf{c m})$ & $\begin{array}{c}\text { DPK } \\
\left(\mathbf{n G y}-\mathbf{c m}^{2} / \mathbf{B q}-\mathbf{h r}\right)\end{array}$ \\
\hline 0.05 & 0.041818 \\
0.1 & 0.041053 \\
0.2 & 0.040348 \\
0.24 & 0.040503 \\
0.3 & 0.040139 \\
0.4 & 0.041279 \\
0.5 & 0.040474 \\
0.6 & 0.041603 \\
0.8 & 0.041914 \\
0.9 & 0.042542 \\
1 & 0.042528 \\
1.11 & 0.04299 \\
1.2 & 0.043133 \\
1.5 & 0.043831 \\
2 & 0.044953 \\
\hline
\end{tabular}


APPENDIX D

Stent Coordinates 
The following table provides the set of Cartesian coordinates of the stent geometry that was used as the radiation source in this project. The stent at $15.5 \mathrm{~mm}$ in length consists of four repeating segments that are joined together to obtain a stent of this specific desired length. Table $C .1$ shows the set of $(x, y, z)$ coordinates for this segment, which are equivalent to one fourth of the total length of the stent.

Table D-1 Stent Coordinates

\begin{tabular}{|c|c|c|}
\hline $\mathrm{X}$ & $\mathrm{Y}$ & $\mathrm{Z}$ \\
\hline 0.0000 & 2.0026 & -7.7500 \\
\hline 1.4161 & 1.4161 & -7.7500 \\
\hline-1.4161 & 1.4161 & -7.7500 \\
\hline 0.0000 & 2.0026 & -7.7500 \\
\hline-2.0026 & 0.0000 & -7.7500 \\
\hline-1.4161 & 1.4161 & -7.7500 \\
\hline-1.4161 & -1.4161 & -7.7500 \\
\hline-2.0026 & 0.0000 & -7.7500 \\
\hline 0.0000 & -2.0026 & -7.7500 \\
\hline-1.4161 & -1.4161 & -7.7500 \\
\hline 1.4161 & -1.4161 & -7.7500 \\
\hline 0.0000 & -2.0026 & -7.7500 \\
\hline 2.0026 & 0.0000 & -7.7500 \\
\hline 1.4161 & -1.4161 & -7.7500 \\
\hline 1.4161 & 1.4161 & -7.7500 \\
\hline 2.0026 & 0.0000 & -7.7500 \\
\hline 0.1321 & 1.9439 & -7.6250 \\
\hline 1.3139 & 1.4423 & -7.6250 \\
\hline-1.3139 & 1.4423 & -7.6250 \\
\hline-0.1321 & 1.9439 & -7.6250 \\
\hline-1.9439 & 0.1321 & -7.6250 \\
\hline-1.4423 & 1.3139 & -7.6250 \\
\hline-1.4423 & -1.3139 & -7.6250 \\
\hline-1.9439 & -0.1321 & -7.6250 \\
\hline-0.1321 & -1.9439 & -7.6250 \\
\hline-1.3139 & -1.4423 & -7.6250 \\
\hline 1.3139 & -1.4423 & -7.6250 \\
\hline 0.1321 & -1.9439 & -7.6250 \\
\hline 1.9439 & -0.1321 & -7.6250 \\
\hline 1.4423 & -1.3139 & -7.6250 \\
\hline 1.4423 & 1.3139 & -7.6250 \\
\hline
\end{tabular}

\begin{tabular}{|c|c|c|}
\hline 1.9439 & 0.1321 & -7.6250 \\
\hline 0.1834 & 1.9221 & -7.5000 \\
\hline 1.2625 & 1.4641 & -7.5000 \\
\hline-1.2625 & 1.4641 & -7.5000 \\
\hline-0.1834 & 1.9221 & -7.5000 \\
\hline-1.9221 & 0.1834 & -7.5000 \\
\hline-1.4641 & 1.2625 & -7.5000 \\
\hline-1.4641 & -1.2625 & -7.5000 \\
\hline-1.9221 & -0.1834 & -7.5000 \\
\hline-0.1834 & -1.9221 & -7.5000 \\
\hline-1.2625 & -1.4641 & -7.5000 \\
\hline 1.2625 & -1.4641 & -7.5000 \\
\hline 0.1834 & -1.9221 & -7.5000 \\
\hline 1.9221 & -0.1834 & -7.5000 \\
\hline 1.4641 & -1.2625 & -7.5000 \\
\hline 1.4641 & 1.2625 & -7.5000 \\
\hline 1.9221 & 0.1834 & -7.5000 \\
\hline 0.2320 & 1.9015 & -7.3750 \\
\hline 1.2139 & 1.4847 & -7.3750 \\
\hline-1.2139 & 1.4847 & -7.3750 \\
\hline-0.2320 & 1.9015 & -7.3750 \\
\hline-1.9015 & 0.2320 & -7.3750 \\
\hline-1.4847 & 1.2139 & -7.3750 \\
\hline-1.4847 & -1.2139 & -7.3750 \\
\hline-1.9015 & -0.2320 & -7.3750 \\
\hline-0.2320 & -1.9015 & -7.3750 \\
\hline-1.2139 & -1.4847 & -7.3750 \\
\hline 1.2139 & -1.4847 & -7.3750 \\
\hline 0.2320 & -1.9015 & -7.3750 \\
\hline 1.9015 & -0.2320 & -7.3750 \\
\hline 1.4847 & -1.2139 & -7.3750 \\
\hline 1.4847 & 1.2139 & -7.3750 \\
\hline 1.9015 & 0.2320 & -7.3750 \\
\hline & & \\
\hline
\end{tabular}




\begin{tabular}{|c|c|c|}
\hline 0.2777 & 1.8821 & -7.2500 \\
\hline 1.1682 & 1.5041 & -7.2500 \\
\hline-1.1682 & 1.5041 & -7.2500 \\
\hline-0.2777 & 1.8821 & -7.2500 \\
\hline-1.8821 & 0.2777 & -7.2500 \\
\hline-1.5041 & 1.1682 & -7.2500 \\
\hline-1.5041 & -1.1682 & -7.2500 \\
\hline-1.8821 & -0.2777 & -7.2500 \\
\hline-0.2777 & -1.8821 & -7.2500 \\
\hline-1.1682 & -1.5041 & -7.2500 \\
\hline 1.1682 & -1.5041 & -7.2500 \\
\hline 0.2777 & -1.8821 & -7.2500 \\
\hline 1.8821 & -0.2777 & -7.2500 \\
\hline 1.5041 & -1.1682 & -7.2500 \\
\hline 1.5041 & 1.1682 & -7.2500 \\
\hline 1.8821 & 0.2777 & -7.2500 \\
\hline 0.3206 & 1.8639 & -7.1250 \\
\hline 1.1254 & 1.5523 & -7.1250 \\
\hline-1.1254 & 1.5223 & -7.1250 \\
\hline-0.3206 & 1.8639 & -7.1250 \\
\hline-1.8639 & 0.3206 & -7.1250 \\
\hline-1.5223 & 1.1254 & -7.1250 \\
\hline-1.5523 & -1.1254 & -7.1250 \\
\hline-1.8639 & -0.3206 & -7.1250 \\
\hline-0.3206 & -1.8639 & -7.1250 \\
\hline-1.1254 & -1.5223 & -7.1250 \\
\hline 1.1254 & -1.5523 & -7.1250 \\
\hline 0.3206 & -1.8639 & -7.1250 \\
\hline 1.8639 & -0.3206 & -7.1250 \\
\hline 1.5223 & -1.1254 & -7.1250 \\
\hline 1.5223 & 1.1254 & -7.1250 \\
\hline 1.8639 & 0.3206 & -7.1250 \\
\hline 0.3607 & 1.8469 & -7.0000 \\
\hline 1.0852 & 1.5393 & -7.0000 \\
\hline-1.0852 & 1.5393 & -7.0000 \\
\hline-0.3607 & 1.8469 & -7.0000 \\
\hline-1.8469 & 0.3607 & -7.0000 \\
\hline-1.5393 & 1.0852 & -7.0000 \\
\hline-1.5393 & -1.0852 & -7.0000 \\
\hline-1.8469 & -0.3607 & -7.0000 \\
\hline-0.3607 & -1.8469 & -7.0000 \\
\hline-1.0852 & -1.5393 & -7.0000 \\
\hline 1.0852 & -1.5393 & -7.0000 \\
\hline 0.3607 & -1.8469 & -7.0000 \\
\hline 1.8469 & -0.3607 & -7.0000 \\
\hline 1.5393 & -1.0852 & -7.0000 \\
\hline 1.5393 & 1.0852 & -7.0000 \\
\hline & & \\
\hline & \\
\hline
\end{tabular}

\begin{tabular}{|c|c|c|}
\hline 1.8469 & 0.3607 & -7.0000 \\
\hline 0.3981 & 1.8310 & -6.8750 \\
\hline 1.0478 & 1.5552 & -6.8750 \\
\hline-1.0478 & 1.5552 & -6.8750 \\
\hline-0.3981 & 1.8310 & -6.8750 \\
\hline-1.8310 & 0.3981 & -6.8750 \\
\hline-1.5552 & 1.0478 & -6.8750 \\
\hline-1.5552 & -1.0478 & -6.8750 \\
\hline-1.8310 & -0.3981 & -6.8750 \\
\hline-0.3981 & -1.8310 & -6.8750 \\
\hline-1.0478 & -1.5552 & -6.8750 \\
\hline 1.0478 & -1.5552 & -6.8750 \\
\hline 0.3981 & -1.8310 & -6.8750 \\
\hline 1.8310 & -0.3981 & -6.8750 \\
\hline 1.5552 & -1.0478 & -6.8750 \\
\hline 1.5552 & 1.0478 & -6.8750 \\
\hline 1.8130 & 0.3981 & -6.8750 \\
\hline 0.4330 & 1.8162 & -6.7500 \\
\hline 1.0130 & 1.5700 & -6.7500 \\
\hline-1.0130 & 1.5700 & -6.7500 \\
\hline-0.4330 & 1.8162 & -6.7500 \\
\hline-1.8162 & 0.4330 & -6.7500 \\
\hline-1.5700 & 1.0130 & -6.7500 \\
\hline-1.5700 & -1.0130 & -6.7500 \\
\hline-1.8162 & -0.4330 & -6.7500 \\
\hline-0.4330 & -1.8162 & -6.7500 \\
\hline-1.0130 & -1.5700 & -6.7500 \\
\hline 1.0130 & -1.5700 & -6.7500 \\
\hline 0.4330 & -1.8162 & -6.7500 \\
\hline 1.8162 & -0.4330 & -6.7500 \\
\hline 1.5700 & -1.0130 & -6.7500 \\
\hline 1.5700 & 1.0130 & -6.7500 \\
\hline 1.8162 & 0.4330 & -6.7500 \\
\hline 0.4652 & 1.8025 & -6.6250 \\
\hline 0.9807 & 1.5837 & -6.6250 \\
\hline-0.9807 & 1.5837 & -6.6250 \\
\hline-0.4652 & 1.8025 & -6.6250 \\
\hline-1.8025 & 0.4652 & -6.6250 \\
\hline-1.5837 & 0.9807 & -6.6250 \\
\hline-1.5837 & -0.9807 & -6.6250 \\
\hline-1.8025 & -0.4652 & -6.6250 \\
\hline-0.4652 & -1.8025 & -6.6250 \\
\hline-0.9807 & -1.5837 & -6.6250 \\
\hline 0.9807 & -1.5837 & -6.6250 \\
\hline 0.4652 & -1.8025 & -6.6250 \\
\hline 1.8025 & -0.4652 & -6.6250 \\
\hline 1.5837 & -0.9807 & -6.6250 \\
\hline & & \\
\hline 10
\end{tabular}




\begin{tabular}{|c|c|c|}
\hline 1.5837 & 0.9807 & -6.6250 \\
\hline 1.8025 & 0.4652 & -6.6250 \\
\hline 0.4949 & 1.7899 & -6.5000 \\
\hline 0.9511 & 1.5963 & -6.5000 \\
\hline-0.9511 & 1.5963 & -6.5000 \\
\hline-0.4949 & 1.7899 & -6.5000 \\
\hline-1.7899 & 0.4949 & -6.5000 \\
\hline-1.5963 & 0.9511 & -6.5000 \\
\hline-1.5963 & -0.9511 & -6.5000 \\
\hline-1.7899 & -0.4949 & -6.5000 \\
\hline-0.4949 & -1.7899 & -6.5000 \\
\hline-0.9511 & -1.5963 & -6.5000 \\
\hline 0.9511 & -1.5963 & -6.5000 \\
\hline 0.4949 & -1.7899 & -6.5000 \\
\hline 1.7899 & -0.4949 & -6.5000 \\
\hline 1.5963 & -0.9511 & -6.5000 \\
\hline 1.5963 & 0.9511 & -6.5000 \\
\hline 1.7899 & 0.4949 & -6.5000 \\
\hline 0.5221 & 1.7784 & -6.3750 \\
\hline 0.9239 & 1.6078 & -6.3750 \\
\hline-0.9239 & 1.6078 & -6.3750 \\
\hline-0.5221 & 1.7784 & -6.3750 \\
\hline-1.7784 & 0.5221 & -6.3750 \\
\hline-1.6078 & 0.9239 & -6.3750 \\
\hline-1.6078 & -0.9239 & -6.3750 \\
\hline-1.7784 & -0.5221 & -6.3750 \\
\hline-0.5221 & -1.7784 & -6.3750 \\
\hline-0.9239 & -1.6078 & -6.3750 \\
\hline 0.9329 & -1.6078 & -6.3750 \\
\hline 0.5221 & -1.7784 & -6.3750 \\
\hline 1.7784 & -0.5221 & -6.3750 \\
\hline 1.6078 & -0.9239 & -6.3750 \\
\hline 1.6078 & 0.9329 & -6.3750 \\
\hline 1.7784 & 0.5221 & -6.3750 \\
\hline 0.5477 & 1.7675 & -6.2500 \\
\hline 0.8982 & 1.6187 & -6.2500 \\
\hline-0.8982 & 1.6187 & -6.2500 \\
\hline-0.5477 & 1.7675 & -6.2500 \\
\hline-1.7675 & 0.5477 & -6.2500 \\
\hline-1.6187 & 0.8982 & -6.2500 \\
\hline-1.6187 & -0.8982 & -6.2500 \\
\hline-1.7675 & -0.5477 & -6.2500 \\
\hline-0.5477 & -1.7675 & -6.2500 \\
\hline-0.8982 & -1.6187 & -6.2500 \\
\hline 0.8982 & -1.6187 & -6.2500 \\
\hline 0.5477 & -1.7675 & -6.2500 \\
\hline 1.7675 & -0.5477 & -6.2500 \\
\hline & & \\
\hline & & \\
\hline & & \\
\hline & & \\
\hline & & \\
\hline
\end{tabular}

\begin{tabular}{|c|c|c|}
\hline 1.6187 & -0.8982 & -6.2500 \\
\hline 1.6187 & 0.8982 & -6.2500 \\
\hline 1.7675 & 0.5477 & -6.2500 \\
\hline 0.7922 & 1.6638 & -6.1250 \\
\hline 0.6538 & 1.7225 & -6.1250 \\
\hline-0.7922 & 1.6638 & -6.1250 \\
\hline-0.6538 & 1.7225 & -6.1250 \\
\hline-1.7225 & 0.6538 & -6.1250 \\
\hline-1.6638 & 0.7922 & -6.1250 \\
\hline-1.6638 & -0.7922 & -6.1250 \\
\hline-1.7225 & -0.6538 & -6.1250 \\
\hline-0.6538 & -1.7225 & -6.1250 \\
\hline-0.7922 & -1.6638 & -6.1250 \\
\hline 0.7922 & -1.6638 & -6.1250 \\
\hline 0.6538 & -1.7225 & -6.1250 \\
\hline 1.7225 & -0.6538 & -6.1250 \\
\hline 1.6638 & -0.7922 & -6.1250 \\
\hline 1.6638 & 0.7922 & -6.1250 \\
\hline 1.7225 & 0.6538 & -6.1250 \\
\hline 0.7464 & 1.6832 & -6.0000 \\
\hline-1.6832 & 0.7464 & -6.0000 \\
\hline-0.7464 & -1.6832 & -6.0000 \\
\hline 1.6832 & -0.7464 & -6.0000 \\
\hline 0.7271 & 1.6913 & -5.8750 \\
\hline-1.6913 & 0.7271 & -5.8750 \\
\hline-0.7271 & -1.6913 & -5.8750 \\
\hline 1.6913 & -0.7271 & -5.8750 \\
\hline 0.7464 & 1.6832 & -5.7500 \\
\hline-1.6832 & 0.7464 & -5.7500 \\
\hline-0.7464 & -1.6832 & -5.7500 \\
\hline 1.6832 & -0.7464 & -5.7500 \\
\hline 0.6538 & 1.7225 & -5.6250 \\
\hline 0.7922 & 1.6638 & -5.6250 \\
\hline-0.7922 & 1.6638 & -5.6250 \\
\hline-0.6538 & 1.7225 & -5.6250 \\
\hline-1.7225 & 0.6538 & -5.6250 \\
\hline-1.6638 & 0.7922 & -5.6250 \\
\hline-1.6638 & -0.7922 & -5.6250 \\
\hline-1.7225 & -0.6538 & -5.6250 \\
\hline-0.6538 & -1.7225 & -5.6250 \\
\hline-0.7922 & -1.6638 & -5.6250 \\
\hline 0.7922 & -1.6638 & -5.6250 \\
\hline 0.6538 & -1.7225 & -5.6250 \\
\hline 1.7225 & -0.6538 & -5.6250 \\
\hline 1.6638 & -0.7922 & -5.6250 \\
\hline 1.6638 & 0.7922 & -5.6250 \\
\hline 1.7225 & 0.6538 & -5.6250 \\
\hline & & \\
\hline
\end{tabular}




\begin{tabular}{|c|c|c|}
\hline 0.5477 & 1.7675 & -5.5000 \\
\hline 0.8982 & 1.6187 & -5.5000 \\
\hline-0.8982 & 1.6187 & -5.5000 \\
\hline-0.5477 & 1.7675 & -5.5000 \\
\hline-1.7675 & 0.5477 & -5.5000 \\
\hline-1.6187 & 0.8982 & -5.5000 \\
\hline-1.6187 & -0.8982 & -5.5000 \\
\hline-1.7675 & -0.5477 & -5.5000 \\
\hline-0.5477 & -1.7675 & -5.5000 \\
\hline-0.8982 & -1.6187 & -5.5000 \\
\hline 0.8982 & -1.6187 & -5.5000 \\
\hline 0.5477 & -1.7675 & -5.5000 \\
\hline 1.7675 & -0.5477 & -5.5000 \\
\hline 1.6187 & -0.8982 & -5.5000 \\
\hline 1.6187 & 0.8982 & -5.5000 \\
\hline 1.7675 & 0.5477 & -5.5000 \\
\hline 0.5221 & 1.7784 & -5.3750 \\
\hline 0.9239 & 1.6078 & -5.3750 \\
\hline-0.9239 & 1.6078 & -5.3750 \\
\hline-0.5221 & 1.7784 & -5.3750 \\
\hline-1.7784 & 0.5221 & -5.3750 \\
\hline-1.6078 & 0.9239 & -5.3750 \\
\hline-1.6078 & -0.9239 & -5.3750 \\
\hline-1.7784 & -0.5221 & -5.3750 \\
\hline-0.5221 & -1.7784 & -5.3750 \\
\hline-0.9239 & -1.6078 & -5.3750 \\
\hline 0.9329 & -1.6078 & -5.3750 \\
\hline 0.5221 & -1.7784 & -5.3750 \\
\hline 1.7784 & -0.5221 & -5.3750 \\
\hline 1.6078 & -0.9239 & -5.3750 \\
\hline 1.6078 & 0.9329 & -5.3750 \\
\hline 1.7784 & 0.5221 & -5.3750 \\
\hline 0.4949 & 1.7899 & -5.2500 \\
\hline 0.9511 & 1.5963 & -5.2500 \\
\hline-0.9511 & 1.5963 & -5.2500 \\
\hline-0.4949 & 1.7899 & -5.2500 \\
\hline-1.7899 & 0.4949 & -5.2500 \\
\hline-1.5963 & 0.9511 & -5.2500 \\
\hline-1.5963 & -0.9511 & -5.2500 \\
\hline-1.7899 & -0.4949 & -5.2500 \\
\hline-0.4949 & -1.7899 & -5.2500 \\
\hline-0.9511 & -1.5963 & -5.2500 \\
\hline 0.9511 & -1.5963 & -5.2500 \\
\hline 0.4949 & -1.7899 & -5.2500 \\
\hline 1.7899 & -0.4949 & -5.2500 \\
\hline 1.5963 & -0.9511 & -5.2500 \\
\hline 1.5963 & 0.9511 & -5.2500 \\
\hline & & \\
\hline & & \\
\hline & & \\
\hline & & \\
\hline & & \\
\hline
\end{tabular}

\begin{tabular}{|c|c|c|}
\hline 1.7899 & 0.4949 & -5.2500 \\
\hline 0.4652 & 1.8025 & -5.1250 \\
\hline 0.9807 & 1.5837 & -5.1250 \\
\hline-0.9807 & 1.5837 & -5.1250 \\
\hline-0.4652 & 1.8025 & -5.1250 \\
\hline-1.8025 & 0.4652 & -5.1250 \\
\hline-1.5837 & 0.9807 & -5.1250 \\
\hline-1.5837 & -0.9807 & -5.1250 \\
\hline-1.8025 & -0.4652 & -5.1250 \\
\hline-0.4652 & -1.8025 & -5.1250 \\
\hline-0.9807 & -1.5837 & -5.1250 \\
\hline 0.9807 & -1.5837 & -5.1250 \\
\hline 0.4652 & -1.8025 & -5.1250 \\
\hline 1.8025 & -0.4652 & -5.1250 \\
\hline 1.5837 & -0.9807 & -5.1250 \\
\hline 1.5837 & 0.9807 & -5.1250 \\
\hline 1.8025 & 0.4652 & -5.1250 \\
\hline 0.4330 & 1.8162 & -5.0000 \\
\hline 1.0130 & 1.5700 & -5.0000 \\
\hline-1.0130 & 1.5700 & -5.0000 \\
\hline-0.4330 & 1.8162 & -5.0000 \\
\hline-1.8162 & 0.4330 & -5.0000 \\
\hline-1.5700 & 1.0130 & -5.0000 \\
\hline-1.5700 & -1.0130 & -5.0000 \\
\hline-1.8162 & -0.4330 & -5.0000 \\
\hline-0.4330 & -1.8162 & -5.0000 \\
\hline-1.0130 & -1.5700 & -5.0000 \\
\hline 1.0130 & -1.5700 & -5.0000 \\
\hline 0.4330 & -1.8162 & -5.0000 \\
\hline 1.8162 & -0.4330 & -5.0000 \\
\hline 1.5700 & -1.0130 & -5.0000 \\
\hline 1.5700 & 1.0130 & -5.0000 \\
\hline 1.8162 & 0.4330 & -5.0000 \\
\hline 0.3981 & 1.8310 & -4.8750 \\
\hline 1.0478 & 1.5552 & -4.8750 \\
\hline-1.0478 & 1.5552 & -4.8750 \\
\hline-0.3981 & 1.8310 & -4.8750 \\
\hline-1.8310 & 0.3981 & -4.8750 \\
\hline-1.5552 & 1.0478 & -4.8750 \\
\hline-1.5552 & -1.0478 & -4.8750 \\
\hline-1.8310 & -0.3981 & -4.8750 \\
\hline-0.3981 & -1.8310 & -4.8750 \\
\hline-1.0478 & -1.5552 & -4.8750 \\
\hline 1.0478 & -1.5552 & -4.8750 \\
\hline 0.3981 & -1.8310 & -4.8750 \\
\hline 1.8310 & -0.3981 & -4.8750 \\
\hline 1.5552 & -1.0478 & -4.8750 \\
\hline & & \\
\hline
\end{tabular}




\begin{tabular}{|c|c|c|}
\hline 1.5552 & 1.0478 & -4.8750 \\
\hline 1.8310 & 0.3981 & -4.8750 \\
\hline 0.3607 & 1.8469 & -4.7500 \\
\hline 1.0852 & 1.5393 & -4.7500 \\
\hline-1.0852 & 1.5393 & -4.7500 \\
\hline-0.3607 & 1.8469 & -4.7500 \\
\hline-1.8469 & 0.3607 & -4.7500 \\
\hline-1.5393 & 1.0852 & -4.7500 \\
\hline-1.5393 & -1.0852 & -4.7500 \\
\hline-1.8469 & -0.3607 & -4.7500 \\
\hline-0.3607 & -1.8469 & -4.7500 \\
\hline-1.0852 & -1.5393 & -4.7500 \\
\hline 1.0852 & -1.5393 & -4.7500 \\
\hline 0.3607 & -1.8469 & -4.7500 \\
\hline 1.8469 & -0.3607 & -4.7500 \\
\hline 1.5393 & -1.0852 & -4.7500 \\
\hline 1.5393 & 1.0852 & -4.7500 \\
\hline 1.8469 & 0.3607 & -4.7500 \\
\hline 0.3206 & 1.8639 & -4.6250 \\
\hline 1.1254 & 1.5523 & -4.6250 \\
\hline-1.1254 & 1.5223 & -4.6250 \\
\hline-0.3206 & 1.8639 & -4.6250 \\
\hline-1.8639 & 0.3206 & -4.6250 \\
\hline-1.5223 & 1.1254 & -4.6250 \\
\hline-1.5523 & -1.1254 & -4.6250 \\
\hline-1.8639 & -0.3206 & -4.6250 \\
\hline-0.3206 & -1.8639 & -4.6250 \\
\hline-1.1254 & -1.5223 & -4.6250 \\
\hline 1.1254 & -1.5523 & -4.6250 \\
\hline 0.3206 & -1.8639 & -4.6250 \\
\hline 1.8639 & -0.3206 & -4.6250 \\
\hline 1.5223 & -1.1254 & -4.6250 \\
\hline 1.5223 & 1.1254 & -4.6250 \\
\hline 1.8639 & 0.3206 & -4.6250 \\
\hline 0.2777 & 1.8821 & -4.5000 \\
\hline 1.1682 & 1.5041 & -4.5000 \\
\hline-1.1682 & 1.5041 & -4.5000 \\
\hline-0.2777 & 1.8821 & -4.5000 \\
\hline-1.8821 & 0.2777 & -4.5000 \\
\hline-1.5041 & 1.1682 & -4.5000 \\
\hline-1.5041 & -1.1682 & -4.5000 \\
\hline-1.8821 & -0.2777 & -4.5000 \\
\hline-0.2777 & -1.8821 & -4.5000 \\
\hline-1.1682 & -1.5041 & -4.5000 \\
\hline 1.1682 & -1.5041 & -4.5000 \\
\hline 0.2777 & -1.8821 & -4.5000 \\
\hline 1.8821 & -0.2777 & -4.5000 \\
\hline & & \\
\hline & & \\
\hline 1250 & \\
\hline
\end{tabular}

\begin{tabular}{|c|c|c|}
\hline 1.5041 & -1.1682 & -4.5000 \\
\hline 1.5041 & 1.1682 & -4.5000 \\
\hline 1.8821 & 0.2777 & -4.5000 \\
\hline 0.2320 & 1.9015 & -4.3750 \\
\hline 1.2139 & 1.4847 & -4.3750 \\
\hline-1.2139 & 1.4847 & -4.3750 \\
\hline-0.2320 & 1.9015 & -4.3750 \\
\hline-1.9015 & 0.2320 & -4.3750 \\
\hline-1.4847 & 1.2139 & -4.3750 \\
\hline-1.4847 & -1.2139 & -4.3750 \\
\hline-1.9015 & -0.2320 & -4.3750 \\
\hline-0.2320 & -1.9015 & -4.3750 \\
\hline-1.2139 & -1.4847 & -4.3750 \\
\hline 1.2139 & -1.4847 & -4.3750 \\
\hline 0.2320 & -1.9015 & -4.3750 \\
\hline 1.9015 & -0.2320 & -4.3750 \\
\hline 1.4847 & -1.2139 & -4.3750 \\
\hline 1.4847 & 1.2139 & -4.3750 \\
\hline 1.9015 & 0.2320 & -4.3750 \\
\hline 0.1834 & 1.9221 & -4.2500 \\
\hline 1.2625 & 1.4641 & -4.2500 \\
\hline-1.2625 & 1.4641 & -4.2500 \\
\hline-0.1834 & 1.9221 & -4.2500 \\
\hline-1.9221 & 0.1834 & -4.2500 \\
\hline-1.4641 & 1.2625 & -4.2500 \\
\hline-1.4641 & -1.2625 & -4.2500 \\
\hline-1.9221 & -0.1834 & -4.2500 \\
\hline-0.1834 & -1.9221 & -4.2500 \\
\hline-1.2625 & -1.4641 & -4.2500 \\
\hline 1.2625 & -1.4641 & -4.2500 \\
\hline 0.1834 & -1.9221 & -4.2500 \\
\hline 1.9221 & -0.1834 & -4.2500 \\
\hline 1.4641 & -1.2625 & -4.2500 \\
\hline 1.4641 & 1.2625 & -4.2500 \\
\hline 1.9221 & 0.1834 & -4.2500 \\
\hline 0.1321 & 1.9439 & -4.1250 \\
\hline 1.3139 & 1.4423 & -4.1250 \\
\hline-1.3139 & 1.4423 & -4.1250 \\
\hline-0.1321 & 1.9439 & -4.1250 \\
\hline-1.9439 & 0.1321 & -4.1250 \\
\hline-1.4423 & 1.3139 & -4.1250 \\
\hline-1.4423 & -1.3139 & -4.1250 \\
\hline-1.9439 & -0.1321 & -4.1250 \\
\hline-0.1321 & -1.9439 & -4.1250 \\
\hline-1.3139 & -1.4423 & -4.1250 \\
\hline 1.3139 & -1.4423 & -4.1250 \\
\hline 0.1321 & -1.9439 & -4.1250 \\
\hline & & \\
\hline 1.25 \\
\hline 1030
\end{tabular}




\begin{tabular}{|c|c|c|}
\hline 1.9439 & -0.1321 & -4.1250 \\
\hline 1.4423 & -1.3139 & -4.1250 \\
\hline 1.4423 & 1.3139 & -4.1250 \\
\hline 1.9439 & 0.1321 & -4.1250 \\
\hline 0.0000 & 2.0026 & -4.0000 \\
\hline 1.4161 & 1.4161 & -4.0000 \\
\hline-1.4161 & 1.4161 & -4.0000 \\
\hline 0.0000 & 2.0026 & -4.0000 \\
\hline-2.0026 & 0.0000 & -4.0000 \\
\hline-1.4161 & 1.4161 & -4.0000 \\
\hline-1.4161 & -1.4161 & -4.0000 \\
\hline-2.0026 & 0.0000 & -4.0000 \\
\hline 0.0000 & -2.0026 & -4.0000 \\
\hline-1.4161 & -1.4161 & -4.0000 \\
\hline 1.4161 & -1.4161 & -4.0000 \\
\hline 0.0000 & -2.0026 & -4.0000 \\
\hline 2.0026 & 0.0000 & -4.0000 \\
\hline 1.4161 & -1.4161 & -4.0000 \\
\hline 1.4161 & 1.4161 & -4.0000 \\
\hline 2.0026 & 0.0000 & -4.0000 \\
\hline & & \\
\hline
\end{tabular}


APPENDIX E

Code for Dose Calculation of a Radioactive Stent with One Radioisotope 
Part A. represents the code for the calculation of the dose surrounding a stent coated with a pure beta emitter such as ${ }^{32} \mathrm{P}$. Part B shows the code of a beta and gamma emitter such as ${ }^{177} \mathrm{Lu}$. Note that the final dose is given by the sum of the dose given by both beta and gamma DPK. Both beta and gamma components are multiplied by their respective attenuation factors.

A.

$\%$ DOSE CALCULATION ALGORITHM FOR RADIOACTIVE STENTS

$\%$ DOSE POINT KERNEL CONVOLUTION

$\%$ Author: Maria Alejandra Caceres

$\%$ Date: May 1, 2003

clear

close all

$\%$ Input Source Points

$\%$ Source points are the coordinates defining the geometry of the stent and are this algorithm's INPUT

$\%$ The coordinates are Cartesian coordinates $(x, y, z)$ and are in a Microsoft Excel format

\% Can include option to select only several slices for a certain radioisotope

tic

xlsread source;

source=ans;

$\mathrm{xs}=$ source(:,1);

$y=\operatorname{source}(:, 2)$;

$z s=$ source $(:, 3)$;

\% Target points are defined in the First Quadrant Only (for computation efficiency purposes).

$\%$ The assumption therefore is that the dose is symmetrical in all quadrants.

$\%$ Loop to find $x$ and $y$ target points

$\mathrm{a}=1$;

for $z=-12: 0.2: 12$;

for $y=0: 0.2: 5$;

for $x=2.1026: 0.2: 5.1026$;

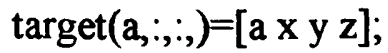

$\mathrm{a}=\mathrm{a}+1$ 


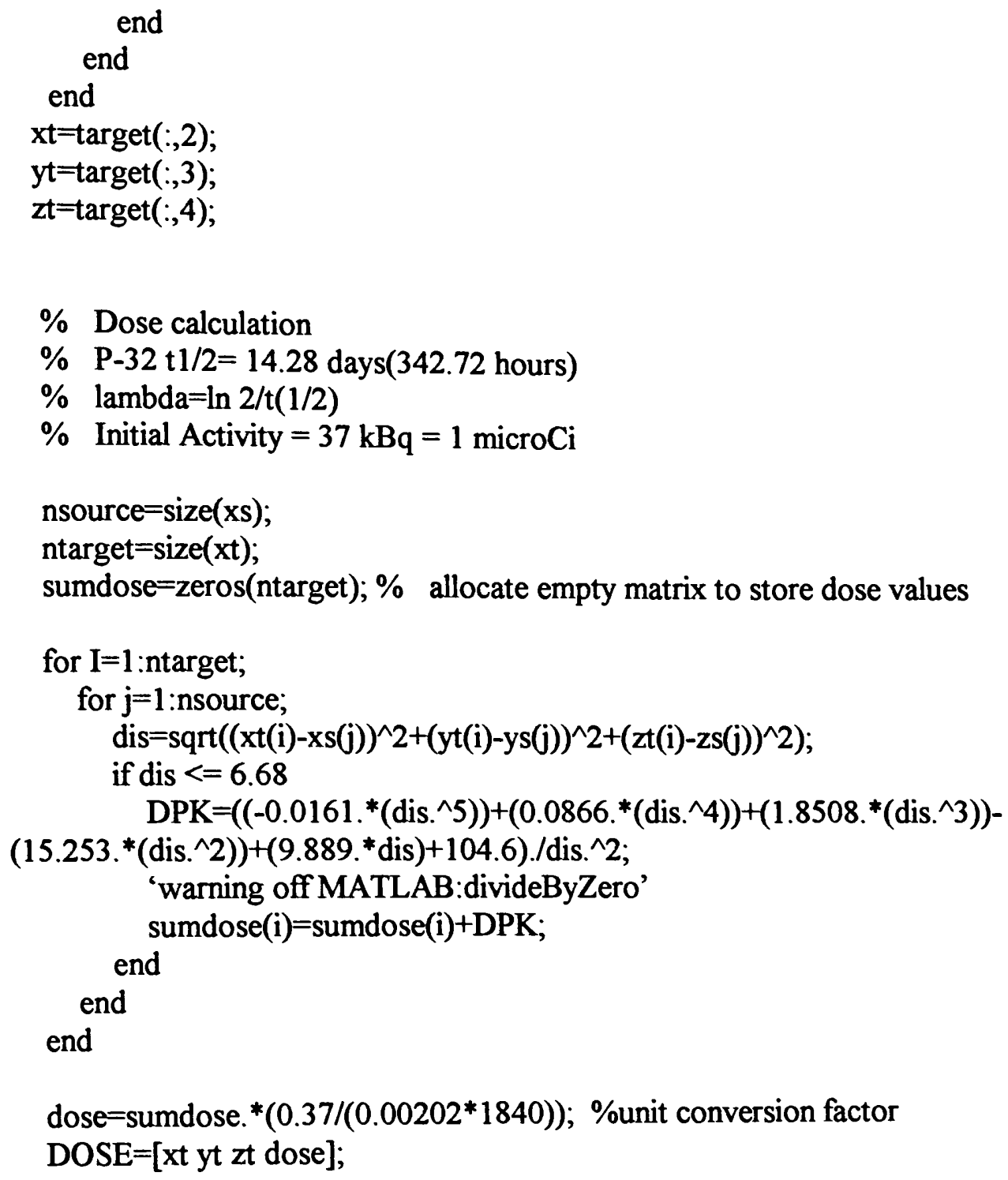

$\%$ PLOT for dose along stent axis for different depths

B.

$\%$ DOSE CALCULATION ALGORITHM FOR RADIOACTIVE STENTS Lu-177

$\%$ DOSE POINT KERNEL CONVOLUTION for both BETA and GAMMA energies

$\%$ Author: Maria Alejandra Caceres

\% Date: June 1, 2003

clear

close all

$\%$ Input Source Points 
$\%$ Source points are the coordinates defining the geometry of the stent and is this algorithm's INPUT

$\%$ The coordinates are Cartesian coordinates $(x, y, z)$ and are in a Microsoft Excel format

$\%$ Can include option to select only several slices for a certain radioisotope

tic

xlsread source2;

source $2=$ ans;

$\mathrm{xs}=\operatorname{source} 2(:, 1)$;

ys=source $2(:, 2)$;

$z s=\operatorname{source} 2(:, 3)$;

xlsread lu177;

lu177=ans;

r=lu177(:,1);

dpk=lu177(:,2);

$\%$ Target Points

$\% \quad$ Target points are defined in the First Quadrant Only (for computation efficiency purposes)

$\%$ The assumption therefore is that the dose is symmetrical in all quadrants.

$\%$ Loop to find $\mathrm{x}$ and $\mathrm{y}$ target points

$\mathrm{a}=1$;

for $\mathrm{z}=0$;

for $\mathrm{y}=0$;

for $x=2.1040775: 0.1: 7.1040775$;

target $(\mathrm{a},: .:,:)=[\mathrm{a} \times \mathrm{y} \mathrm{z}]$;

$\mathrm{a}=\mathbf{a}+1$

end

end

end

$\mathrm{xt}=\operatorname{target}(:, 2)$;

yt=target(:,3);

zt=target(:,4);

\% Dose calculation using Lu-177

$\% \quad$ Lu-177 $\mathrm{t} 1 / 2=6.734$ days $=161.6160$ hours

$\% \quad$ lambda $=\ln 2 / \mathrm{t}(1 / 2)=0.693 / 161.6160=0.0043$

$\%$ Initial Activity $=37 \mathrm{kBq}=1$ microCi

$\% \quad$ \# of struts=1840

$\%$ unit conversion factor, $\mathrm{k}=0.37$

nsource $=\operatorname{size}(x s)$;

ntarget $=\operatorname{size}(x t)$; 
sumdose $1=$ zeros(ntarget); \% allocate empty matrix to store dose values

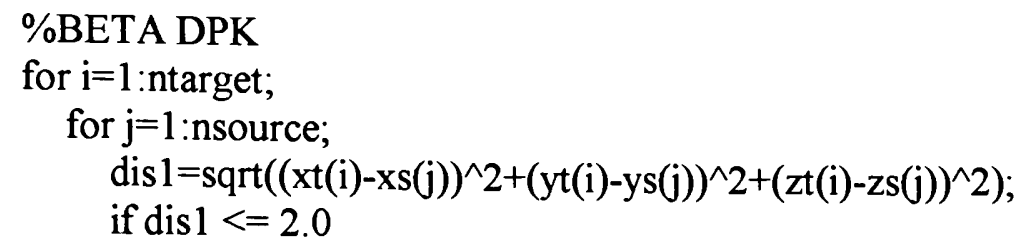


$\%$ PLOT for dose along stent axis for different depths

$1=z t(1: 26: \operatorname{size}(z t)) ; \quad m=\operatorname{dose}(1: 26: \operatorname{size}(x t)) ; n=\operatorname{dose}(2: 26: \operatorname{size}(x t)) ; 0=\operatorname{dose}(3: 26: \operatorname{size}$ $(x t)) ; p=\operatorname{dose}(6: 26: \operatorname{size}(x t)) ; q=\operatorname{dose}(11: 26: \operatorname{size}(x t))$; plot(1,m, 'b-', 1,n,'r-', l,o,'m-', 1,p,'y-', 1,q,'g-')

grid on

xlabel('Z(mm)')

ylabel('Dose (cGy/uCi)')

title ('Dose along stent axis')

legend('0.1mm', '0.3 mm', '0.5 mm', '1.0 mm', '2.0 mm') 


\section{APPENDIX $\mathrm{F}$ \\ Code for Dose Calculation of a Radioactive Stent with Two Radioisotopes}


$\%$ DOSE CALCULATION ALGORITHM FOR HYRBID (More than one radioisotope) RADIOACTIVE STENT

$\%$ DOSE POINT KERNEL CONVOLUTION

$\%$ Author: Maria Alejandra Caceres

$\%$ Date: May 21, 2003

clear

close all

$\%$ Input Source Points

$\%$ Source points are the coordinates defining the geometry of the stent and is this algorithm's INPUT

$\%$ The coordinates are Cartesian coordinates $(\mathrm{x}, \mathrm{y}, \mathrm{z})$ and are in a Microsoft Excel format

\% Can include option to select only several slices for a certain radioisotope

tic

xlsread source;

source=ans;

$\%$ Selection of slices of source for a specific radioisotope

$\%$ Selection of slices corresponding to the body of the stent

sl=source (461:1380,:.:.:.);

\%Selection of slices corresponding to the stent edges

s2=[source $(1: 460,: .,:, ;) ; \operatorname{source}(1381: 1840,: .,:,:)]$;

$$
\begin{aligned}
& \text { xs } 1=s 1(:, 1) ; \\
& \text { ys } 1=s 1(:, 2) ; \\
& \text { zs } 1=s 1(:, 3) ; \\
& \text { xs2 }=s 2(:, 1) ; \\
& \text { ys } 2=s 2(:, 2) ; \\
& \text { zs2 } 2=s 2(:, 3) ;
\end{aligned}
$$

$\%$ Target Points

$\%$ Target points are defined in the First Quadrant Only (for computation efficiency purposes)

$\%$ The assumption therefore is that the dose is symmetrical in all quadrants.

$\%$ Loop to find $\mathrm{x}, \mathrm{y}, \mathrm{z}$ target points

$\mathrm{a}=1$;

for $z=-10: 0.2: 10$;

for $y=0: 0.2: 5$;

for $x=2.1026: 0.2: 5.1026$;

$$
\begin{aligned}
& \operatorname{target}(\mathrm{a},:,:,:)=[\mathrm{a} \text { x y z]; } \\
& \mathrm{a}=\mathrm{a}+1
\end{aligned}
$$

end

end

end 


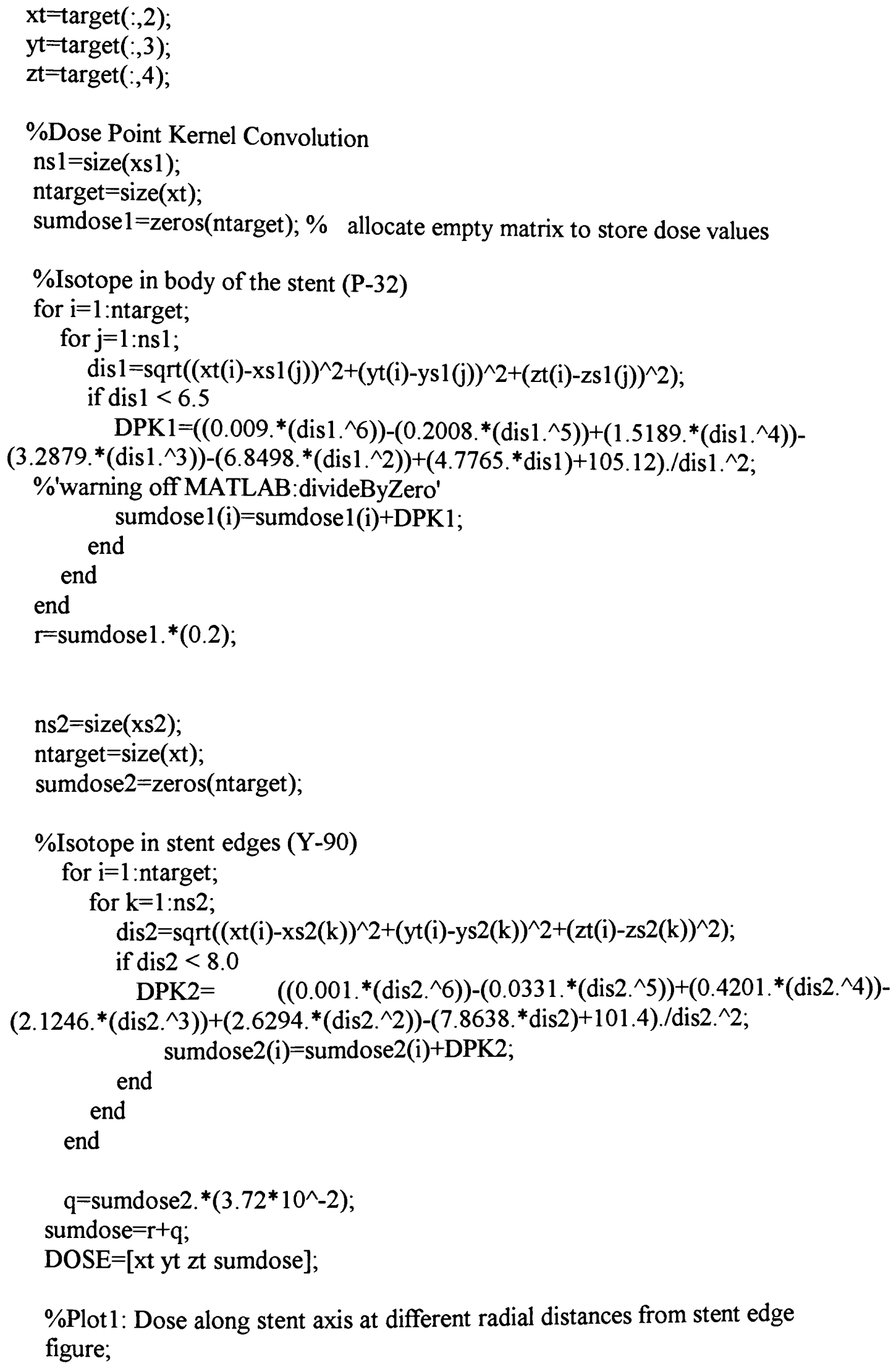

\%Plot 1: Dose along stent axis at different radial distances from stent edge figure; 
$c=z t(1: 416: \operatorname{size}(x t)) ; \quad b=$ sumdose $(1: 416:$ size $\quad$ (sumdose) $) ; d=$ sumdose $(2: 416:$ size (sumdose));e=sumdose(3:416:size (sumdose)); f=sumdose(6:416:size (sumdose)); $\mathrm{g}=\mathrm{r}(11: 416$ :size (sumdose));

plot(c,b,'b-', c,d,'r-', c,e,'m-', c,f,'y-', c,g,'g-')

grid on

xlabel(' $Z(\mathrm{~mm})$ ')

ylabel('Dose (cGy)')

title ('Dose along stent axis')

legend('0.1mm', '0.3 mm', '0.5 mm', '1.0 mm', '2.0 mm')

$\%$ Plot 2: Dose as a function of radial distance calculated at three $\%$ stent planes: a) $z=0, b) z=4$ c) $z=8$

figure;

$\mathrm{zl}=0.1: 0.2: 3.1$;

$\mathrm{a}=$ sumdose (20801:20816);

$\mathrm{b}=$ sumdose $(29121: 29136)$;

$\mathrm{c}=$ sumdose(37025:37040);

plot(z1,a,'b-s', z1,b,'r-.', z1,c,'g-x')

grid on

xlabel('distance (mm)')

ylabel('Dose (cGy)')

title('Dose as a function of radial distance at different $\mathrm{z}$ planes')

legend (' $z=0 \mathrm{~mm}$ ', ' $z=4 \mathrm{~mm}$ ', ' $z=8 \mathrm{~mm}$ ') 


\section{APPENDIX G \\ Code for Calculation of Biological Equivalent Dose (BED) \\ for Radioactive Stents with One Radioisotope}


$\%$ Radiobiological Model for P-32 stent

$\%$ Author: Maria Alejandra Caceres

$\%$ Date: May 25, 2003

$\%$ Repair half-time is 0.5 hours ( $30 \mathrm{~min}$.)

$\%$ alpha/beta ratio is $8 \mathrm{~Gy}$

$\%$ lambda is $0.00202 \mathrm{~h}^{-1}$

$\%$ repair half-life of tissue $u=1.38 \mathrm{~h}^{-1}$

clear

close all

tic

load dose;

$\%$ Dose rate is equal to total dose $\mathrm{x}$ decay constant (hours)

doserate $=$ dose ${ }^{*}(0.00202)$;

$\%$ Relative effectiveness per unit dose (RE)

$\mathrm{RE}=1+$ doserate.$/((1.386+0.00202) * 0.08)$;

$\%$ Calculation of Biological Equivalent Dose

$\mathrm{BED}=$ dose. ${ }^{*} \mathrm{RE}$;

table $=[$ dose BED $]$;

toc

$\mathrm{t}=$ toc 


\section{APPENDIX H \\ Code for Calculation of Biological Equivalent Dose (BED) \\ for Radioactive Stents with Two Radioisotopes}


$\%$ Radiobiological Model for stent containing two radioisotopes

$\%$ Author: Maria Alejandra Caceres

$\%$ Date: May 25, 2003

$\%$ Repair half-time is 0.5 hours $(30 \mathrm{~min}$.)

$\%$ alpha/beta ratio is $8 \mathrm{~Gy}(.08 \mathrm{cGy})$

clear

close all

tic

load dose;

$\%$ Dose rate is equal to total dose $\mathrm{x}$ decay constant of radioisotope(hours)

$\mathrm{r}=\operatorname{DOSE}(:, 4)$;

$\% \mathrm{a}=$ dose from isotope1 (P-32)

$\% \mathrm{~b}=$ dose from isotope $2(\mathrm{Lu}-177)$

$\% \mathrm{Ll}=$ decay constant of $\mathrm{P}-32$

$\% \mathrm{~L} 2=$ decay constant of $\mathrm{Lu}-177$

$\% \mathrm{P}-32$

doserate $1=\mathrm{a} . *(0.00202)$;

\%Lu-177

doserate $1=b .{ }^{*}(0.00428)$;

$\mathrm{u}=1.386$

$\mathrm{L} 1=0.00202$

$\mathrm{L} 2=0.00428$

\%Relative effectiveness per unit dose

$\mathrm{RE}=1+\left(0.08^{*}\left(\left(\right.\right.\right.$ doserate $\left..^{\wedge} 2 . /\left(\mathrm{L} 1 .^{*}(\mathrm{~L} 1+\mathrm{u})\right)\right)+\left(\right.$ doserate2 $\left..^{\wedge} 2 . /\left(\mathrm{L} 2 .^{*}(\mathrm{~L} 2+\mathrm{u})\right)\right)+\left(2^{*}(\right.$ dosera te1. ${ }^{*}$ doserate2. $\left.\left.{ }^{*}\left(\mathrm{~L} 1+\mathrm{L} 2+2 .{ }^{*} \mathrm{u}\right)\right) . /\left((\mathrm{L} 1+\mathrm{L} 2) .{ }^{*}(\mathrm{~L} 1+\mathrm{u}) .{ }^{*}(\mathrm{~L} 2+\mathrm{u})\right)\right) . /(($ doserate $1 . / \mathrm{L} 1)+($ dose rate2.(L2)))

$\%$ Calculation for Biologically Equivalent Dose

$\mathrm{BED}=\mathrm{r}$. $\mathrm{RE}$;

table $=[\mathrm{r}$ BED];

toc

$\mathrm{t}=$ toc 